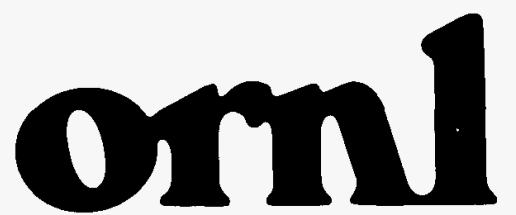

OAK RIDGE

NATIONAL

LABORATORY

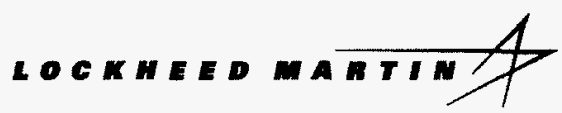

\section{Army National Guard (ARNG) Objective Supply Capability Adaptive Redesign (OSCAR) End-User Manual}

CW3 Robert P. Pelath

K. A. Rasch

\author{
By authority
}

Chief, National Guard Bureau

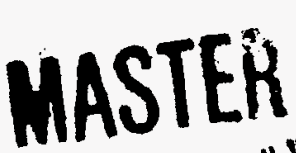

닌 
This report has been reproduced directly from the best available copy.

Available to DOE and DOE contractors from the Office of Scientific and Technical Information, P.O. Box 62, Oak Ridge, TN 37831; prices available from (423) 576-8401, FTS 626-8401.

Available to the public from the National Technical Information Service, U.S. Department of Commerce, 5285 Port Royal Rd., Springfield, VA 22161.

This report was prepared as an account of work sponsored by an agency of the United States Government. Neither the United States Government nor any agency thereof, nor any of their employees, makes any warranty, express or implied, or assumes any legal liability or responsibility for the accuracy, completeness, or usefulness of any information, apparatus, product, or process disclosed, or represents that its use would not intringe privately owned rights. Peference herein to any specific commercial product, process, or service by trade name, trademark, manufacturer, or otherwise, does not necessarily constitute or imply its endorsement, recommendation, or favoring by the United States Government or any agency thereof. The views and opinions of authors expressed herein do not necessarily state or reflect those of the United States Government or any agency thereof.

\section{THIS PUBLICATION IS NOT AVAILABLE THROUGH THE US ARMY ADJUNCT GENERAI PUBLICATION CENTER.}

REQUEST COPIES THROUGH

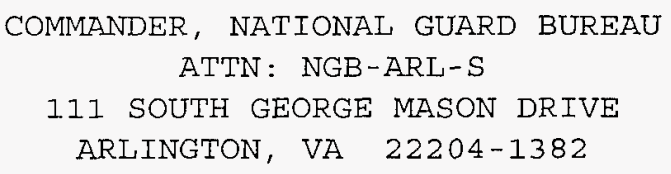


ORNL/M-6137

NGB-ARL-S (700)

Computational Physics and Engineering Division

By authority

Chief, National Guard Bureau

Automated Information System Manual

ARMY NATIONAL GUARD (ARNG)

OBJECTIVE SUPPLY CAPABILITY ADAPTIVE REDESIGN (OSCAR)

END-USER MANUAL

CW3 Robert P. Pelath*

Kevin A. Rasch

* National Guard Bureau, Arlington Hall Station, 111 South George Mason Drive, Arlington, Virginia 22204-1382

December 1997

Prepared by the

Oak Ridge National Laboratory

Oak Ridge, Tennessee 37831 managed by

LOCKHEED MARTIN ENERGY RESEARCH CORP.

for the

U.S. DEPARTMENT OF ENERGY

under contract DE-AC05-96OR22464 
SECTION 1 GENERAL

1.1 Purpose of the End-User Manual 1-1

1.2 Objectives 1-1

1.3 Methods and Procedures without Program 1-2

1.4 References 1-2

1.5 Security 1-2

1.5.1 Hardware Security $1-3$

1.5.2 Software and File security 1-3

1.6 Request for and Change to Manual 1-3

1.7 System Maintenance 1-3

SECTION 2 SYSTEM SUMMARY

2.1 General

2.2.1 Application Summary

2.2 System Environment

2.2.1 Main-Frame Hardware Requirement

2.2.2 Personal Computer Requirements

SECTION 3 ACCESS TO THE SYSTEM

3.1 First-Time User of System

3.2 Access Control

3.2.1 Initiating a session

3.2.2 File option selections

3.2.3 Disposition

3.2 .4 Document

3.2.5 Database

3.3 Illustrations

through
3-1

2-1

$2-1$

$2-1$

2-1

2-1

2-2

3-1

3-1

3-1

3-2

3-2

3-3

Figure 3-1

Figure 3-8 
SECTION 4 EXCESS MANAGEMENT PROCESS

4.1 General 4-1

4.2 Excess Management Process (Manual) 4-1

4.2.1 Customer Transactions 4-1

$4-2$

$4-3$

$4-4$

4.2.2 NGB Manager Disposition 4-5

$4-6$

4.3 Illustrations

Figure 4-1

through

Figure 4-32

SECTION 5 CATALOG PROCESS
5.1 General
$5-1$
5.2 Catalog Update Process
$5-1$
5.3 Catalog Inquiry
5-1

SECTION 6 DISPOSITION TABLE UPDATE PROCESS
6.1 General
$6-1$
6.2 Disposition Table Update Procedures 6-1
6.2.1 Disposition Code Description
$6-1$
6.2.2 Table Format
$6-2$
6.2 .3 Report
$6-2$
6.3 Illustrations
through
Figure 6-1
Figure 6-22

SECTION 7 SETUP PROCESS

7.1 . General 7-1

SECTION 8 RVARS RETRIEVAL PROCESS
8.1 General
$8-1$
8.2 RVARS Data Retrieval
$8-1$
$8-2$
8.3 How to utilize RVARS Export Process 8-3
$8-6$
8.4 Illustrations
through
Figure 8-1
Figure 8-14 
TABLE OF CONTENTS

PAGE

SECTION 9 NGB EXCESS MANAGEMENT WEB SITE

9.1 General 9-1

SECTION 10 REPORTS

10.1 General 10-1

10.2 Standard Reports 10-1

$10-2$

SECTION 11 INQUIRY PROCESS

11.1 General 11-1

SECTION 12 STATE/TERRITORY

12.1 General $12-1$

12.1.1 References $12-1$

12.1.2 state/Territory Responsibilities $12-1$

$12-2$

$12-3$

12.2 Reports $12-4$

$12-5$

$12-6$

12.2.1 NGB-ARL-E Semi Annual Report $12-7$

$\begin{array}{ll}12.3 \text { Cancellation } & 12-7\end{array}$

$12-8$

12.4 NGB Master File Description $12-8$

12.5 Exceptions for Reportable Items . 12-10

12.6 DOD Activity Address File (DODAAF) $12-10$

12.7 Defense Automated Addressing System 12-11 (DAAS)

12.8 Shipping Discrepancy

$12-11$

12.9 Excess Reports forwarded to ICP $12-12$

12.10 Aviation Assets $12-12$

12.11 SARSS-1 Responsibilities 12-13

12.12 SARSS-2AC Responsibilities 12-13 
TABLE OF CONTENTS

PAGE

APPENDIX A REFERENCES, TERMS AND ABBREVIATIONS

References

A - 1

A -2

A -3

Abbreviations

A -4

Terms

A -5

A- 6

APPENDIX B FILE AND REPORT DESCRIPTION

$\begin{array}{ll}\text { How to Read OSCAR Daily Disposition Report } & \text { B-1 } \\ & \text { B-4 } \\ \text { OSCAR Daily Report (Reporting state) } & \text { B-5 } \\ \text { OSCAR Daily Report (Receiving state) } & \text { B-6 } \\ \text { OSCAR Table Description } & \text { B-7 } \\ & \text { B-8 } \\ \text { OSCAR Message Table } & \text { B-9 } \\ \text { Standard Operating Procedures (SOP) on } & \\ \text { Reporting Excess Major end items to NGB } & \text { B-10 } \\ \text { OSCAR Daily Report (Manager Report) } & \text { B-11 }\end{array}$

APPENDIX C FORMS, SQL, AND LISTINGS

Standard Query statement (SQI)

Routing SARSS 'ngbam3' file through DAAS C-1

C- 2

C-3

C- 4

DD1348A1 which is a Result of NGB Customer

Response (FTR)

C -5

APPENDIX D ADDITIONAL NGB GUIDANCE

$\begin{array}{ll}\text { NGB Directive/Instructions/Guidance } & \mathrm{D}-1 \\ \text { Auto-Disposition Table (IIN) } & \mathrm{D}-2 \\ & \mathrm{D}-3 \\ & \mathrm{D}-4 \\ & \mathrm{D}-5 \\ & \mathrm{D}-6 \\ \text { NGB Aviation Reportable IIN(s) } & \mathrm{D}-7 \\ & \mathrm{D}-8 \\ & \mathrm{D}-9 \\ & \mathrm{D}-10\end{array}$

vi 
The Objective Supply Capability Adaptive Redesign (OSCAR) project is designed to identify and develop programs which automate requirements not included in standard army systems. This includes providing automated interfaces between standard army systems at the National Guard Bureau (NGB) level and at the state/territory level. As part of the OSCAR project, custom software has been installed at NGB to streamline management of major end items. This software allows item managers to provide automated disposition on excess equipment to states operating the standard Army Retail Supply System Objective (SARSS-O). It also accelerates movement of excess assets to improve the readiness of the Army National Guard (ARNG) while reducing excess on hand.

The purpose of the End-User Manual is to provide direction and guidance to the customer for implementing the ARNG Excess Management Program.

The OSCAR project team is as follows:

PROPONENT: NGB-ARL-E

System Development: NGB-ARL-S

Arlington Hall station

111 South George Mason Drive

Arlington, VA 22204-1382

NGB-ARL-S Project Manager

Mr. William E. Watkins

NGB-ARL-S Functional Analysis

CW3 Robert P. Pelath

NGB-ARL-E Functional Manager

Mr. Harold E. Johnson

Project Contractor

Oak Ridge National Laboratory

Mr. Richard W. Reid, Program Manager

Mr. Kevin A. Rasch, Project Manager 
THIS PAGE NOT USED

viii 


\section{SECTION 1. GENERAL}

1.1 Purpose of the END-User Manual: This end-user manual has been developed for the National Guard Bureau (NGB) Excess manager, providing the user with information to allow for a better understanding of the Redistribution Program requirements:

a. System requirements that serve as the basis of mutual understanding between the user and the developer.

b. Performance requirement information, preliminary design, and user impacts.

c. A basis for development of system tests.

d. The procedures in this manual comply with Department of the Army (DA) policy and apply only to the ARNG. If this manual conflicts with any policy, conflicts should be reported to CNGB, ARNGRC, ATTN: NGB-ARL-S, 111 S. George Mason Drive, Arlington, VA 22204-1382.

\subsection{Objectives of the ARNG Excess Program:}

a. Provide an interface between States/Territories and NGB Managers for the purpose of automating the Reporting and Disposition of Major End Item Excess Materiel within the Army National Guard (ARNG).

b. Allow for an automated means of providing lateral distribution of available assets to enhance the readiness posture of the ARNG.

c. Reduce the time frame for providing disposition, enhance ship time and receipt of assets within the ARNG.

d. Establish a database that will utilize active/inactive history files to automate the control, follow up, and tracking of major end Item assets within the ARNG.

e. Interface with the Standard Army Retail Supply System Objective (SARSS-0) and the Defense Automatic Addressing System (DAAS) to take advantage of near real-time processing. 
1.3 Methods and Procedures without the ARNG Management Redistribution Programs:

a. States must report excess assets offline in a monthly batch to the NGB computer center where the NGB materiel manager would review and provide hard-copy instructions on what actions were required.

b. NGB materiel managers would review excess assets using the REQVAL database to determine redistribution and formulate a message with instructions on what actions should be taken by States/Territories.

c. States would act upon the NGB written instructions and enter information manually into the Supply Accounting Management Information System (SAMIS) or Standard Army Retail Supply System Objective (SARSS-O) and/or type manual shipping documents for the transfer of assets.

d. NGB/States/Territories would use various manual methods to trace and/or track disposition results.

\subsection{References: See Appendix B and/or AR 725-50.}

1.5 Security. The automated data processing system security officer (ADPSSO) is responsible for developing a physical security plan. Managers and supervisors are responsible for implementation and compliance with this requirement.

a. A plan must ensure that the ARNG Management System software and hardware are protected against computer-related crimes. It must prevent unauthorized use of automated data processing equipment (ADPE) and improper use of, or access to, ARNG Management data.

b. Additional physical security guidelines are located in AR 380-19 or may be obtained from the ADPSSO.

c. The Standard Operating Procedures (SOP) should include the plan. It should outline the duties and functions for each level of responsibility and include standard procedures and practices for routine actions. It should also provide guidance for non-routine and unusual circumstances. 
1.5.1 Hardware Security. NGB equipment should be located in an area with controlled, restricted access. This area should provide physical security protection equal to or greater than the security requirements of the users command.

1.5.2 Software and File Security. User identification codes (IDs) and password control will be needed to access the NGB Management Programs. The system administrator will assign user IDs and passwords, allowing only assigned personnel to operate the system and access certain processes. This password protection prevents unauthorized access to system files and processing.

1.6 Request for and Changes to Manual. Request for additional copies and suggestions for changes to the manual go to the CNGB, ATTN: NGB-ARL-S (Marked For: ARNG Excess Management Program), 111 South George Mason Drive, Arlington, VA 22204-1382. E-MAIL: pelathr@arngrc-emh2.army.mil.

a. Submit request for this manual in Memorandum form. Include justification for replacement copies and for new or revised requirements. Provide all information necessary for proper shipment of materiel. Also include a point of contact, activity, building number, office symbol, and telephone number.

b. Send inquires or suggested changes to this manual in memorandum form to NGBARL-SS through NGB-ARL-S, ATTN: Chief, Logistic Supply Division.

1.7 System Maintenance. The NGB-ARL-S branch maintains this system. Submit recommendations concerning changes to automated processes on Engineering Change Proposals-Software (ECP-S), DA Form 5505-R, through NGB-ARL-S to NGB-ARL-SS. 
THIS PAGE NOT USED 


\section{SECTION 2. SYSTEM SUMMARY}

2.1 General. NDI stands for non-developmental item. The NGB Management programs were developed to take advantage of the utilization of NDI hardware. Generic PC clones are an excellent example of the cost savings available when using NDI hardware. DOS, UNIX, and WINDOWS NT environments and other various application programs on the commercial market are all samples of DOD cost savings.

2.1.1 Application Summary. The NGB Management Programs supports the NGB/MACON level operations and interface with the Standard Army Retail Supply System Objective (SARSS-O) at the State/Territory level. It performs time-sensitive functions, including receiving SARSS-O excess reports, providing customer response, responding to customer follow-up, receipt for property, as well as maintaining an activity and history file of actions taken.

2.2 System Environment. Information about the equipment configuration and software required to support systems operations follows:

2.2.1 Main Frame Hardware Required. Sun SPARCstation 20 running Solaris 2.4 and Informix 7.1. Informix Connect, Informix ESQL/C and Intersolv DataDirect ODBC driver for Informix required.

2.2.2 Intel Pentium-based personal computer running Windows NT 4.0. or Higher.

a. Sun SPARCstation 20 
b. Master Workstation hardware includes PC Clone 486, Pentium, or Pentium PRO system. Software requirements:

(1) $486 / 25 \mathrm{Mhz}$ or higher processor.

(2) $12 \mathrm{MB}$ of memory: $16 \mathrm{MB}$ recommended.

(3) $110 \mathrm{MB}$ of available hard-disk space.

(4) CD-ROM drive or access to a CD-ROM over computer network.

(5) VGA or higher-resolution display adapter.

(6) Microsoft mouse or compatible pointing device.

(7) Ethernet card 


\section{SECTION 3. ACCESS TO TEE SYSTEM}

3.1 First-Time User of System. This section provides the guidance and procedures necessary for operating the NGB Management System. The User needs no formal training, but must have an authorized User ID and password to access the system. By following this manual, one should be able to perform the daily operations of excess Management at NGB level.

3.2 Access Control. The NGB Excess Management Program is a password-protected system that works in the WINDOWS environment. To enter the NGB Management System, click on the NGB Management ICON on the Master Menu. The user will be prompted to enter User ID and password. Once a valid ID/Password has been entered, the NGB Management window will open and appear as in Figs. 3-4 through 3-14.

3.2.1 Initiating a Session. Once the user clicks on the OSCAR Client ICON, the "Enter Password" screen appears. Enter User ID and password (Figs. 3-2 and 3-3). When a valid password has been entered, the OSCAR Excess Management Client Window will open and appear as in Figs. 3-4 through 3-14.

\subsubsection{File option selections are as follows:}

a. Export - This option will allow the user to retrieve Requisition Validation Automated Redistribution System (RVARS) data from the NGB Master File. Refer to Sect. 8 , RVARS Retrieval Process for user guidance.

b. Import - This will allow the user two (2) options:

(1) Catalog - Refer to Sect. 5, Catalog/DODAAF Update Process for user guidance.

(2) DODAAC - Refer to Sect. 5, Catalog/DODAAF Update Process for user guidance. 
c. Print Reports - Refer to Sect. 10, "REPORTS" for user guidance.

d. Print Setup - This is the printer setup in WINDOWS, and the user should use the WINDOWS user manual for guidance.

e. Exit - Allows the user to exit the Excess Management Process and return to the WINDOWS NT Main Menu.

3.2.3 Disposition - This option allows the user to select the following options to provide disposition on Customer excess reports (FTE(s)). User guidance can be found in Sect. 4, "ARNG Excess Management Process (Manual)."
a. FTD - Delay status
b. FTR - Send Response to state
c. Pass FTE to ICP

3.2.4 Document - This option allows the user to enter the following transaction. User guidance can be found in sect. 4, "ARNG Excess Management Process (Manual)."
a. AC - Customer request for cancellation
b. AE - Customer Status
c. AS - Shipment Status
d. D6 - Receipt of shipment
e. FTC - Cancellation of Excess Report
f. FTE - Customer Excess Report
g. ETF - Eollow up 
h. FTL - Shipment Delay Status

i. FTM - Shipment status

j. FTz - Materiel Receipt status

3.2.5 Database - This option allows the NGB manager or supervisor to update OSCAR system tables. Tables are as follows :

a. Condition Code Table

b. Disposition Table

c. Priority Table

d. RICC Table

e. Setup Table

f. State Table

g. Source of Supply Table

h. User/SOS Access Table

i. User Table

j. Aviation Table

k. Restricted UIC Table

1. Manager sos Table 
THIS PAGE NOT USED

$3-4$ 


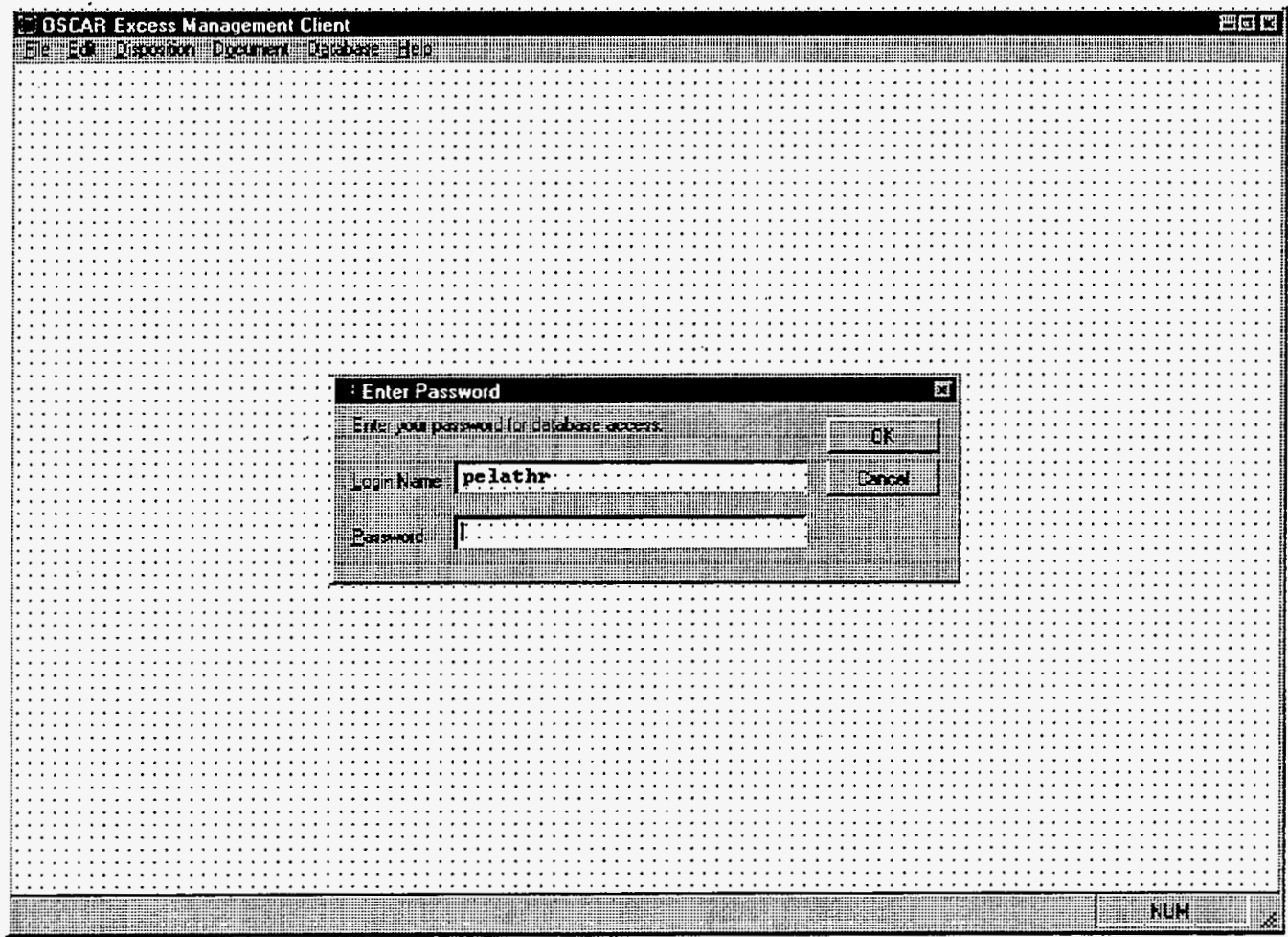

Once the user Clicks On the "OSCAR" icon, the <Enter Password $>$ screen will appear. User must enter his/her user password.

* User passwords are issued by the System Administrator.

When a wrong or expired password is entered, the screen on Fig. 3-2 will appear.

\section{GO TO NEXT PAGE}

Figure 3-1 


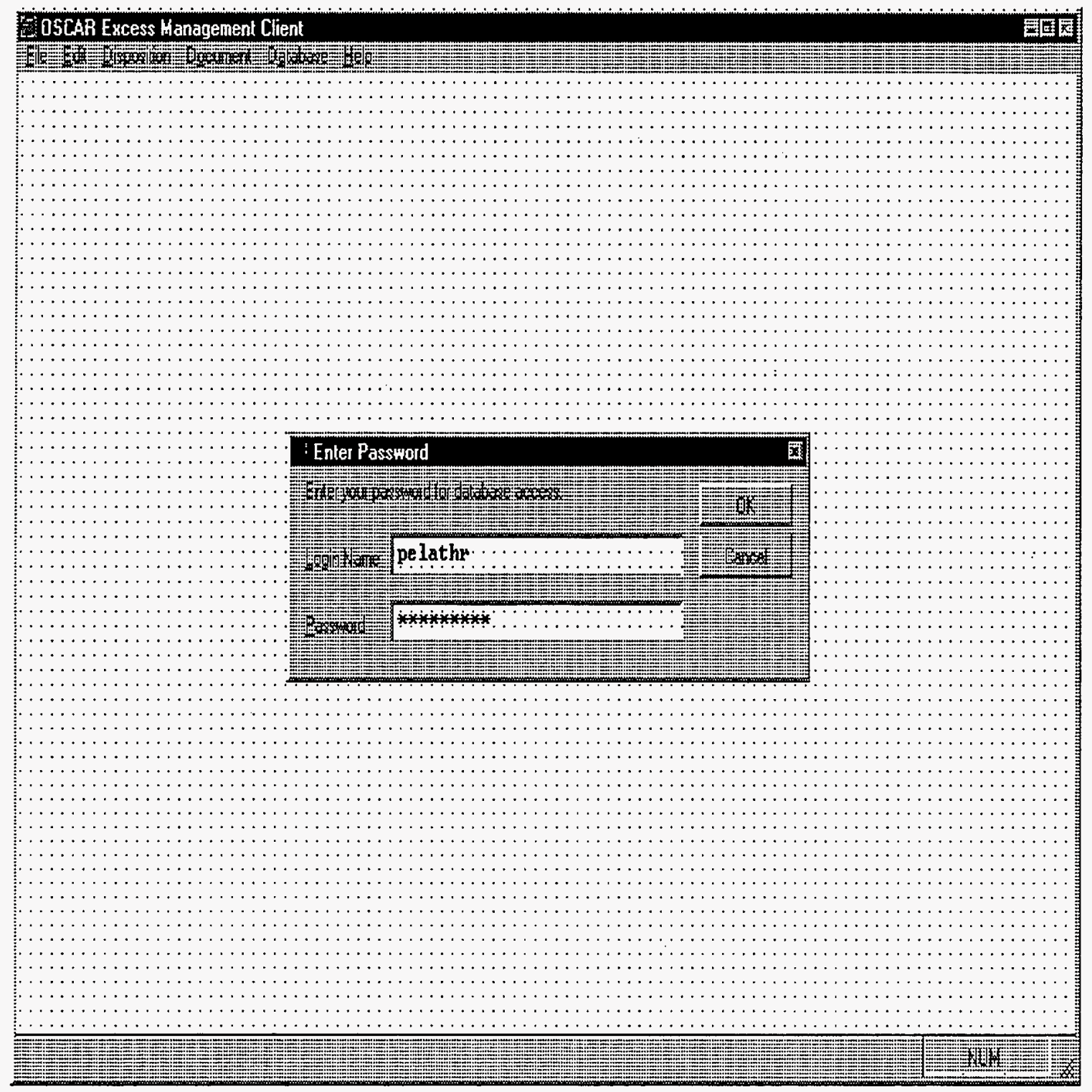

When user enters a password, it will look like this.

Once entered press Enter or $<\mathrm{OK}>$.

\section{GO TO NEXT PAGE}

Figure 3-2 


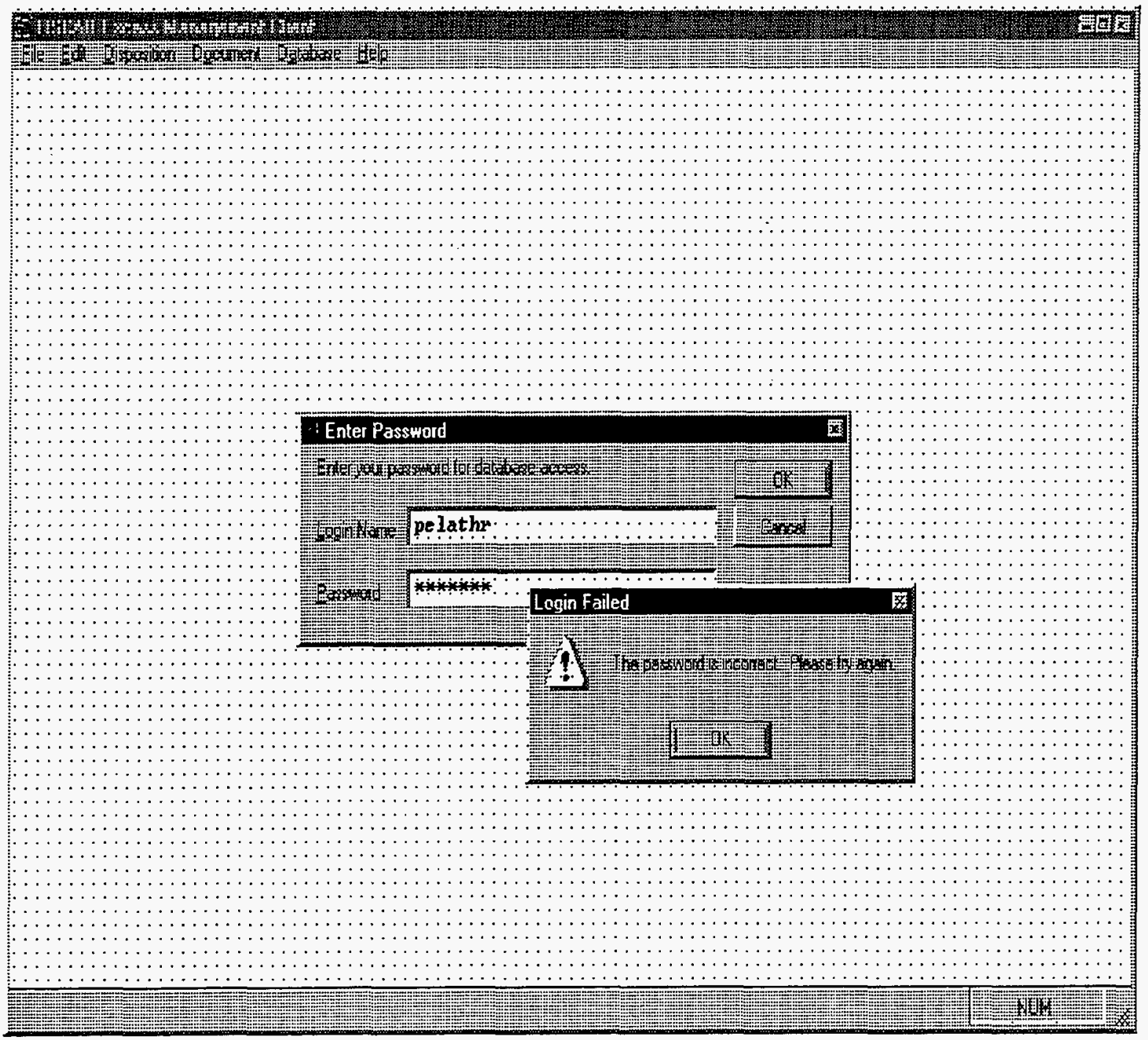

When the "Login Failed" prompt appears, the user has either entered an invalid password or his/her password has expired.

When the "Login Failed" message continues to appear, contact you supervisor or System Administrator for assistance.

Once a valid password has been entered, the screen on Fig. 3-4 will appear.

\section{GO TO NEXT PAGE}

Figure 3-3 


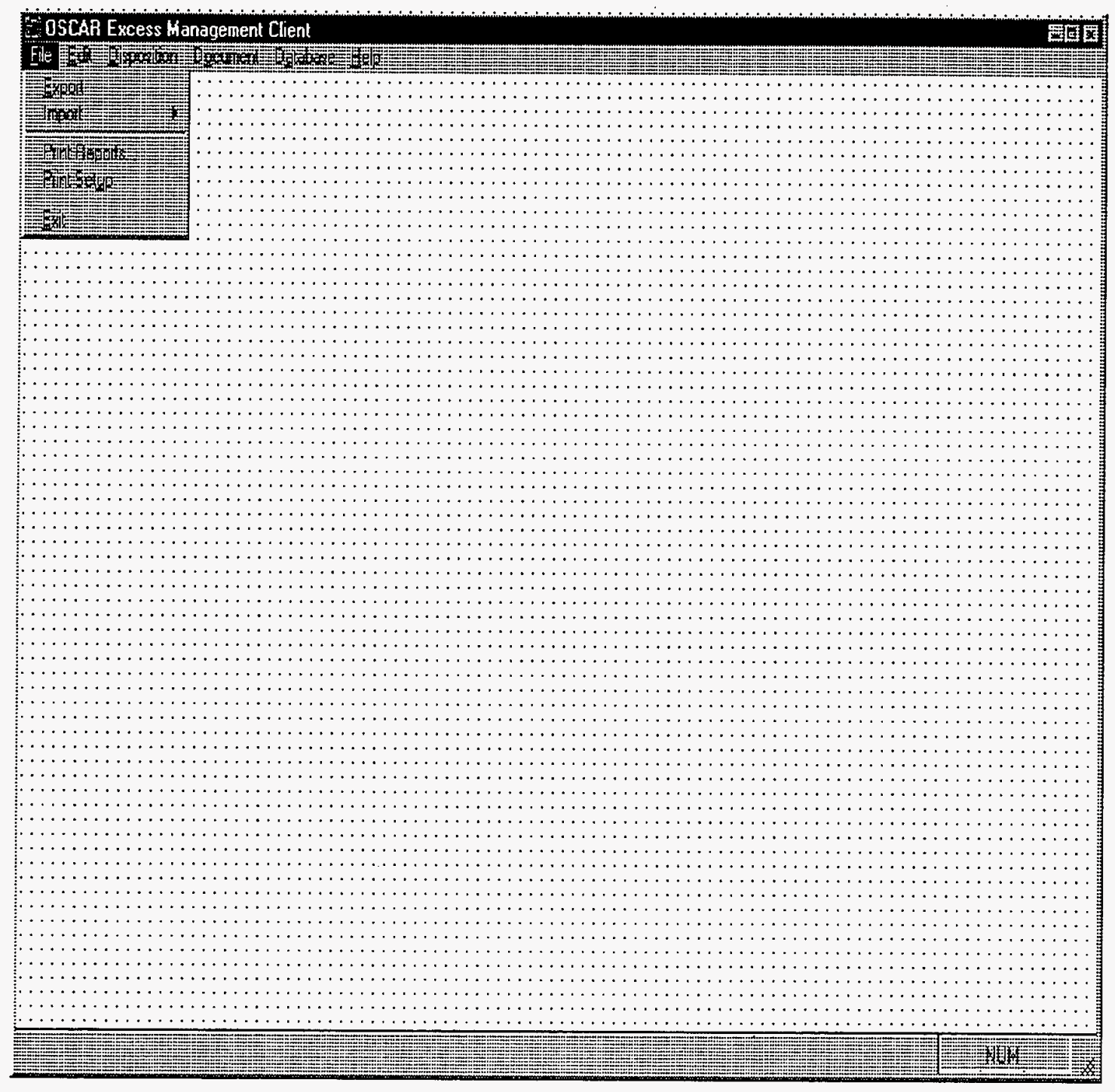

The screen above will appear.

When user Clicks On $<$ File $>$ the following options will appear:

Export - This option allows the user to retrieve customer excess reports (FTE) from the Master File for processing . Refer to Sect. 8, "RVARS RETRIEVAL PROCESS" for user guidance.

Import - Option will allow the Supervisor/System Administrator to read in Catalog and/or DODAAC information. Refer to Sect. 5, "CATALOG PROCESS."

Print Reports - This option will allow the user to print various reports. Refer to Sect. 10, "REPORTS" for user information.

Print Setup - This option will allow the user to enter the WINDOWS environment to set up a printer.

\section{GO TO NEXT PAGE}




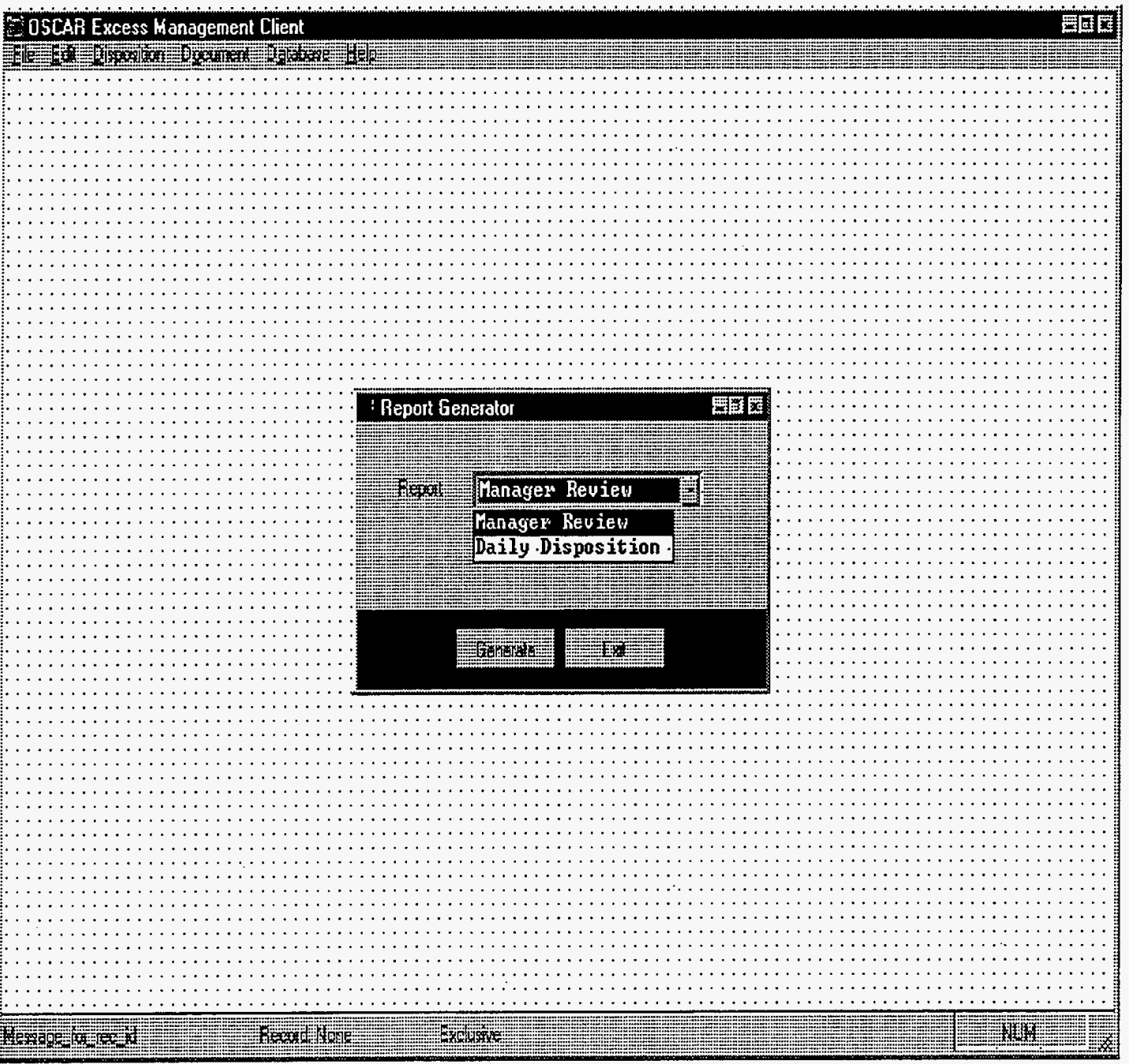

The "Manager Review Report" is the first option.

User can Click On the arrow to the right of the "Manager Review Report" to see other options.

To create a report, the user must highlight the report required and Click On <Generate $>$.

Once the report has been generated, the user can send it to the printer.

\section{GO TO NEXT PAGE}




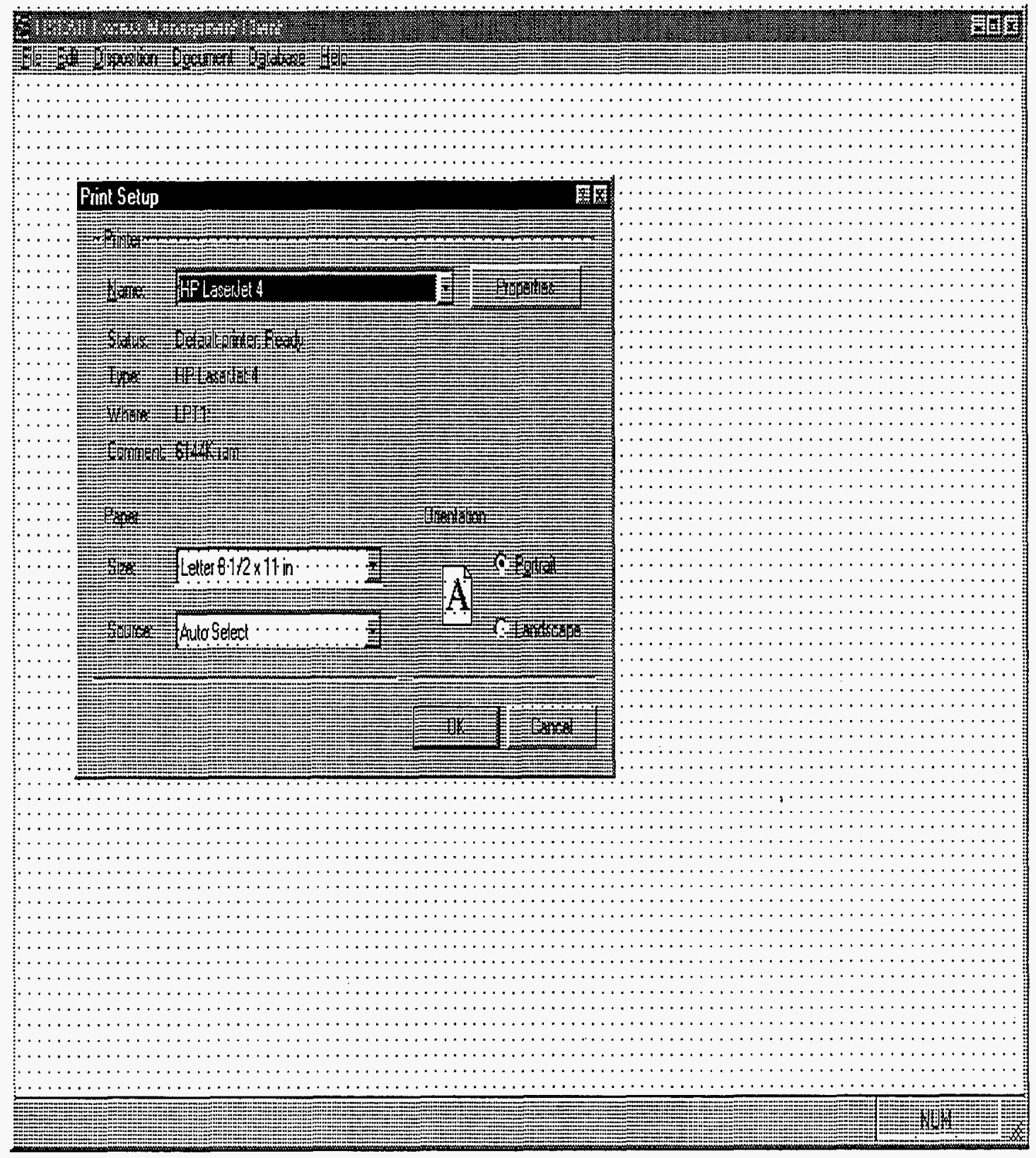

Once the above screen appears, you are in the WINDOWS environment.

Printer Setup is the same as WINDOWS.

User can refer to the WINDOWS manual for guidance.

\section{GO TO NEXT PAGE.}




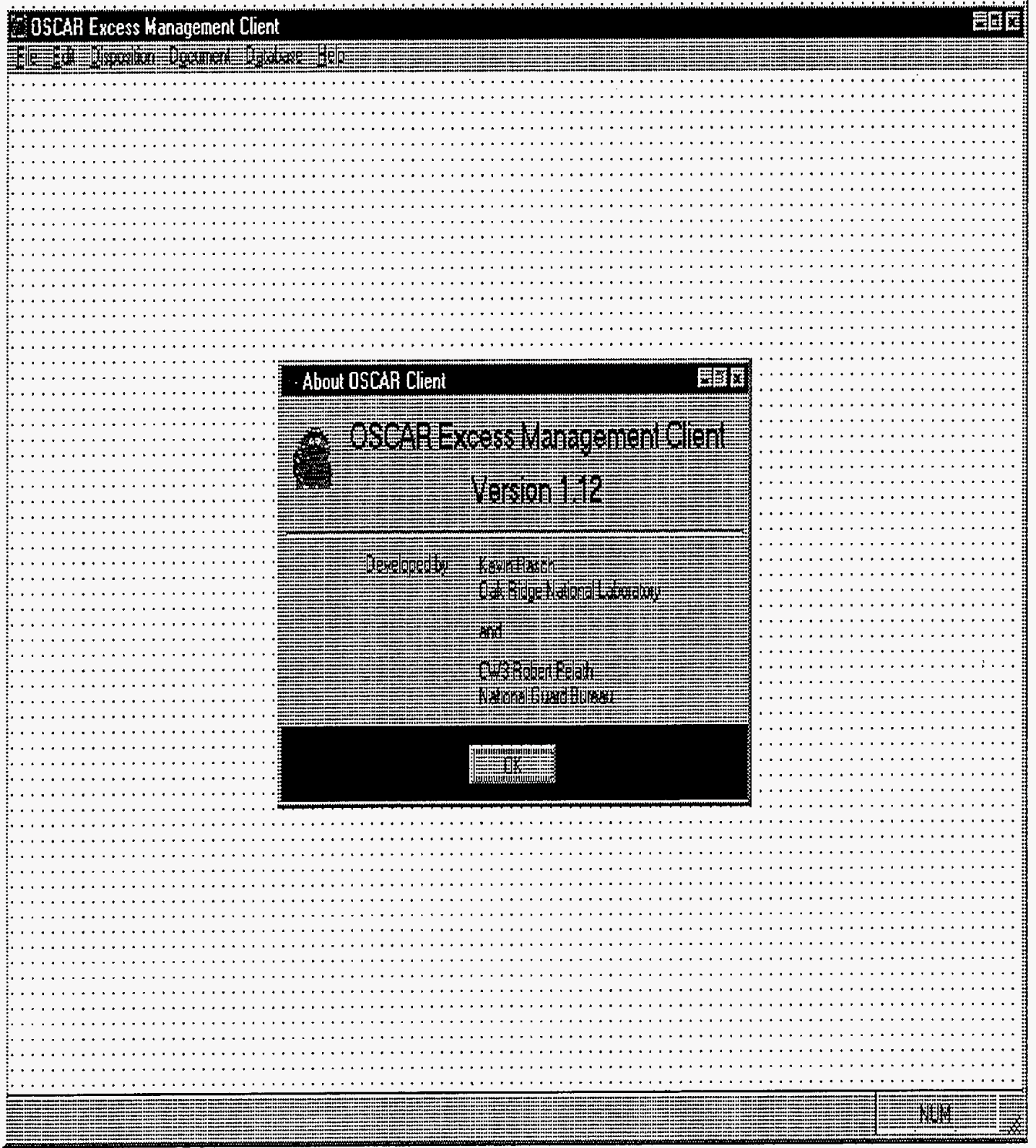

When user Clicks On the $<$ help $>$ function on the Main Menu the screen above will appear. This screen allows the user to check the latest version of the OSCAR Client Program.

When this version does not match the OSCAR mainframe version, the user will not be able to process transactions from the PC. The supervisor or the System Administrator can tell you what version your $P C$ should be on. 
THIS PAGE NOT USED

Figure 3-8 


\section{SECTION 4. EXCESS MANAGEMENT PROCESS}

4.1 General. The Excess Management Process is designed to allow the NGB Manager to react to Customer Excess Reports (FTEs), create transactions that will update the NGB Master File and send disposition instructions and/or information to the customer.

4.2 Excess Management Process (Manual). This process will allow the NGB/State manager to create manually the following transactions to the NGB Master File and furnish customer dispositions or information. The following transactions can be created by the NGB Manager; AC-, AE-, D6/D4, FTC, FTD, FTE, FTF, FTI, FTM, FTR, AND FTZ. Transactions that can be created by the state manager are as follows; AC/AK, FTC, FTF, FTL; FTM, or D6/D4.

\subsubsection{Customer Transaotions.}

a. AC/AK transactions can be created by clicking on the Document portion from the OSCAR Excess Management Client menu, then clicking on the ACl Cancellation request. User will be prompted to enter the Document Number to be cancelled. The following actions will occur:

1. Edit-AC/AK must have a matching AE/FTE/FTR in the NGB Master File.

2. NGB Master File will be flagged as Complete.

3. AE2 status " $B Q$ " will be provided to customer canceling due-in.

4. The following action will be taken for the Customer Excess Report: 
(a) When the cancellation request is for the entire quantity of the original Excess Report, the report will be re-established in the NGB Master File with an "A" in the Activity-Indicator code, which will allow the manager to provide another disposition to customer.

(b) If the cancellation is for a partial quantity, the customer excess report will be cancelled with an FTR status "SA".

5. Images of all transactions created will be posted to the NGB Master File.

b. D6/D4 transactions can be created by the manager when an asset has been received by the customer, but for some reason has not been posted to the NGB Master File. The manager can create this transaction by clicking on the D6/D4 Receipt of Shipment prompt from the Document portion of the OSCAR Excess Management Client Master Menu and then entering the Document Number. The following actions will occur:

1. Edit-D6/D4 must have matching AE/FTE/FTR in the Master File.

2. Master File will be flagged as completed.

3. FTz transaction will be furnished to customer reporting excess.

4. Images of all transactions will be posted to the Master File. 
c. FTC Cancellation transaction can be created when an asset is no longer available for shipment. The user can select the FTC Cancel excess report from the OSCAR Excess Management Client Document portion. The user will be prompted to enter the Document Number. The following actions will occur:

1. The Master File will be flagged as completed.

2. When Disposition has been furnished to ship to another state, an AE2 with status "CB" will be furnished to the receiving state. The state canceling the excess asset is responsible for a telephone conversation or forwarding an E-MAIL/FAX Message informing the receiving state.

3. Images of all transactions will be posted to the Master File.

d. FTF Excess Report Follow-up can be created by the user to furnish information on an Excess Report to the customer. The manager can click on the FTF Follow-up from the Document Option of the OSCAR Excess Management Client option and enter the Document Number.

1. FTC present in the Master File will cause the program to generate an FTR cancellation with status "SA" to the customer.

2. FTD in the Master File will cause the program to generate another FTD to the customer.

3. FTR in the Master File will cause the program to generate an FT6 to the customer.

4. FTL/FTM/FTT in the Master File will cause the program to create an image of the transaction for the customer. 
e. FTL Excess Shipment Delay status can be created by the user when the customer indicates there is a delay in shipment. The user can click on the FTL Shipment Delay Status from the Document Option of the OSCAR Excess Management Client and then enter the Document Number.

1. Edit-Document Number must match a record in the Master File.

2. The System will generate an $A E-$ with "BD" status to the receiving state.

3. The Master File record will be flagged as delayed shipment.

4. Transaction will be posted to the Master File.

f. FIM Excess Shipment status can be created when the customer has indicated the excess asset has been shipped. User can click on the FTM Shipment status from the Document portion of the OSCAR Excess Management Client option.

1. The program will generate an AS- Shipment Status to the receiving state/activity.

2. Post images of all transactions to Master File.

g. FTZ Materiel receipt can be created by the user when the receiving state has indicated the asset has been received. The user can click on the FTZ Materiel Receipt Status from Document portion of the OSCAR Excess Management client option.

1. An image of the FTZ will be furnished to the reporting state to close out SARSS files.

2. Images of all transactions will be posted to the Master File. 


\subsubsection{NGB Manager Disposition.}

a. FTD-Customer Delay status. The NGB manager can choose to furnish the customer a delay status by clicking on the Disposition portion of the OSCAR Excess Management Client option. (See Fig. 4-1 through Fig. 4-8.)

1. Short-Term-Delay status. The number of days delay is determined by the days_sterm delay parameter in the setup table. WThen short-Term Delay has been indicated, the Activity-Indicator will remain an "A", which means the FTE will be retrieved each time the manager requests assets for RVARS.

2. Iong-Term-Delay Status. The number of days delay is determined by the days_lterm_delay parameter in the setup table. When Iong-TermDelay option is chosen, the asset is considered to be on NGB HOID and the Activity-Indicator is changed to " $D$ ". After the long-term-hold date has been exceeded, the system will automatically return the Activity-Indicator to "A". The Manager has the option of retrieving or not retrieving long-term-hold items to RVARS.

b. FTR-Reply to Customer Excess Report. The manager can provide a reply by clicking on the ETR Send Response to state portion from the Disposition option of the OSCAR Excess Management Client menu. (See Fig. 4-10 through Fig. 4-24.) 
1. FTR with advice "TB" and the SHIP-TO state/activity in position 54-56. The supplementary address field will contain the Unit Identification Code (UIC) of the unit/activity authorized the asset. The priority will be determined by the Equipment Readiness Code (ERC) and the Force/Activity Designator (FAD) of the receiving unit/activity. Once an FTR has been sent, the ActivityIndicator is changed to an "I".

2. FTR with advice "TC" transferring the asset to the Defense Re-utilization and Marketing Office (DRMO). When "TC" advice has been given, the Activity-Indicator is changed to a " $C$ " as completed.

3. FTR with advice "SA" will automatically be provided by the program when a Customer Excess Report (FTE) is received and the DODAAC of the record does not match the program's DODAAF.

c. Pass FTE to ICP. This option is used when the manager determines that the ARNG has no valid need for the asset and has selected to pass it on to the Inventory Control Point (ICP) for actions. Upon notification of this action, the states must furnish any technical inspection and/or supporting documentation required by the ICP(s). (See Fig. 4-25 through Fig. 4-31.) 


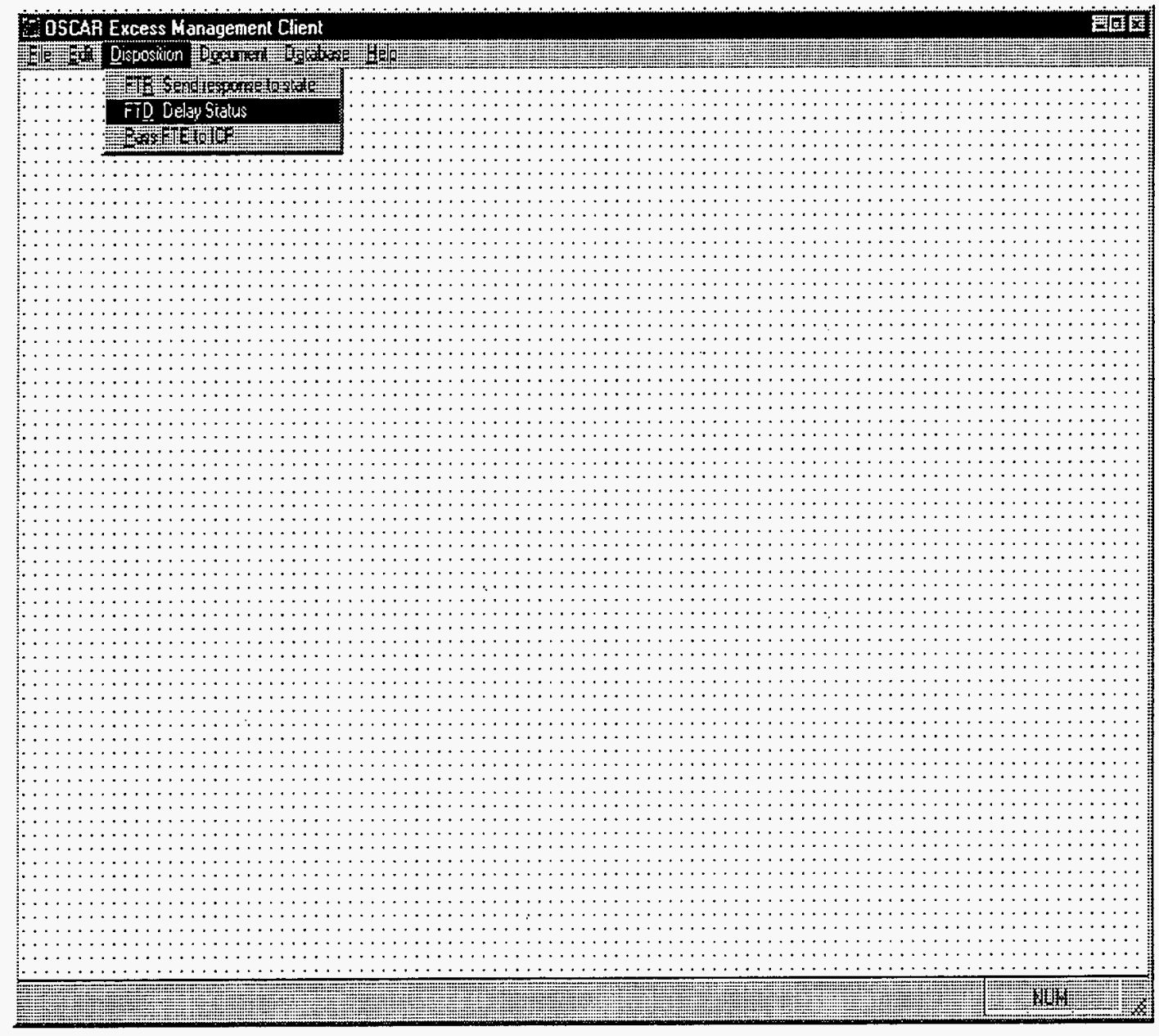

Click On <Dispostion> from the OSCAR Excess Management Client Main Menu.

THEN

Click On <FTD Delay Status $>$

\section{GO TO NEXT PAGE}

Figure 4-1 


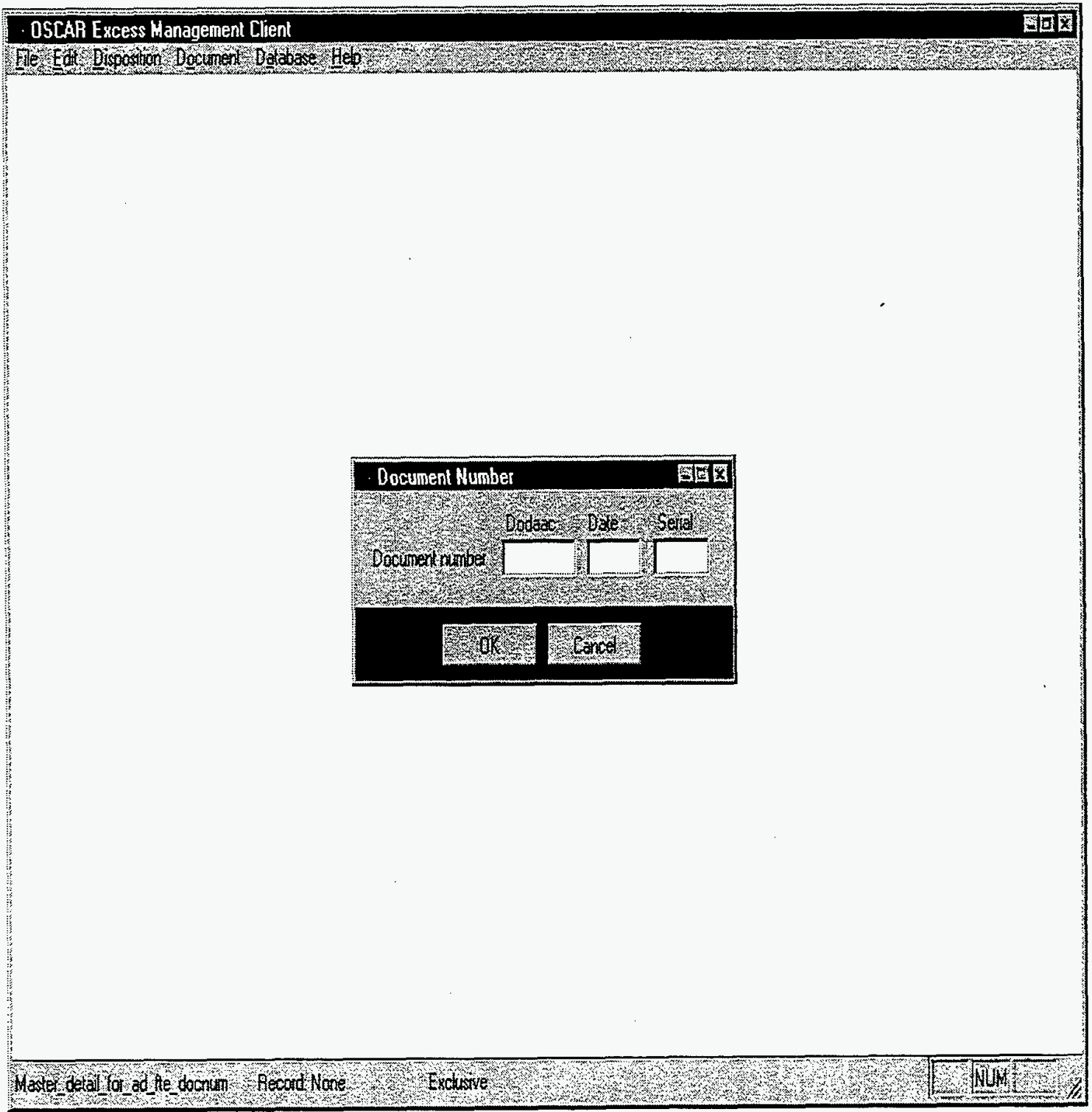

USER MUST ENTER DOCUMENT NUMBER.

DOCUMENT NUMBER MUST HAVE A MATCHING EXCESS REPORT (FTE) IN MASTER FILE.

\section{GO TO NEXT PAGE}

Figure 4-2 


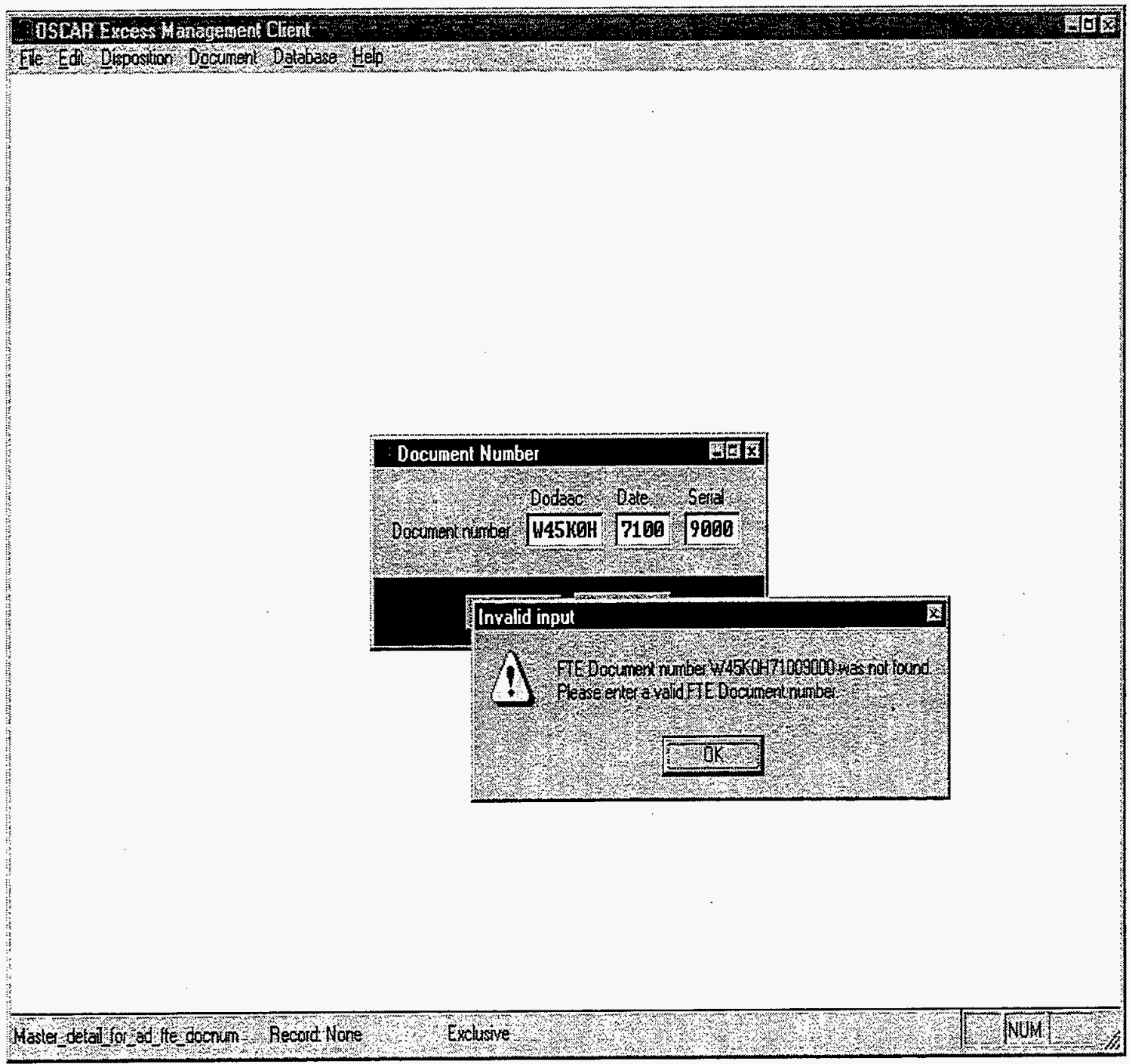

WHEN NO MATCHING RECORD IS FOUND, THE MESSAGE ABOVE WILL DISPLAY.

USER SHOULD CHECK DOCUMENT NUMBER ENTERED. IF NOT CORRECT, RE-ENTER.

WHEN RECORD IS REQUIRED, USER CAN ADD THE EXCESS REPORT (FTE) TO MASTER FILE THROUGH THE DOCUMENT PROCESS BEFORE CONTINUING.

\section{GO TO NEXT PAGE}

Figure 4-3 


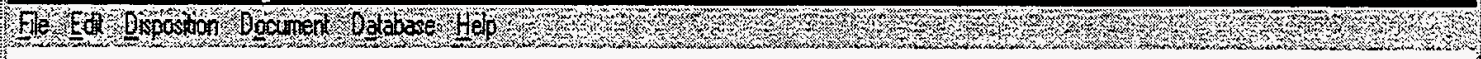

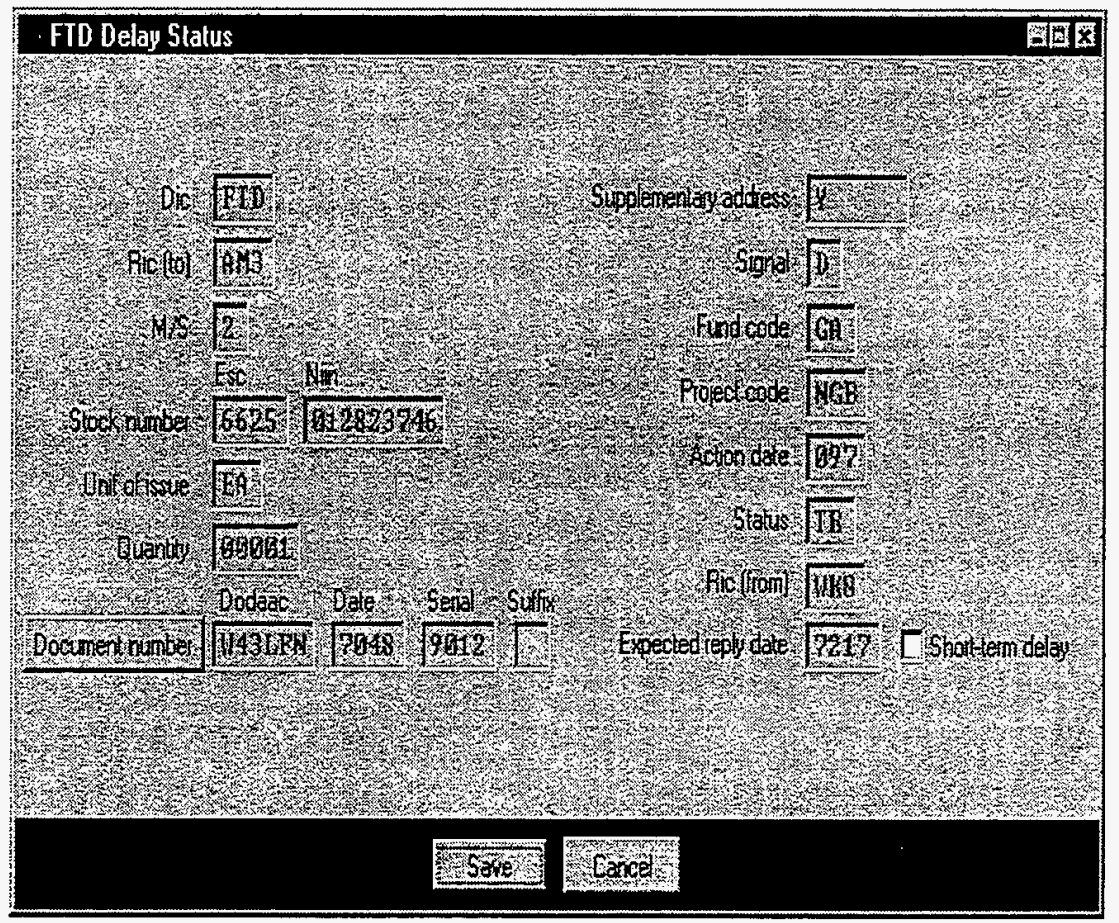

WHEN A MATCHING RECORD HAS BEEN FOUND, THE WINDOW ABOVE WILL APPEAR.

\section{THE FOLLOWING OPTIONS ARE AVAILABLE:}

CLICK ON <Document Number $>$ TO ENTER A DIFFERENT DOCUMENT NUMBER.

CLICK ON $<$ Short-term delay $>$ [Short-term delay is forty five (45) days.]

CLICK ON $<$ Save $>$ to accept the long-term delay default.

(Long-term delay is one hundred and twenty (120) days.)

NOTE: ANY FTR RESPONSE MUST BE COMPLETED PRIOR TO PLACING ASSET ON long-term delay.

Figure 4-4 


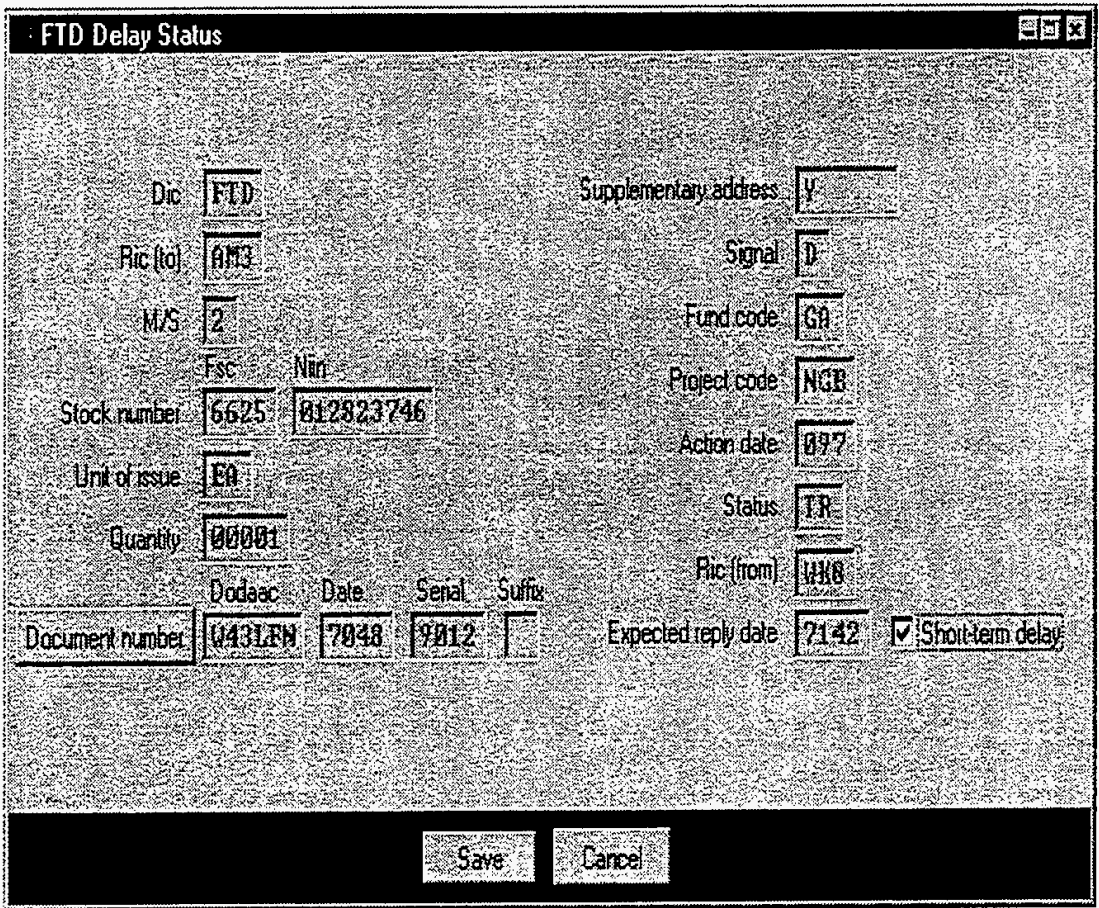

WHEN USER CLICKS ON THE BLOCK < Short-term delay> A CHECKMARK WILL APPEAR AND THE $<$ Expected reply date $>$ will change to forty five (45) days. CLICK ON $<$ Save $>$ to accept actions.

\section{GO TO NEXT PAGE}

Figure 4-5 


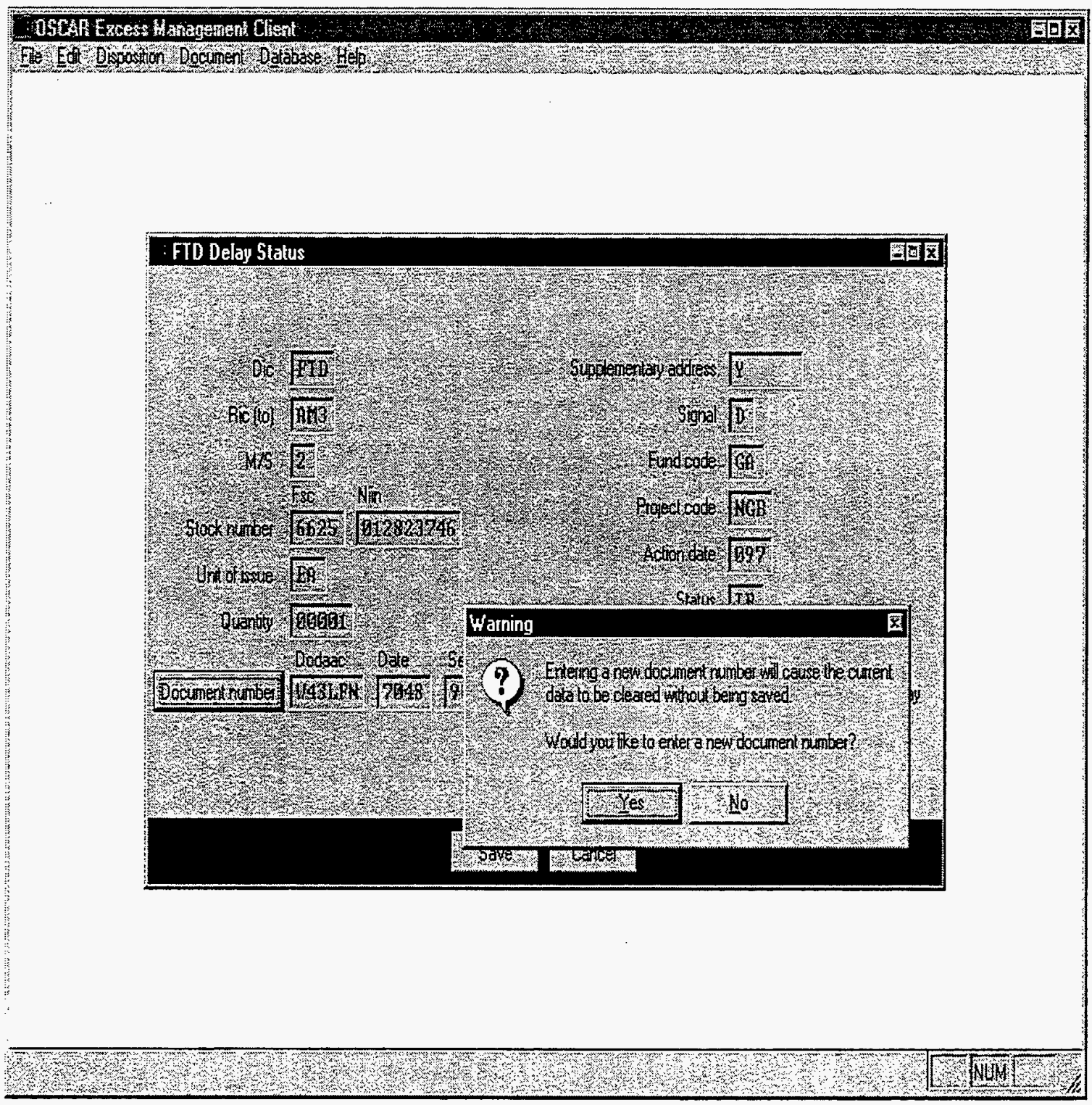

WHEN USER CLICKS ON THE <Document Number> OPTION. THE MESSAGE ABOVE WILL APPEAR.

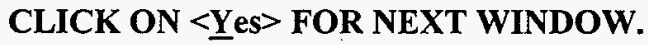
CLICK ON $<\underline{\text { No}}>$ TO RETURN TO PREIVIOUS WINDOW $>$

\section{GO TO NEXT PAGE}

Figure 4-6 


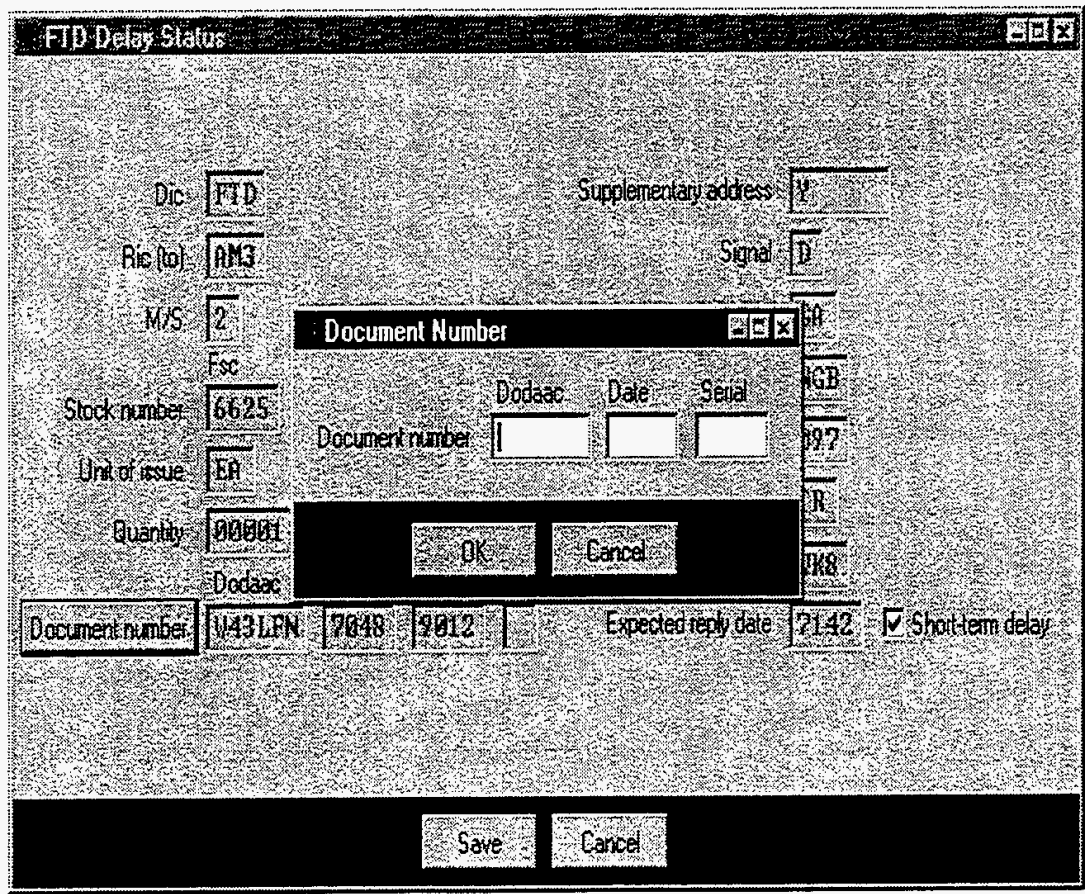

WHEN THE WINDOW ABOVE APPEARS, THE USER CAN ENTER A NEW DOCUMENT NUMBER AND CLICK ON $<$ OK > OR CLICK ON <Cancel $>$ TO RETURN TO PREVIOUS WINDOW.

\section{GO TO NEXT PAGE}

Figure 4-7 


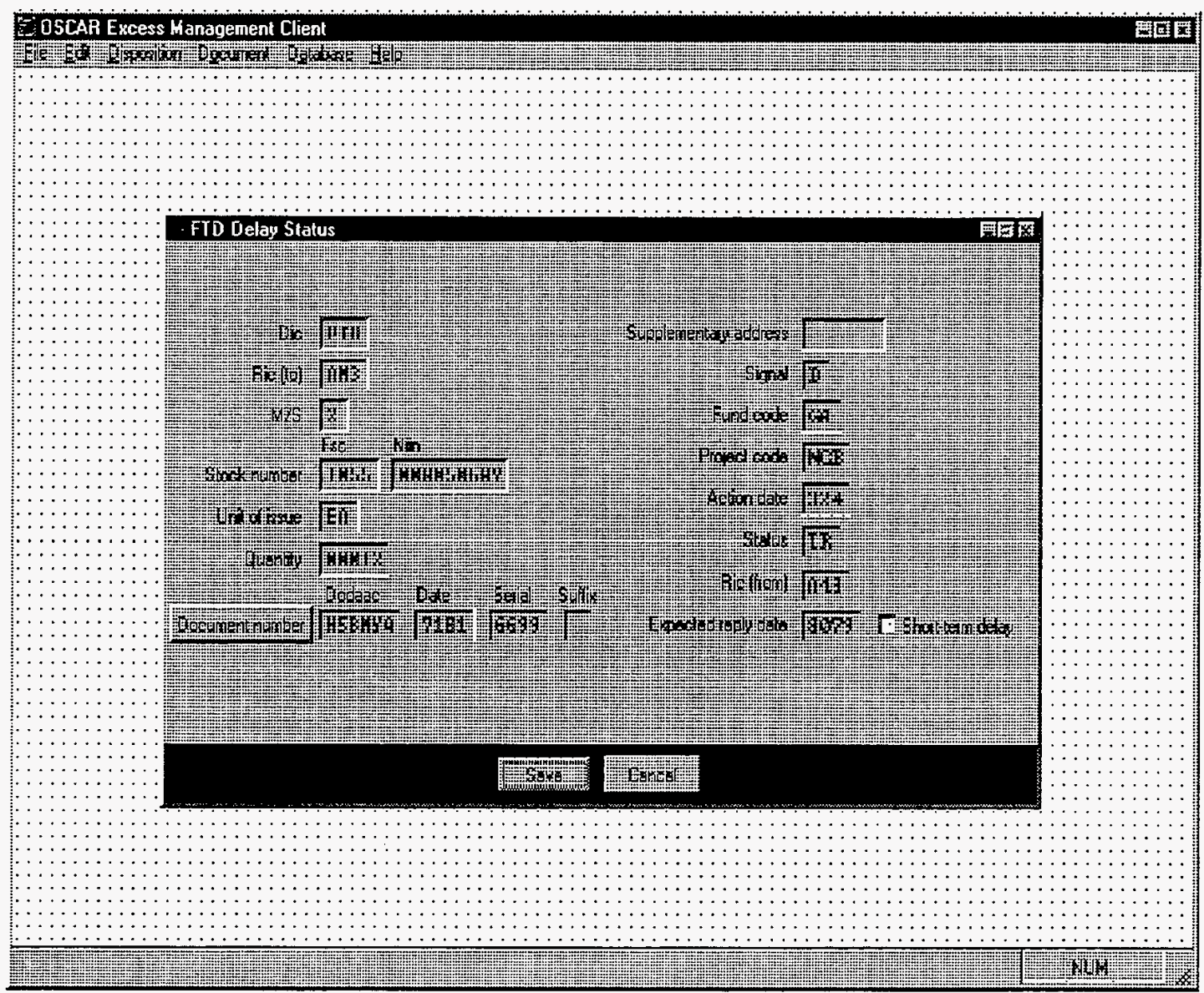

Once a new Document Number is selected and user Clicks $<\mathbf{O K}>$ or presses $<$ Enter $>$, The Window will display with the corresponding information.

User must verify information then Click On $<$ Save $>$ to accept action.

User can Click On $<$ Cancel $>$ to return to the Main Menu without processing the transaction.

\section{GO TO NEXT PAGE}

Figure 4-8 


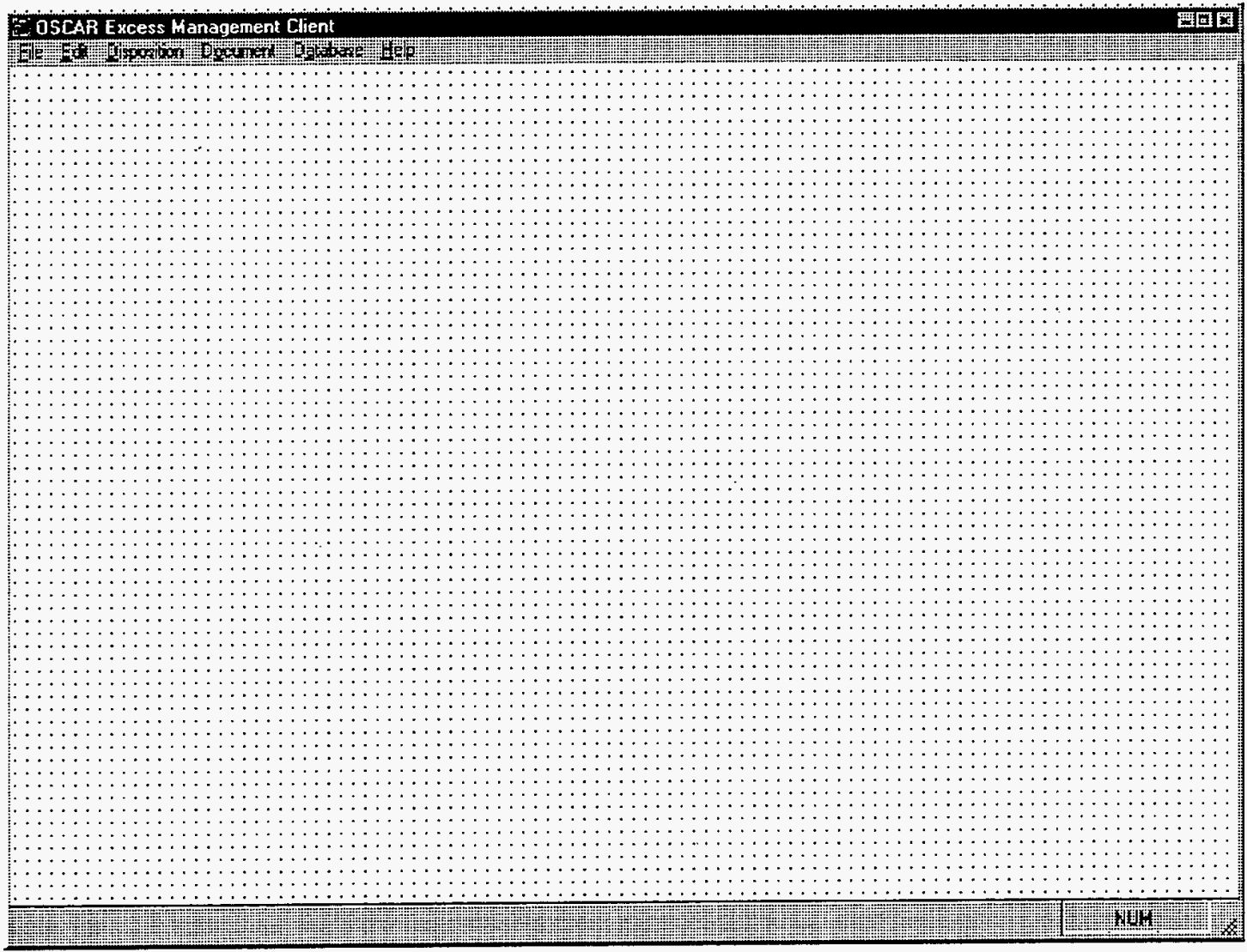

When the user presses $<$ Cancel $>$, the window shown above will display.

User has returned to the OSCAR Excess Management Client Master Menu. 


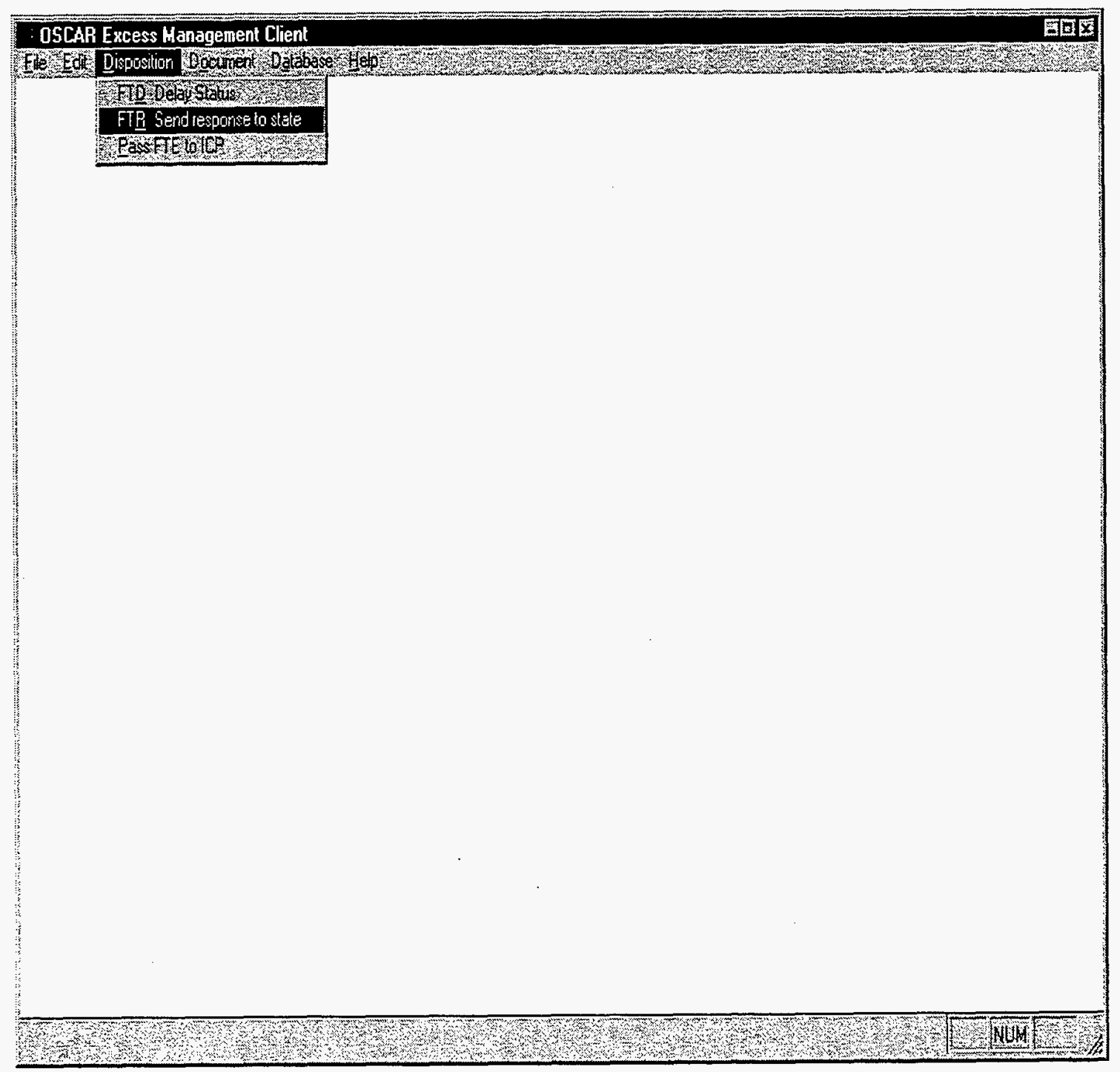

FROM THE OSCAR Excess Management Client Menu

CLICK ON <FTR Send Response to State>

\section{GO TO NEXT PAGE}

Figure 4-10 


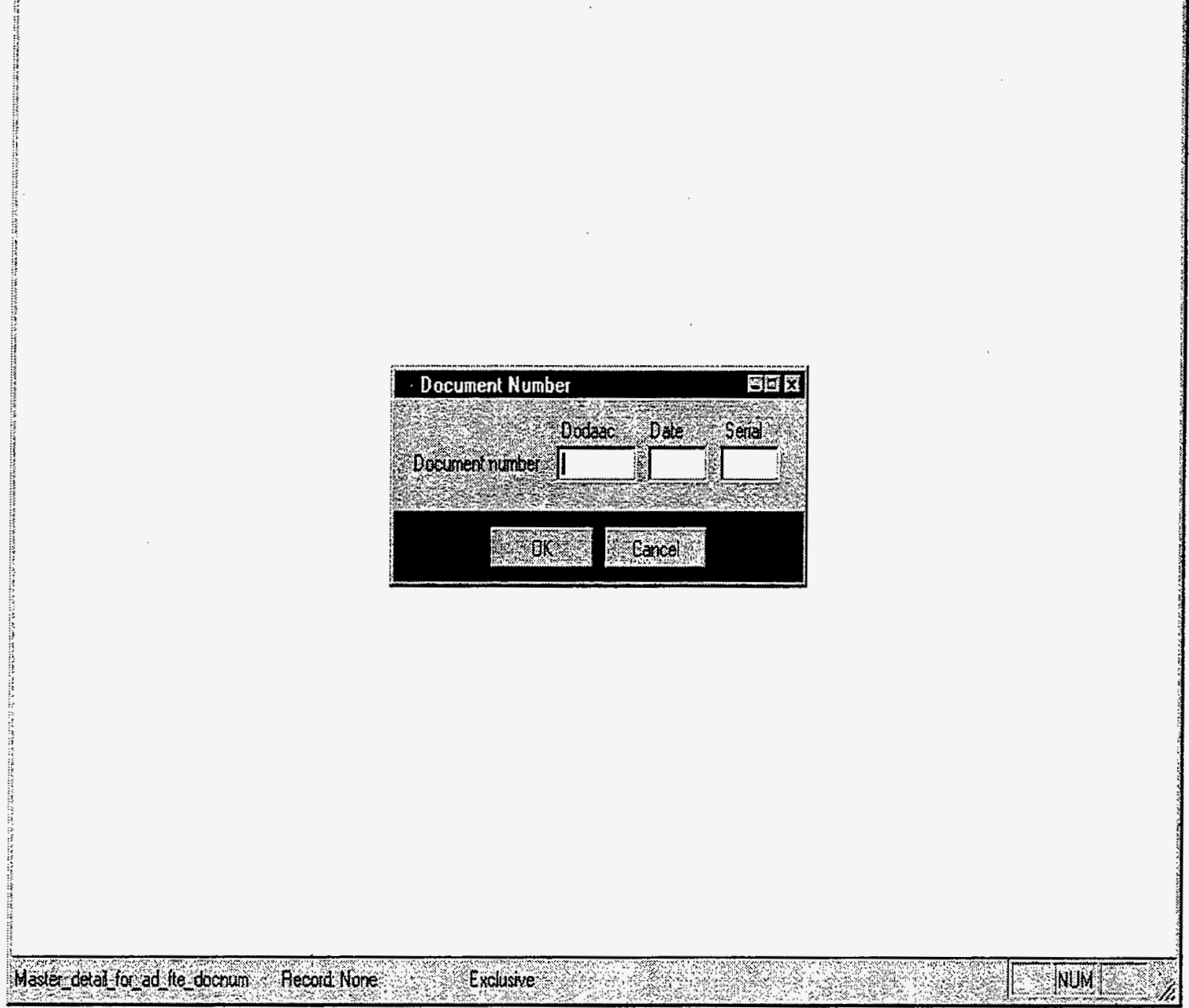

USER MUST ENTER A DOCUMENT NUMBER THAT MATCHES THE NGB MASTER FILE.

\section{GO TO NEXT PAGE}

Figure 4-11 


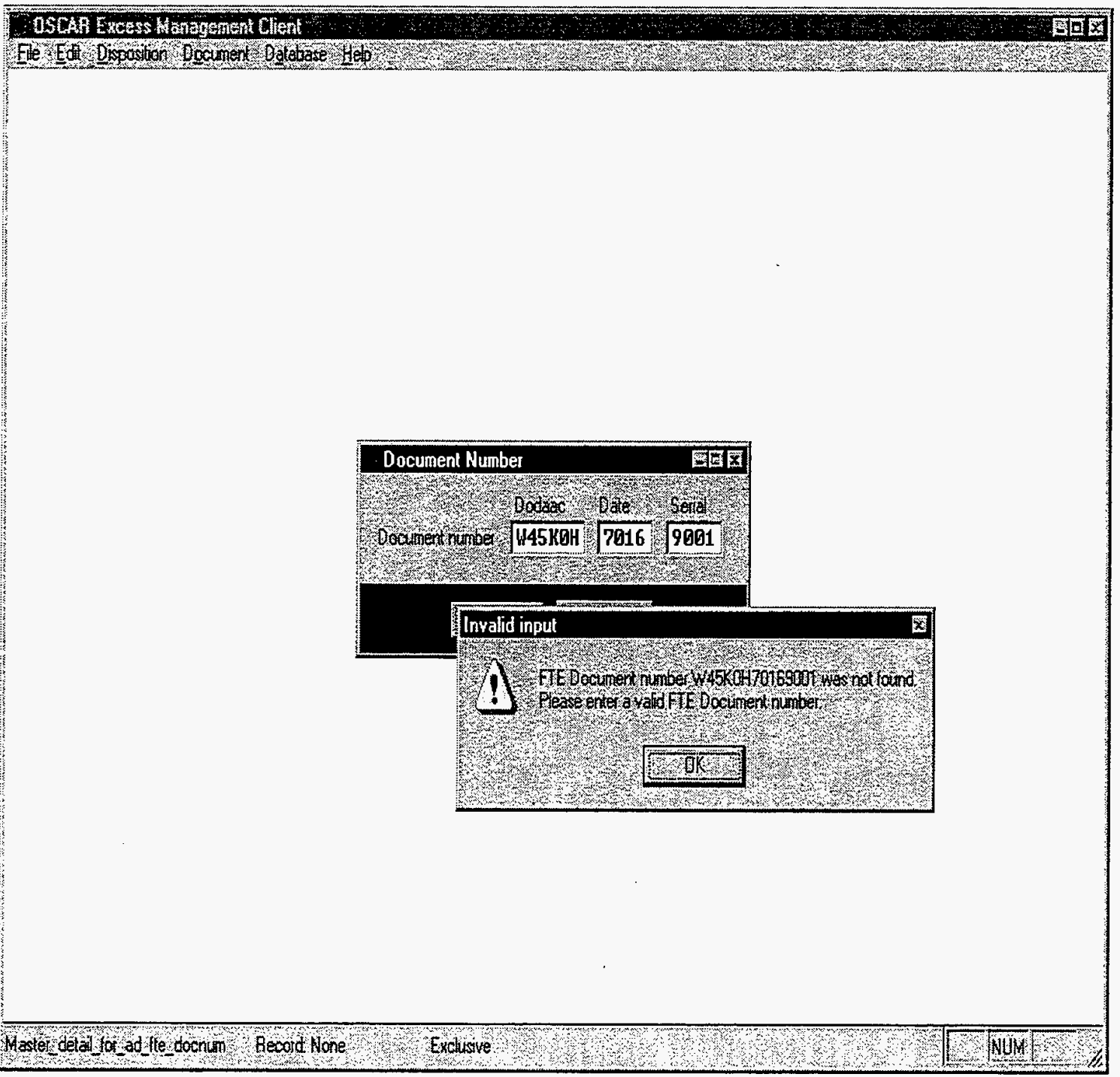

WHEN DOCUMENT NUMBER DOES NOT MATCH A RECORD IN THE MASTER FILE, THE MESSAGE ABOVE WILL APPEAR.

USER SHOULD CHECK INFORMATION FOR CORRECTNESS.

IF NOT CORRECT,

CLICK ON <OK> AND RE-ENTER THE CORRECT DOCUMENT NUMBER.

USER CAN GO TO THE MAIN MENU UNDER < Document> AND ENTER A FTE DOCUMENT IF REQUIRED. (Document Number must match an Excess Report Number in Master File)

\section{GO TO NEXT PAGE}

Figure 4-12 


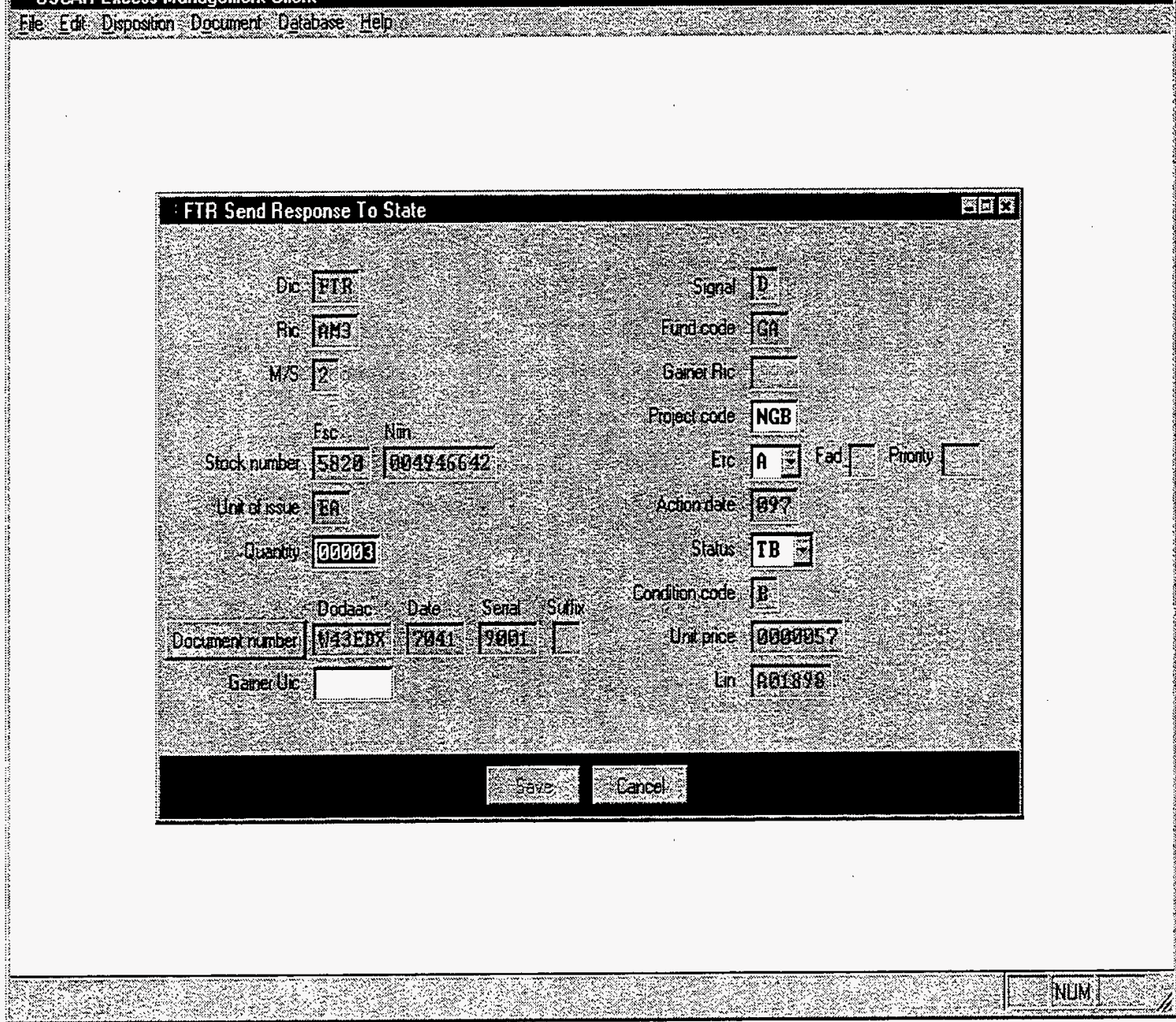

WHEN DOCUMENT NUMBER ENTERED MATCHES AN EXCESS REPORT (FTE) IN MASTER FILE, THE WINDOW ABOVE WILL OPEN AND INFORMATION WILL DISPLAY.

\section{THE FOLLOWING FIELDS CAN BE CHANGED:}

\section{QUANTITY}

GAINER UIC (Mandatory Entry)

PROJECT CODE

EQUIPMENT READINESS CODE (ERC)

\section{STATUS}

\section{GO TO NEXT PAGE}

Figure 4-13 


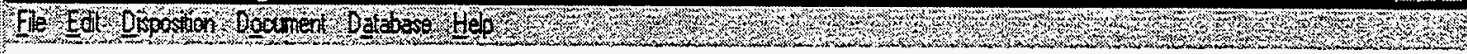

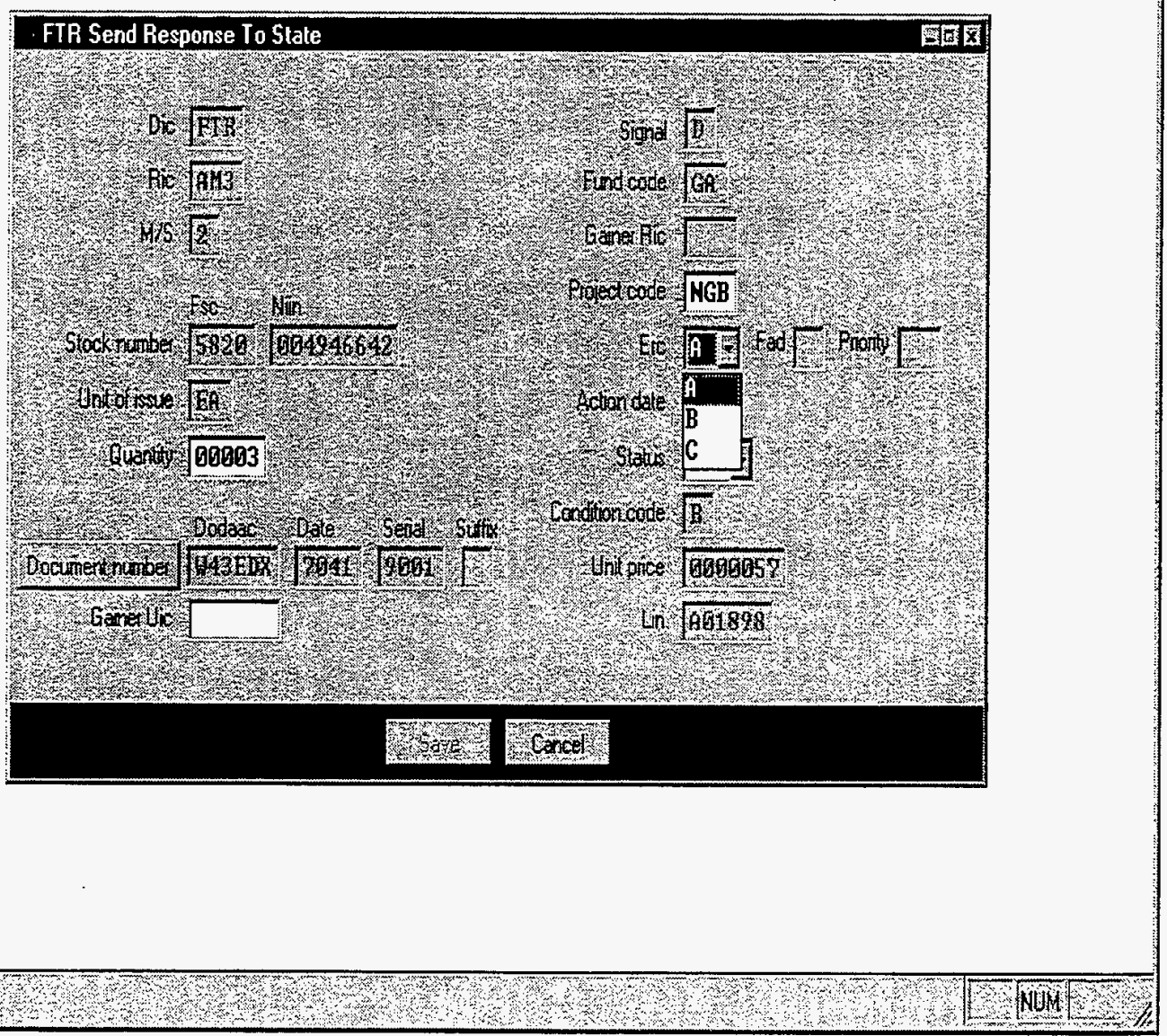

USER CAN SELECT THE EQUIPMENT READINESS CODE (ERC) OR ACCEPT THE DEFAULT OPTION WHICH IS ERC 'A'.

CLICK ON THE DOWN ARROW TO THE RIGHT OF THE ERC FOR OPTIONS. HIGHLIGHT THE OPTION AND CLICK TO ACCEPT. 


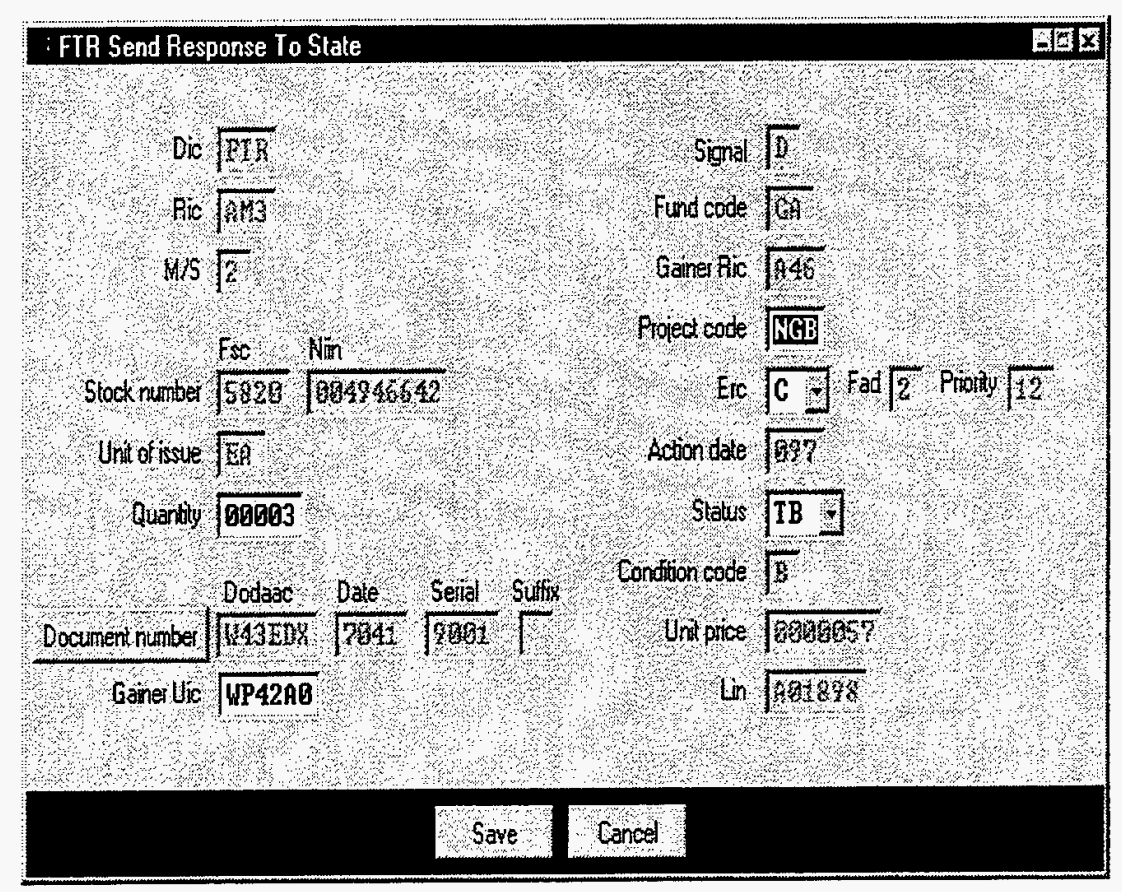

USER MUST ENTER THE < Gainer UIC> (Gainer UIC must match DODAAF) IF UIC DOES NOT MATCH DODAAF. IT MUST BE ADDED BEFORE CONTINUING.

ONCE A VALID UIC HAS BEEN ENTERED, THE Gainer RIC FOR THE Gainer UIC STATE WILL AUTOMATICALLY APPEAR. ALSO THE FAD OF THE UIC AND PRIORITY WILL APPEAR. (Priority is based on the Gainer UIC FAD and the ERC. )

CHECK ALL OTHER INFORMATION. IF EVERY THING IS CORRECT CLICK ON <Save> TO ACCEPT ACTIONS.

IF NOT, CONTINUE TO NEXT PAGE

Figure 4-15 


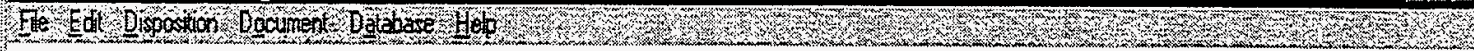

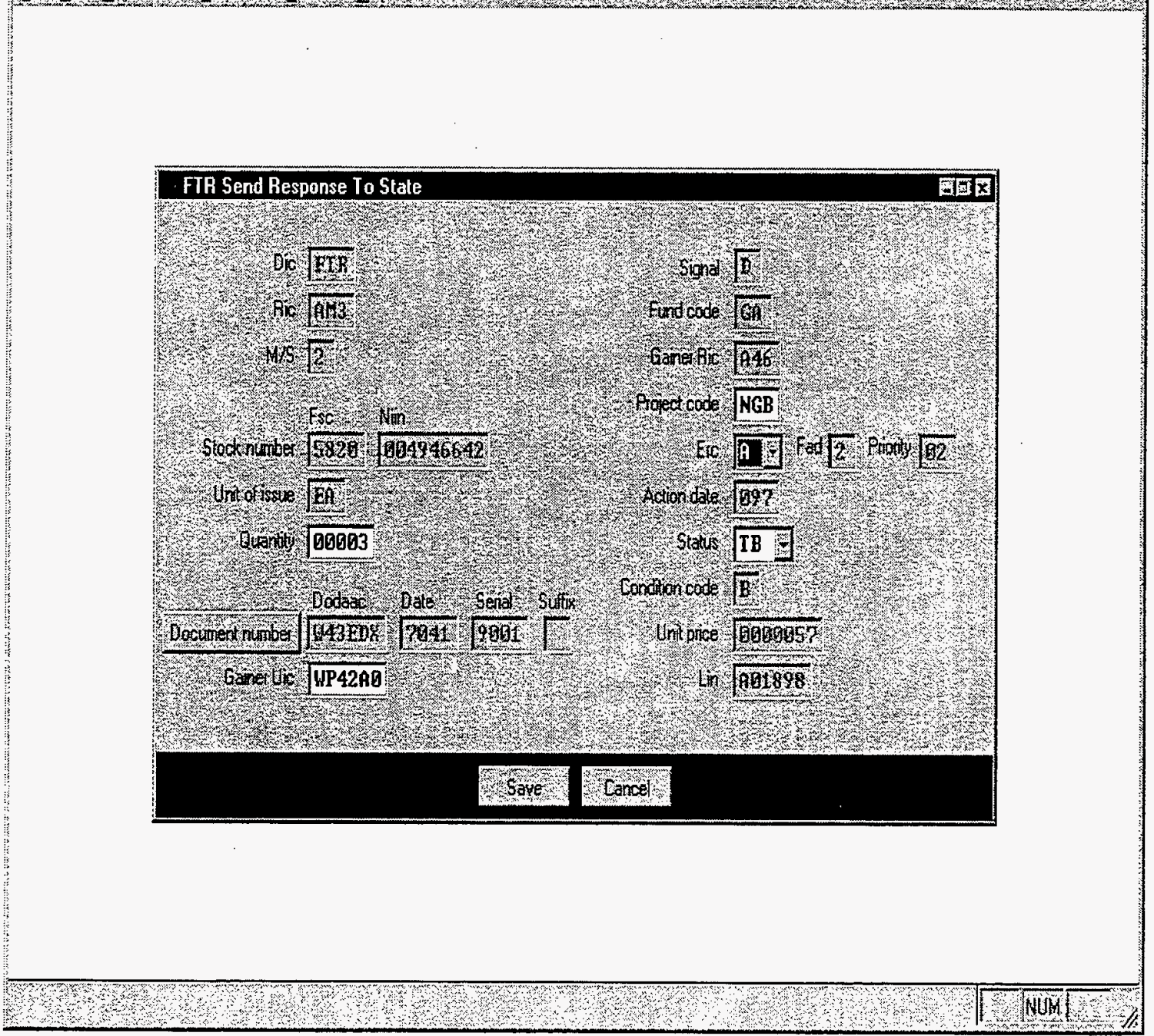

NOTE: THE PRIORITY CHANGED WHEN ERC 'A' IS ENTERED.

\section{GO TO NEXT PAGE}

Figure 4-16 


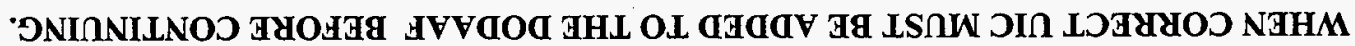

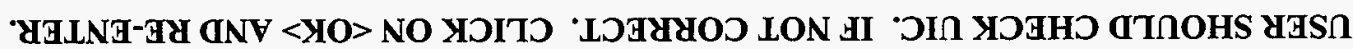
NHdO TTIM G GOGV

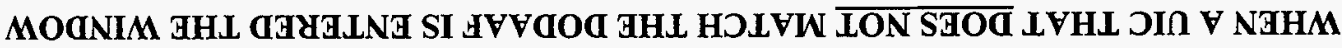

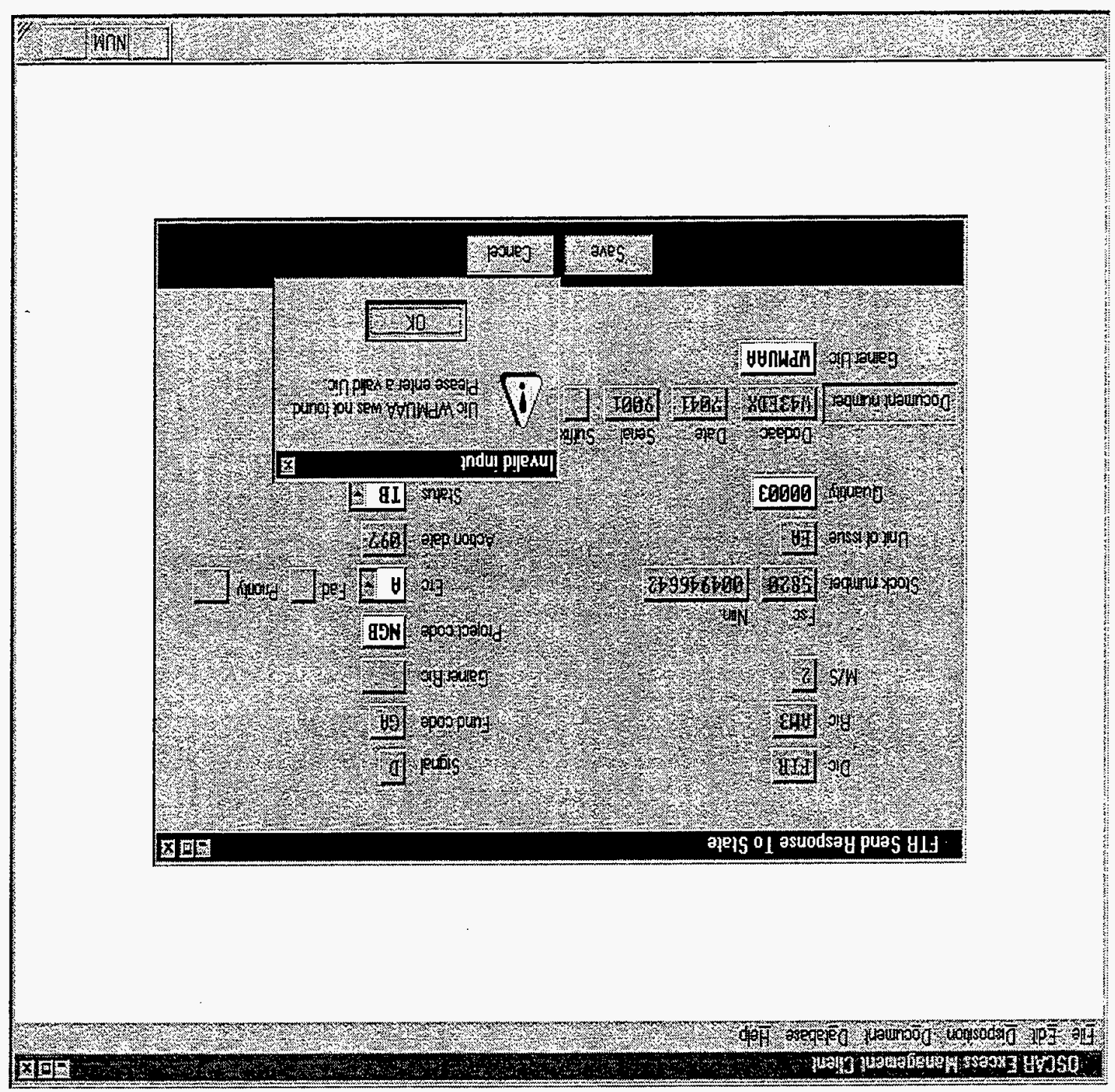




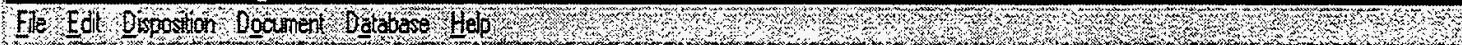

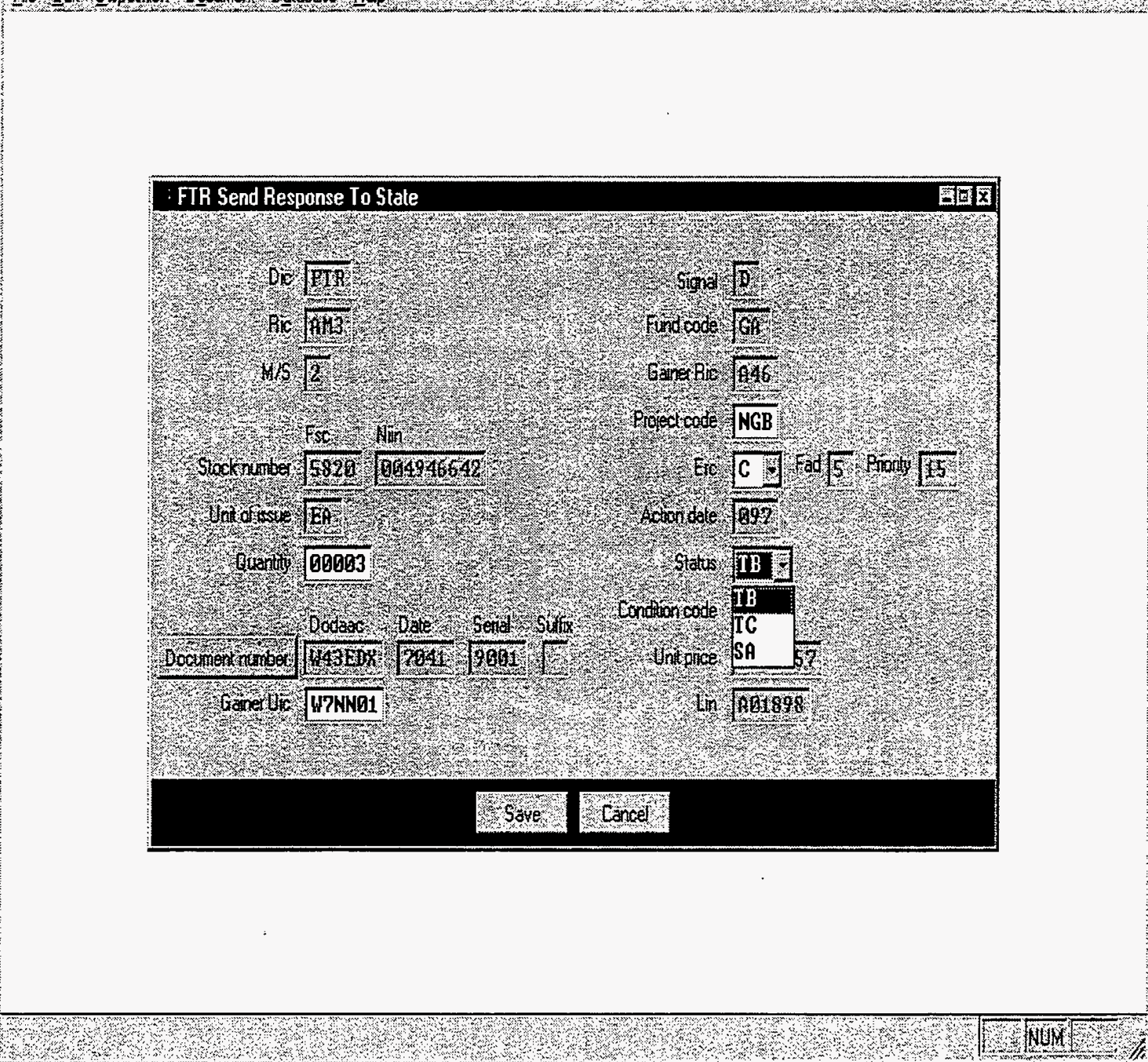

\section{WHEN USER CLICKS ON THE DOWN ARROW NEXT TO $<$ Status $>$ THE FOLLOWING OPTION WILL APPEAR.}

'TB' Status is used when manager wishes to ship asset to another state.

(Gainer UIC must be entered.)

'TC' Status is used when manager wishes to send asset to DRMO.

(UIC and RIC of state submitting the Excess Report (FTE) will automatically appear.)

'SA' Status is used when manager wishes to Cancel the Excess Report back to the Customer. (UIC and RIC of state submitting the Excess Report (FTE) will automatically appear.)

\section{GO TO NEXT PAGE}

Figure 4-18 


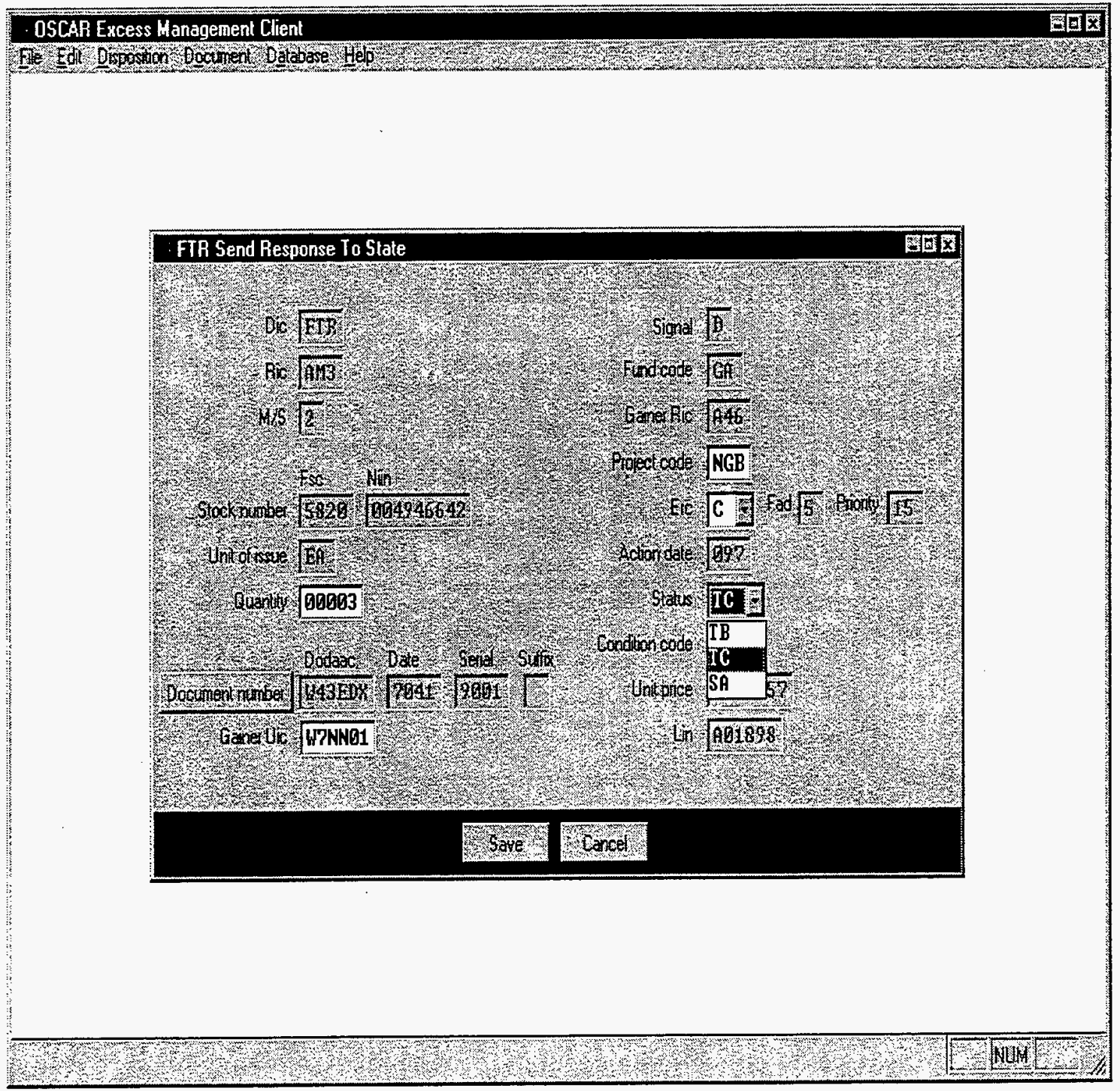

WHEN USER SELECTS 'TC' Status asset will be directed to DRMO.

WHEN INFORMATION IS CORRECT, CLICK ON < Save> TO ACCEPT ACTIONS.

\section{GO TO NEXT PAGE}

Figure 4-19 


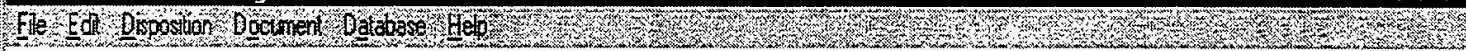

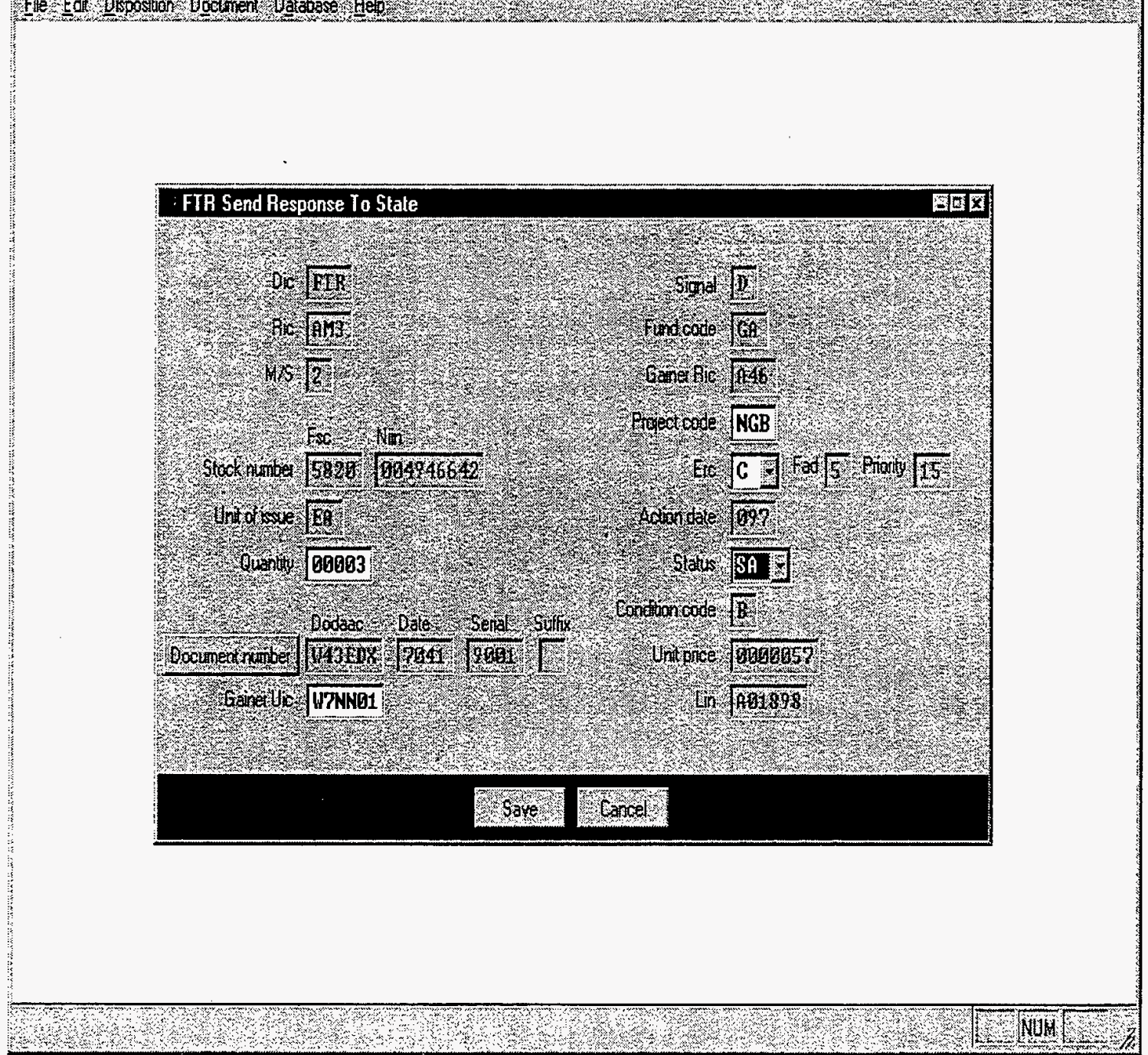

WHEN USER SELECTS 'SA' Status, THE ASSET WILL BE CANCELLED BACK TO THE STATE REPORTING.

WHEN INFORMATION IS CORRECT, CLICK ON < Save $>$ TO ACCEPT ACTIONS.

\section{GO TO NEXT PAGE}

Figure 4-20 


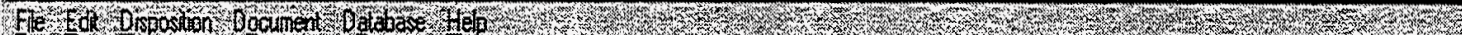

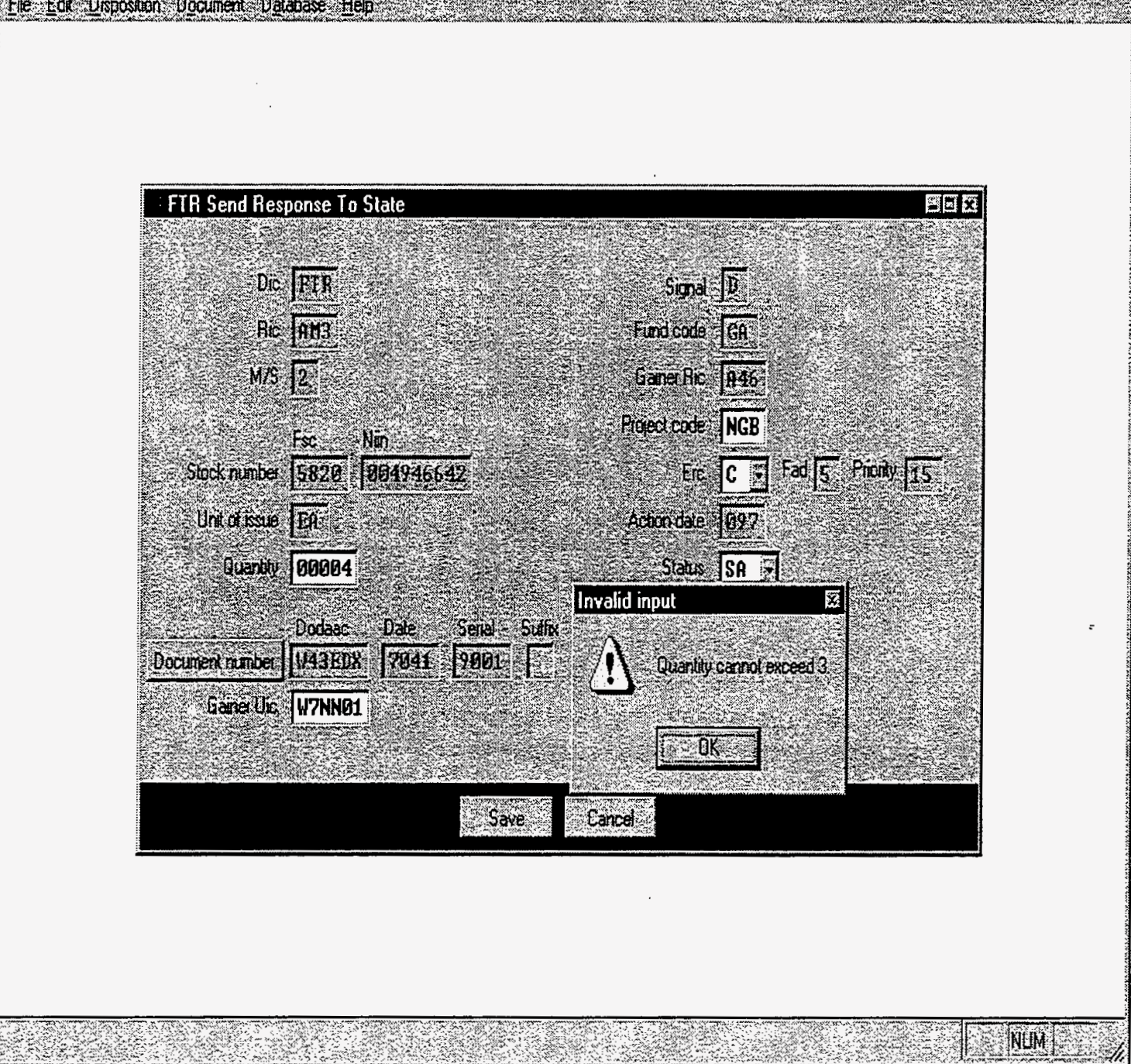

WHEN USER CHANGES QUANTITY FIELD THE QUANTITY CANNOT BE GREATER THAN THE EXCESS REPORT QUANTITY.

THE MESSAGE ABOVE WILL APPEAR WHEN THE QUANTITY CHANGED IS GREATER THAN THE EXCESS REPORT QUANTITY.

\section{GO TO NEXT PAGE}

Figure 4-21 


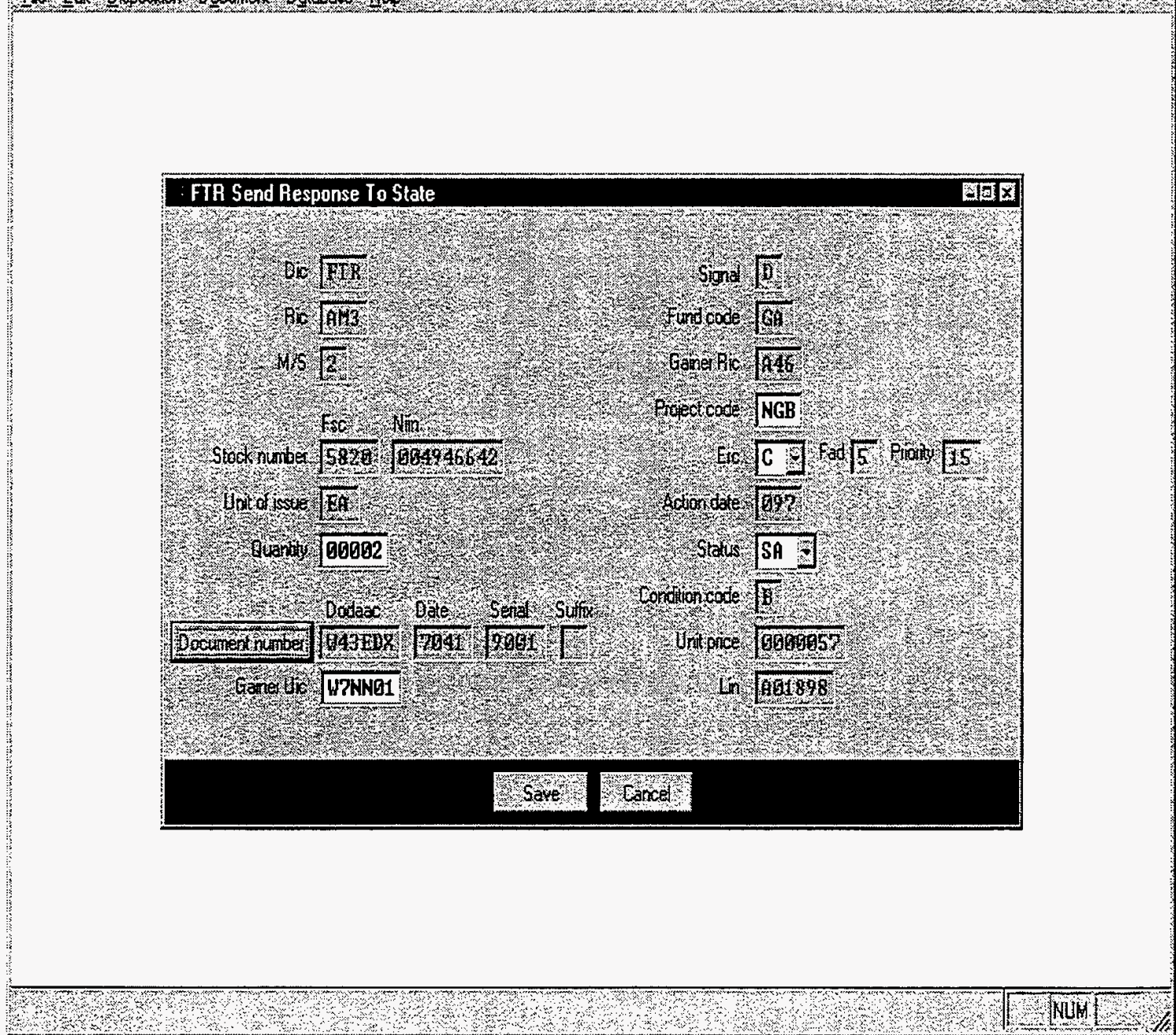

THE QUANTITY FIELD CAN BE LESS THAN THE EXCESS REPORT QUANTITY.

THE SYSTEM WILL AUTOMATICALLY SUFFIX THE FTR AND FTE.

WHEN THE FTR QUANTITY CHANGES, THE REMAINING FTE QUANTITY WILL BE RETURNED TO THE MASTER FILE. WHEN RVARS IS RUN AGAIN, THE FTE WILL BE SELECTED AGAIN.

AN FTR FOR THE CHANGED QUANTITY WILL BE FURNISHED TO THE STATE WITH A SUFFIX.

\section{GO TO NEXT PAGE}

Figure 4-22 
: OSCAA Excess Management Client

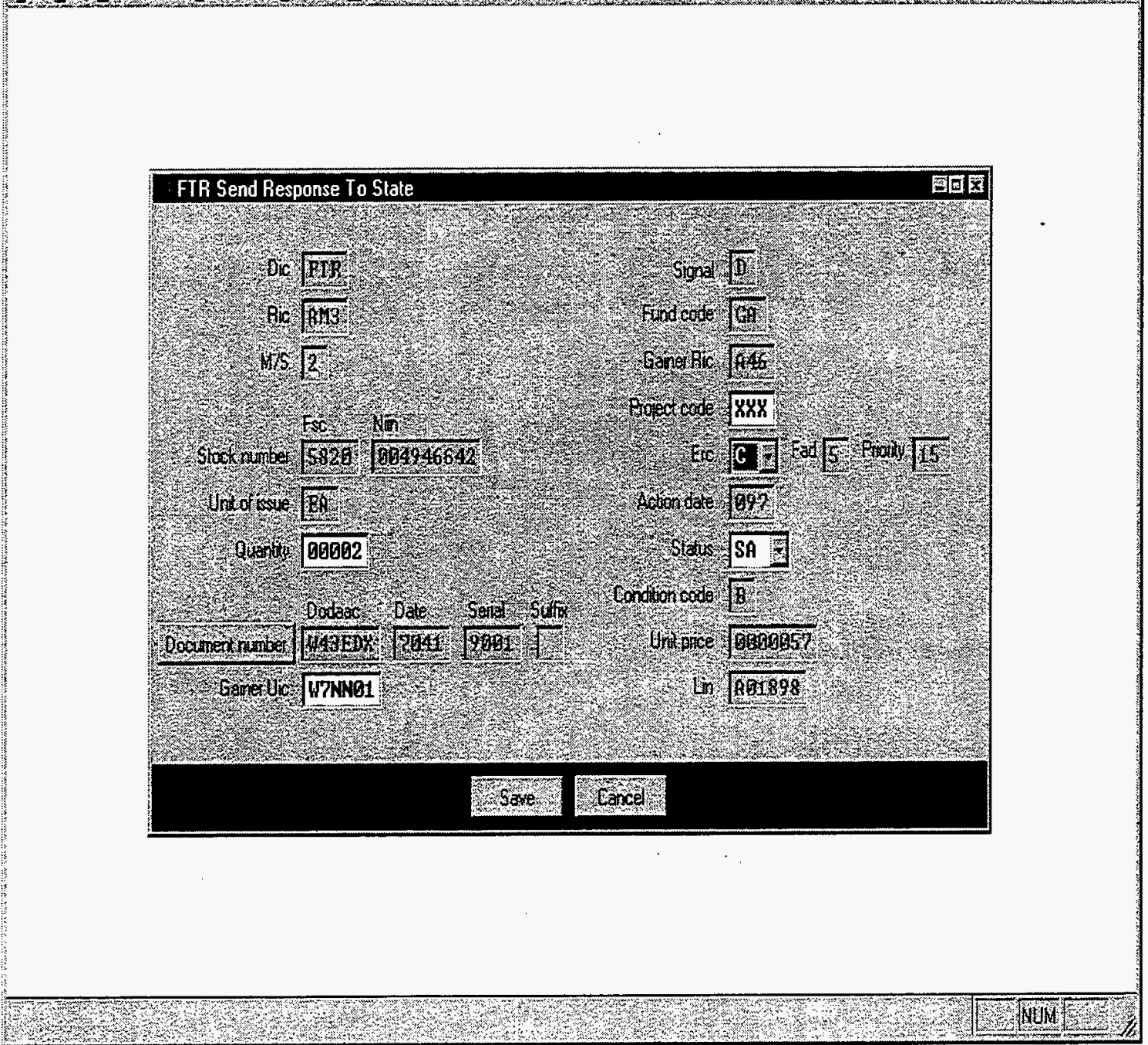

THE USER CAN CHANGE THE PROJECT CODE of the FTR.

THE DEFAULT IS ‘NGB’ , BUT ANY PROJECT CODE CAN BE ENTERED.

\section{GO TO NEXT PAGE}

Figure 4-23 


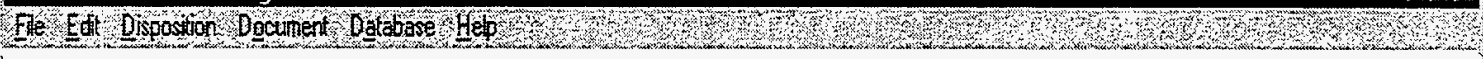

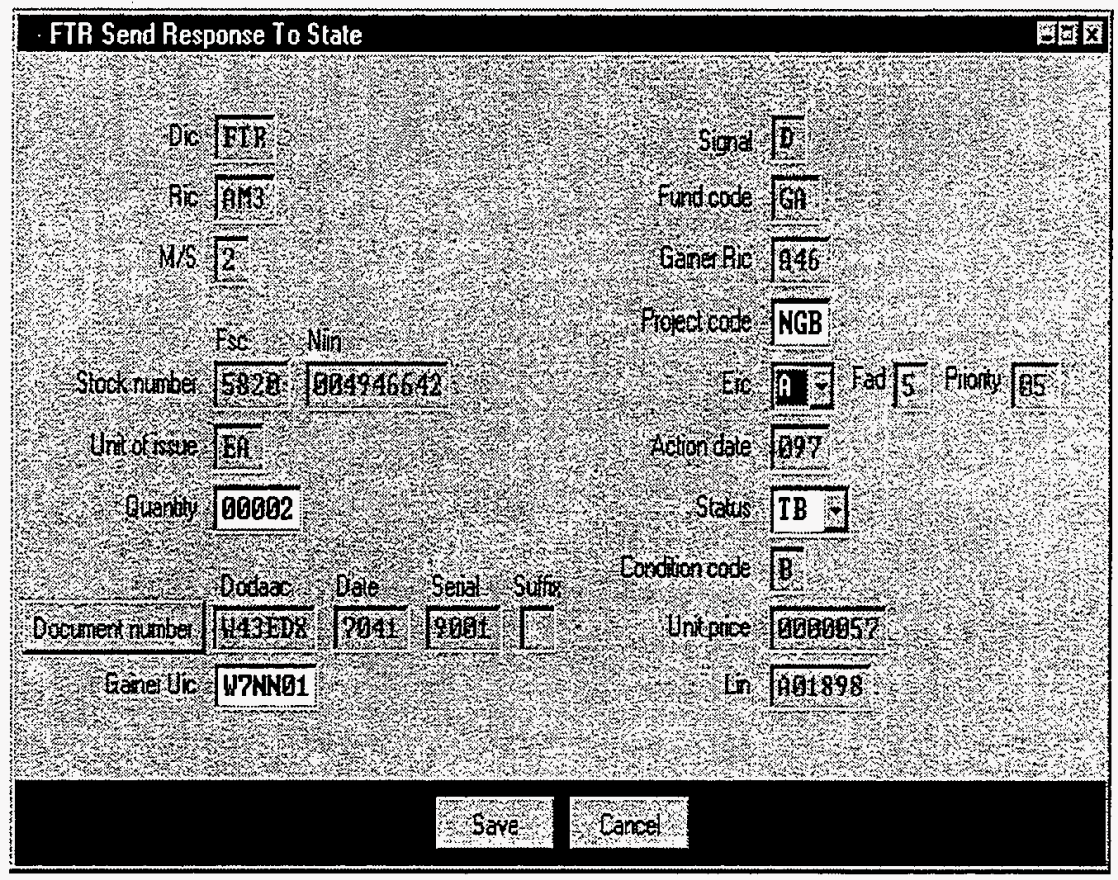

r.

EXAMPLE: The Information above will provide an 'FTR' with 'TB' status for a quantity of two (2) each to the Customer Reporting the Excess asset. The Project Code will be 'NGB', Priority is '05', and Suppaddr is 'W7NN01'. The Gainer State RIC is 'A46'.

IF INFORMATION IS CORRECT, USER MUST CLICK ON < Save> TO CONFIRM ACTIONS.

\section{GO TO NEXT PAGE}

Figure 4-24 


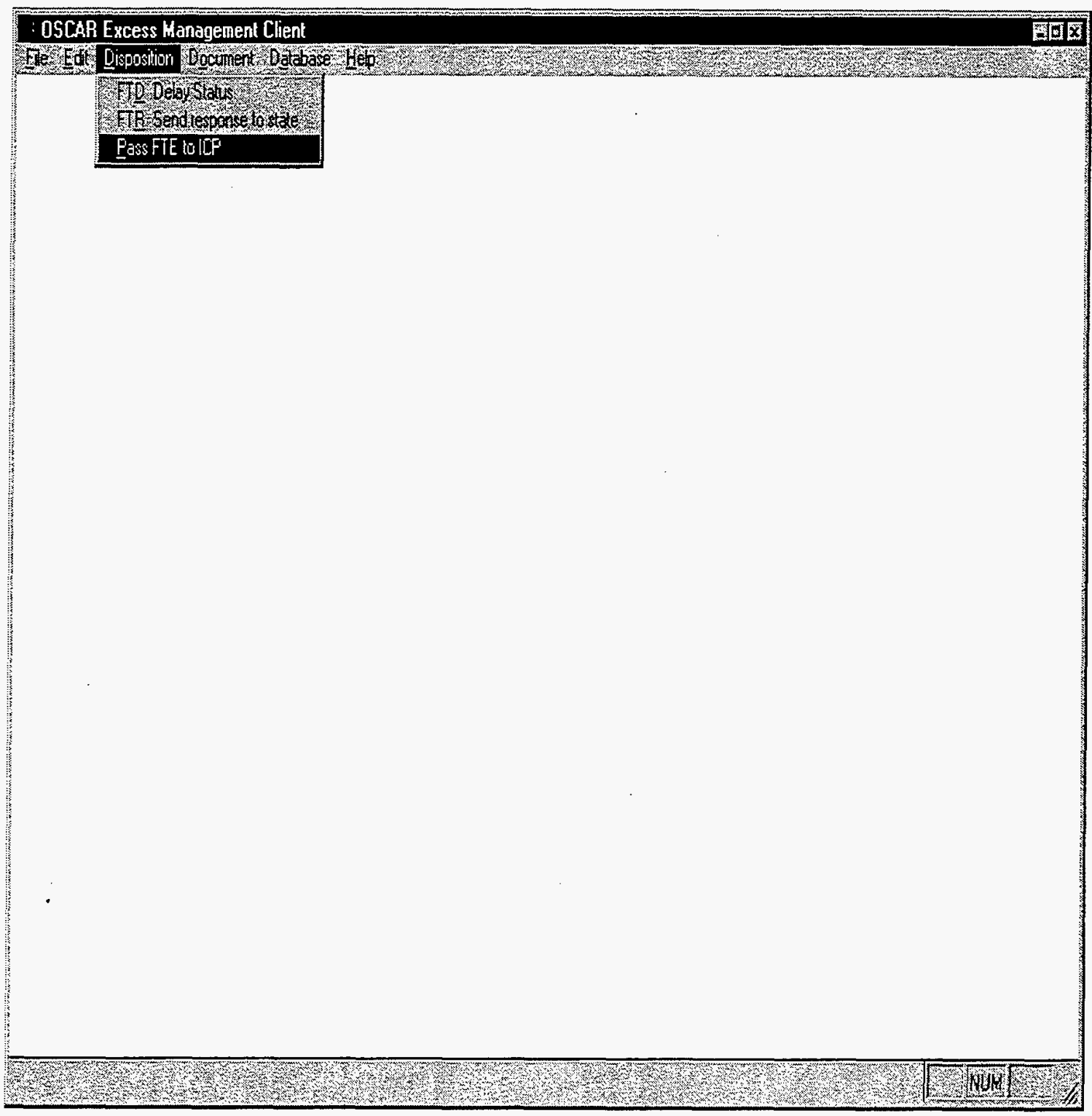

CLICK ON $<$ Disposition $>$ from the OSCAR Excess Management Client Main Menu. THEN

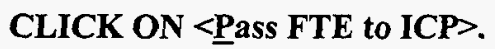

\section{GO TO NEXT PAGE}

Figure 4-25 


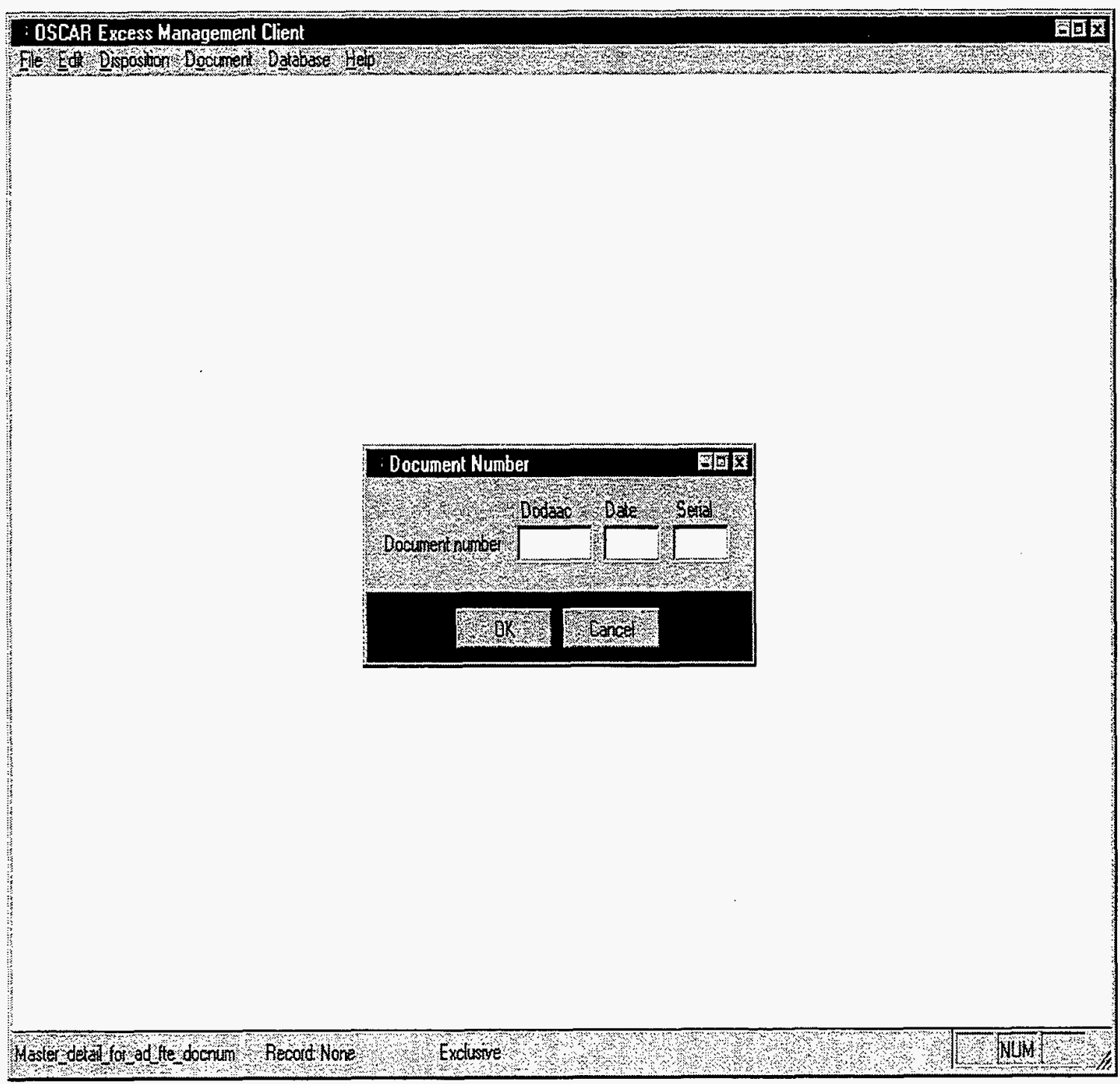

THE WINDOW ABOVE SHOULD APPEAR.

USER MUST ENTER THE DOCUMENT NUMBER OF THE EXCESS REPORT (FTE) TO BE FORWARDED TO ICP. (Document Number must match an FTE in the Excess Management Master File.)

\section{GO TO NEXT PAGE}

Figure 4-26 


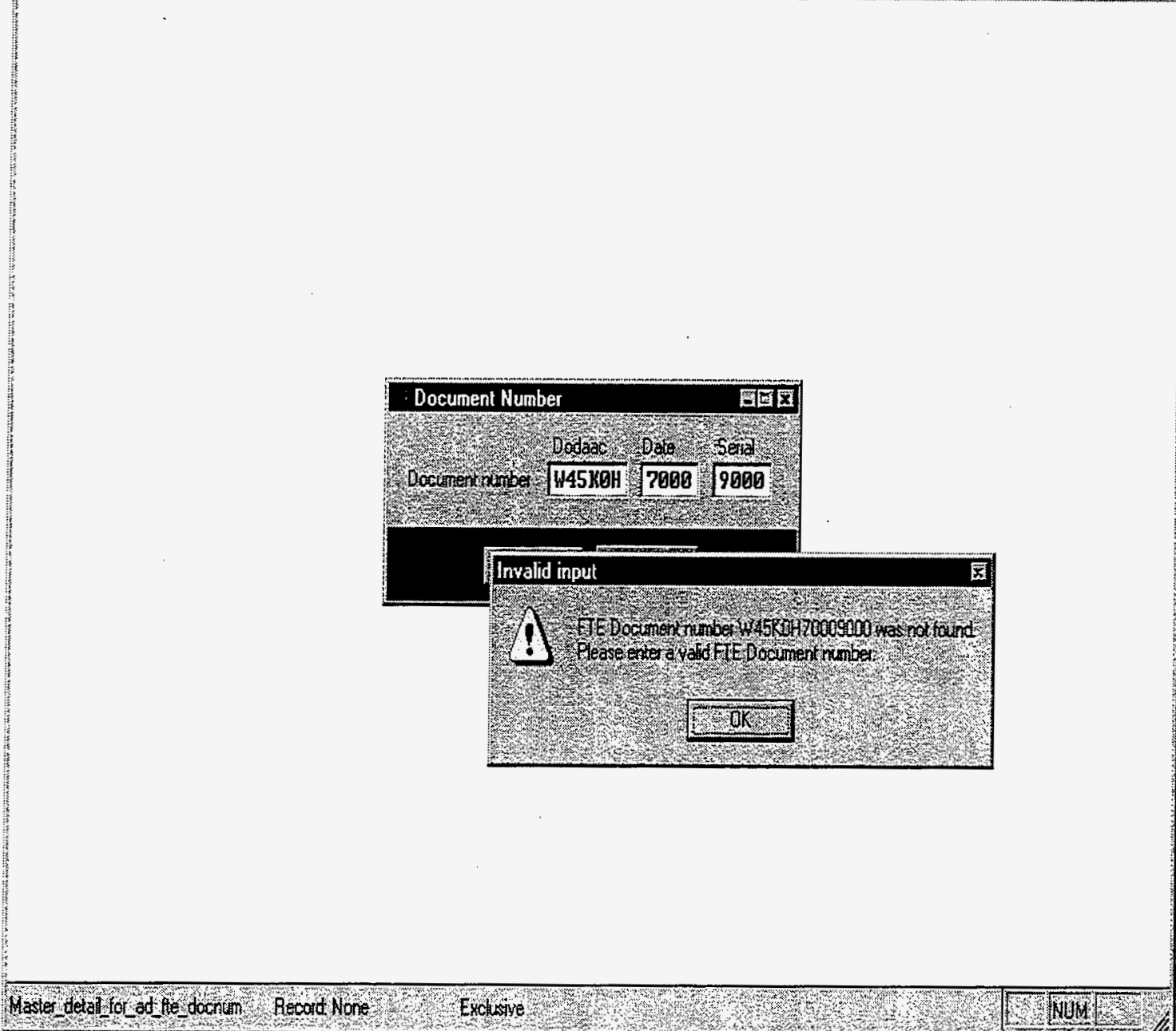

WHEN USER ENTERS A DOCUMENT NUMBER THAT DOES NOT MATCH THE NGB EXCESS MANAGEMENT MASTER FILE, THE MESSAGE ABOVE WILL APPEAR.

USER CAN CLICK ON <OK> AND ENTER ANOTHER DOCUMENT NUMBER.

OR GO TO THE DOCUMENT PORTION OF THE OSCAR EXCESS MANAGEMENT CLIENT MENU AND ADD THE FTE FOR THE DOCUMENT NUMBER REQUIRED.

THEN RETURN TO $<$ Pass FTE to ICP $>$ PROCESS.

THE DOCUMENT NUMBER ADDED TO THE MASTER FILE WILL BE AVAILABLE TO PasS to ICP.

GO TO NEXT PAGE

Figure 4-27 
Gile EElt Disposition Dociment Database Help

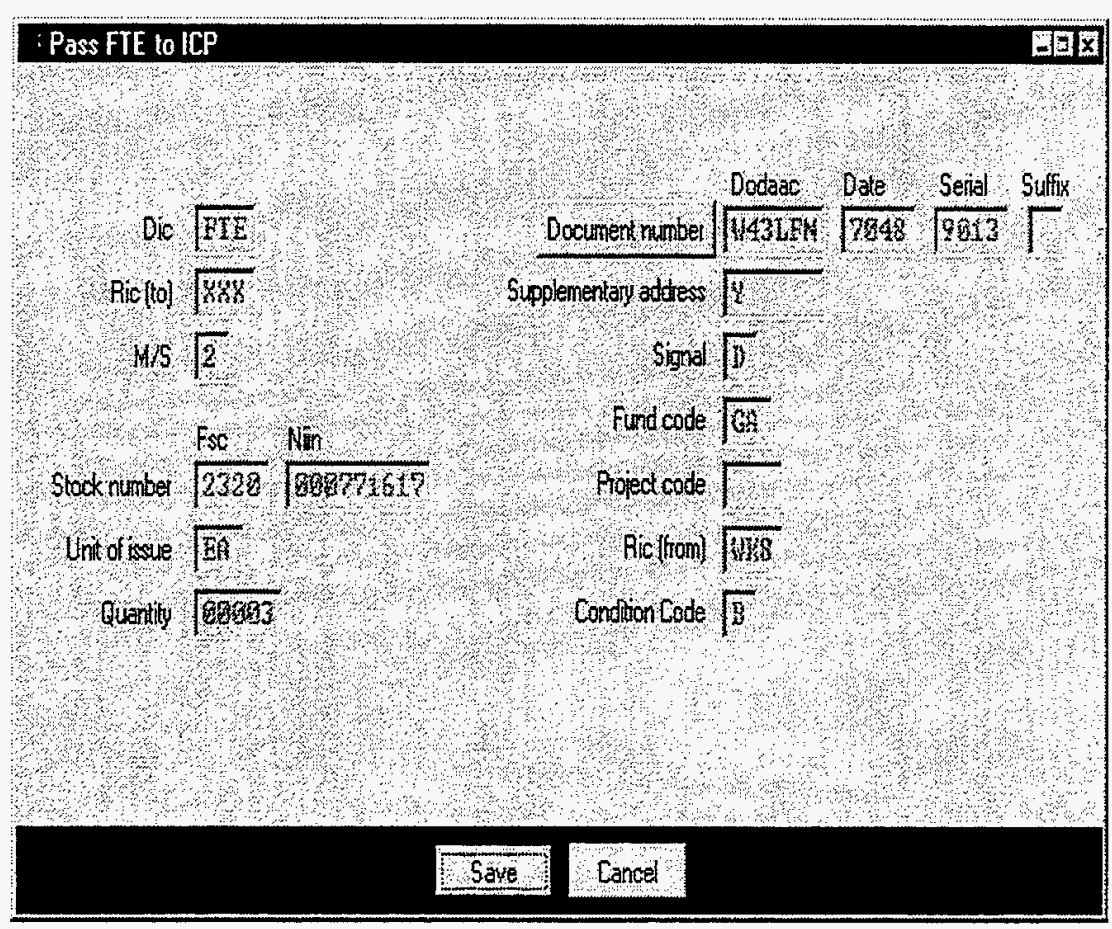

WHEN A DOCUMENT NUMBER THAT MATCHES THE NGB MASTER FILE IS ENTERED, THE WINDOW ABOVE WILL DISPLAY.

THE USER SHOULD REVIEW THE INFORMATION ON SCREEN. ONCE IT HAS BEEN DETERMINED THAT THE EXCESS REPORT (FTE) DISPLAYED CAN BE SENT TO THE ICP.

USER WILL CLICK ON <Save> (This will release the asset to the ICP.)

Reminder: FTR Customer Responses and FTD Customer Delay Status must be processed first. IF RECORD DISPLAYED IS IN ERROR. USER CAN CLICK ON < Document Number> 


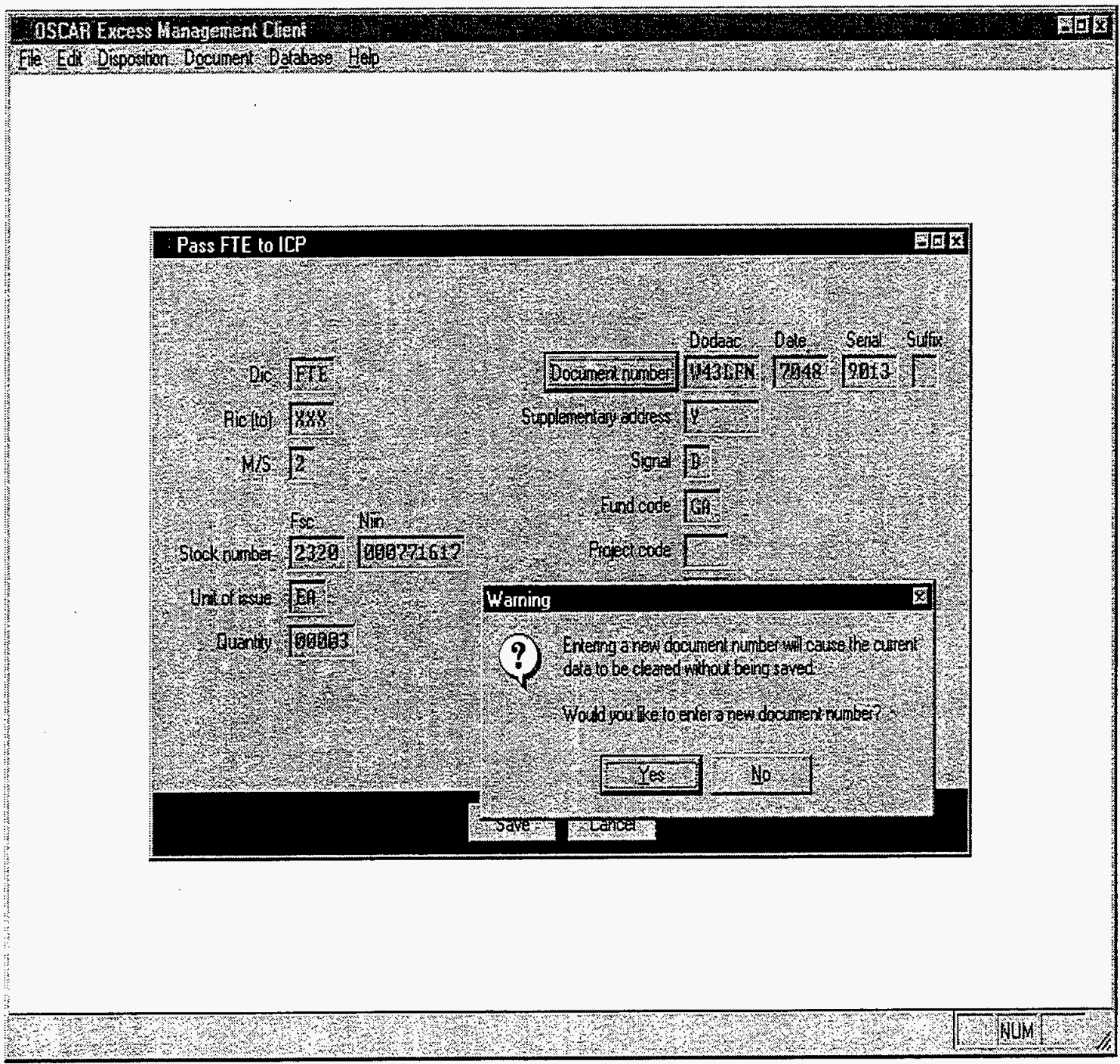

THE WINDOW SHOWN ABOVE WILL DISPLAY.

ENTER $<\underline{\text { Yes }}>$ FOR NEXT WINDOW

ENTER $<\underline{\text { No }}>$ TO RETURN TO RECORD DISPLAYED.

\section{GO TO NEXT PAGE}

Figure 4-29 


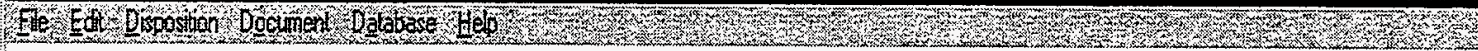

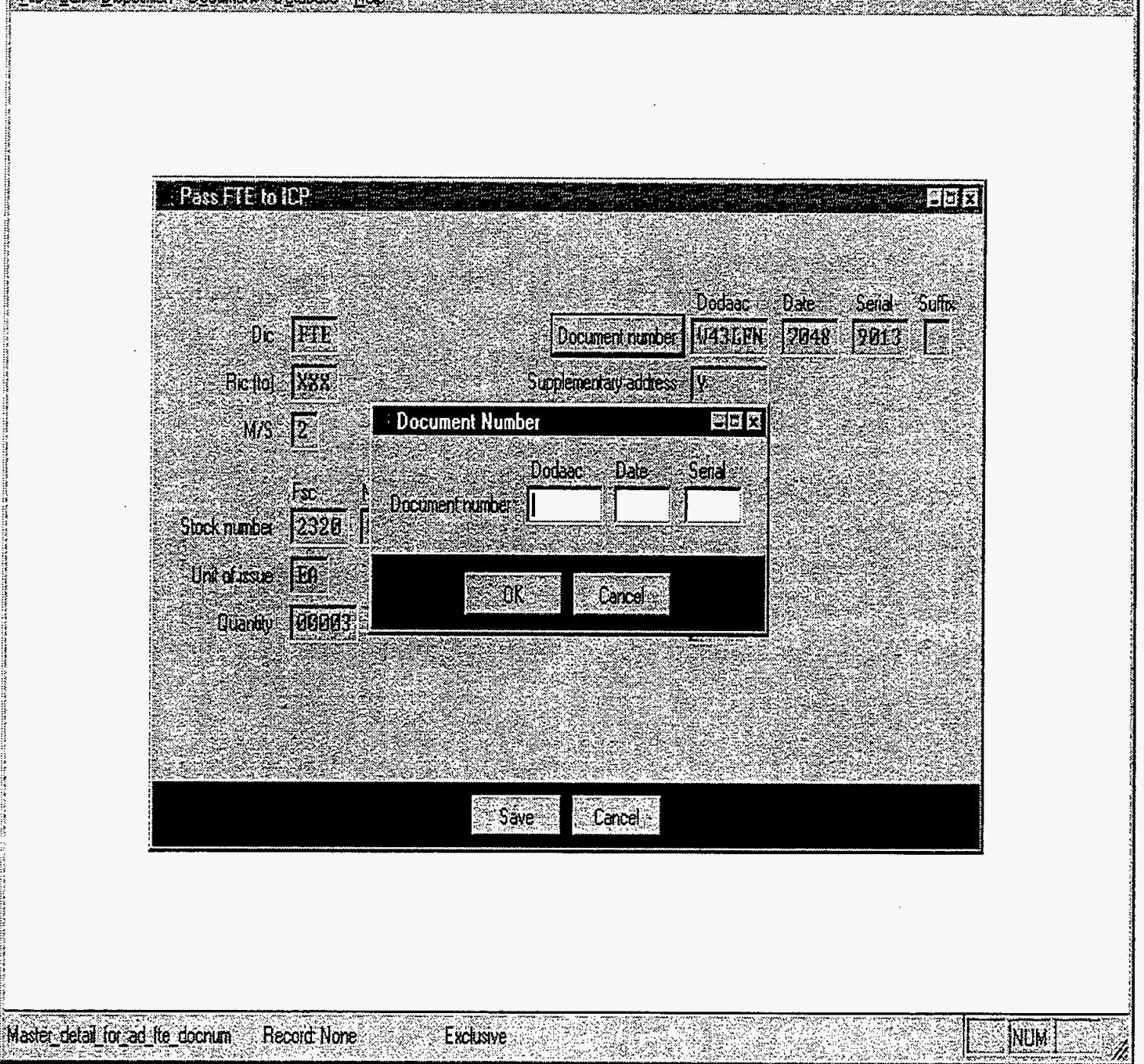

\section{WHEN THE WINDOW SHOWN ABOVE DISPLAYS,}

USER CAN ENTER A NEW Document Number and press Enter or Click on <OK>.

\section{GO TO NEXT PAGE}

Figure 4-30 


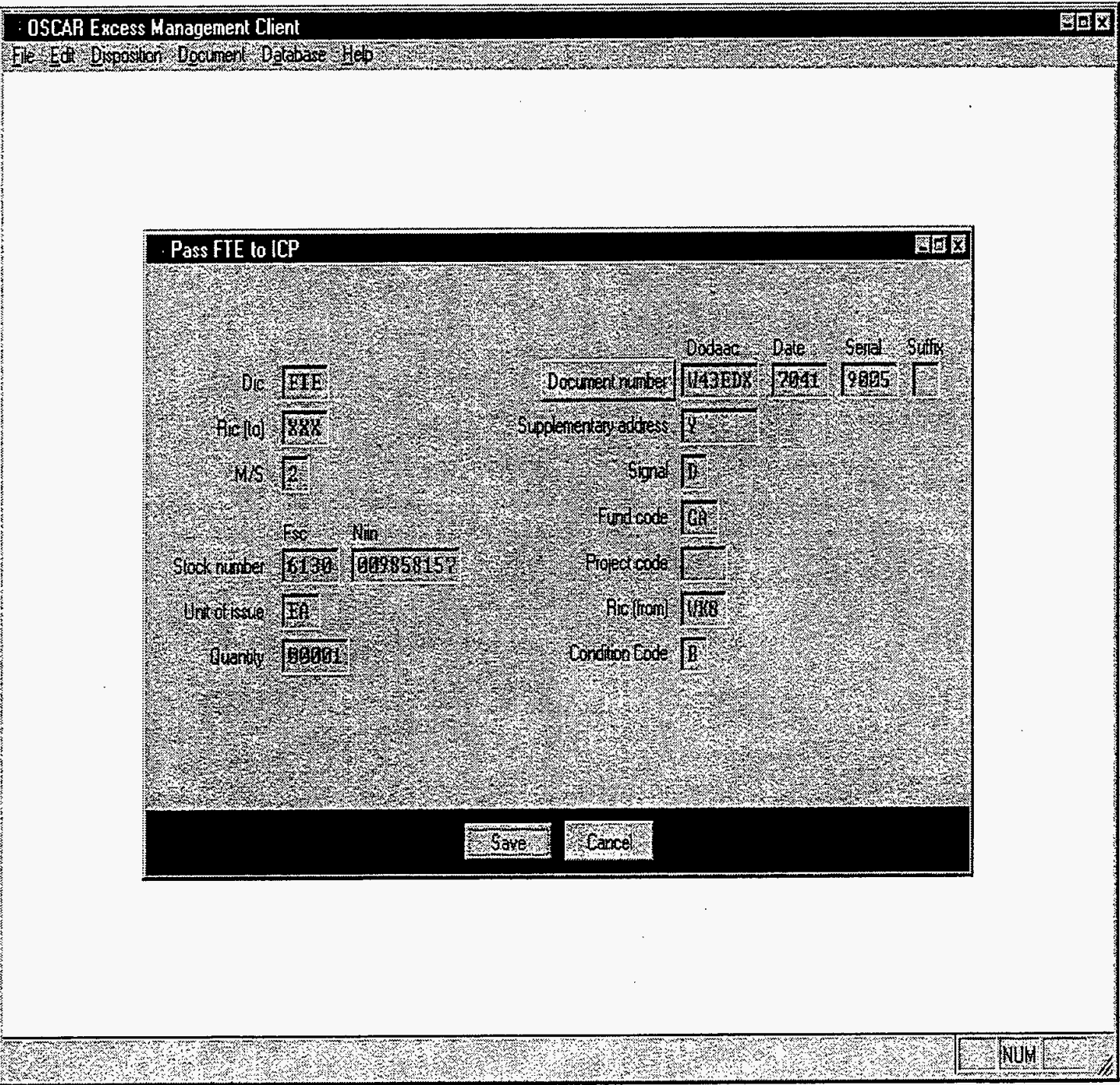

WHEN A DOCUMENT NUMBER THAT MATCHES THE NGB MASTER FILE IS ENTERED, THE WINDOW ABOVE WILL DISPLAY.

USER SHOULD REVIEW THE INFORMATION ON SCREEN. ONCE IT HAS BEEN DETERMINED THAT THE EXCESS REPORT (FTE) DISPLAYED CAN BE SENT TO THE ICP,

USER WILL CLICK ON <Save > (This will release the asset to the ICP.)

Reminder:. FTR Customer Responses and FTD Customer Delay Status must be processed first.

IF RECORD DISPLAYED IS IN ERROR. USER CAN CLICK ON <Document Number $>$ OR $<$ Cancel $>$

GO TO NEXT PAGE $\quad$ Figure 4-31 


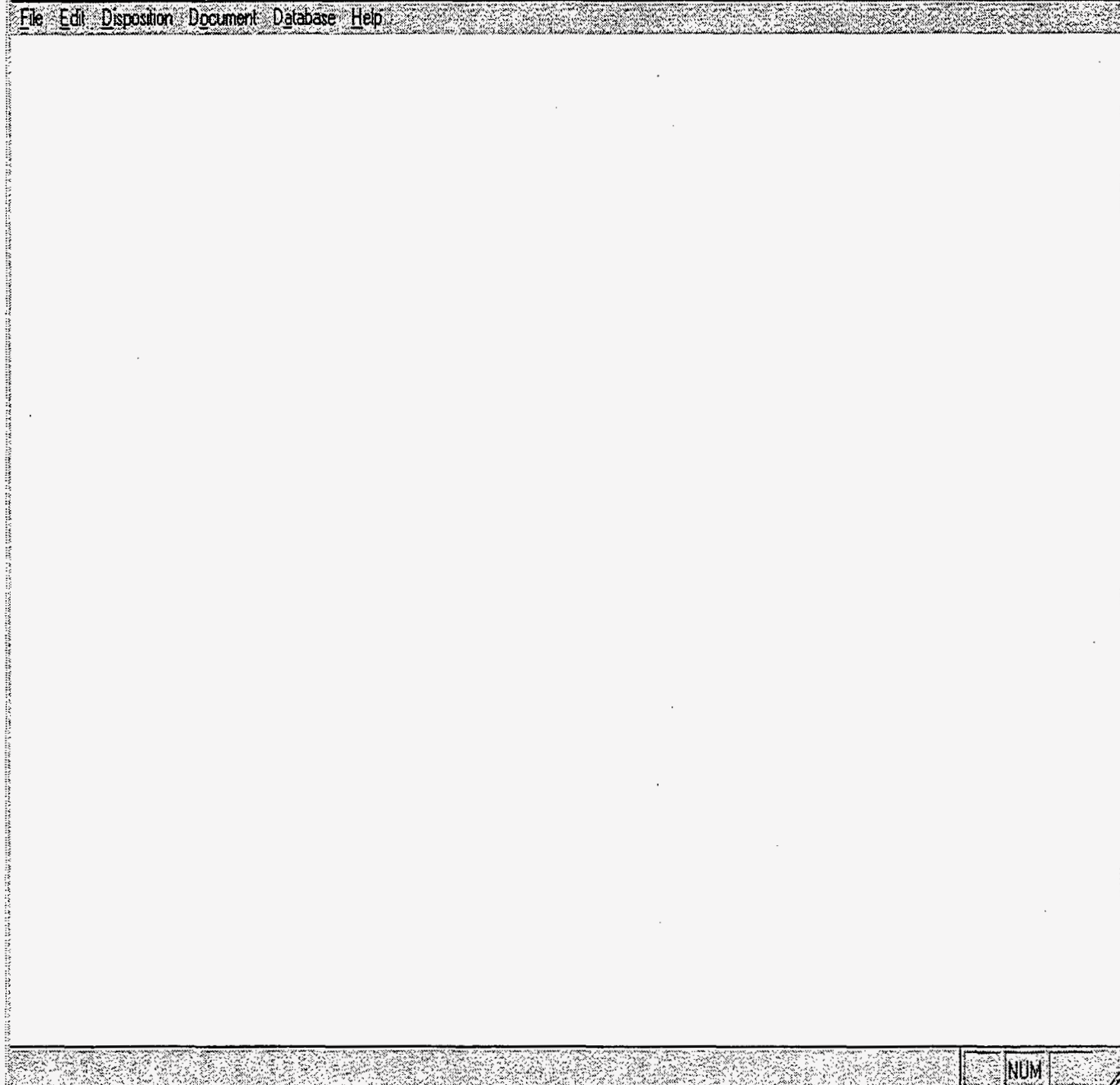

WHEN USER PRESS <Cancel> THE WINDOW SHOWN ABOVE WILL DISPLAY.

USER HAS RETURNED TO THE OSCAR Excess Management Client Master WINDOW.

Figure 4-32 


\section{SECTION 5: CATALOG PROCESS}

5.1 General. The catalog process is designed to utilize the latest version of the FEDLOG provided by AMCLOGSA to incorporate information required for managers to make decisions. The FEDLOG catalog has been tailored to incorporate only National stock Numbers (NSN) that are associated with Line Item Numbers (IIN). Customer Excess Reports (FTE) are edited against catalog information to determine if they are subject to NGB management controls. Items that are not required or are in error will be immediately returned to customer and/or forwarded on to the Defense Automated Addressing System (DAAS). The following catalog information is extracted for manager use:
a. NSN - National stock Number
b. IIN - Iine Item Number
c. LCC - Logistics Control Code
d. RICC - Reportable Item Control Code
e. U/I - Unit of Issue
f. U-Price - Unit Price
g. ARC - Account Requirement Code
h. ACQ - Acquisition Advice Code
I. SOS - Source of Supply (ICP)

5.2 Catalog Update Process

TO BE DEVELOPED

5.3 Catalog Inquiry

TO BE DEVELOPED 
THIS PAGE NOT USED 
SECTION 6. DISPOSITION TABLE UPDATE PROCESS

6.1 General. The Disposition Table Process was developed to give the Manager the ability to provide automated disposition on assets that are not required and/or have a standard disposition. It allows the manager to enter an IIN, NIIN, Condition Code and Disposition Code and/or Send to Source of Supply (SOS). (See Fig. 6-1 through Fig. 6-22). Assets in this table will be automatically directed as indicated:
a. DISP-CD "I"- Forward to ICP.
b. DISP-CD "2"- Transfer to DRMO.
c. DISP-CD "3"- NGB Hold/Long-Term-Delay Status
d. DISP-CD "4"- Produce Customer Response (FTR) to SOS in Table.

6.2 Disposition Table Update Procedures.

6.2.1 DISPOSITION CODE DESCRIPTION - All automated actions will be recorded in the NGB Management Process Activity Master File.

a. DISP-CD "1"- All assets in the Disposition Table with DISP-CD " 1 " will allow the system to format a Customer Excess Report Information Status to the reporting state/Territory and forward the Excess Report (FTE) to the catalog Inventory Control Point (ICP) .

b. DISP-CD "2"- AlI assets in the Disposition Table with DISP-CD "2" will allow the system to format a Reply to Customer Excess Report (FTR) with advice "TC" to the reporting state/Territory directing the asset to be transferred to the Defense Reutilization and Marketing Office (DRMO). 
c. DISP-CD " 3 "- All assets identified in the

Disposition Table with DISP-CD "3" will allow the system to format a Disposition Instruction Delay Status with the Expected Reply Date (ERD) of one hundred and twenty (120) days. These will be considered Iong-Term Hold or NGB HOID assets.

d. DISP-CD "4"- All assets identified in the Disposition Table with DISP-CD "4" will require a RIC/SOS in the Disposition Table. The system will automatically create an FTR with status code "TB" to the RIC/SOS identified in the Disposition Table.

\subsubsection{TABLE FORMAT}

a. IIN-Mandatory field. This is the Iine-Item Number of the asset identified for automatic disposition action.

b. NIIN-National Item Identification Number. NIIN must correspond to IIN. When left blank, all NIINs for the given IIN will be considered for actions.

c. Condition Code-Individual condition code can be entered, or, if all condition codes require actions, a one (1) may be entered.

d. Send to source of Supply (SOS)-The sos is used only with Disposition Code Four (4). Assets will be directed to the RIC/SOS identified.

6.2.3 REPORTS-A report on items in the Disposition Code Table will be made monthly or as required. 


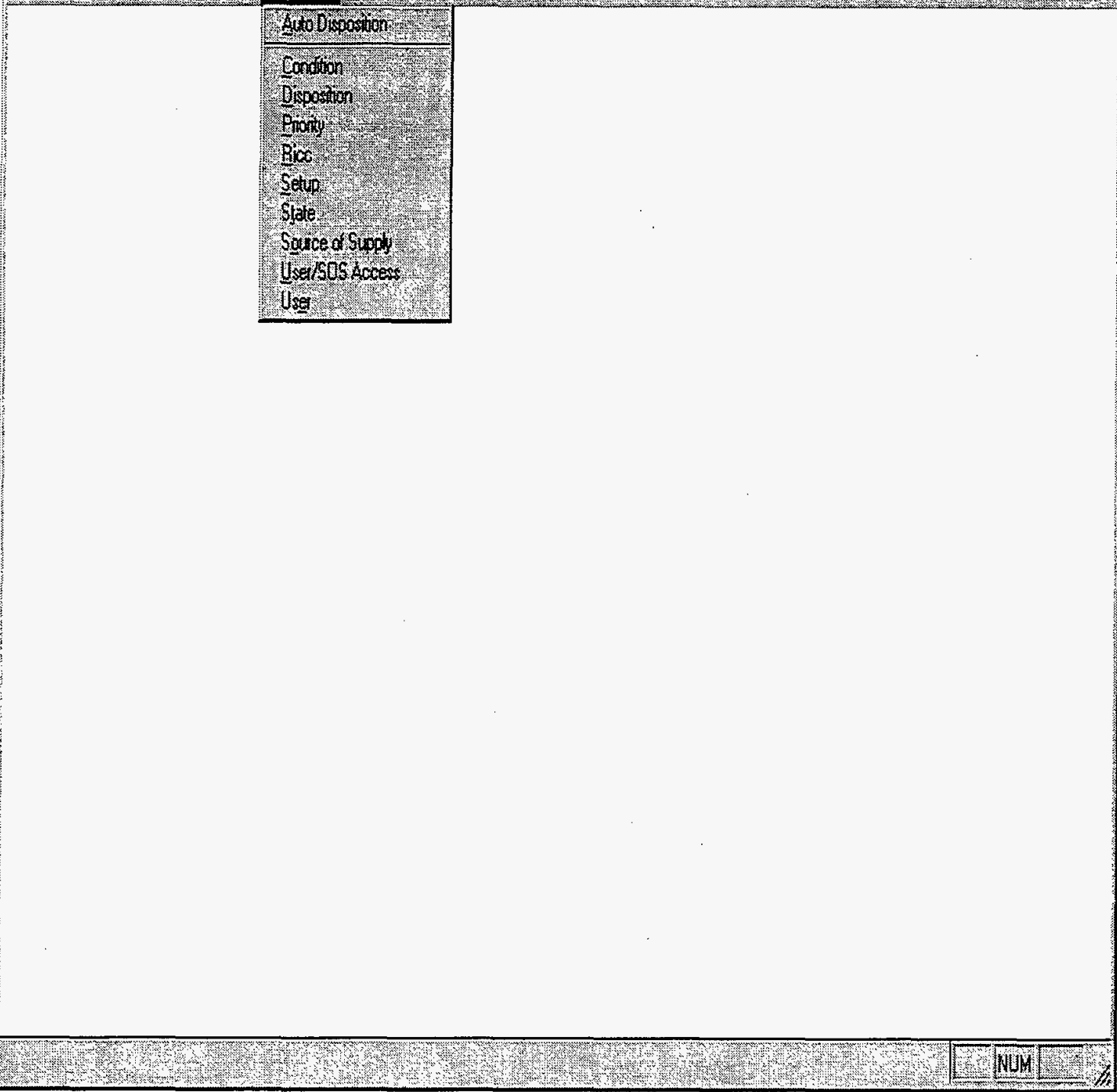

CLICK ON: OSCAR from the NT Main Menu

THEN: CLICK ON: Database (The options above will display)

CLICK ON : Auto Disposition

\section{GO TO NEXT PAGE}

FIGURE 6-1 


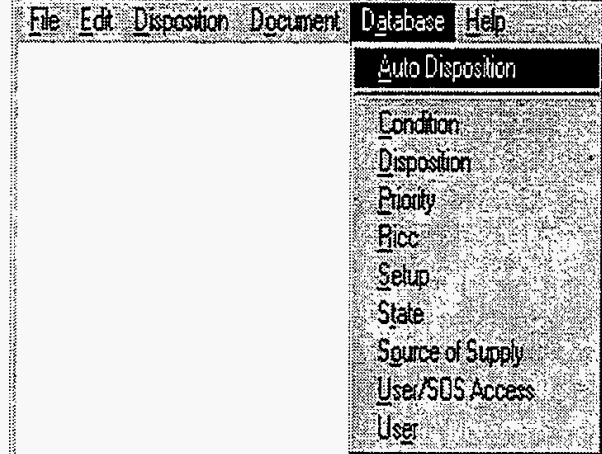
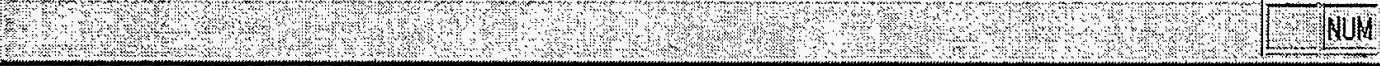

DOUBLE CLICK ON < A uto Disposition>

\section{GO TO NEXT PAGE}

FIGURE 6-2 


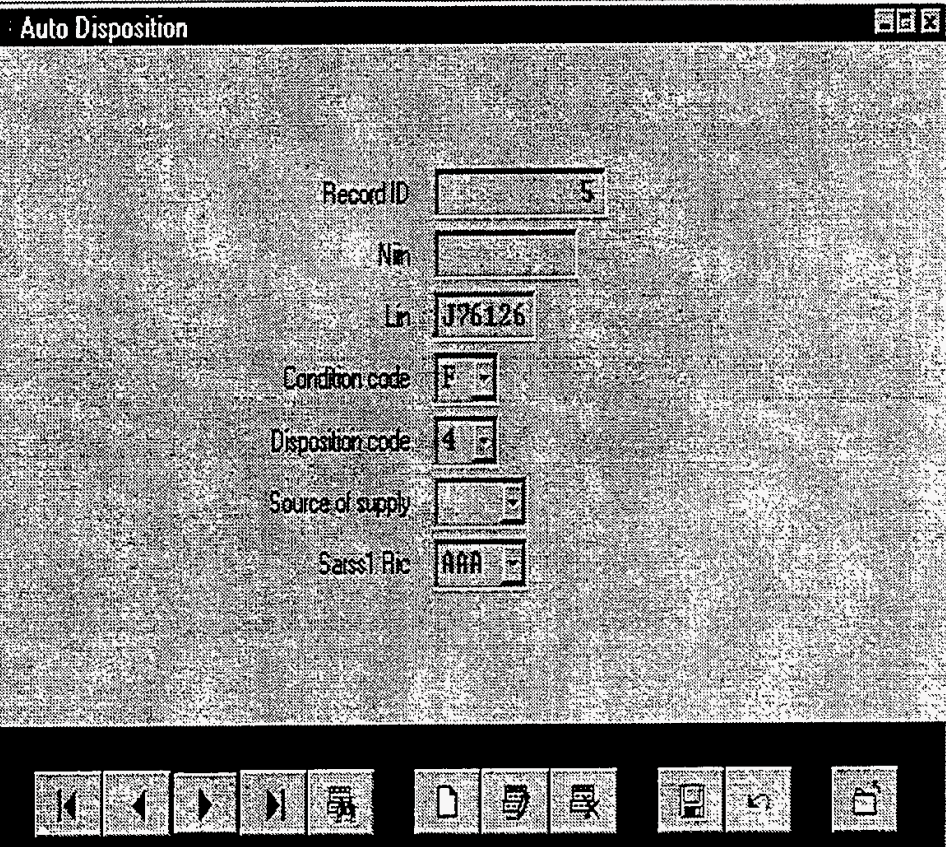

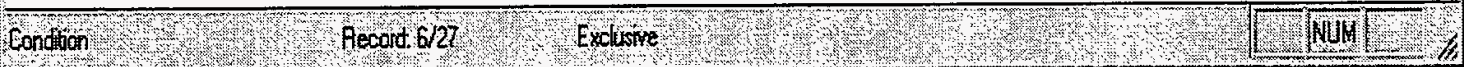

IF USER CLICKS ON ONE OF THE FIVE BUTTONS AT BOTTOM LEFT OF SCREEN:

LEFT BUTTON - <First> This will take you to the first record in the Disposition Table. SECOND FROM LEFT - <Previous $>$ This will take you to the record previous to what is on screen.

THIRD FROM LEFT - <Next $>$ This will take the user to the next record in the Disposition Table.

FOURTH FROM LEFT - <Last> This will take the user to the last record in the Disposition Table.

BOTTON ON THE RIGHT - <Find $>$ This will allow the user to enter a NIIN or LIN and find a record in the Disposition Table.

\section{GO TO NEXT PAGE}

Figure 6-3 


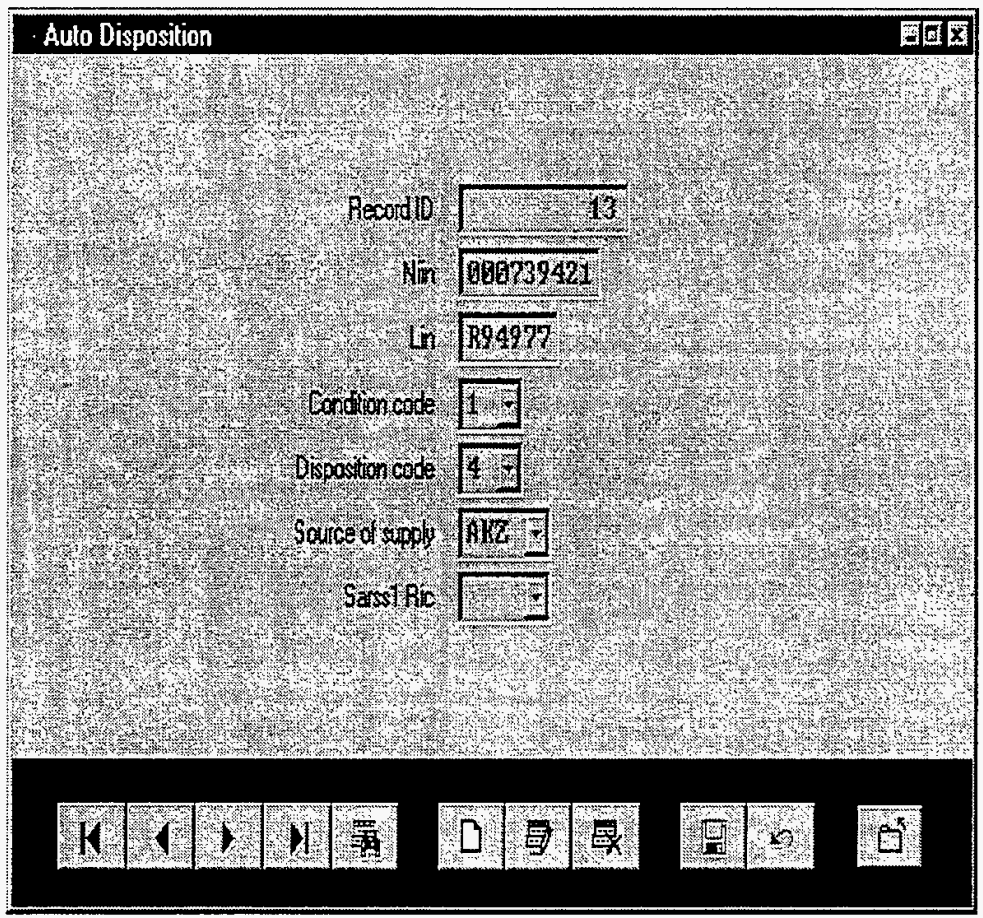

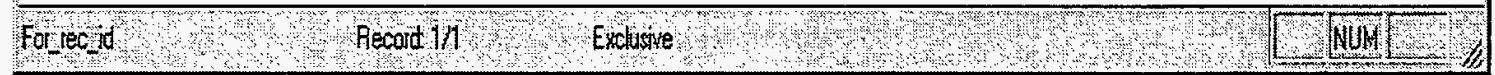

\section{IF USER CLICKS ON ONE OF THE THREE MIDDLE BUTTONS:}

LEFT BUTTON - <NEW > Used when user wishes to add a new record to the Disposition Table. MIDDLE BUTTON - <Edit> Used when the user wishes to edit or change an existing record. RIGHT BUTTON - <Delete $>$ Used when the user wishes to delete the record on the screen from the Disposition Table. 


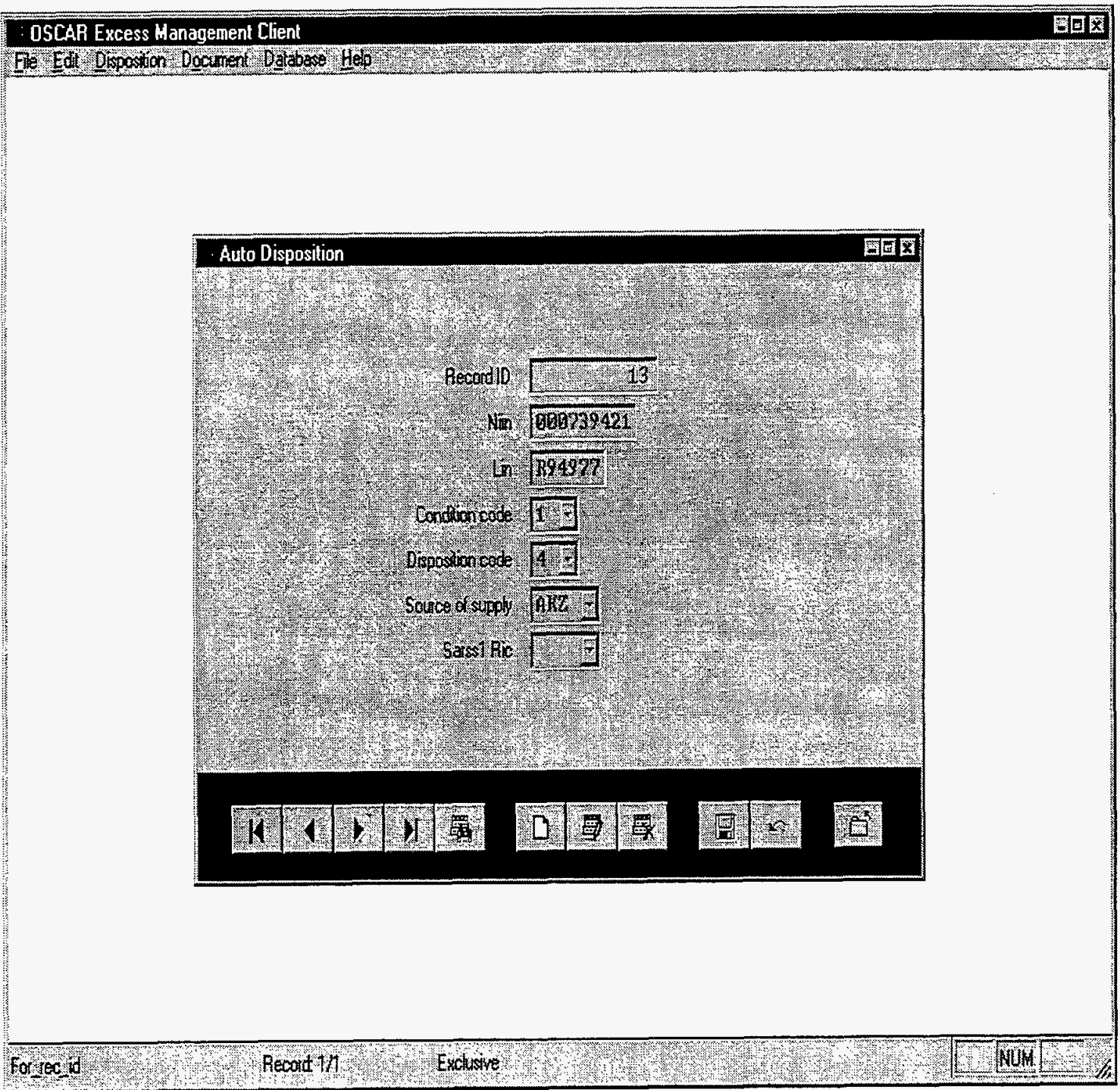

\section{WHEN USER CLICKS ON ONE OF THE TWO BUTTONS ON RIGHT OF SCREEN:}

LEFT BUTTON $-<$ Save $>$ The user must save the record that has been added/changed. If the record added or changed is not saved. No action has been taken.

RIGHT BUTTON - <Cancel $>$ This will allow the user to cancel any actions that have not been saved.

\section{GO TO NEXT PAGE}

FIGURE 6-5 


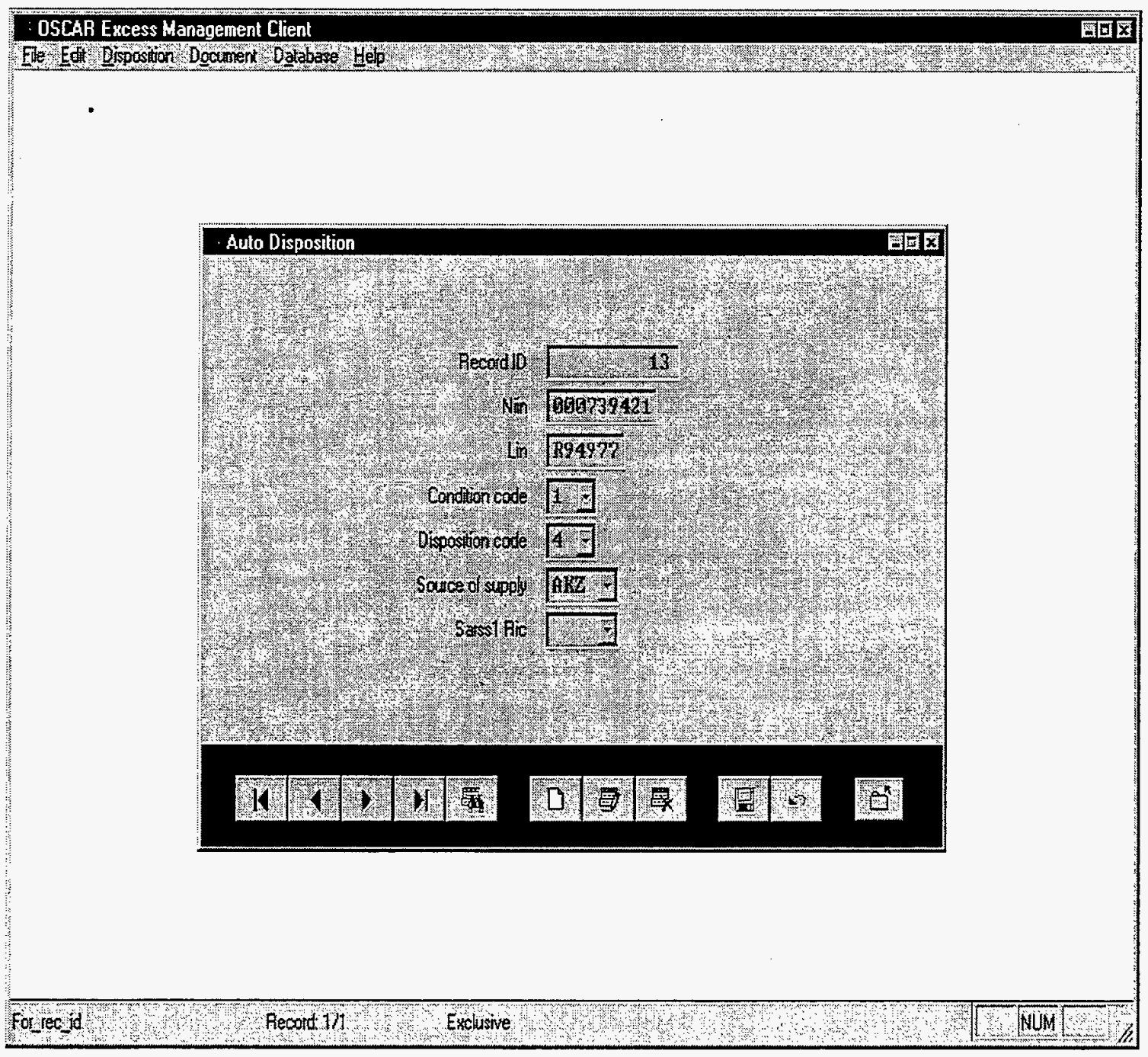

\section{WHEN USER CLICKS ON THE FAR RIGHT BUTTON ON THE SCREEN:}

FAR RIGHT BUTTON - THE USER WILL RETURN TO THE OSCAR EXCESS MANAGEMENT MAIN MENU.

\section{GO TO NEXT PAGE}

FIGURE 6-6 


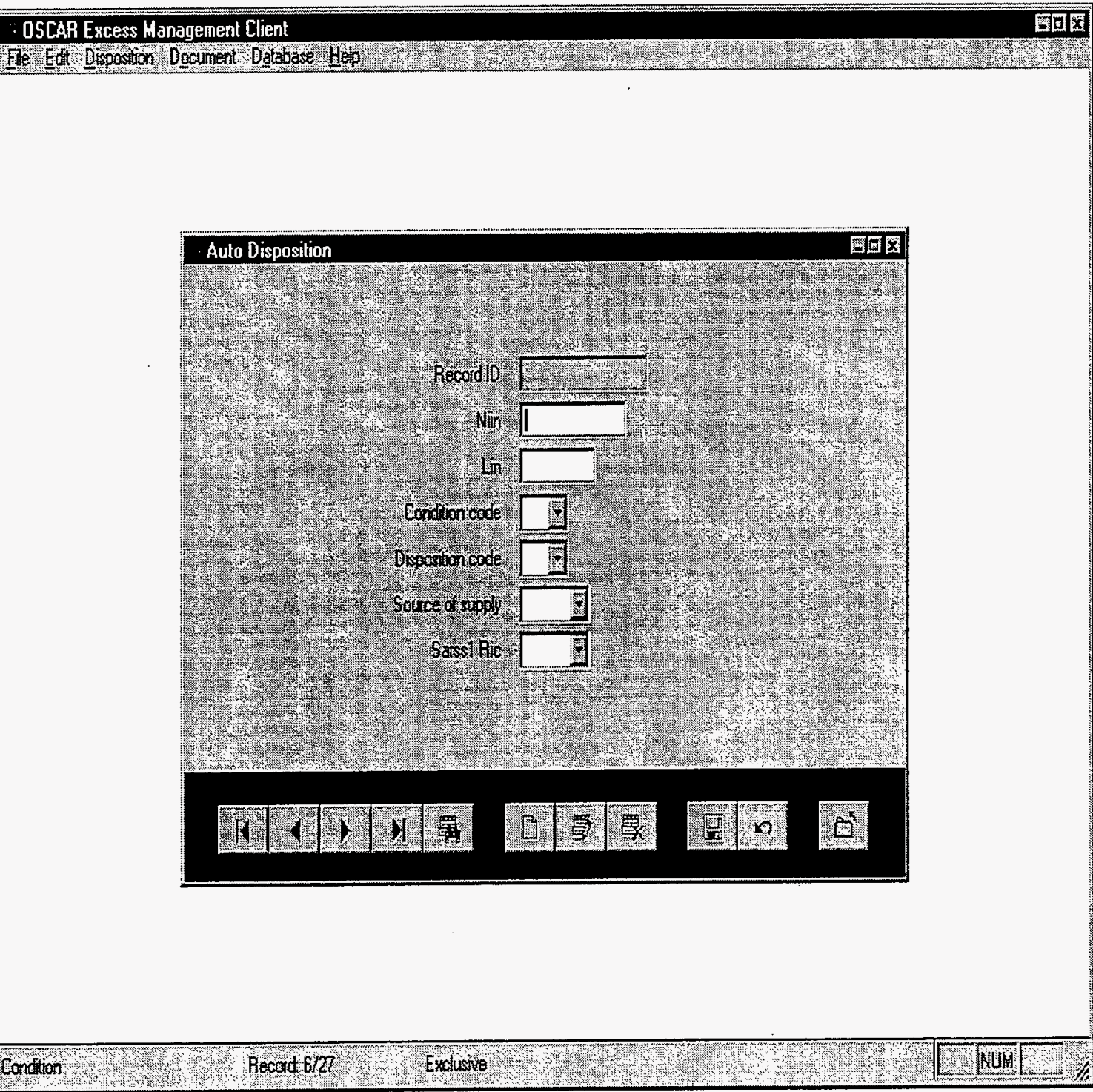

WHEN THE USER WISHES TO ADD A NEW RECORD:

CLICKS ON THE LEFT BUTTON OF THE MIDDLE THREE BUTTONS: <NEW>

THE SCREEN ABOVE WILL APPEAR.

USER CAN ENTER A 'Niin' OR A 'LIN'.

WHEN ENTERING A 'Niin'. The Niin must match a catalog record. When a matching record is found, the 'LIN' will automatically appear in the LIN field. If not a message will appear 'No matching record found'. When this occurs the user should check to see if the Niin was entered correctly. If so, the Niin will have to be added to the catalog before a record can be added to the Auto Disposition Table.

Remarks: Niin is not an mandatory entry. When Niin field is blank, the program will assume that all Niin's for the LIN/condition code will apply to the disposition code for action.

\section{GO TO NEXT PAGE}

FIGURE 6-7 


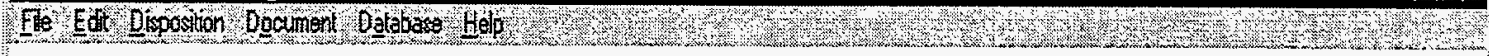

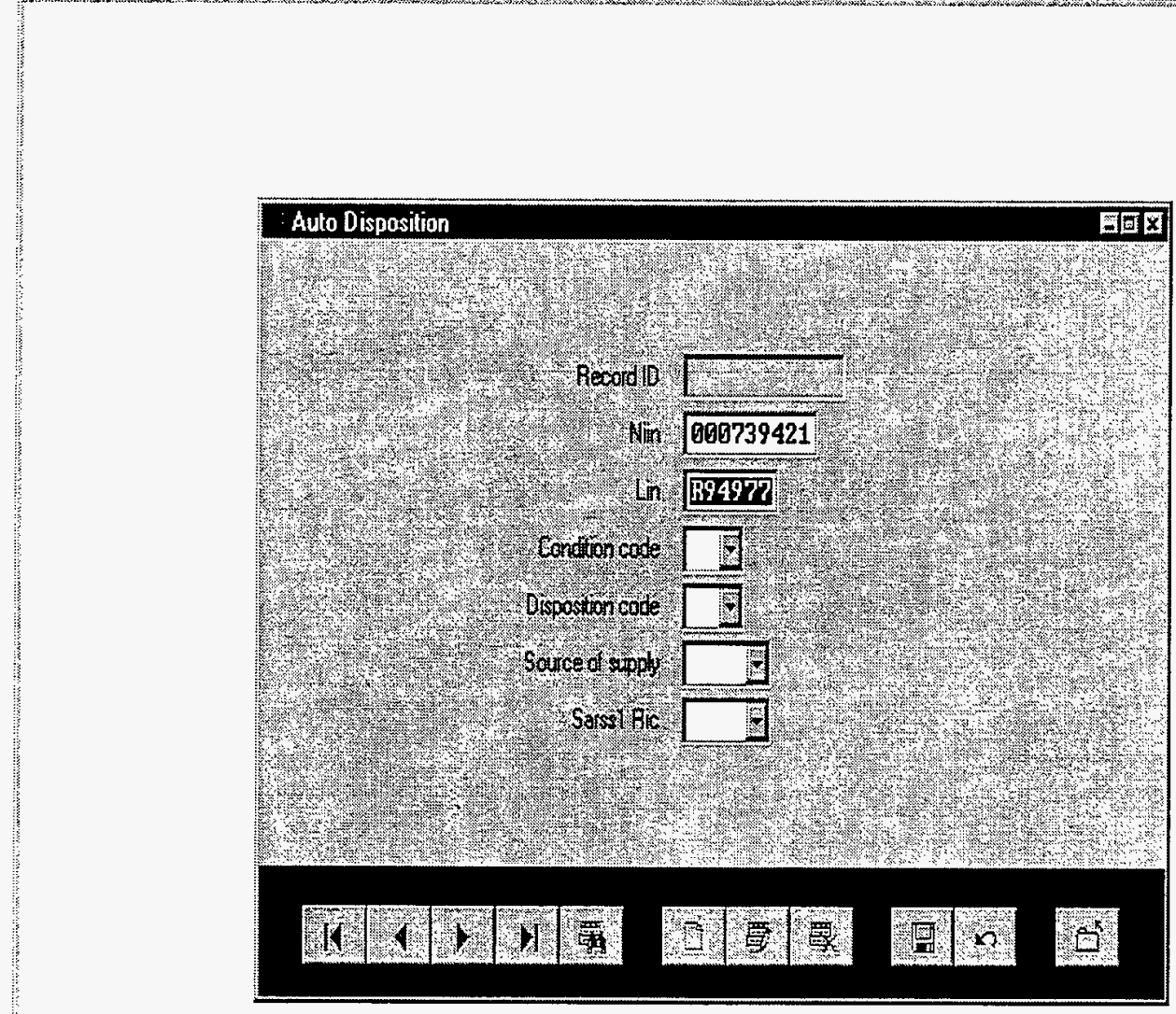

Condition

Recote 2727

Exclusive

Novim

Example of a Niin correctly entered.

GO TO NEXT PAGE

FIGURE 6-8 


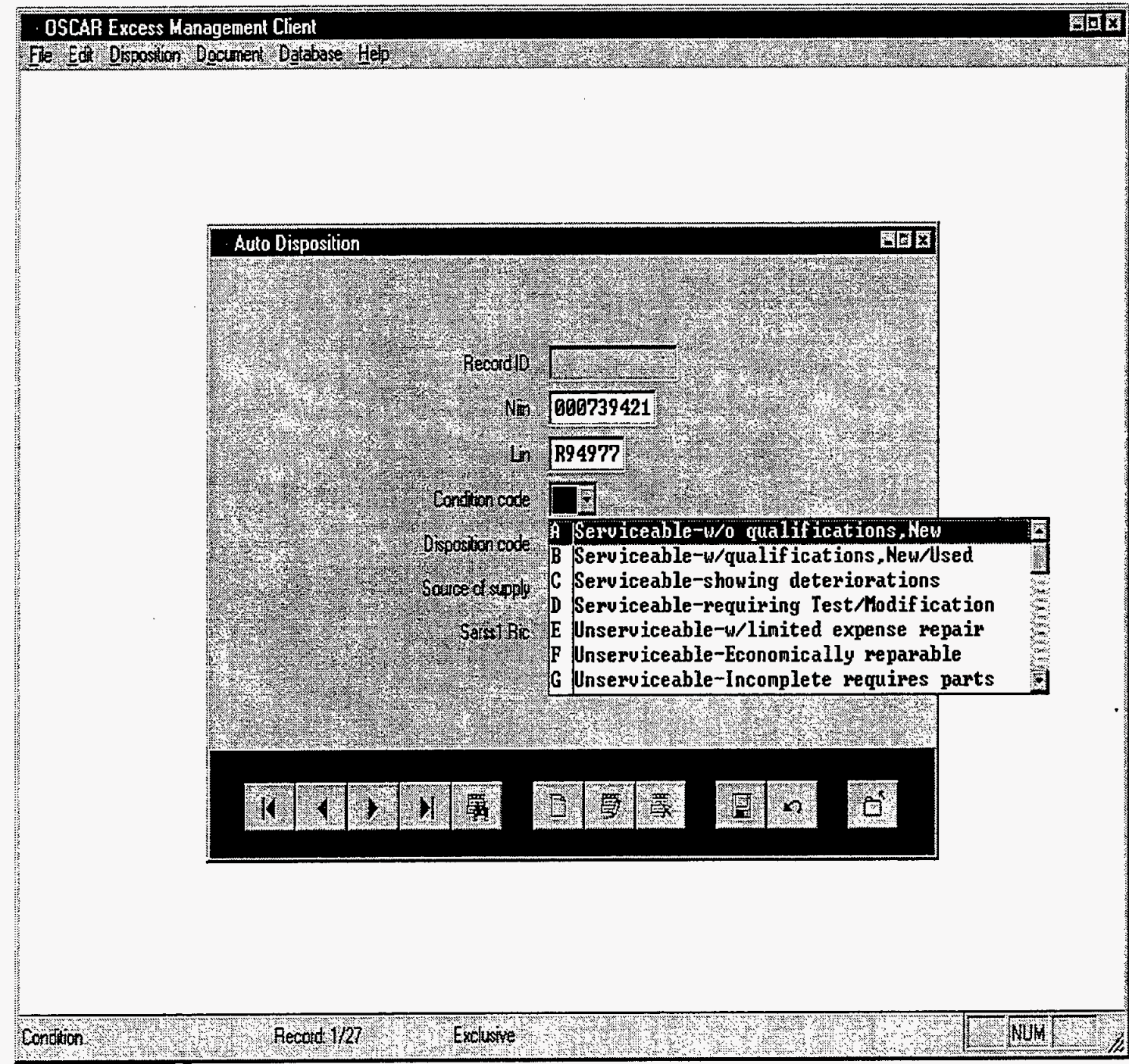

Once the Niin and LIN have been selected. The user must enter a condition code. CLICK ON THE ARROW TO THE RIGHT OF Condition code for selections. User may enter an individual Condition code or enter a one (1) for all Condition codes. (All Condition codes in AR 725-50 are listed.)

\section{GO TO NEXT PAGE}

FIGURE 6-9 


\section{SCAR Excess Hanagement Clienk}

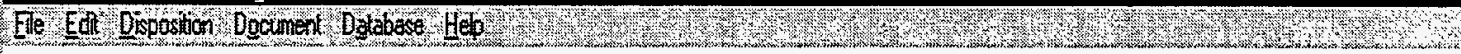

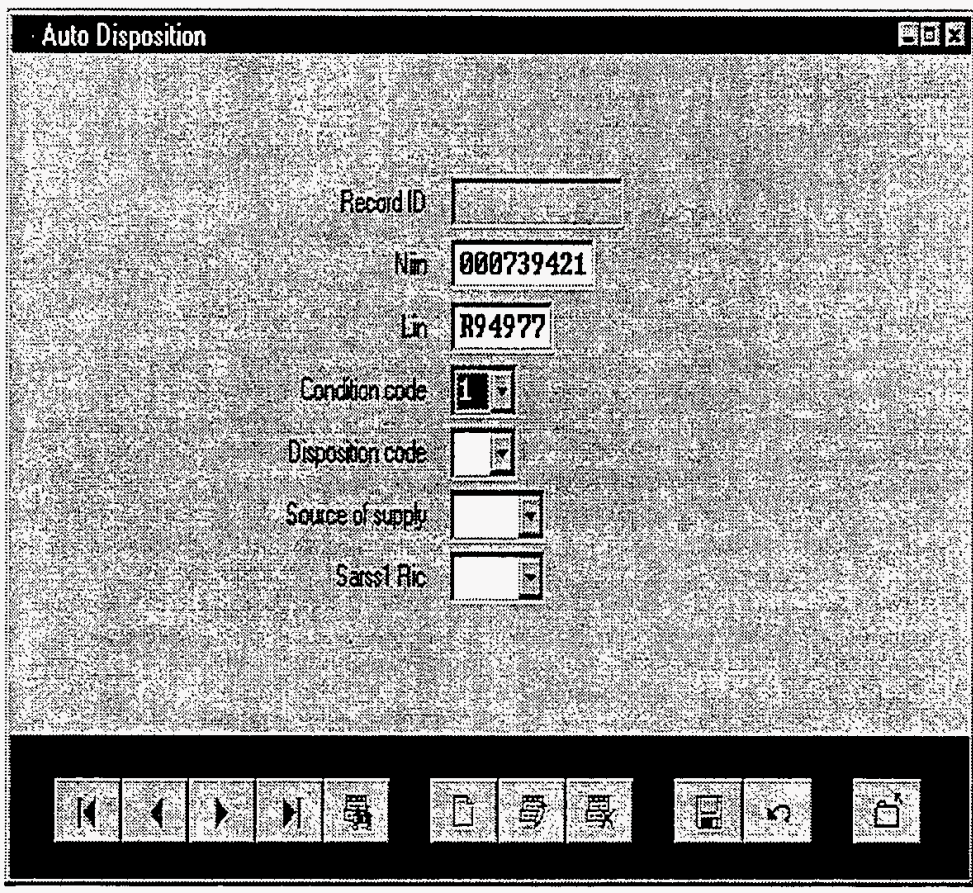

Condtion 4 Record 2727 . Exclusie

EXAMPLE: For this Niin and LIN all Condition codes have been selected.

\section{GO TO NEXT PAGE}

FIGURE 6-10 
0SCAR Excess Wanagement Client

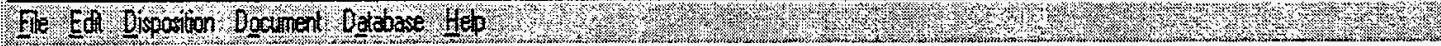

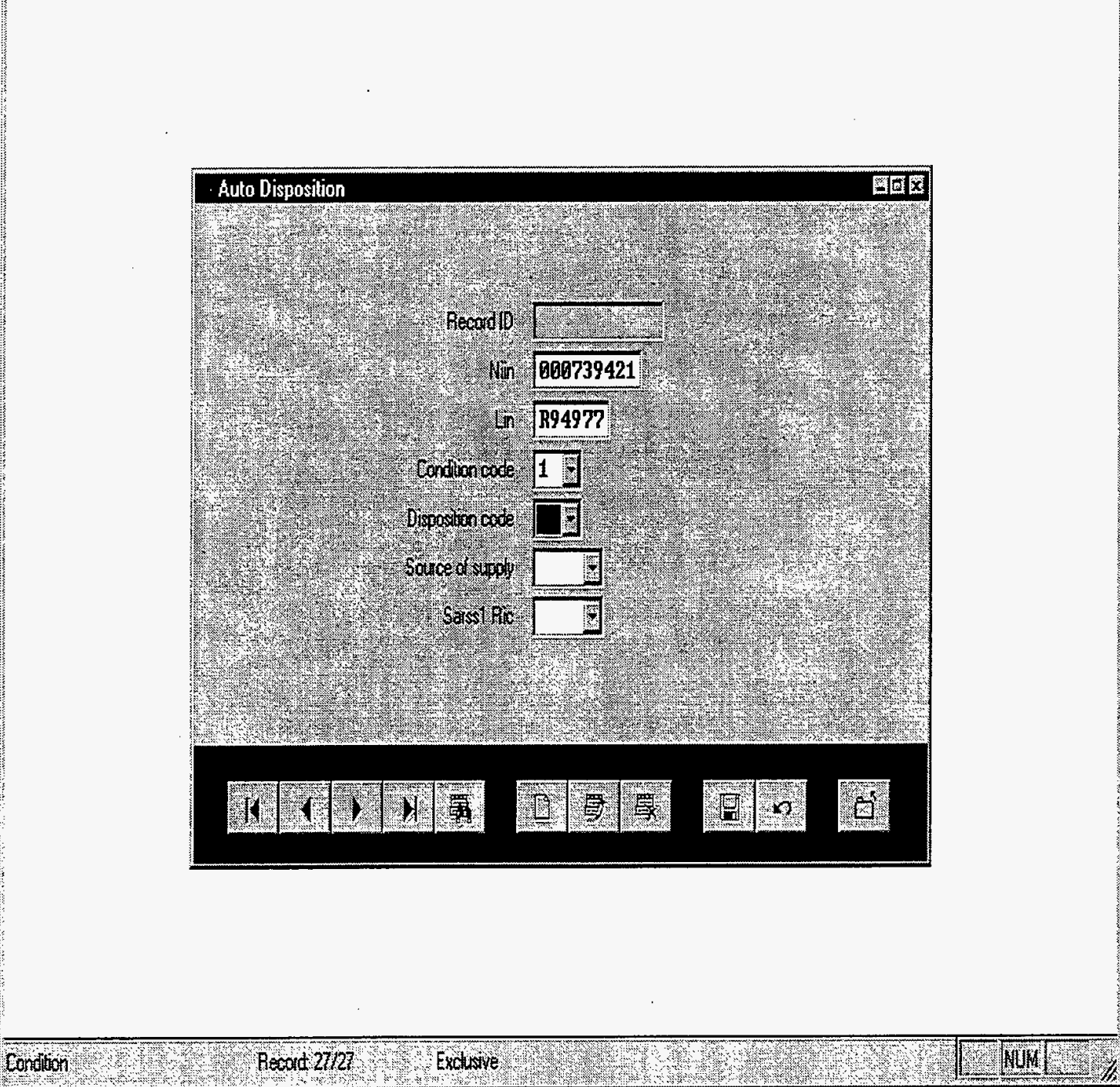

ONCE A CONDITION CODE HAS BEEN SELECTED,

USER MUST SELECT A DISPOSITION CODE.

CLICK ON ARROW TO THE RIGHT OF < Disposition code field> FOR CHOICES.

\section{GO TO NEXT PAGE}

FIGURE 6-11 


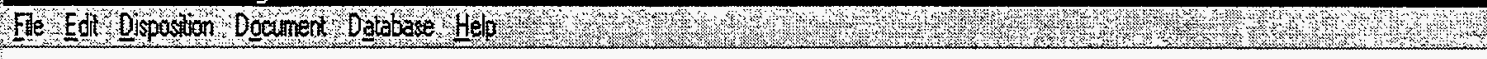

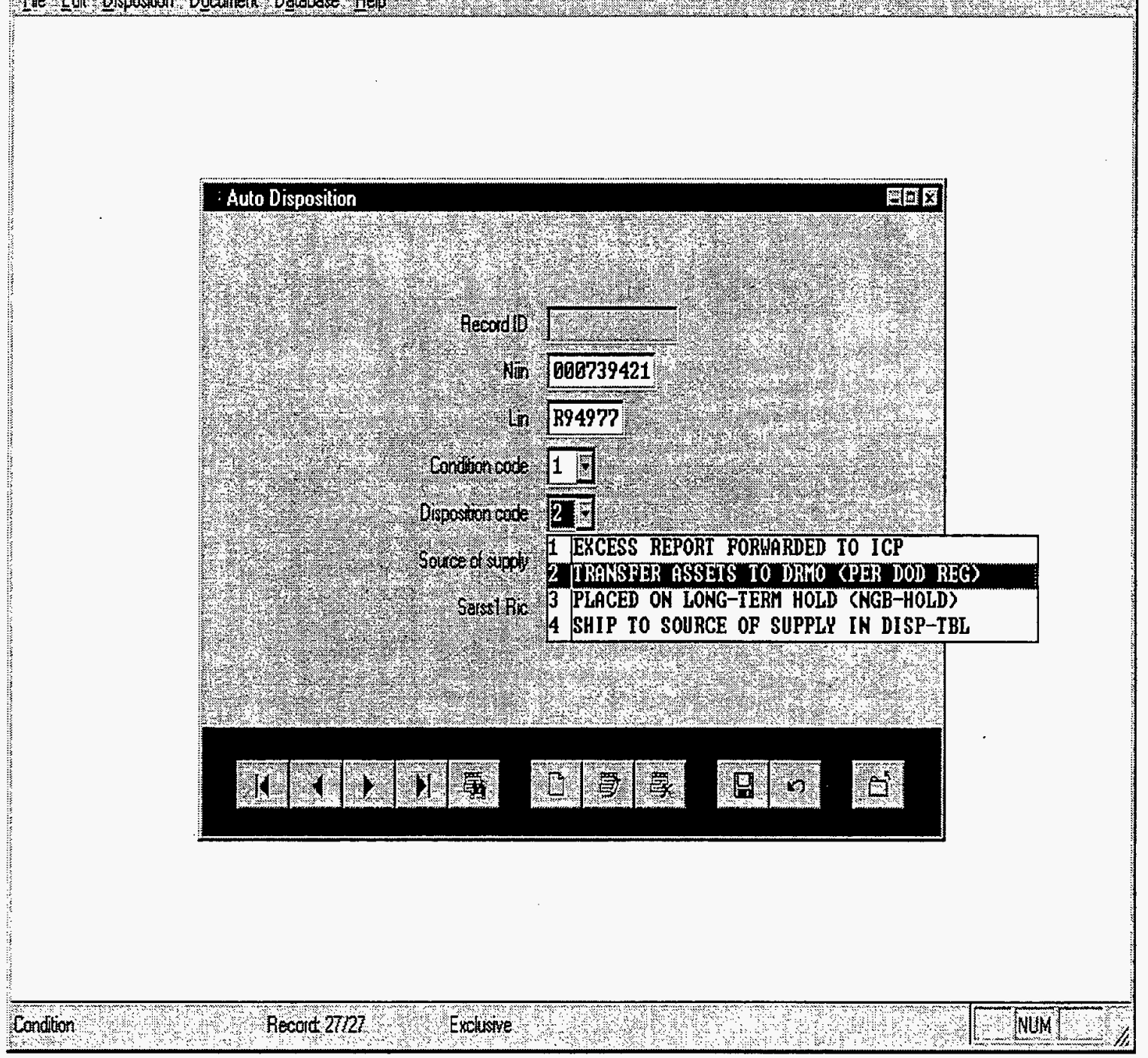

USER CAN MAKE THE FOLLOWING SELECTIONS:

1 = SENDING THE EXCESS REPORT (FTE) ON THE INVENTORY CONTROL POINT FOR ACTIONS.

$2=$ THE PROGRAM WILL PRODUCE AN CUSTOMER RESPONSE (FTR) WITH ADVICE 'TC' DIRECTING THE ASSET TO BE TRANSFERRED TO DRMO.

3 = THE PROGRAM WILL CREATE A CUSTOMER DELAY STATUS (FTD) WITH A ESTIMATED DELAY DATE (EDD) OF ONE HUNDRED AND TWENTY DAYS (120).

$4=$ THE PROGRAM WILL CREATE A CUSTOMER RESPONSE (FTR) WITH ADVICE 'TB' DIRECTING THE ASSET TO BE SHIPPED TO THE RIC ENTERED IN EITHER THE SOURCE OF SUPPLY (SOS) OR SARSS-1 FIELD. (WHEN DISPOSITION CODE FOUR (4) IS SELECTED IT IS MANDATORY THAT THE USER ENTER A 'RIC' IN EITHER THE SOS OR SARSS-1 FIELD.)

\section{GO TO NEXT PAGE}

FIGURE 6-12 


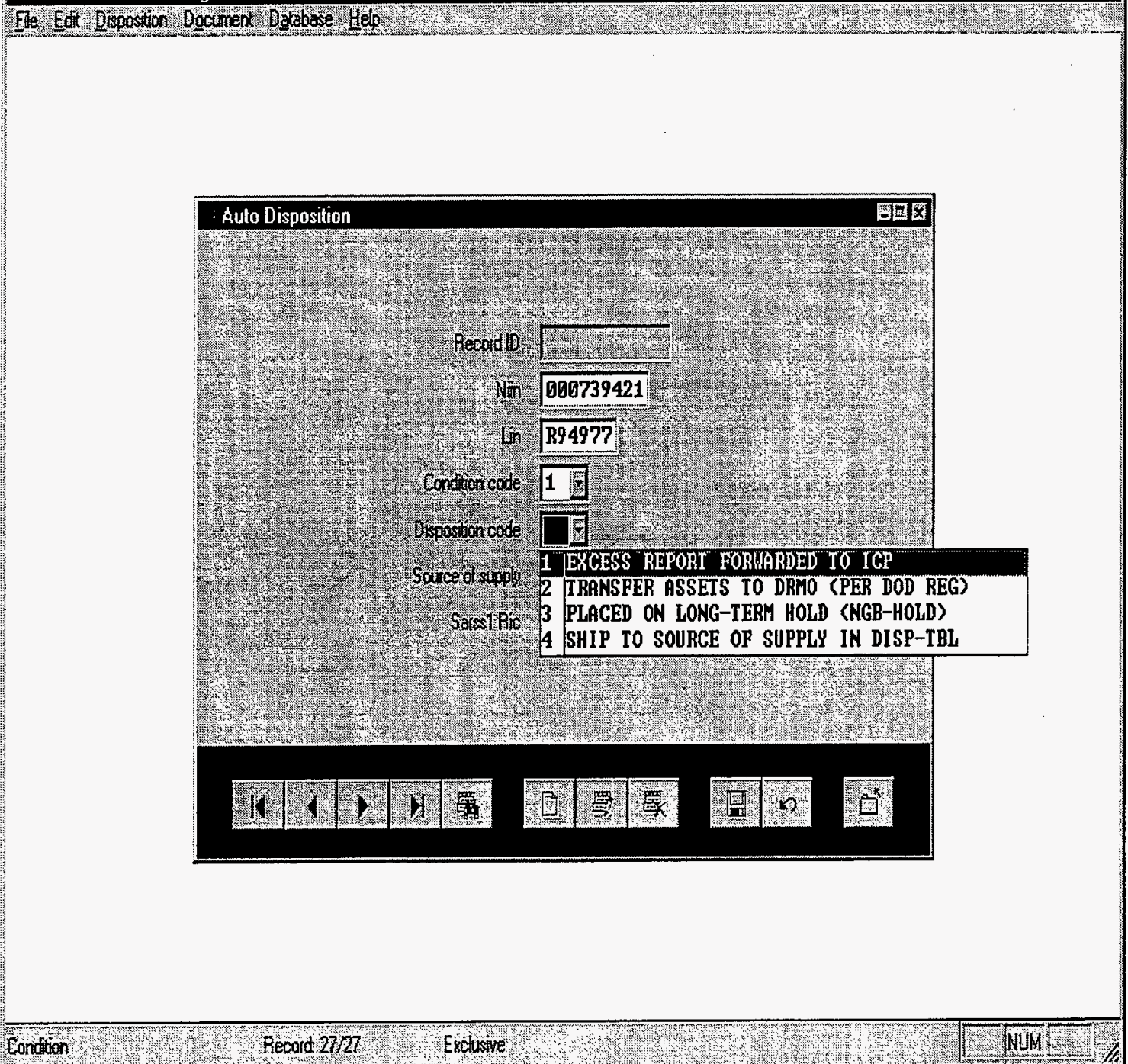

EXAMPLE: THE Niin/LIN FOR ALL CONDITION CODES WILL BE FORWARDED ON TO THE INVENTORY CONTROL POINT (ICP) FOR ACTIONS.

\section{GO TO NEXT PAGE}

FIGURE 6-13 


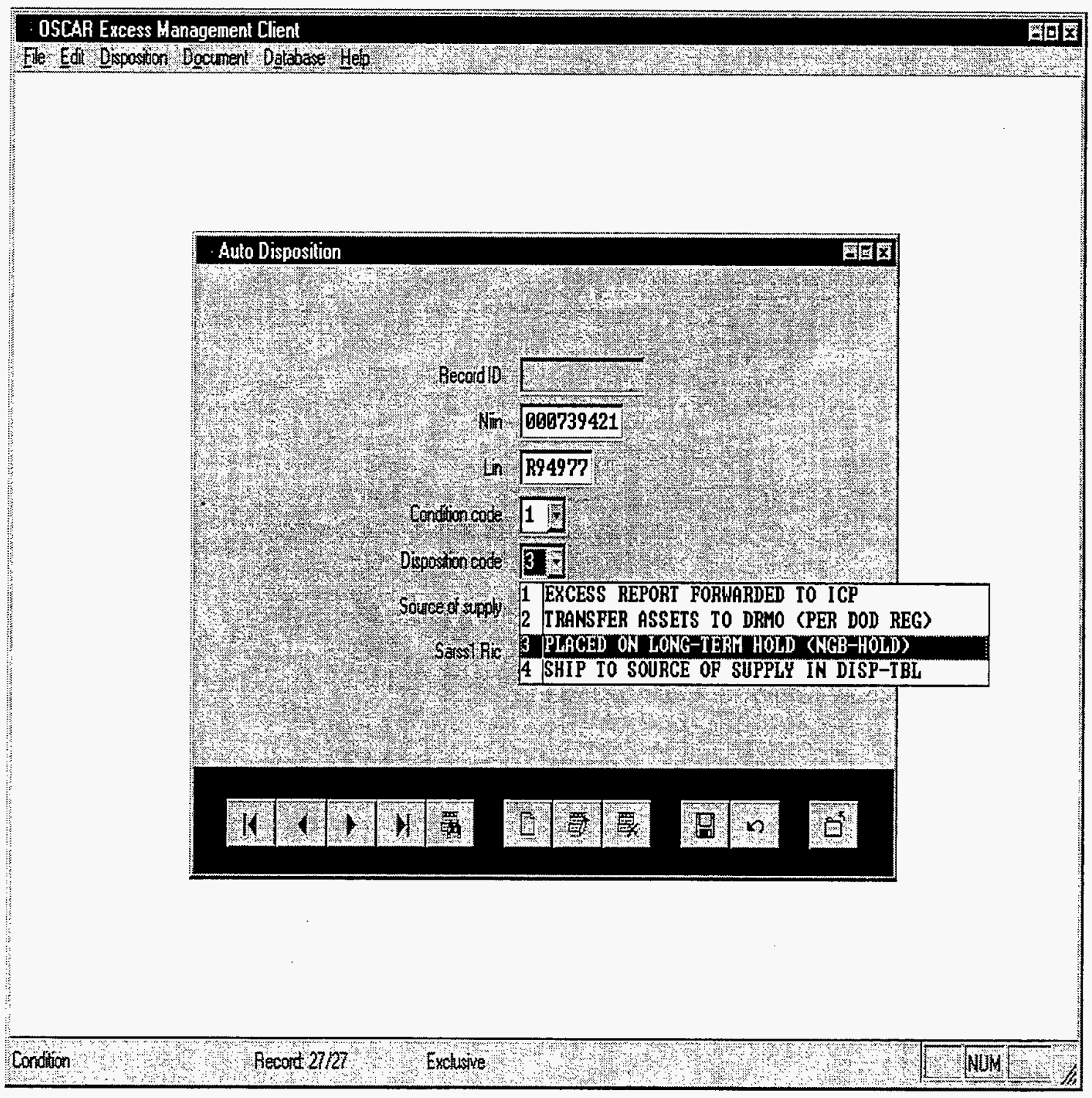

EXAMPLE THE Niin/LIN FOR ALL CONDITION CODES WILL BE PLACE ON NGB HOLD.

GO TO NEXT PAGE

FIGURE 6-14 
SI-9 สมกDIม

ত্রDVd LXAN OL OD

(SOS) XTddחS HO GวצחOS HHL OL GAddIHS

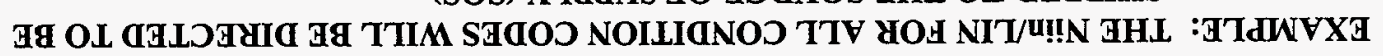

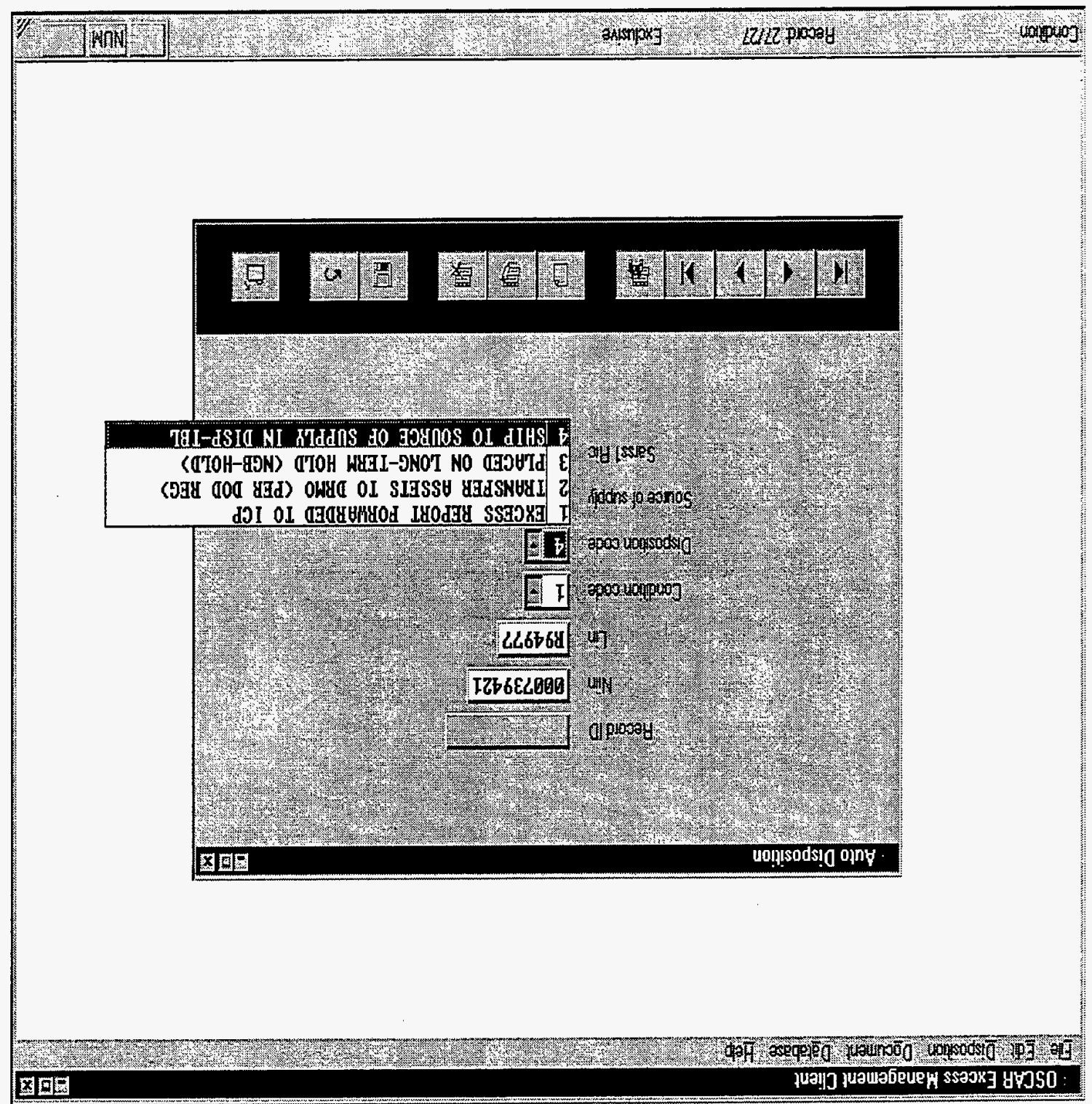




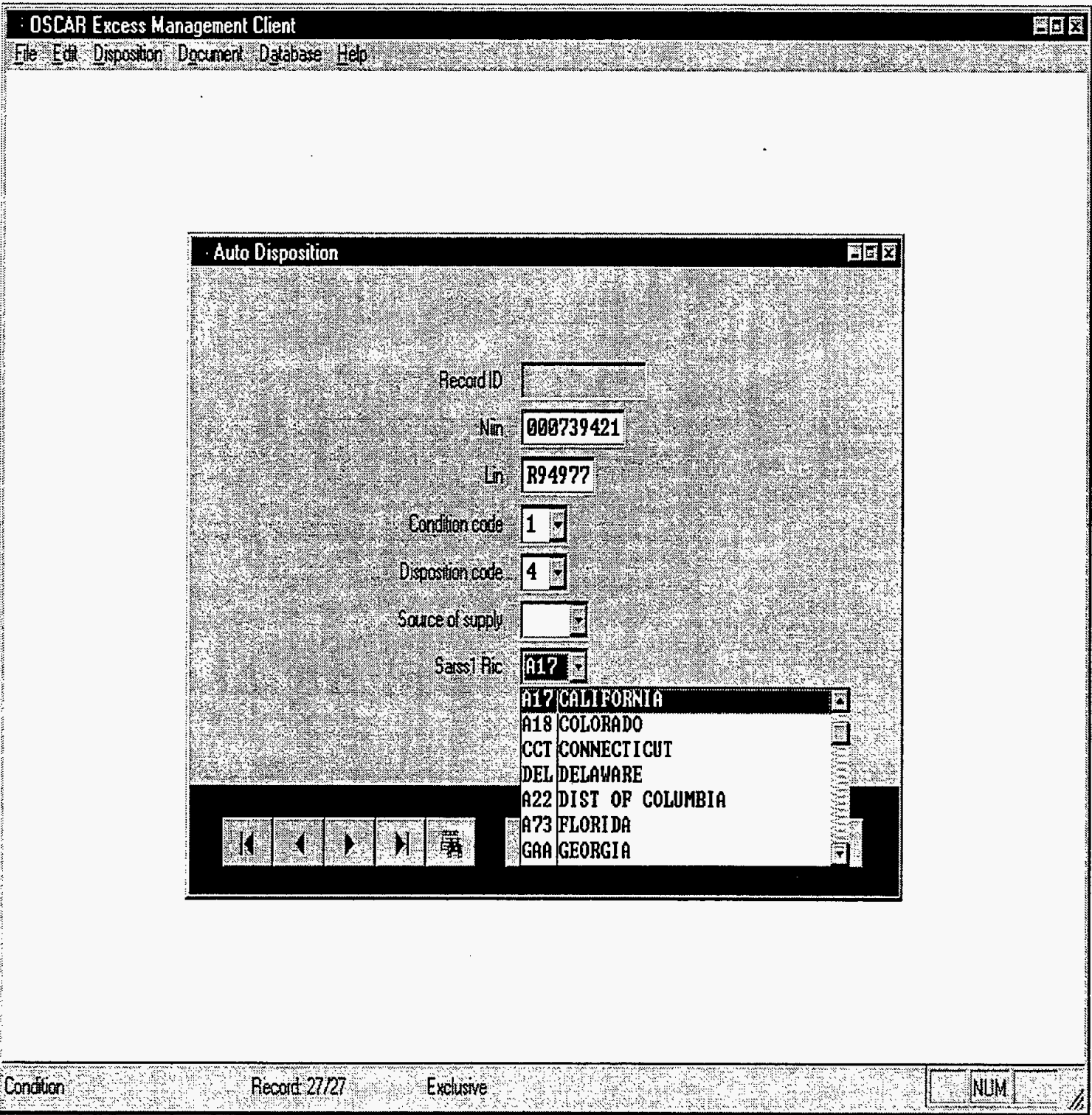

EXAMPLE: An FTR with advice 'TB' \& 'A17' in position 54-56 will be sent to the reporting state. (NGB has directed that any Excess Report with Niin '1005-00-073-9421' LIN R94977 regardless of Condition code be shipped to 'A17' California.)

\section{GO TO NEXT PAGE}

FIGURE 6-16 


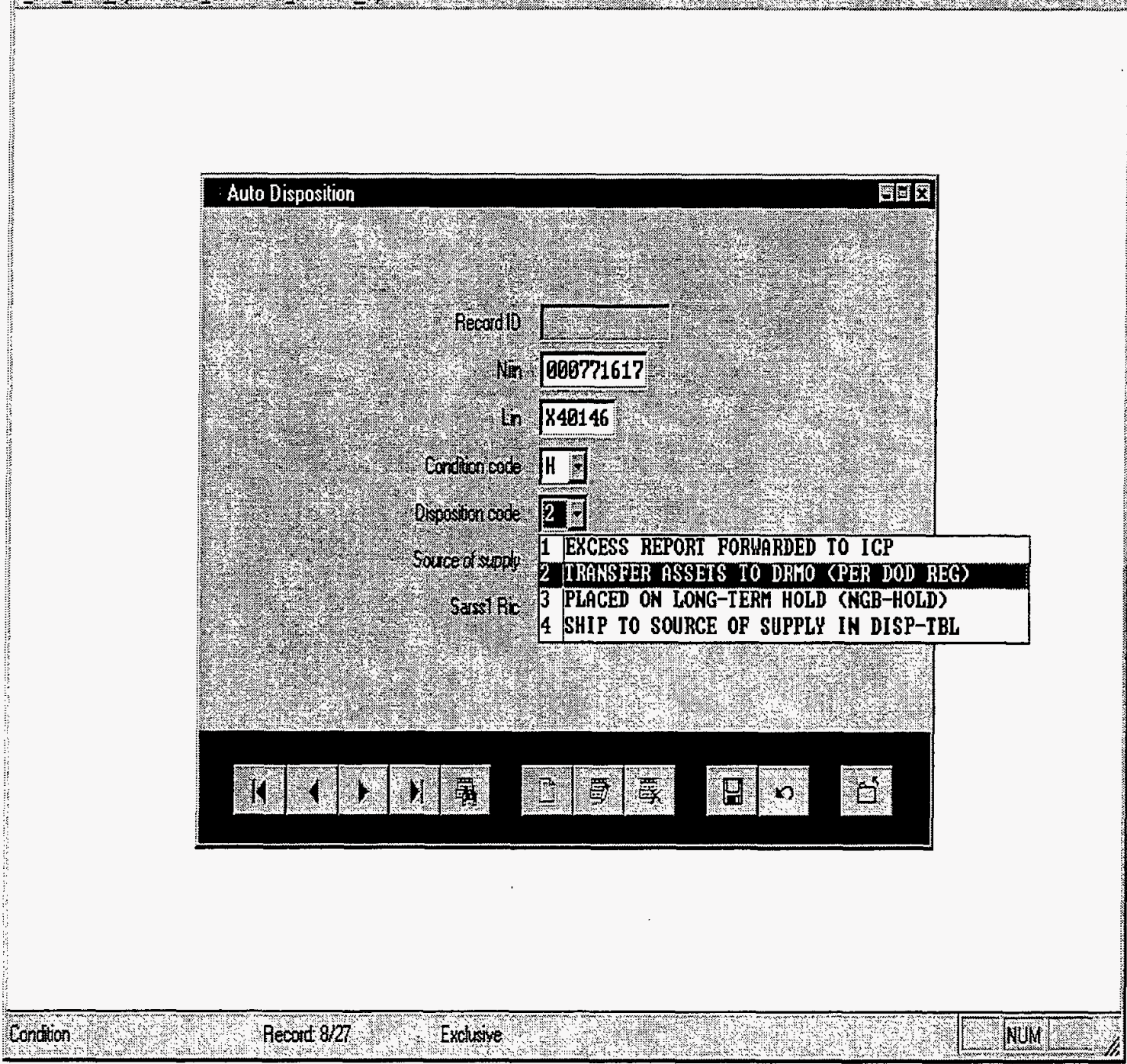

EXAMPLE: Reporting State will receive an FTR with advice 'TC'. (NGB has directed that any Excess Report for Niin '2320-000771617' and LIN 40146 with Condition code equal to ' $H$ ' be sent to DRMO).

\section{GO TO NEXT PAGE}

FIGURE 6-17 
Gle Ed Dipostion Documen Dajoare He

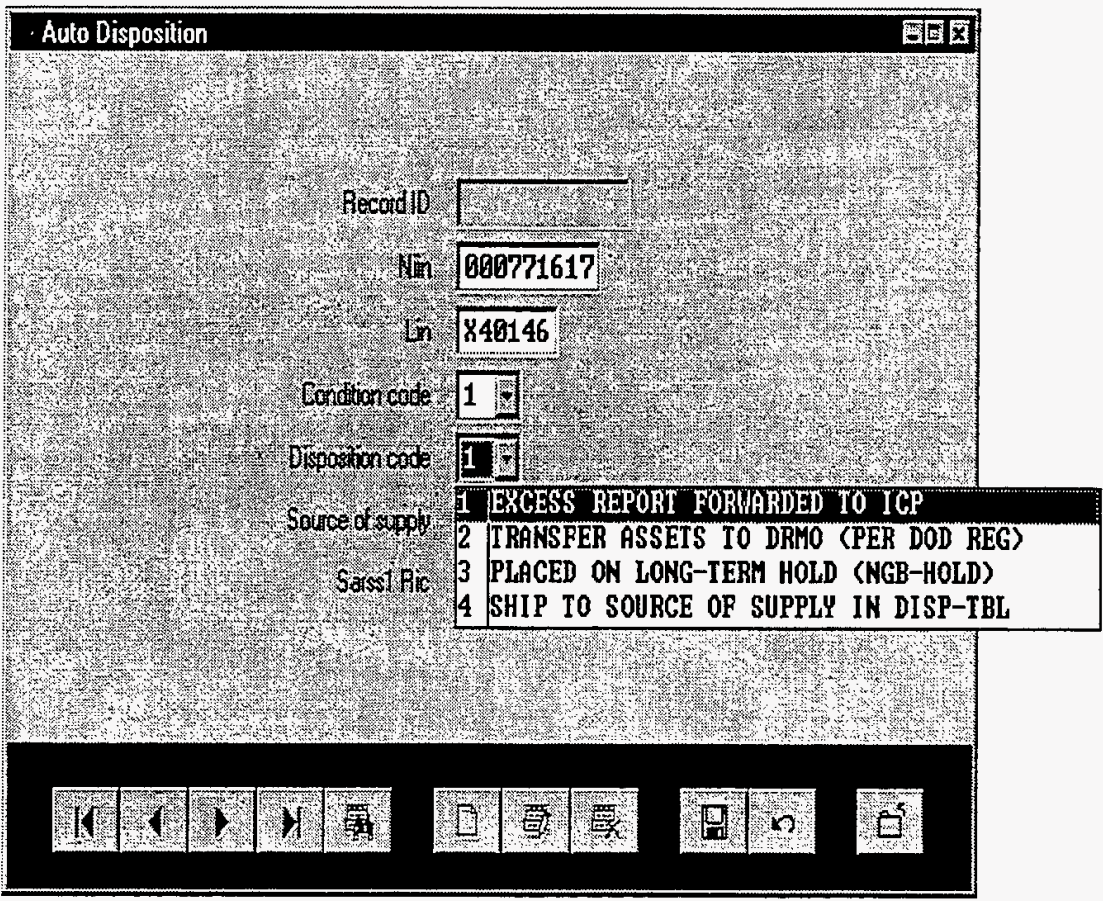

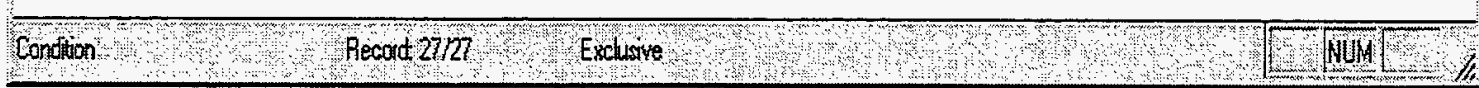

EXAMPLE: Any Excess Report received for Niin '2320-00-077-1617' and LIN X40146 regardless of Condition codes be forwarded on the to ICP for Disposition. 
OSCAR Excess Hanagement Client

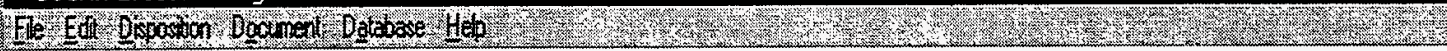

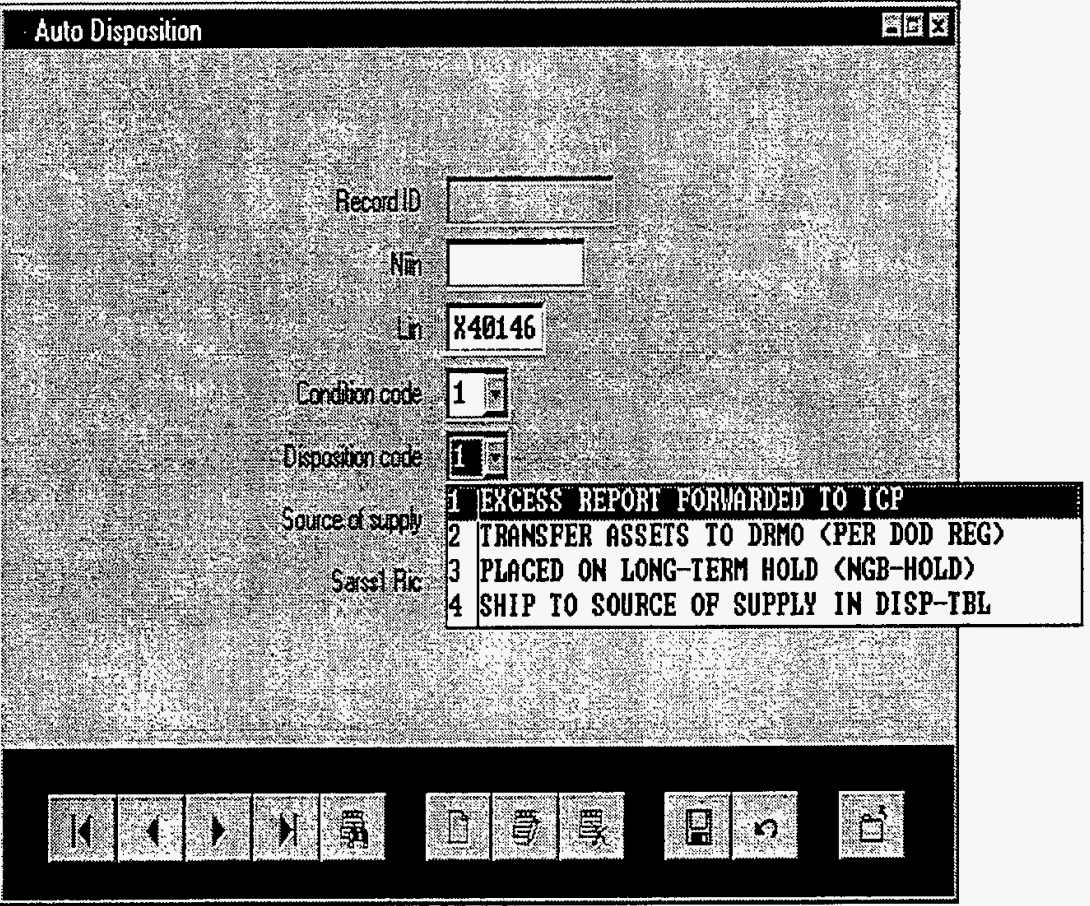

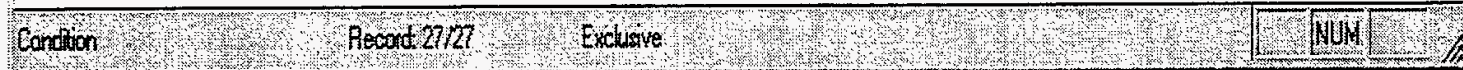

EXAMPLE: NGB has directed that an Excess Report for the above LIN 'X40146' regardless of Condition code to be forwarded on to the ICP.

\section{GO TO NEXT PAGE}

FIGURE 6-19 
Ele Ed Dispostion Document Database Help

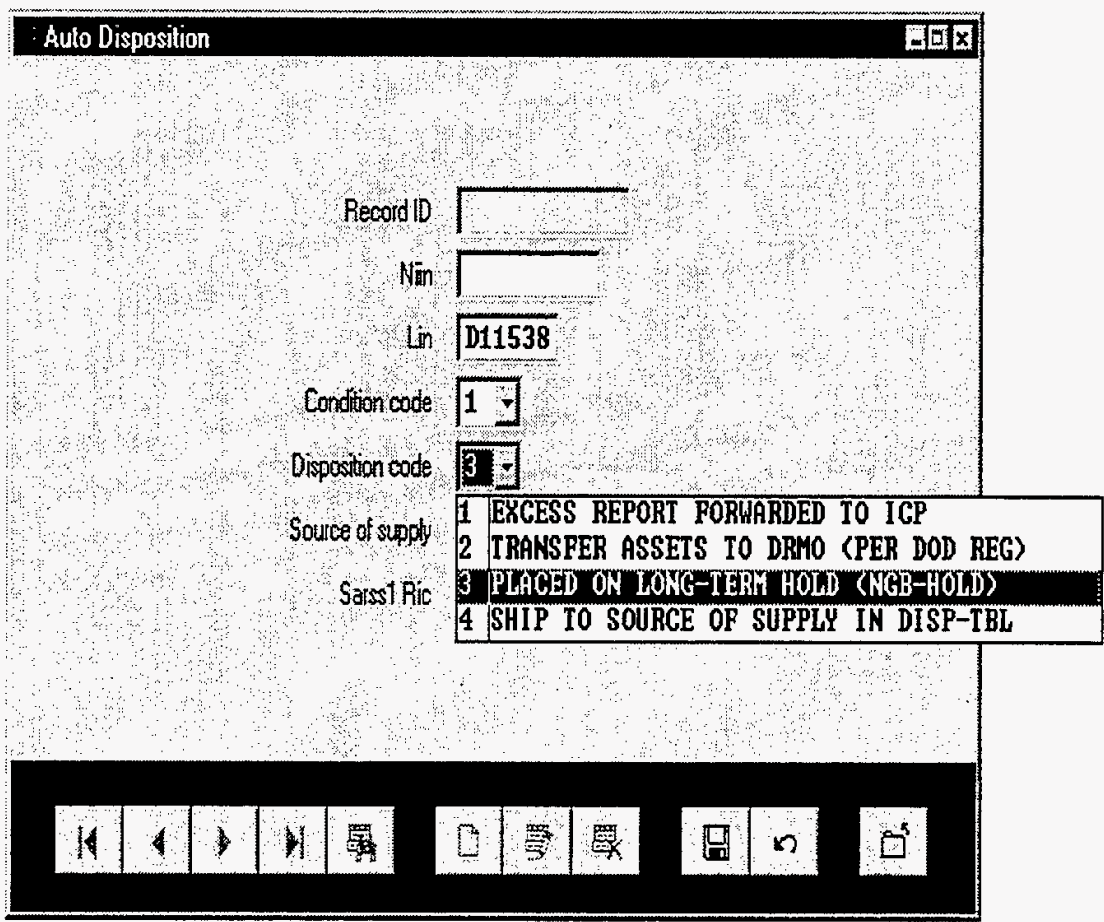

Condition Record 27/27 Excluse

EXAMPLE: NGB has directed that any Excess Report for LIN 'D11538' regardless of Condition code will be place on Long-Term Hold . Excess Report customer will receive a Disposition Delay Status (FTD).

\section{GO TO NEXT PAGE}

FIGURE 6-20 


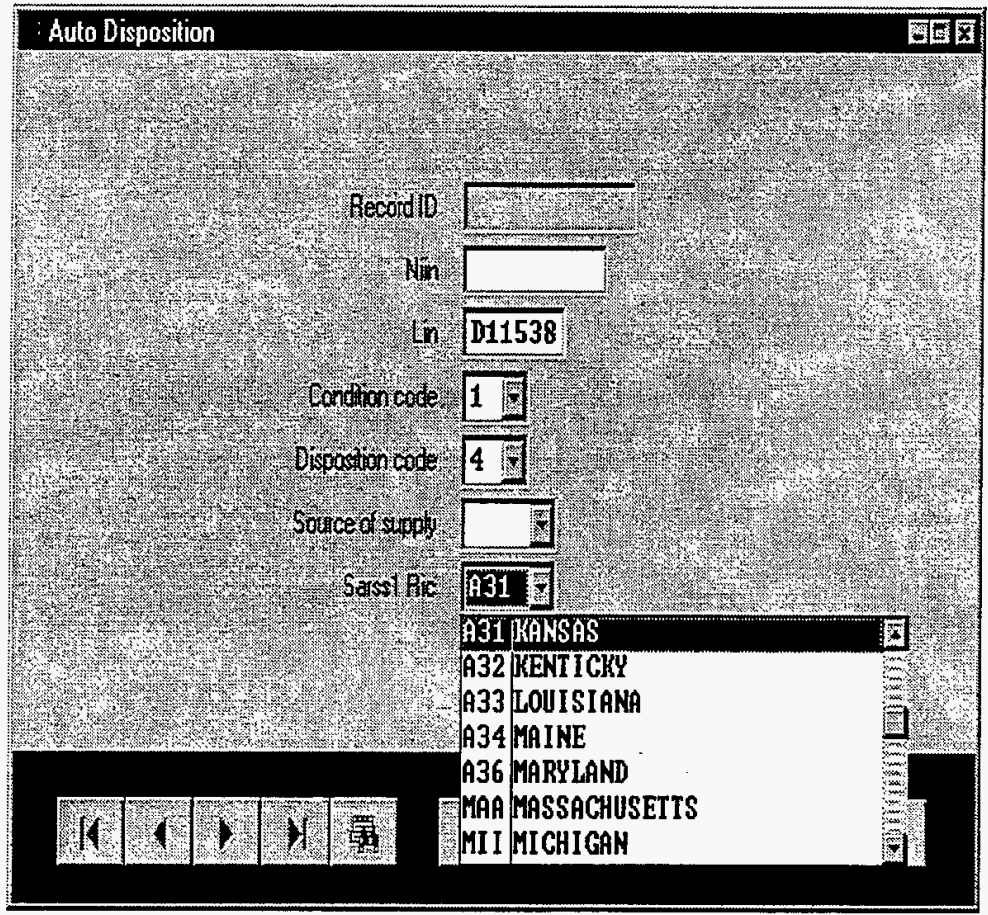

EXAMPLE: NGB has directed that any Excess Report (FTE) received for LIN 'D11538 regardless of Condition code be sent to RIC 'A31' Kansas.

A Customer Response (FTR) with advice 'TB' and RIC 'A31' in position 54-56 will be sent to state reporting excess and an AE1 will be sent to receiving state RIC 'A31' with status 'BA'.

\section{GO TO NEXT PAGE}

FIGURE 6-21 


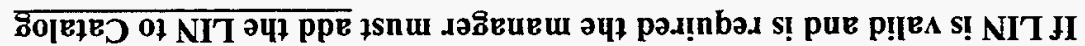

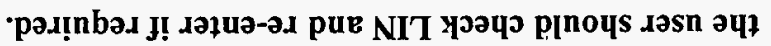

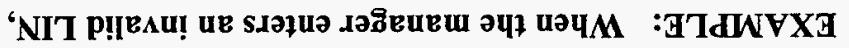

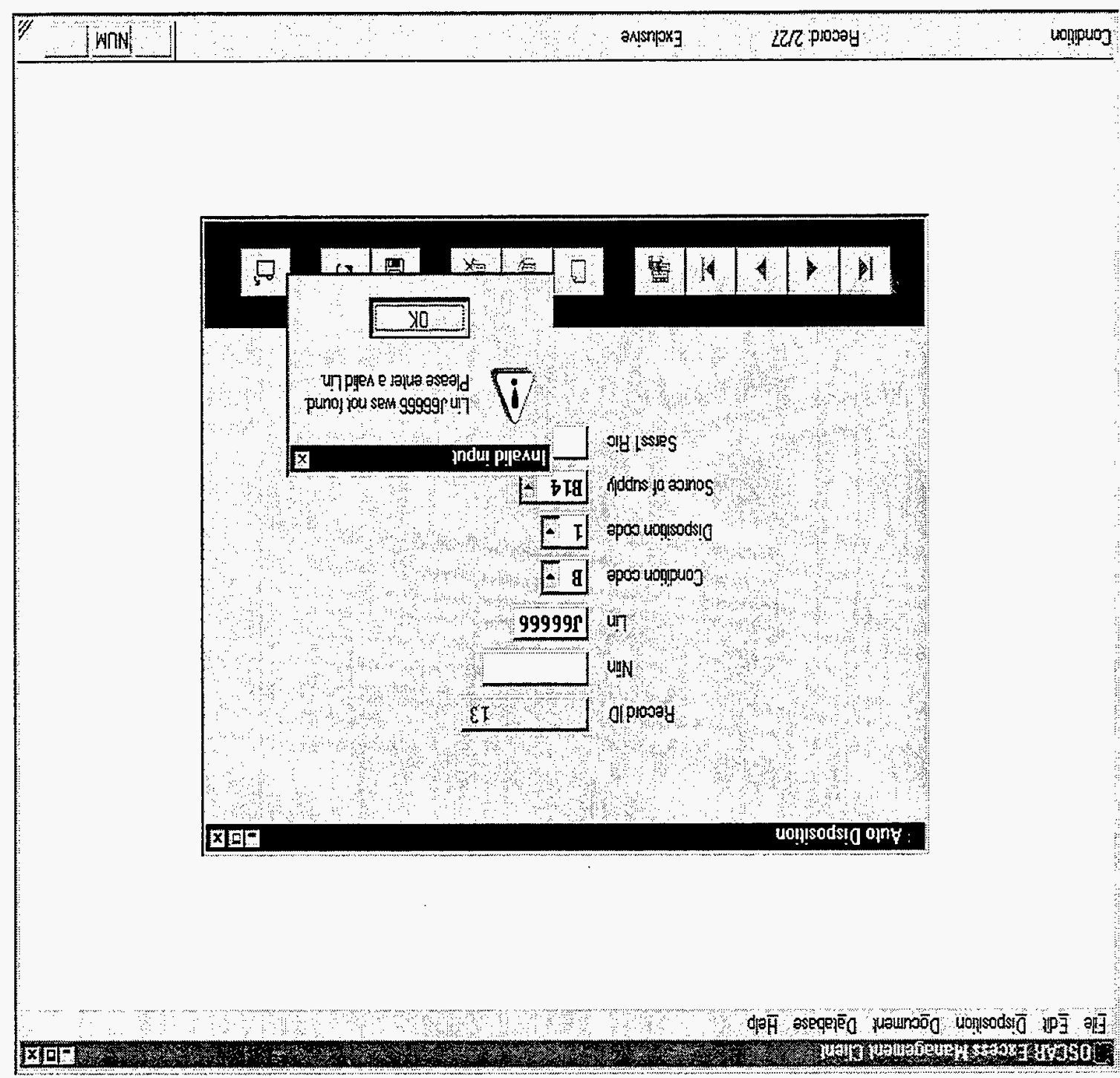


SECTION 7. SET UP PROCESS

7.1 General. This section is designed to furnish information on how the set Up process will operate within the OSCAR Excess Management Program.

TO BE DEVELOPED 
THIS PAGE NOT USED 
SECTION 8. RVARS RETRIEVAI PROCESS

8.1 General. The RVARS Retrieval Process was designed to allow the NGB manager to extract data and information from the NGB Master File to the user's PC. The process uses the USER-ID Table so that only the data authorized by a particular manager can be extracted. Information can be obtained by USER-CD, SOS/RIC, STATE-CD, and/or IIN. USER-CD is a mandatory field. Once the USER-CD has been entered, the system will edit to see if the user is authorized based on SOS/RIC in USER-CD Table. The NGB Manager can only extract data/information for which he/she is authorized.

8.2 RVARS DATA RETRIEVAL. This process is designed to extract active Excess Reports [FTE(s)] which require disposition actions by NGB managers and create an RVARS Input File. Those FTE(s) that have been received but not acted upon and/or those items that have been place on LongTerm Hold (NGB Hold Items) by NGB managers. (See Fig. 8-1 through 8-14.)

a. The NGB managex must select the ICON for ASSET RETRIEVAL PROCESS.

b. The System will ask the NGB Manager to enter his/her USER-CD. When a valid USER-CD is entered, connectivity with the Master Database will occur.

c. The NGB Manager will be asked if he/she wishes Iong-Term Delay/NGB Hold items included.

1. When manager answers "Yes," then all active FIE(s) in the Master File will be extracted.

2. When the manager chooses "No," only those active FTE(s) without a Long-Term Delay/NGB Hold flag will be extracted.

d. A screen will appear which will allow the manager to further indicate his/her requirements. 
1. When the USER-CD is entered with no other fields selected and the process button is pressed, the manager will retrieve all FTE(s) in the Master File for all the sos/RIC(s) identified in the USER-CD TABLE for that User.

2. When the sOS/RIC is entered along with the USER$C D$, the manager will retrieve only those FTEs for sos/RIC selected.

3. STATE-CD - This feature allows the manager to process data particular to one (1) state.

(a) The manager can extract all sos/RIC for the state by only entering the STATE-CD and pressing the Process Button.

(b) One sos/RIC for the state can be retrieved by entering the STATE-CD, the SOS/RIC and pressing the Process Button.

(c) One (1) particular IIN for the state can be retrieved by entering the STATE-CD, SOS/RIC, IIN and then pressing the Process Button.

4. IIN - When the IIN is entered, it must be compatible with the sos/RIC.

(a) When manager enters USER-CD and IIN and presses the Process Button, all active FTE(s) for that particular IIN will be extracted.

(b) If the manager enters the USER-CD, IIN, plus STATE-CD and presses the Process Button, the IIN for that particular state will be extracted.

5. When there are no records that meet the above conditions, a message reading, "No records were retrieved to RVARS Input File." will be sent to the manager. 


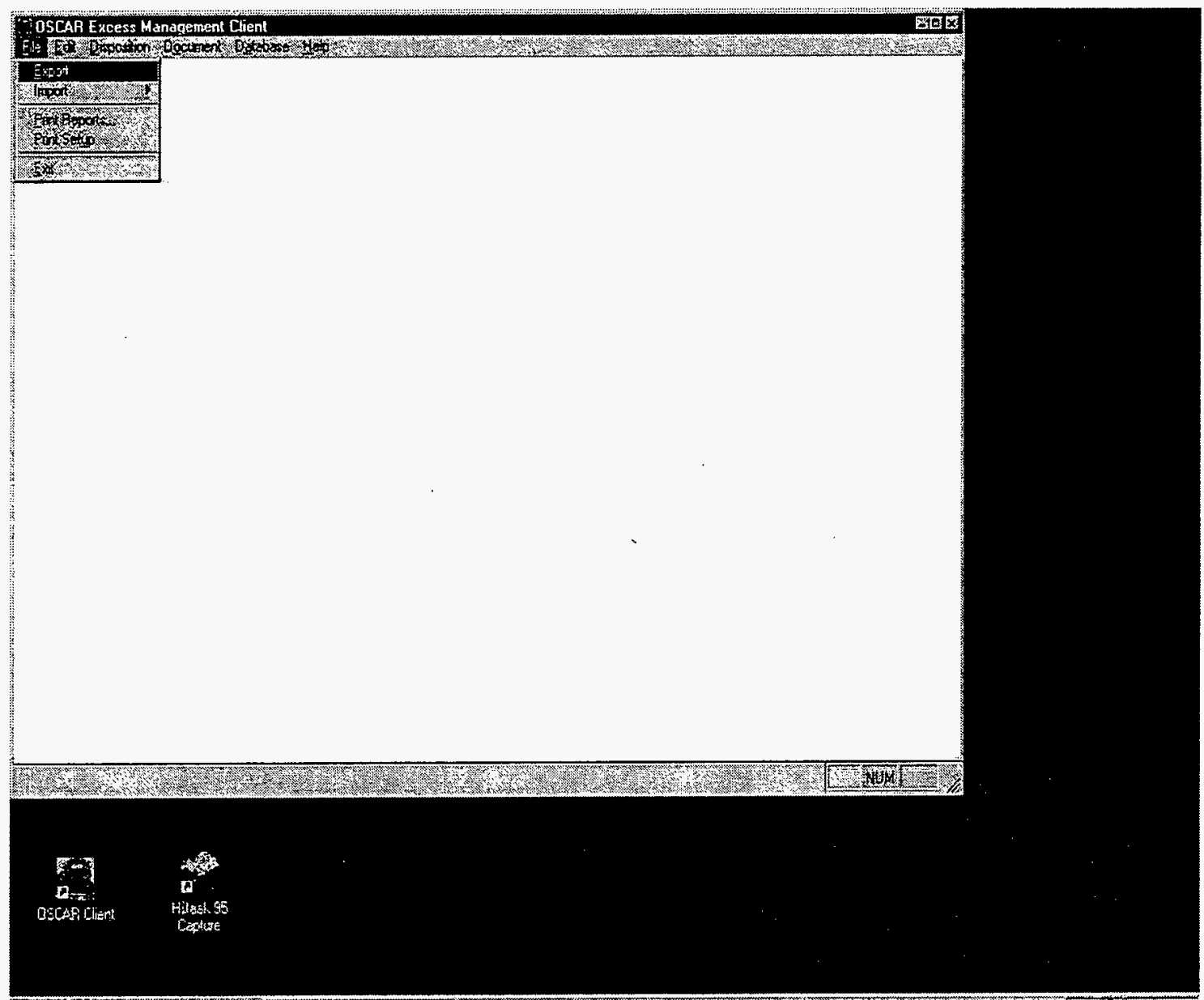

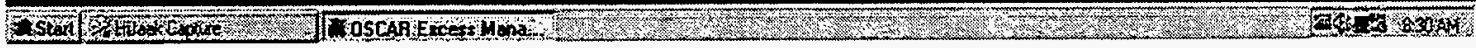

CLICK ON: OSCAR from the NT Main Menu

THEN: $\quad$ CLICK ON: $<$ File $>$ (The options above will display)

DOUBLE CLICK ON: <Export>

\section{GO TO NEXT PAGE}

FIGURE 8-1 


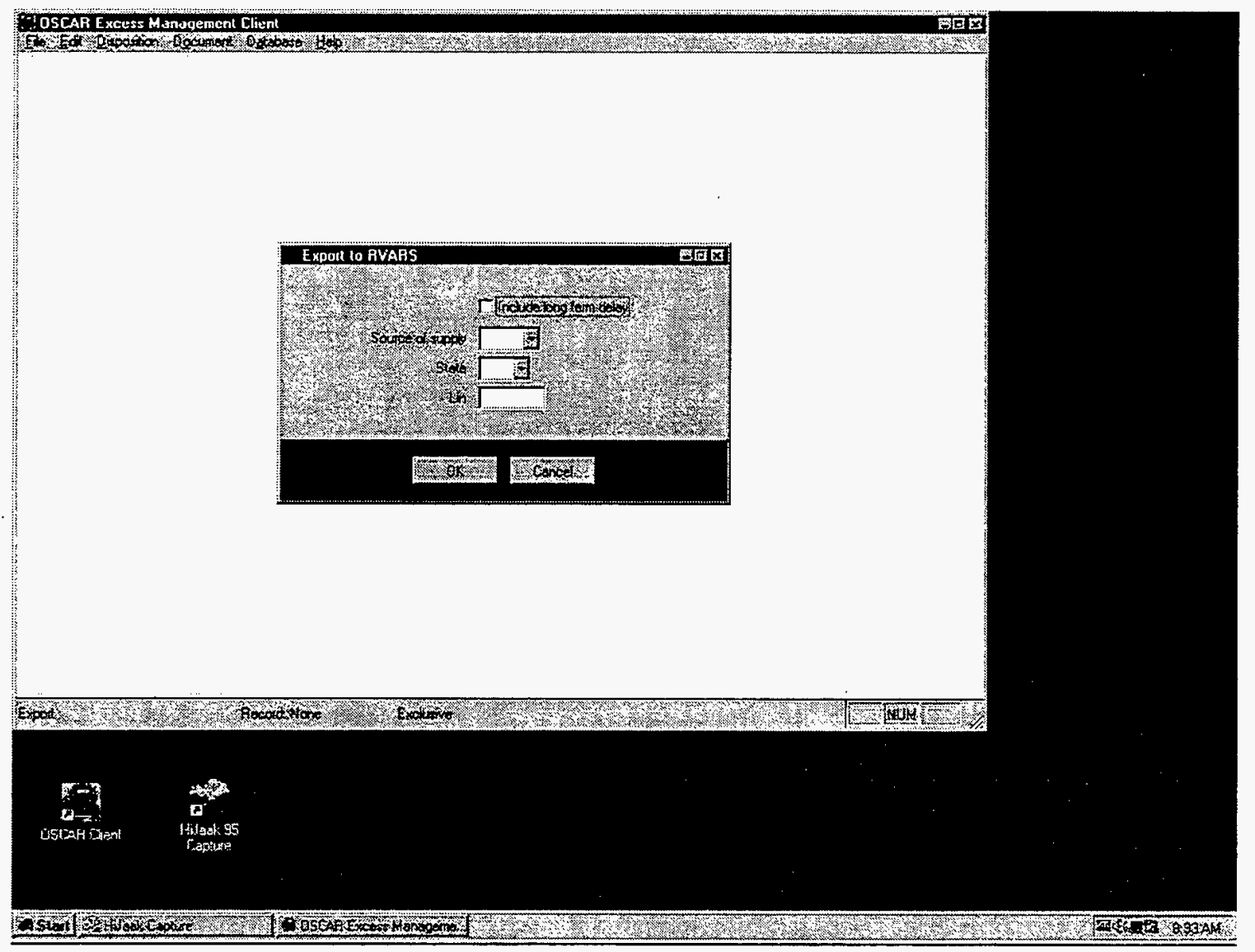

When user Clicks on $<$ Export $>$ the above screen will appear.

If user does not require any special options, they can Click $<\mathrm{OK}>$

All Customer Excess Reports with Activity-Indicator equal to ' $A$ ' that are for the users Source of Supply (SOS) will be retrieved to a file in RVARS format.

Remarks: Excess reports that have previously been place on 'Long-term delay' will not be selected.

\section{GO TO NEXT PAGE}

FIGURE 8-2 


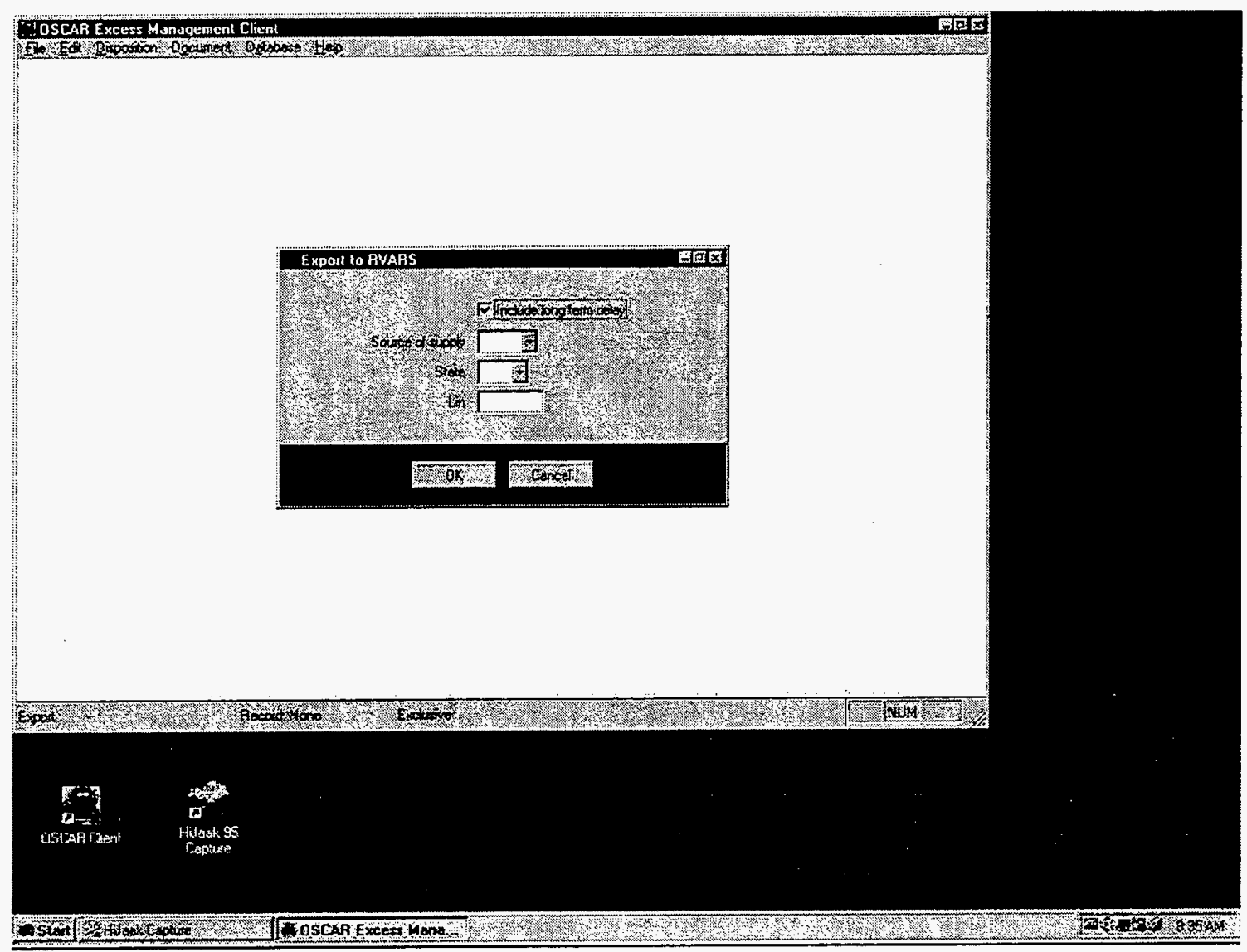

When user clicks on the block to the left of $<$ Long-term delay $>$ a check will appear.

When user clicks on $<\mathrm{OK}>$, all Customer Excess Reports in the Master File will be retrieved, including those previously place on 'Long-term delay'.

\section{GO TO NEXT PAGE}

FIGURE 8-3 


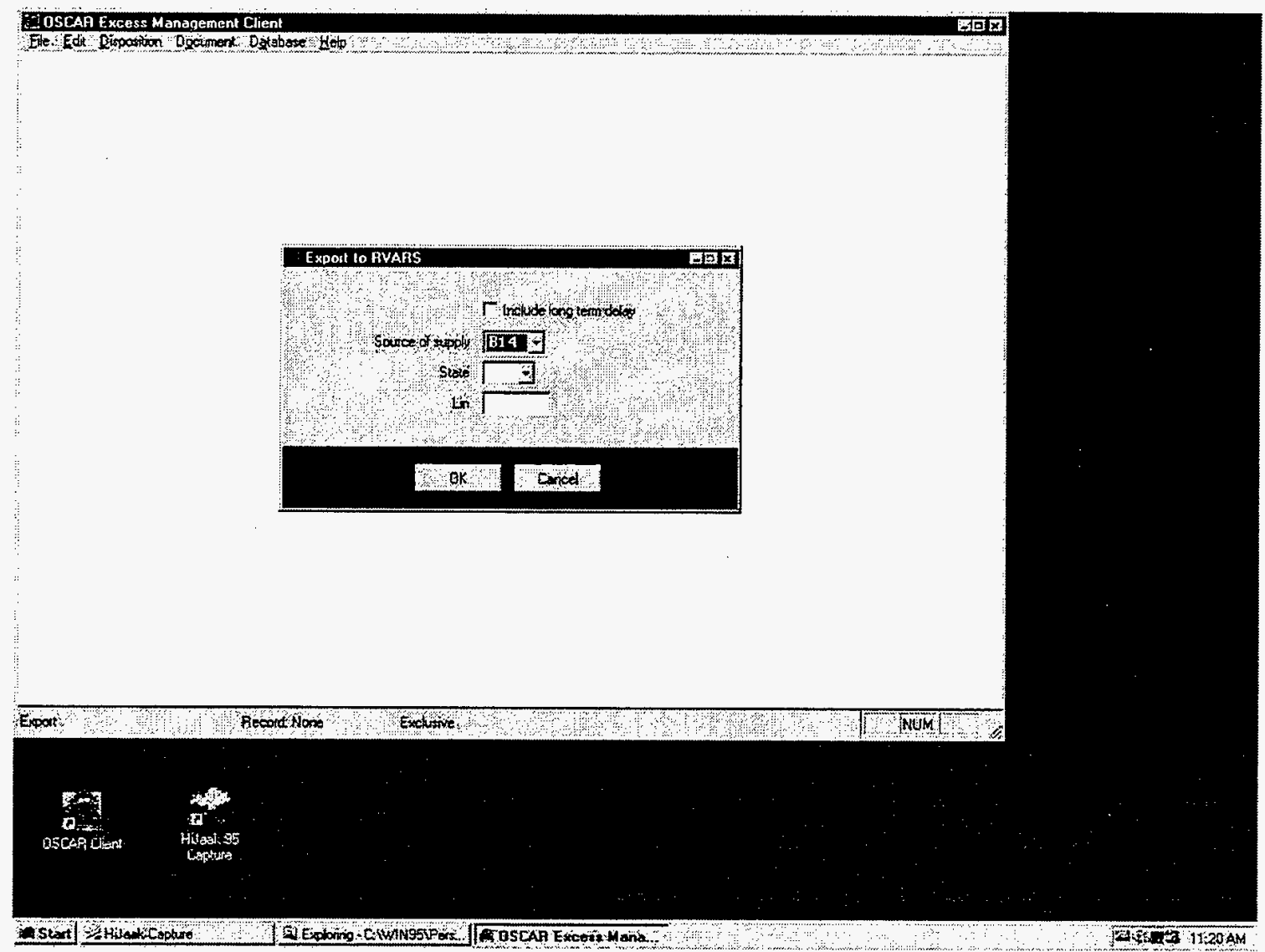

User can click on the arrow to the right of Source of Supply (SOS), and a range of Inventory Control Point (ICP) Routing Identifier Codes (RIC) will appear. When user selects a SOS RIC, only those excess reports for that particular RIC will be selected.

Remarks: User can also select the $<$ Long-term delay $>$ option when they wish to retrieve the 'longterm delay' reports for that SOS. 


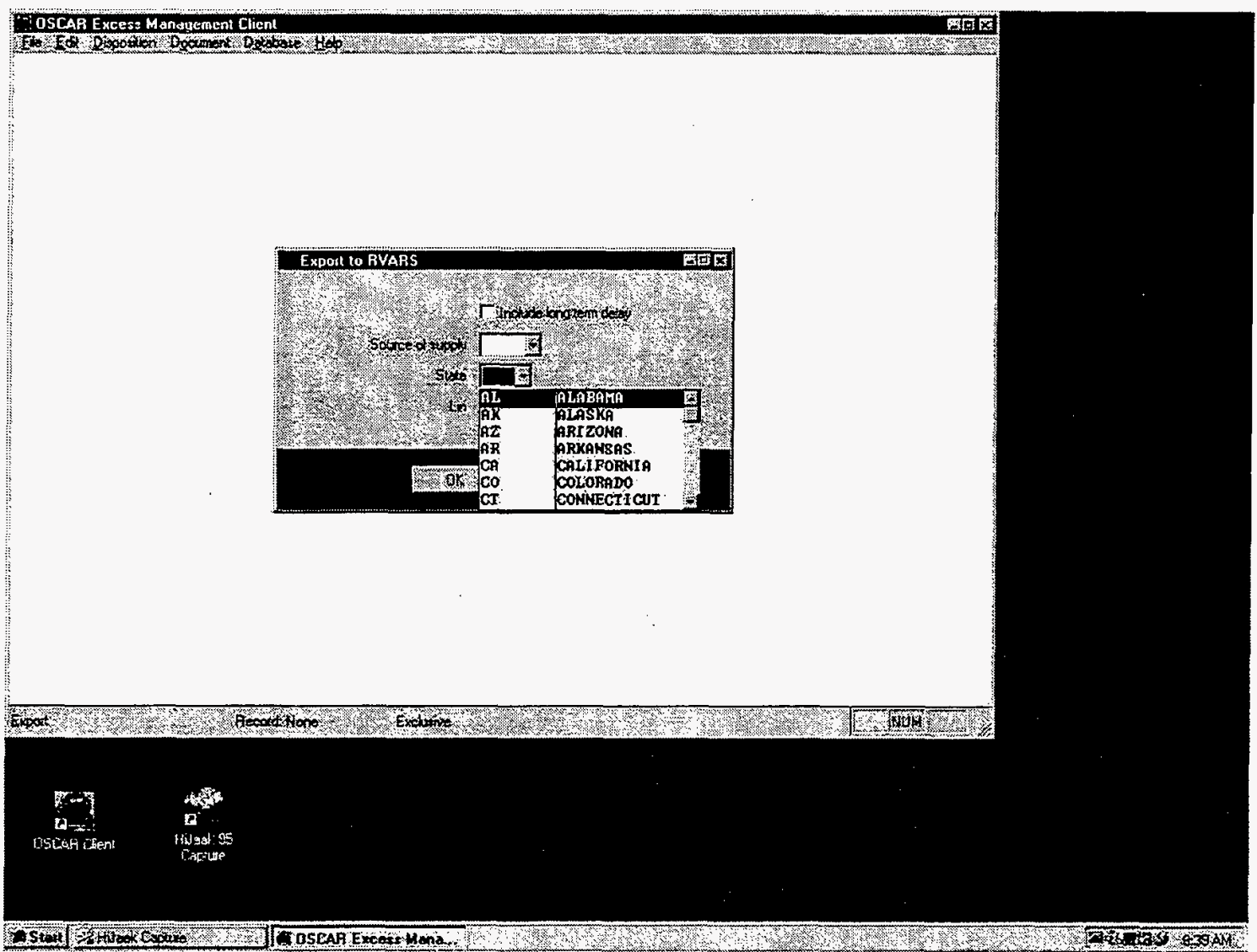

When the user chooses to select a particular 'State', the user can click on the arrow to the right of the 'State' field on the screen. Options for different states will appear and the user can click on the state that they would like to select. Once the user has selected a particular state, only those excess reports from that state will be retrieved for RVARS.

Remarks: User can also select $<$ long-term delay> reports for the state selected.

\section{GO TO NEXT PAGE}

FIGURE 8-5 


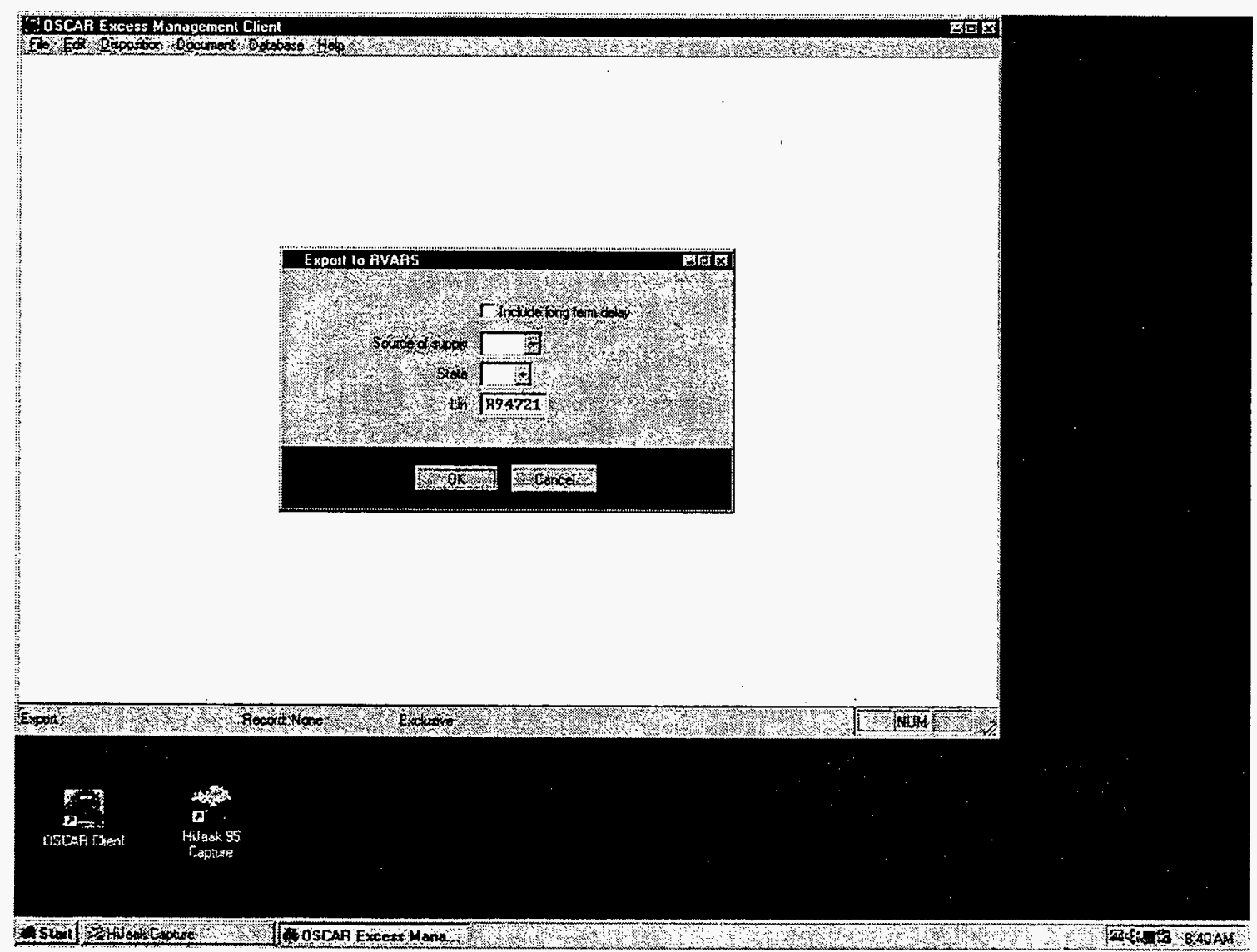

When the user chooses to select a particular 'Lin'. They can click on the block next to Lin and enter the Lin. Only excess reports for the Lin entered will be selected for RVARS.

Remarks: User can also select $<$ Long-term delay> assets for the lin.

\section{GO TO NEXT PAGE}

FIGURE 8-6 


\section{L-8 ЯับกDIH}

TगVd LXGN OI OD

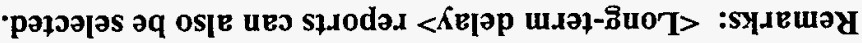

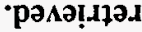

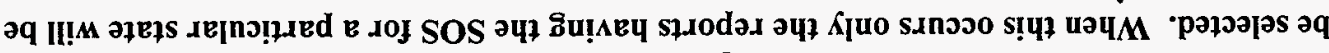

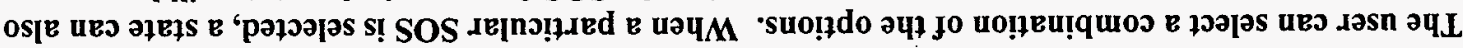

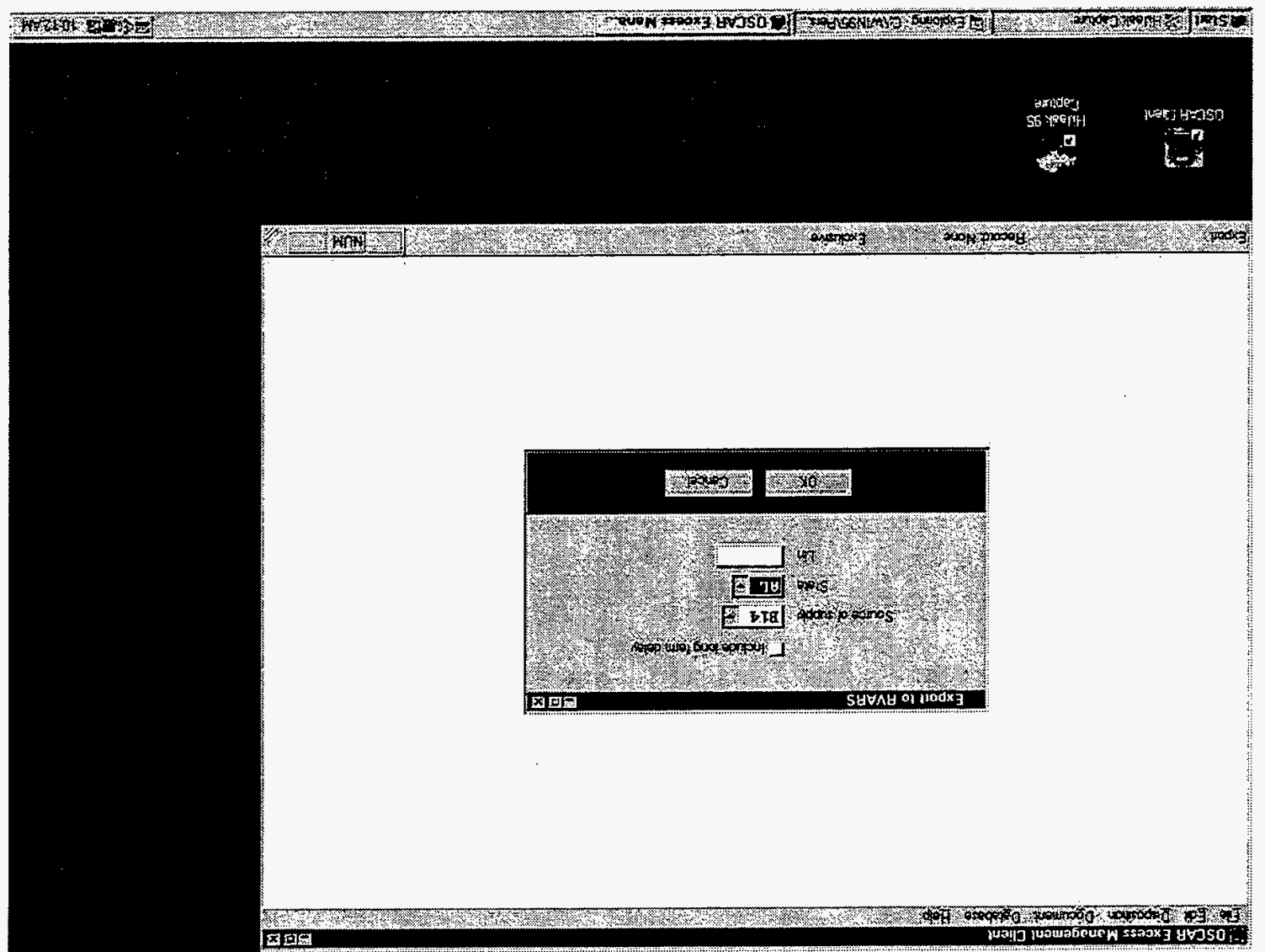




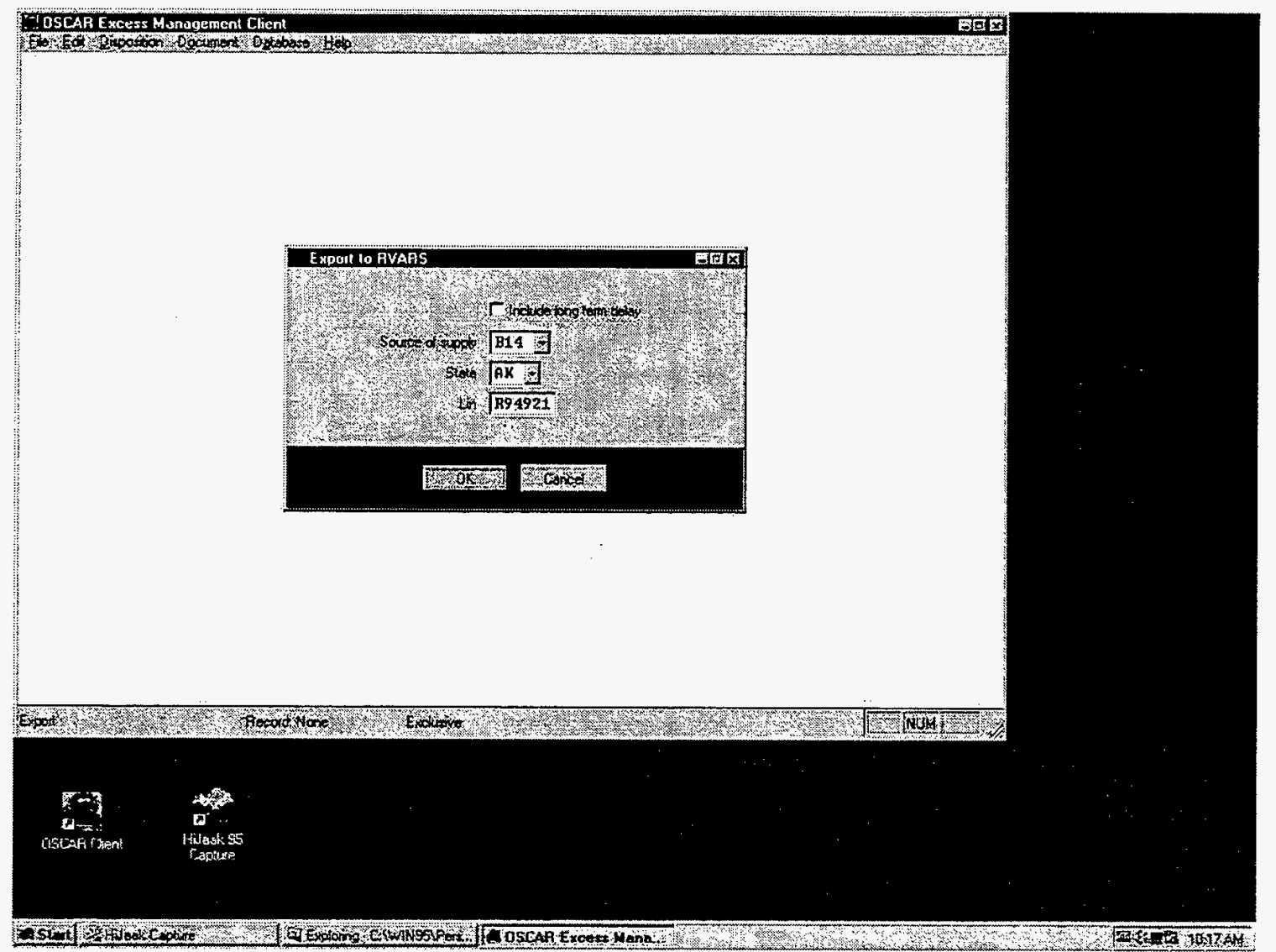

When the options shown above are selected, the user will retrieve only those excess reports for the state identified with the SOS of 'B14' and a Lin of 'R94921'.

Remarks: The 'long-term delay' assets can also be selected by checking the block next to the $<$ Long-term delay $>$ field.

\section{GO TO NEXT PAGE}

FIGURE 8-8 


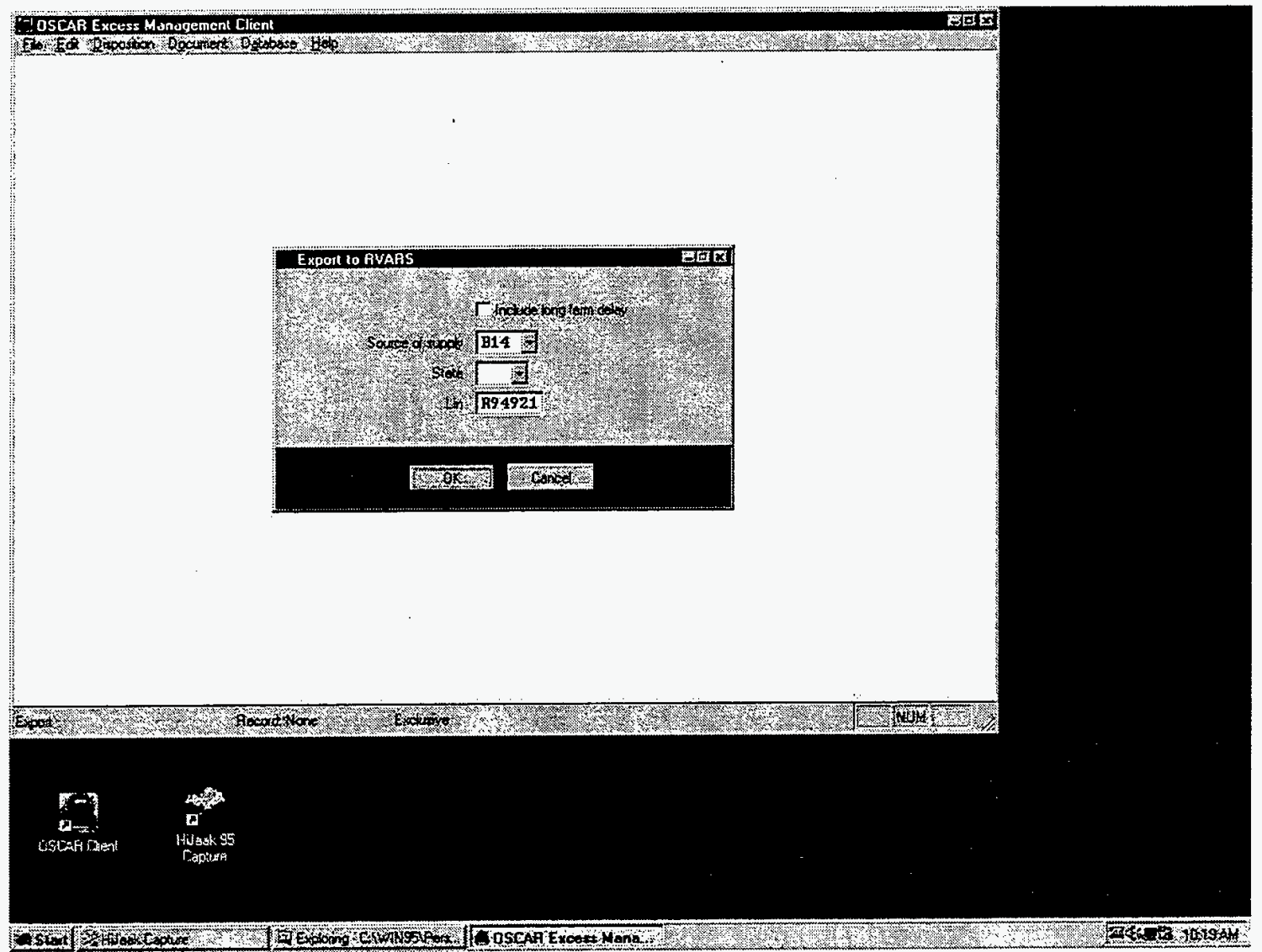

When the user selects the options above they will retrieve the active excess reports for ' $\mathrm{B} 14$ ' for Lin 'R94921'.

Remarks: The 'long-term delay' assets can also be selected by checking the block next to the $<$ Long-term delay $>$ field.

\section{GO TO NEXT PAGE}

FIGURE 8-9 


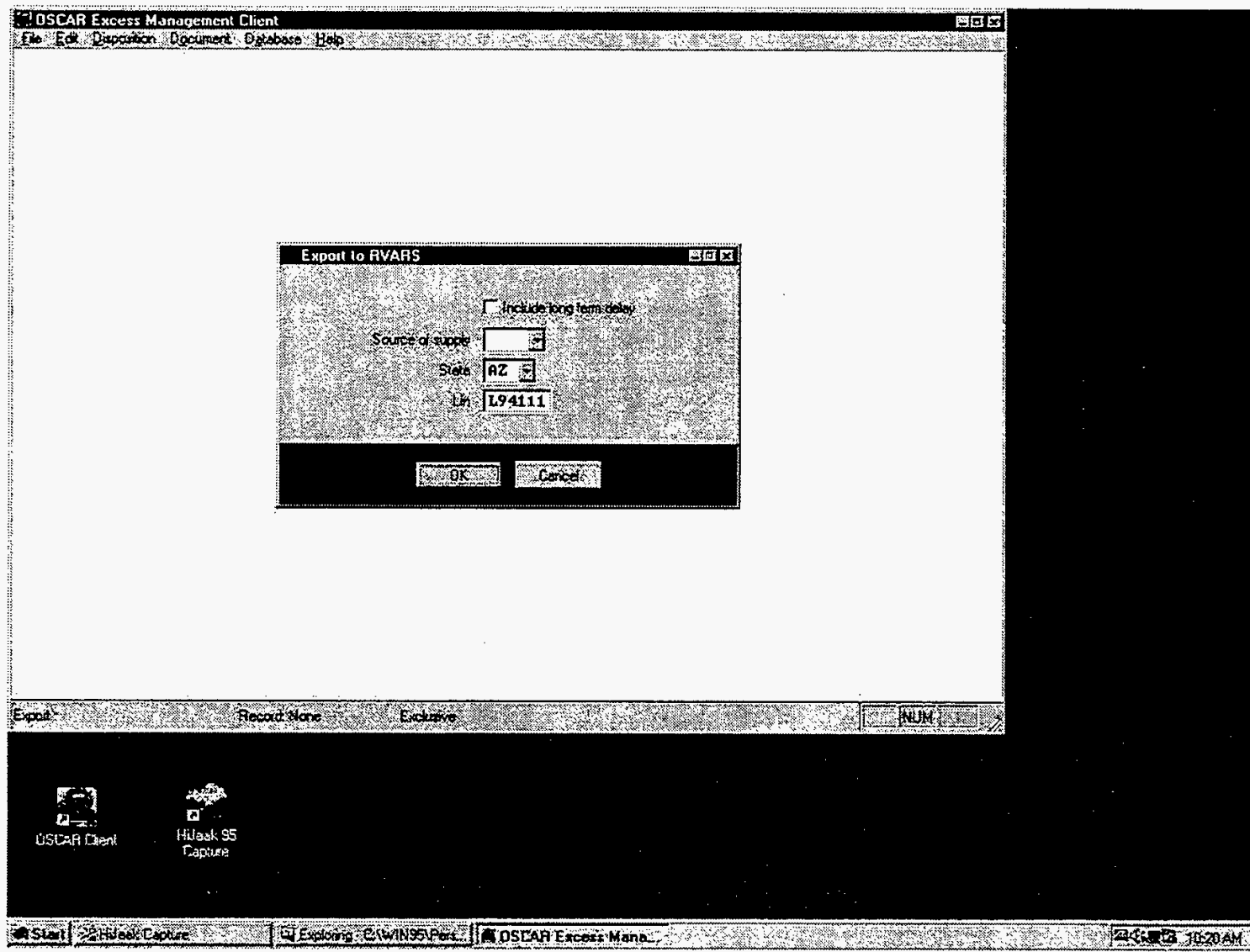

The option shown will retrieve active excess reports for the 'State' selected for that particular ' $L i n$ '.

Remarks: The 'long-term Delay' assets can also be selected by checking the block next to the $<$ Long-term Delay $>$ field.

\section{GO TO NEXT PAGE}

FIGURE 8-10 


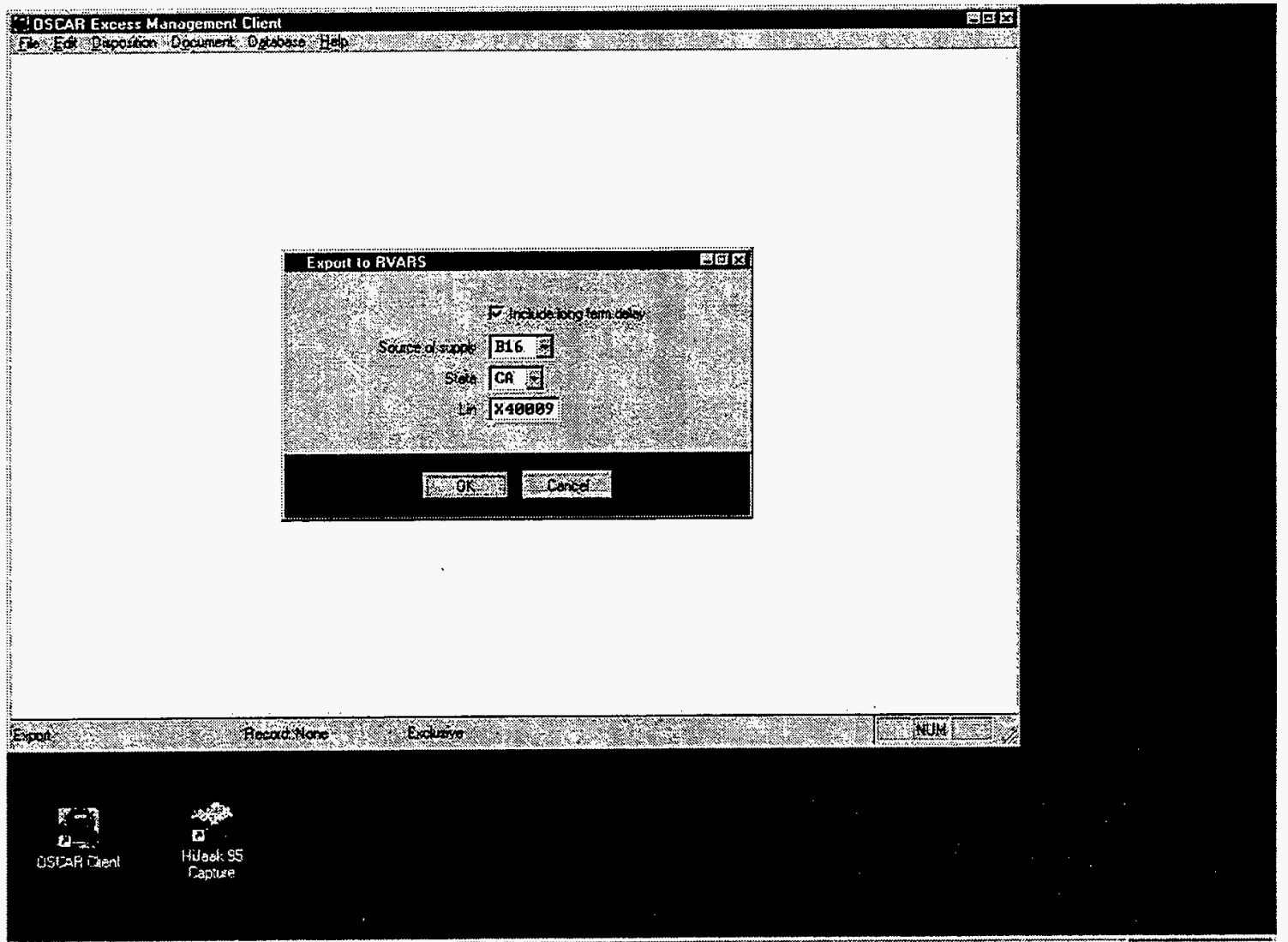

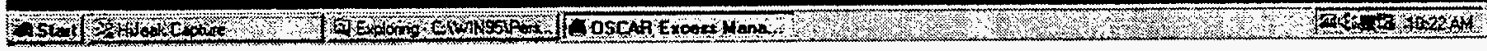

The option shown above will select active/Long-term Delay 'California' excess reports for SOS 'B14' with Lin 'X40009'.

Remarks: Many options are available to the user.

\section{GO TO NEXT PAGE}

FIGURE 8-11 


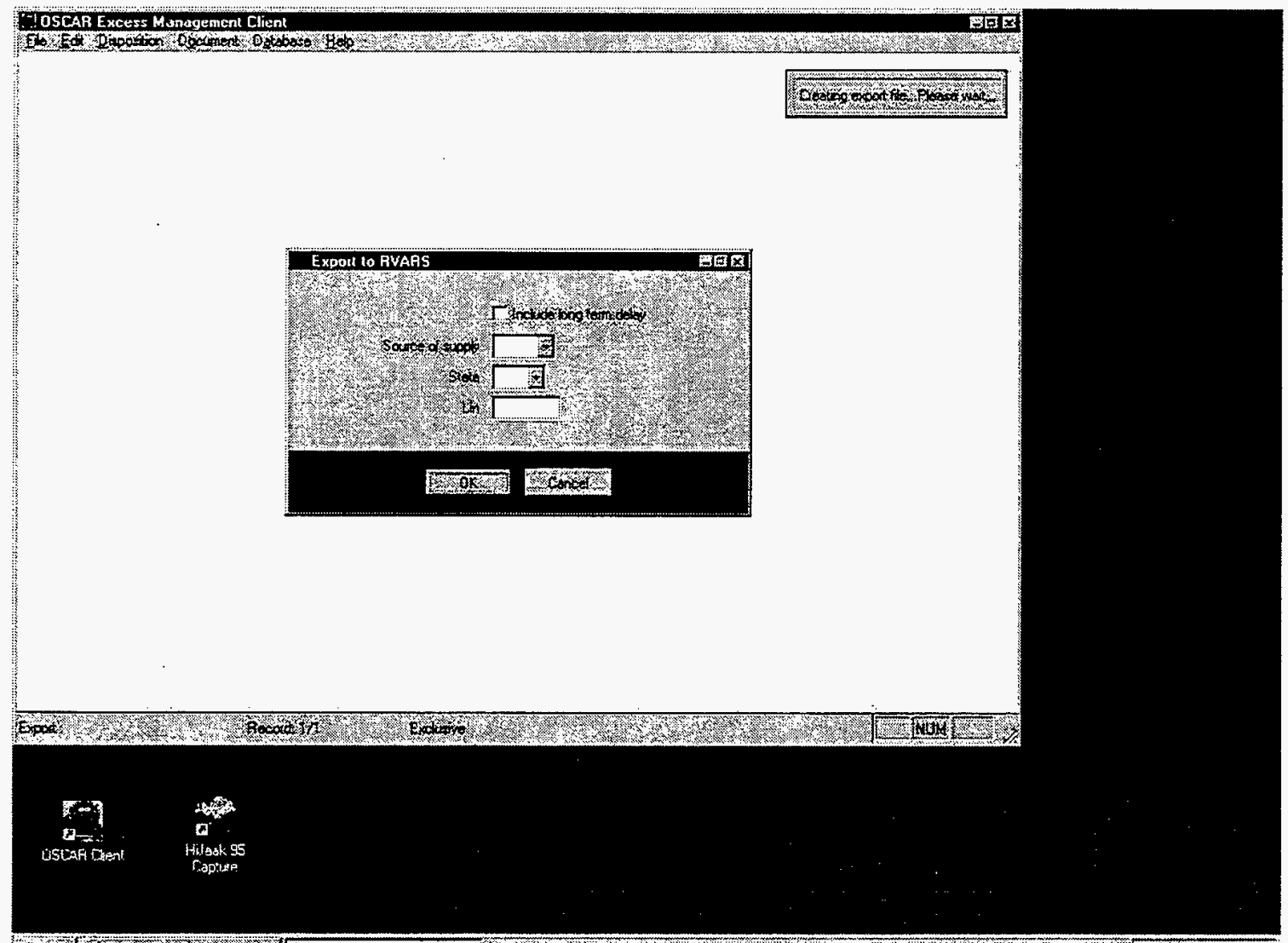

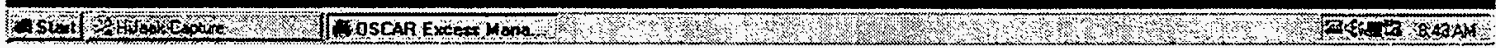

Once the user has made the selection and pressed $<\mathrm{OK}>$ the message in the top right corner will appear until processing is complete.

\section{GO TO NEXT PAGE}

FIGURE 8-12 


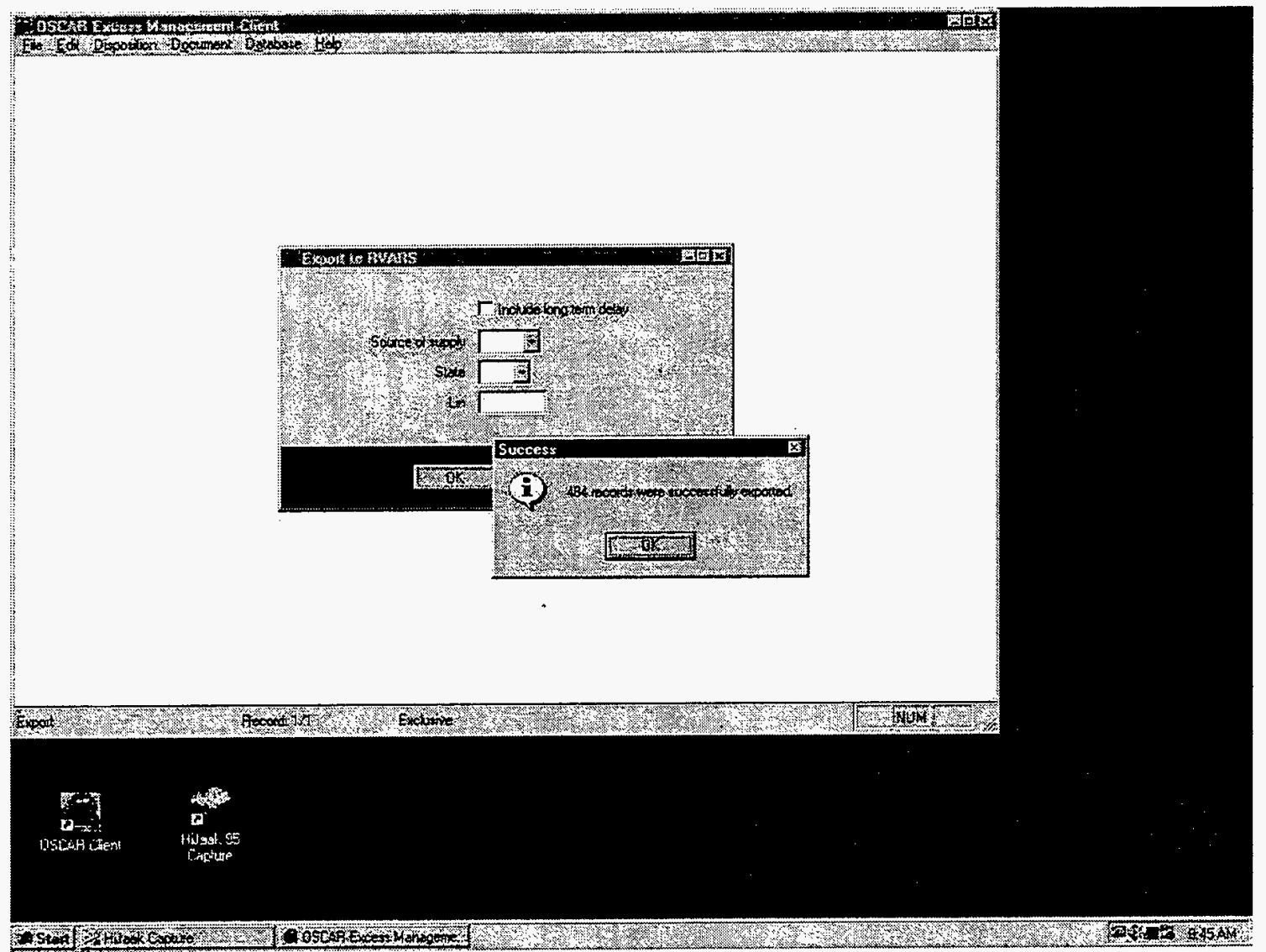

When processing is complete, the message above will appear.

Remarks: When no records have been selected and user feels there should have been records, please contact system administrator for assistance. 


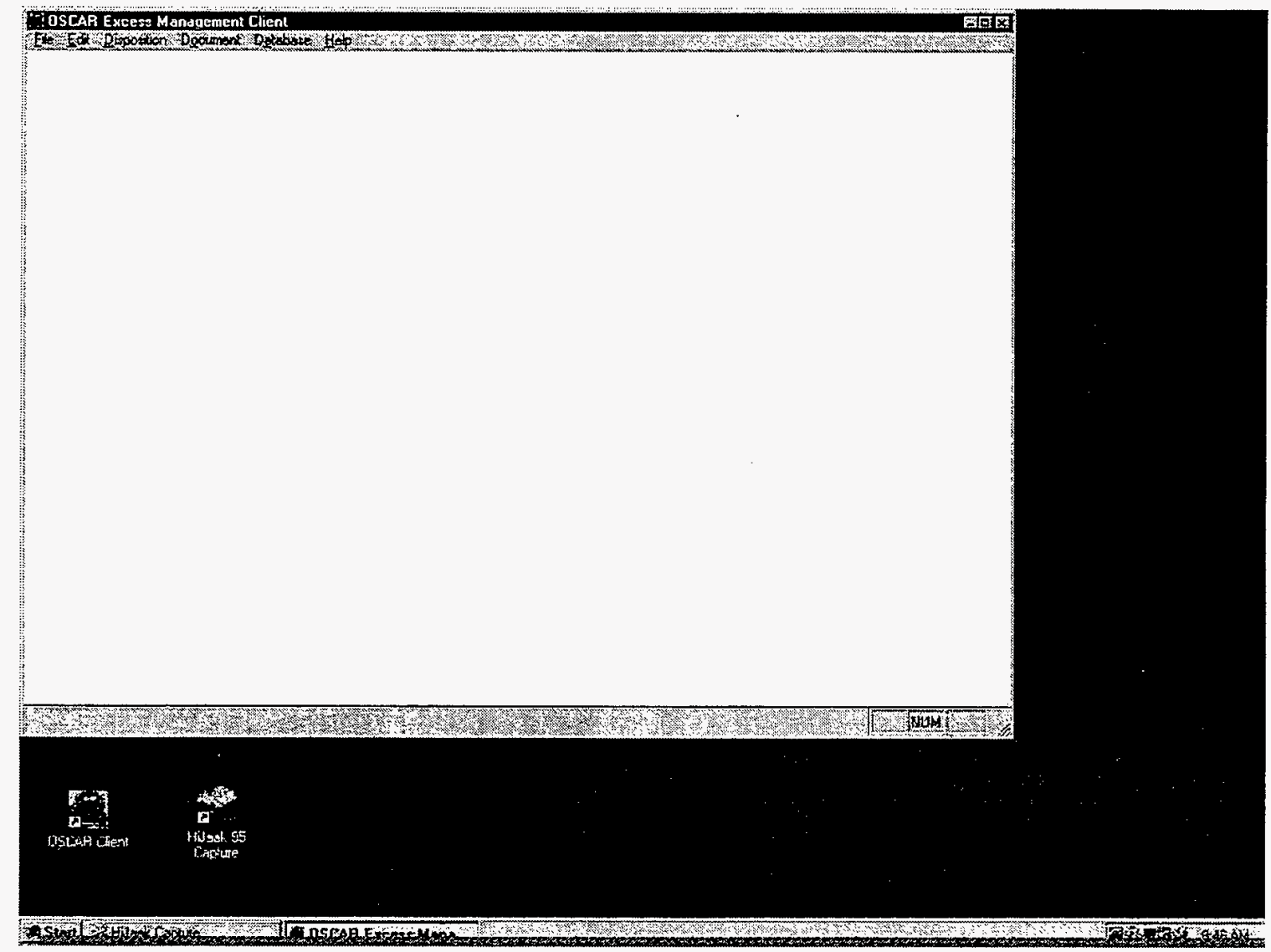

Once excess reports have been retrieved, the manager can now execute RVARS program.

Session is complete.

FIGURE 8-14 
SECTION 9. NGB WEB SITE

9.1 General. This section is designed to give the information on how to enter the NGB Management Programs WEB site.

TO BE DEVELOPED 
THIS PAGE NOT USED

9-2 


\section{SECTION 10. REPORTS}

10.1 General. This section is designed to give the information on standard reports that are available within the NGB Management Programs.

10.2 Standard Reports - The following NGB Excess Management reports will be provided or are available in the system. All reports will be provided in the same general format. (Example of format is Appendix C.)

a. OSCAR Daily Disposition Report - Three (3) reports will be furnished daily or upon request whenever a manager furnishes disposition actions to excess customers.

(Disposition: Keep until all actions are completed.)

(1) OSCAR Daily Disposition Report (Receiving State)

(2) OSCAR Daily Disposition Report (Reporting State)

\section{OSCAR Manager Report (NGB Manager)}

b. Monthly Report - This report is furnished based on the days_report1 parameter to NGB Managers/states/ Territories. The report is a listing of items that have been added, opened, or completed during a thirty-day period. (Disposition: Keep for sixty (60) days from completion of actions)

c. Quarterly/Semi-Annual/Annual Report - This report will be furnished to NGB Managers/States/Territories based on days_report3 parameter or upon request. The report is a listing of all Excess Reports in the NGB Master File (active, inactive, and/or completed). Items will be purged from the NGB Master File when they have been completed for 365 days. (Disposition: Keep for two (2) years.)

d. NGB-HOLD Report - This report will be furnished based on days_report4 parameter or upon request. The listing contains those Excess Reports that have been placed on Long-Term Delay or NGB HOID by the Manager. (Disposition: Keep until new report is received.) 
e. FTI Report - This report will be furnished based on the days report 6 parameter or upon request. This is a listing of assets that are delayed for shipment by shipping state. (Disposition: Keep until next report is received.)

f. FTM Report - This report will be furnished based on the days_report6 parameter or upon request. This is a listing of assets that have been processed for shipment either by the state or by NGB. (Disposition: Keep until next report is received.)

g. D6S Report - This report will be furnished based on the days_report7 parameter or upon request. This is a listing of assets that have been determined to have been received. (Disposition: Keep until next report is received.)

h. Ship To Advice Report - This report will be furnished based on the days report8 parameter or upon request. This is a listing of assets where the receiving activity has been furnished an " $A E^{\prime}$ " transaction, a "BA" or an "AS" Shipment status. Report will be sent to NGB Managers/Shipping and Receiving state. (Disposition: Keep until next report is received.)

i. Send to ICP - This listing includes all assets that NGB managers have forwarded on to the ICP without actions. This report will be printed weekly. (Disposition: Dispose of when no longer required.) 
SECTION 11. INQUIRY PROCESS

11.1 General. This section is designed to furnish information on how to make inquiries within the NGB Management Programs.

TO BE DEVELOPED

$11-1$ 
THIS PAGE NOT USED

$11-2$ 


\section{SECTION 12. STATE/TERRITORY}

12.1 General. This section is designed to give the state Excess Manager directions/information for interfacing with the NGB Management Programs. NGB-ARI-E is the proponent of this chapter.

12.1.1 References. The following references will be used for guidance in reporting excess materiel.

a. Unit Supply Update X-XX, AR 710-2, Inventory Management Supply Policy Below the Wholesale Level.

b. AR 725-50 Requisitioning, Receipt, and Issue System, Chapter 7 Materiel Returns Program (MRP).

c. DA Pamphlet 710-4, Management of Excess and Materiel Returns.

\subsubsection{State/Territory Responsibilities.}

a. States/Territories will identify excess assets within their control and ensure that they are turned in to the SARSS-1 activity within ten (10) calendar days per [paragraph 2-13 6 (2a), AR 710-2]. The following reasons may cause state/territories to generate excess:

(1) Changes in authorization documents. [Table of Organizational Equipment/Modified Table of Organizational Equipment (TOE/MTOE); Table of Distribution and Allowances (TDA); and Common Table of Allowances (CTA)]

(2) Modernization or cross-leveling of newer equipment.

(3) Duplication of Depot/NGB shipments.

(4) Erroneous requisitions. 
(5) Policy and/or procedures not followed.

(6) Inaccurate or timely receipt/issue processing.

b. States/Territories are responsible for conducting in-state searches to fill authorized shortages and making lateral transfers prior to approving and forwarding excess reports to NGB. Appendix $\mathbf{E}$ contains a standard Query Language (SQI) statement which could assist in determining excess requirements. This statement will search for Excess Reports (FTE) in the SARSS-2AC Manager Review File (MRF) and create a formatted file that can then be processed through the Requisition Validation Automated Redistribution System (RVARS) program. RVARS will determine if there are requirements within your state/territory with recommendations. This process will be run prior to forwarding Excess Reports (FTE) to NGB through DAAS.

c. Reports contained in the "ngbam3" directory can be forwarded to NGB through the Defense Automatic Addressing System (DAAS) Content Identifier 'IHAE' as often as required, but must be reported at least weekly.

d. Assets in condition code " $H$ or $P$ " or with a Source of Supply (SOS) equal to "A35, AP5, A1T, S9A, S9T, S9I, S9P, S9Q, S9S, GSA, S9C, S9E and S9G" will not be reported to NGB. Consult AR 725-50, Chapter 7, to determine when or if assets must be reported directly to the National Inventory Control Point (NICP).

e. States/Territories must comply with the NGB manager disposition instructions or request cancellation within the time frame established by shipment priority assigned. 
f. States/Territories must coordinate disposition between activities. Activities should follow, but not be limited to the guidelines below.

(1) Shipping state/territory should contact receiving state to determine if assets are required.

(2) Obtain shipping address information.

(3) Provide equipment and shipment status.

(4) Determine best mode of shipment.

(5) Get Mark for Information.

(6) Receiving state must contact Shipping state when asset is not required and SARSS-1 submit an ACtransaction through DAAS to NGB.

g. Equipment directed to be shipped must meet 10/20 maintenance standards prior to shipment and have required components per AR 750-1.

h. Process Automatic Return Items (ARI) as directed by AR 710-1.

i. Return excess assets to depot or ship to other activities as directed by the National Inventory Control Point (NICP).

j. Transfer assets to the Defense Reutilization and Marketing Office (DRMO) in accordance with DOD 4160.21-M as directed by NGB or NICP. 
k. Ensure that appropriate Technical Inspections (TI) are forwarded to NICP when required (i.e. DA 461-5, DA Form 2404, DD 3590). Excess Report Number must be clearly annotated on TI. TI documentation must arrive at the NICP within five (5) work days of NGB forwarding the FTE.

1. Ensure assets placed on NGB-HOLD are maintained in reported condition.

12.2 System Reports. The following reports will be furnished by NGB. States/Territories are responsible for reviewing reports for accuracy and/or providing corrective actions. Appendix B, pages $B-1$ through $B-4$ is a memorandum on How to read the OSCAR Daily Disposition Reports. Report format can be found in Appendix $C$.

a. OSCAR Daily Disposition Reports - These are reports listing customer excess and dispositions which affect the state/territory. The reports are furnished at the end of each day or when a manager provides disposition to the customer. Example: Appendix C. These reports should be furnished to SARSS-1 for cross reference purpose.

b. Monthly Action Report - This report shows each record in the NGB Master File with status. The excess reports have either been received, are awaiting actions, and/or have been completed within the last thirty (30) days. Excess Reports (FTE) are assigned ACTIVITY-IND which relates to the status of that report.

(1) ACTIVITY-IND " $A$ " indicates that the report has been received, and the NGB manager has not provided any disposition to this point. 
(2) ACTIVITY-IND " $C$ " indicates that the excess report is considered to be complete in the master file. These records will be moved to an archive file after three hundred sixty-five (365) days have elapsed.

(3) ACTIVITY-IND "D" indicates that the excess asset has been placed on long-term hold or NGB-HOLD. Disposition has been delayed until a future date.

(4) ACTIVITY-IND "I" indicates that the NGB Manager has provided disposition instructions and state/territory actions are pending.

(5) ACTIVITY-IND "P" indicates the excess report has been passed on to the Inventory Control Point (ICP). NGB considers their actions are completed. ICP will furnish disposition instructions. When required, the state is responsible for forwarding TI/Check list to the ICP within five (5) work days.

c. Quarterly/Semi-Annual/Yearly Report - This report lists all records in the NGB Master File with status.

d. NGB-HOID Report - Lists all Excess Reports in the NGB Master File that have been placed on NGB-HOLD (furnished monthly). 
e. Ship To Advice Report - Iists all AE/AS advice that has been provided to customer indicating NGB has directed assets to your activity. Also contains the Customer Response (FTR) of the shipper for cross-reference purposes. This report will be provided to the Shipping and Receiving State/Territory. This report should be passed to SARSS-1 (furnished weekly).

f. State Delayed Shipment Report - This listing is produced based on an FTL Supply. Status transaction provided by the shipping state which indicates a delay in an NGBdirected shipment. An FTL_FLAG equal to ' $S$ ' indicates that the transaction was created by the system and not by a response from a customer (furnished monthly).

g. Shipment Report - This is a listing of all records that are still active in the NGB Master File where the State/Territory has forwarded an FTM Shipment status, but the asset has not been received. An FTM_FIAG equal to ' $S$ ' indicates that the transaction was created by the system and not by a customer's response (furnished monthly).

h. Shipment Receipt Report - This report lists all assets in the NGB Master File which have been received. Actions on these Excess Reports are considered complete. D6S_FLAG equal to ' $S$ ' indicates that the transaction was A created by the system and not by a customer's response (furnished monthly).

i. Master File Archive Report - This is a listing of records that have been archived to another media for storage. Criteria for archiving records is based on the days_archive perimeter, which is defaulted at three-hundred sixty-five (365) days. Records that meet the criteria are moved to an archive hold area to be written to a backup tape as determined by the NGB Systems Administrator.

j. Pass to ICP Report - This report is a listing of all assets that have been passed to the Inventory Control Point (ICP) (furnished weekly). 
12.2.1 NGB-ARL-E Semi-Annual Excess Identification Reports - These reports will be executed in the standard Property Book System Redesign (SPBS-R) and the standard Army Retail Supply System Objective (SARSS-O) for the purpose of allowing the NGB Managers to identify excess assets within states/territories. Report SQI, and descriptions are still to be determined.

\section{a. Standard Property Book System Redesign (SPBS-R) \\ b. Standard Army Retail Supply System Objective (SARSS-O)}

12.3 Cancellation - There are two (2) ways a cancellation can be made: One is by the Reporting state; the other, by the SHIP-TO state. The request for cancellations will be processed as follows:

a. Reporting state will notify the SHIP-TO state asset is not available and submits an FTC Excess Report Cancellation.

(1) NGB will automatically consider asset not available for shipment.

(2) When disposition has been directed to another state, NGB will produce an AE- with a "CB" status to SHIP-TO state.

(3) State requesting cancellation is responsible for coordinating with the sHIP-To state. Message can be by telephone, written, faxed, and/or by E-mail. 
b. SHIP-TO state coordinates cancellation with Shipping state to ensure asset is not shipped then SARSS-1 submits AC/AK Requests for Cancellation.

(1) NGB will respond with an $A E-$ Status "BQ".

(2) Reporting states FTE will be processed as follows.

(a) If AC/AK Cancellation is for FTE Excess Report total quantity, NGB will change the Activity-Indicator to an "A" and return the report to the NGB Manager for disposition action.

(b) When $\mathrm{AC} / \mathrm{AK}$ is for partial or against a partial quantity of the FTE, NGB will furnish the Reporting state an FTR with "SA" status. Excess assets will have to be re-reported.

\section{4 Master File Description - The NGB OSCAR Excess} Management program database will receive and edit Customer Excess Reports (FTE). The FTE is used as the master record in the NGB Master File. All corresponding transactions will be posted to file. Master File record description is found in Appendix B. The following is a description of records utilized within the NGB Excess Management Program:

\section{a. AC/AK-Customer Cancellation. If NGB receives an} $\mathrm{AC} / \mathrm{AK}$ from a customer, the system will cancel the due-in and re-establish the FTE quantity when the FTE quantity is not a partial quantity. If the cancelled quantity is for a partial quantity, the FTE will be cancelled also. 
b. AE-Customer status. NGB will furnish receiving state an AE2 status with an NGB Document Number and the SARSS-1 DODAAC in the SUP-ADDR with "BB" advice and a Project Code equal to shipping states RIC.

c. As-Shipment status. NGB will furnish receiving state/territory an AS2 transaction upon receipt of an FTM Shipment status from shipping/reporting state/territory.

d. D6-Materiel Receipt Acknowledgement. NGB will send an FTZ advice "TQ" and unit price field zero filled to close states excess report.

e. FTC-Cancellation of Customer Excess Report. If NGB has directed shipment of the excess asset, an AE2 with "CB" status will be furnished the SHIP-TO state.

f. FTD-Disposition Instruction Delay Status. NGB will respond immediately upon receipt of an FTE Customer Excess Report with status "TR" and a short-term delay date in $x p$ 70-73. NGB can also respond to Customer Excess Report with a long-term delay status "TR". These assets will be on NGB-HOLD.

g. FTE-Customer Excess Report. This is the Master Record in the NGB Excess Management File (EMF).

h. FTF-Customer Excess Report follow-up. Program will respond to follow-up with latest status or a FTD status "TR" and short-term delay date in Ip 70-73. A report listing all follow-ups will be furnished NGB Managers.

i. FTL-Supply Status. Upon receipt of an FTL from state, NGB will furnish the SHIP-TO state an AE2 with "BD" status. The NGB Excess Management Program will automatically create an FTL transaction when an FTM has not been received within a reasonable time frame. 
j. FTM-Shipment Status. NGB will furnish the SHIP-TO state an AS2 with the mode of shipment and/or TCN/GBI from the FTM. When an FTI is on the NGB Master File and the ESD has been exceeded, the system will create an ETM/AS2 transaction.

k. FTQ-Customer Excess Report Information Status. When NGB forwards the Customer Excess Report to NICP, DAAS will furnish an FTQ. When required states are responsibleable for furnishing any related $T / I$ or component listing to NICP.

1. FTR-Reply to Customer Excess Report. NGB will also furnish the SHIP-TO state an AE2 with an NGB Document Number and "BB" status.

m. FTZ-Materiel Receipt Status Advice "TQ". Upon receipt of D6- Receipt transaction from the SHIP-TO state, NGB will furnish the FTZ to close out the reported excess.

12.5 Exceptions for Reportable Item. These are items that cannot be reported through the automated system. Reporting criteria can be found in Appendix D.

12.6 Department of the Army Activity Address File (DODAAF). The NGB Management Program utilizes the RVARS/REQVAI data base unique DODAAF. 
12.7 Defense Automated Addressing System (DAAS) Interface. Records received from DAAS will be edited by the NGB Management Program. Only those with DODAACs that do not match the NGB DODAAF Table will be rejected. All other transactions not required by NGB will be returned to DAAS for routing.

12.8 Shipping Discrepancy - Upon receipt of redistributed assets an inspection should be conducted to determine condition and/or shortages.

a. Shortages in Shipment - Shipping states are responsible for including all components with shipment or providing funds to the receiving state to cover shortages. When states receive assets that are short components, the receiving state is responsible for identifying shortages. Once shortages have been identified, the shipping state should be contacted to determine if the items can be provided or funds transferred to complete the shipment.

b. Receipt of assets not within $10 / 20$ standards. Receiving state is responsible for identifying the cost to repair and for contacting the shipping state for transferal of funds to complete the shipment.

c. Problems that cannot be rectified between states should be elevated to NGB-ARI-E or NGB-AVN-I in writing. 


\subsection{Items Passed to Inventory Control Point (ICP)}

a. A report of excess reports that have been forwarded to ICP will be furnished weekly.

b. When it is determined that you have a requirement for an asset that has been passed to ICP, contact the reporting state to determine if asset is still available.

(1) When item is available, coordinate for shipment of the asset. Reporting state must cancel Excess Report.

(2) When requirements still exist for the asset notify NGB-IIE-IM item manger.

12.10 Aviation Assets. Customer Excess reports for aviation assets will be forwarded to NGB-AVN-AS for。 disposition. Disposition will be provided in the same manner as for NGB-ARI-E. When the AVN Code on the OSCAR daily Report is 'Yes'. State managers should contact NGBAVN-AS with any question concerning the excess report. DSN: 327-7755.

12.10.1 Excess Aviation assets are forwarded in the same manner as other Major End Items through DAAS to NGB. 


\subsection{SARSS-1 Responsibilities.}

(a) Ensure that assets are in 10/20 maintenance standards (AR750-1) before shipment.

(b) When Materiel Release Order (MRO) has a Project Code of 'NGB' ensure that the manager has contacted the receiving state to verify shipment requirement.

(c) Ensure that MRO(s) released and later cancelled are return to stock at SARSS-1 for accountability.

(d) Ensure the NGB (W81RUP) Receiving state document number is crossed referenced on the shipping document.

(e) storage and care of property. Assuring property is maintained in the same condition reported.

\subsection{SARSS-2AC Responsibilities.}

(a) Administer State/Territory Major End Item Excess Management Program.

(b) Ensure SARSS-1 receives copies of the OSCAR Daily Reports. (Receiving/Reporting state).

(c) Ensure excess assets are not required within state/territory prior to reporting to NGB. NGB.

(d) Approve Excess reports to be released to DAAS for

(e) Ensure approved excess reports are released to NGB per para $12.1 .2 \mathrm{c}$ above.

(f) Coordinate shipment and receipt of assets between states/territories. 
THIS PAGE NOT USED

$12-14$ 
APPENDIX A

REFERENCES

A. 1 General. This appendix contains references used in development of the NGB Excess Management Program.

A.1.1 Army Regulation (AR):

a. AR 40-61 Medical Logistics Policies and Procedures.

b. AR 310-34 Equipment Authorization and Utilization Policies and Criteria and Common Tables of Allowances.

c. AR 380-40 Policy for Safeguard and Controlling CoMSEC Information.

d. AR 385-11 Ionizing Radiation Protection (Licensing, Control, Transportation, Disposal and Radiation Safety).

e. AR 710-1 Centralized Inventory Management of the Army Supply System.

f. AR 710-2 Supply Policy Below the Wholesale Level.

g. AR 710-3 Asset and Transaction Reporting System.

h. AR 725-50 Requisitioning, Receipt and Issue System.

i. AR 735-5 Basic Policies and Procedures for Property Accounting.

A.1.2 Department of the Army Pamphlet (DA PAM).

a. DA PAM 710-1 Aviation Intensive Management Item Program.

b. DA PAM 710-2-1 Using Unit Supply System.

c. DA PAM 710-2-2 Supply Support Activity Supply system.

d. DA PAM 710-4 Management of Excess Materiel and Materiel Returns.

e. DA PAM 738-750 The Army Maintenance Management System (TAMS).
A.1.3 Department of Defense - DOD 4160.21-M Defense Utilization and Disposal Manual.
A.1.4 Supply Bulletin (SB) SB-700-20 Army Adopted/Other Items Selected for Authorization/Iist of Reportable Items. 
APPENDIX A

REFERENCES (continued)

A.1.5 Technical Manuals (TM)

a. TB 380-40-22 Security Standards for Controlled Cryptographic Items.

b. TB 380-41 Procedures for Safeguarding, Accounting and Supply Control of COMSEC Material.

c. TB 750-8-1 Maintenance Expenditure Limits for Medical Material.

A.1.6 National Guard Bureau (NGB) Directives/Letters/Memorandums

A.1.7 Army National Guard, Excess Management, End User Manual 
APPENDIX A

ABBREVIATIONS AND TERMS

A.2 General. This appendix contains terms and abbreviations that are unique to the NGB Excess Management Program development. Additional abbreviations and terms can be found in AR 725-50, Glossary, Sect. 1 Abbreviations and Sect. 2 - Terms.

A.2.1 Section 1 - Abbreviations

AM3 - National Guard Bureau (NGB) Routing Identifier Code (RIC)

OSCAR - Objective Supply Capability Adaptive Redesign 
APPENDIX A

ABBREVIATIONS AND TERMS (continued)

\section{A.2.2 Section 2 - Terms}

ACIIVITY-IND - a one (1) position code added to the FTE record to indicate the status of the report in the NGB Master File. ' $A$ ' - Indicates the excess report has been received by NGB and is active, but requires NGB Manager response. ' $C$ ' - Indicates the record is considered complete in the NGB Master File. ' $D$ ' - Indicates that the State/Territory has received a Long-Term Delay status or has been placed on NGB Hold. ' $I$ ' - Indicates that NGB manager has provided a response to customer, but there are still actions pending. ' $P$ ' indicates the excess report has been passed to the Inventory Control Point (ICP) for actions, and ' $z$ ' indicates that the excess report has been passed to the NGB Aviation Directorate for actions.

DISPOSITION CODE - A code that identifies an action take by the NGB manager. Disposition "1" Forward to ICP. Disposition "2" Transfer to DRMO.

Disposition "3" Place on NGB Hold. Disposition code "4" Direct assets to a known Source of Supply (SOS).

DISPOSITION TABLE - A table designed to provide the NGB Manager with means to automate disposition that is constant. NGB manager can forward customer Excess Reports to Inventory Control Point (ICP), Transfer assets to DRMO, provide customer response to a Source of Supply (SOS) and/or place assets on NGB hold.

Export - To retrieve data from the Master File on the Master Server to the Personal Computer (PC).

Import - To bring data into the automated system from an external source, such as DODAAC or Catalog. 


\section{APRENDIX A}

\section{ABBREVIATIONS AND TERMS (continued)}

NGB-HOID - When the NGB Manager for some reason cannot provide a response, assets are place on NGB-HOID and a Disposition Instruction Delay Status (FTD) will be furnished to customer with a one-hundred and twenty (120) expected reply date.

NGB-Master File - a file created within OSCAR to receive, post, and maintain a history of reported excess. All transactions related to excess reports are posted and maintained in this file for three-hundred and sixty five (365) after competition. Records are considered complete when the report has been forwarded to the Inventory Control Point (ICP), Cancelled, Directed to DRMO, or Directed to another and the state has issued a receipt for the asset.

OSCAR - An NGB Project, in conjunction with the Oak Ridge National Laboratory (ORNL) for development of programs which are unique to the ARNG, but are required to interface with standard Army Systems. The ARNG Excess Management module is an example of a program developed under this project.

OSCAR Daily Report - This report is produced daily to provide the State/Territory manager information on Excess Reports (ETE) s received, passed to the Inventory Control Point (ICP) and/or NGB Manager has provided disposition Instructions. This report should be kept until all actions are completed.

RVARS - Requisition Validation Automated Redistribution System - a program developed by AMCLOGSA to assist the manager in determining asset requirements and recommending redistribution actions. 
PAGE NOT USED

A- 6 
APPENDIX B

NGB-ARL-S (700)

Memorandum for Information

SUBJECT: How to read the OSCAR Daily Disposition Reports

1. The purpose of this memorandum is to provide information on the NGB-ARL-E OSCAR Daily Disposition Reports which provide information on instructions given to states/territories.

2. The OSCAR Daily Disposition Reports are produced at the end of each day and contain information on all actions taken within that time frame. The ARNG Excess Management Program assigns an Act-Ind with messages that indicate the status of Reported Excess. The Act-Ind codes are as follows:

a. Act-Ind ' $A$ ' indicates that NGB has received the customer excess report and is in the process of determining disposition. (Message: 'NGB DELAY STATUS')

b. Act-Ind ' $C$ ' indicates that all actions have been completed for this excess report and NGB considers this report completed. (Message: 'EXCESS REPORT (COMPLETE)')

c. Act-Ind ' $D$ ' indicates that the NGB Manager has placed the excess report on Long-Term Hold or NGB-HOLD. Disposition will be furnished in the next one-hundred and twenty (120) days. (Message: 'NGB LONG-TERM HOLD (NGBHOLD)') 
APPENDIX B

SUBJECT: How to read the OSCAR Daily Disposition Reports (continued)

d. Act-Ind ' $I$ ' indicates that the NGB Manager has furnished disposition to ship the reported asset to another state and there are state actions pending. (Message: 'DISP-SHIP TO RIC IN POS 54-56')

e. Act-Ind ' $P$ ' indicates that NGB has forwarded the excess report on to the Inventory Control Point (ICP) for actions. NGB considers its actions are complete.

(Message: 'NGB HAS FORWARDED TO ICP')

Remarks: When Activity-Indicator is ' $P$ ', states should forwarded any Technical Inspections or Check List required to ICP.

3. The OSCAR Daily Disposition Report has been devided into two (2) separate reports.

a. OSCAR Daily Disposition Report (Reporting state) which gives information on the actions taken on your states/territory excess reports.

b. OSCAR Daily Disposition Report. (Receiving State), which provides information on assets that are to be shipped to your state/territory.

Note: The only difference in the two (2) reports is that the Reporting state will have a Receiving Ric/state field and the Receiving state Report will have a Reporting Ric/state field. 
APPENDIX B

SUBJECT: HOw to read the OSCAR Daily Disposition Reports (continued)

4. Report description follows:

a. Header Record indicates the state that has reported the excess asset or is to receive assets.

(Example: AL A13 W31LPY MONTGOMERY AL 36109-4801 is for Alabama.)

b. 'Record Description' is the accrual transaction received or created by NGB Program. When FTR disposition to another state has been provided, position 54-56 will contain the RIC of the state/territory to which the asset is to be shipped.

c. 'Act-Ind' is the Activity Indicator that describes actions taken or pending, as per para 2 above (a thru e).

d. 'Receiving RIC/State' is the state to which NGB has directed the reported asset. Reporting RIC/state is the RIC of the state reporting.

e. 'IIN' is the Line Item Number of the asset reported. 


\begin{abstract}
APPENDIX B
SUBJECT: How to read the OSCAR Daily Disposition Reports (continued)
\end{abstract}

f. Avi Item indicates when the report is an aviation item or not. When Avi Item field is equal to ' $Y$ ', contact NGB-AVAS at (703) 607-7755 or DSN: 327-7755 with any inquiries you might have. When the field is ' $N$ ', contact NGB-ARL-E Item manager with inquiries.

g. 'Message' indicates actions taken (Messages are per Appendix B, page B-9) .

4. The OSCAR Daily Report will list all transactions received or created within the time frame. Reports will be Mailed/FAX/EMAILED to all states listed in report. First Record list at top of page is the state Header Record for the reports.

5. The OSCAR Daily Disposition Reports are for information purposes and can be destroyed when coordinations and actions are completed. The Customer Response (FTR) is the actual authority for shipment.

6. Point of Contact (POC) for additional information is NGB-ARL-E, Mr. Harry Johnson at CML: (703) 607-7478, DSN: 327-7478 or NGB-ARL-S, CW3 Robert Pelath at CML: (703) 6077458, DSN: 327-7458, DSNFAX: 327-8529 or EMAIL pelathr@ARNGRC-EMH2.army.mil. 


\begin{tabular}{|c|c|c|c|c|c|c|c|c|c|}
\hline & 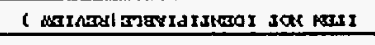 & 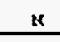 & & & ב & 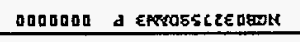 & 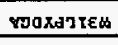 & 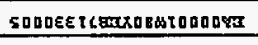 & 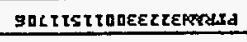 \\
\hline $\begin{array}{ll}8 x y \\
8 \pi x y \\
\end{array}$ & 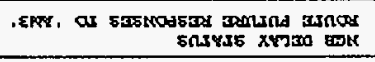 & M & 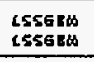 & & a & 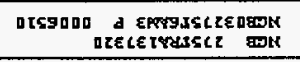 & 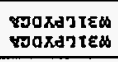 & 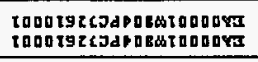 & 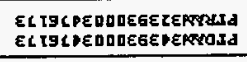 \\
\hline $\begin{array}{l}\text { pig } \\
\text { pitg } \\
\end{array}$ & 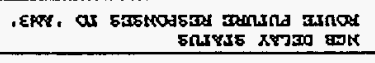 & $\begin{array}{l}M \\
*\end{array}$ & $\begin{array}{l}\operatorname{rsingd} \\
\text { Zstrgd } \\
\end{array}$ & & 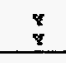 & 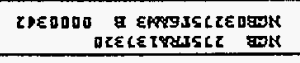 & $\begin{array}{l}800 \\
800 \\
\end{array}$ & 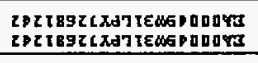 & 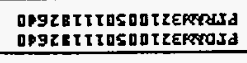 \\
\hline 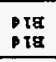 & 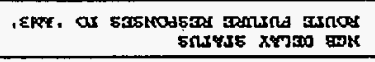 & $\begin{array}{l}x \\
x \\
\end{array}$ & $\begin{array}{l}\text { ggbeno } \\
\text { gabe } 00\end{array}$ & & $\stackrel{q}{q}$ & 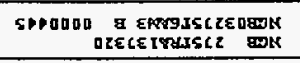 & $\begin{array}{l}2 c 8 \\
z<8 \\
\end{array}$ & 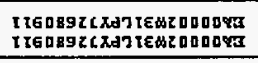 & 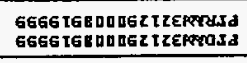 \\
\hline $\begin{array}{l}958 \\
\text { 9sa }\end{array}$ & 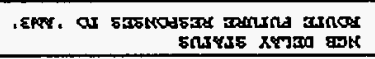 & $\begin{array}{ll}x \\
\text { x }\end{array}$ & $\begin{array}{l}\text { g9cspa } \\
\text { ggLspa }\end{array}$ & & $q$ & 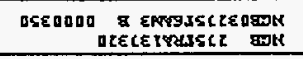 & $\begin{array}{c}850 \\
\text { צpo } \\
\end{array}$ & 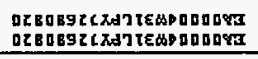 & 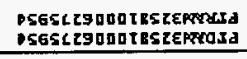 \\
\hline $\begin{array}{ll}859 \\
859 \\
\end{array}$ & 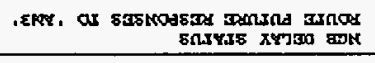 & א & $\begin{array}{l}\text { GSCBPA } \\
\text { GSLBPM } \\
\end{array}$ & & $\mathbf{Y}$ & 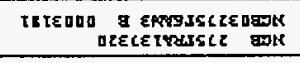 & $\begin{array}{ll}2<Y \\
2<Y\end{array}$ & 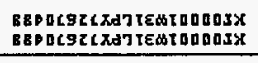 & 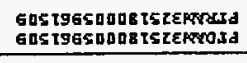 \\
\hline $\begin{array}{l}850 \\
859 \\
850\end{array}$ & 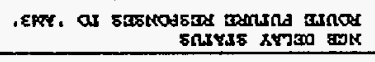 & $\underset{N}{\mathbb{x}}$ & $\begin{array}{l}\text { DLGePM } \\
\text { PLGEPA } \\
\end{array}$ & & 8 & 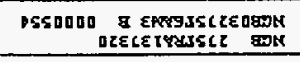 & $\begin{array}{ll}z<8 \\
z<Y\end{array}$ & 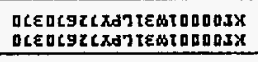 & 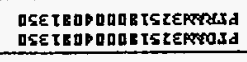 \\
\hline $\begin{array}{ll}889 \\
885 \\
885\end{array}$ & 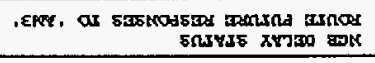 & $\begin{array}{c}x \\
x \\
\end{array}$ & $\begin{array}{c}\text { TPTCPS } \\
\text { IPTCPS } \\
\end{array}$ & & $\dot{z}$ & 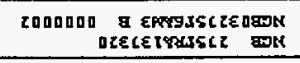 & $\begin{array}{l}208 \\
z<8 \\
\end{array}$ & 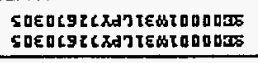 & 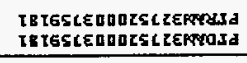 \\
\hline $\begin{array}{l}850 \\
950 \\
\end{array}$ & 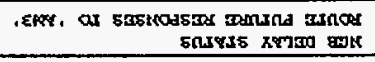 & K & $\begin{array}{l}\text { gegpeA } \\
\text { RPgBEA }\end{array}$ & & $\begin{array}{l}4 \\
8 \\
\end{array}$ & 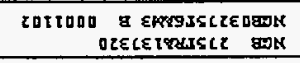 & $\begin{array}{l}214 \\
218 \\
\end{array}$ & 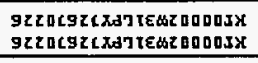 & 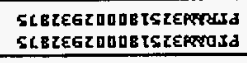 \\
\hline $\begin{array}{l}2 \pi 8 \\
214\end{array}$ & 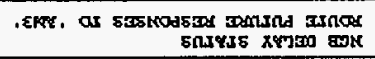 & $\begin{array}{ll}N \\
k \\
K\end{array}$ & 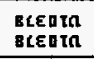 & & 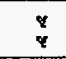 & 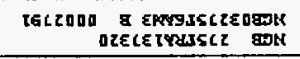 & צต0 & 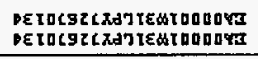 & 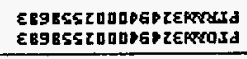 \\
\hline $\begin{array}{l}8 \times 4 \\
8 \times y \\
8 \times 4\end{array}$ & 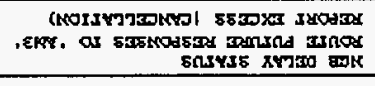 & $\begin{array}{l}K \\
\kappa \\
k \\
\end{array}$ & $\begin{array}{l}\text { LTDEgD } \\
\text { LTPEgJ } \\
\text { LTDEgS } \\
\end{array}$ & & $\begin{array}{l}\mathbf{3} \\
\mathbf{3} \\
\mathbf{3}\end{array}$ & 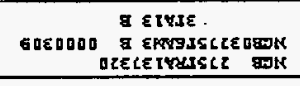 & $\begin{array}{l}\tau c Y \\
i c Y \\
z<Y\end{array}$ & 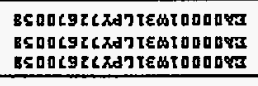 & 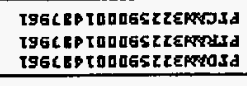 \\
\hline $\begin{array}{l}\text { Big } \\
\text { Btg } \\
\end{array}$ & 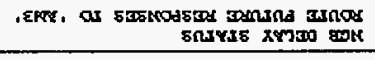 & $\begin{array}{l}x \\
x \\
\end{array}$ & $\begin{array}{l}\operatorname{caCBC5} \\
\operatorname{caCBCS} \\
\end{array}$ & & $\dot{q}$ & 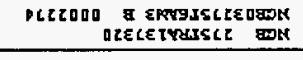 & 800 & 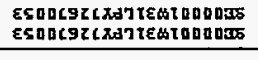 & 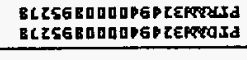 \\
\hline P IT & 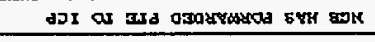 & 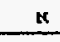 & ELZ6P马 & & 4 & 8 EIYse & 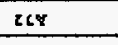 & 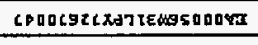 & 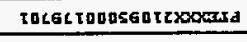 \\
\hline $\begin{array}{ll}\operatorname{siY} \\
\operatorname{LTY} \\
\end{array}$ & 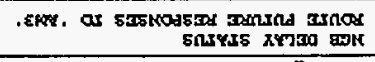 & $\begin{array}{l}x \\
*\end{array}$ & $\begin{array}{l}\text { Tpizia } \\
\text { IDtzia }\end{array}$ & & כa & 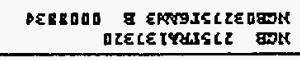 & พvo & 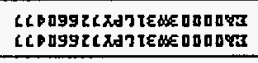 & 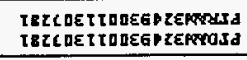 \\
\hline गय & diess Jom & $\begin{array}{l}\text { nI } \\
\text { usy }\end{array}$ & นั7 & 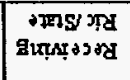 & $\begin{array}{l}\mathrm{PuI} \\
\mathrm{PV}\end{array}$ & & & & 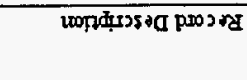 \\
\hline & & & & & & $287 \cdot 6059 \varepsilon$ & & XYAMUAYXOY & AdTEM \\
\hline
\end{tabular}

TNT-

อ7e7S sulquodey 


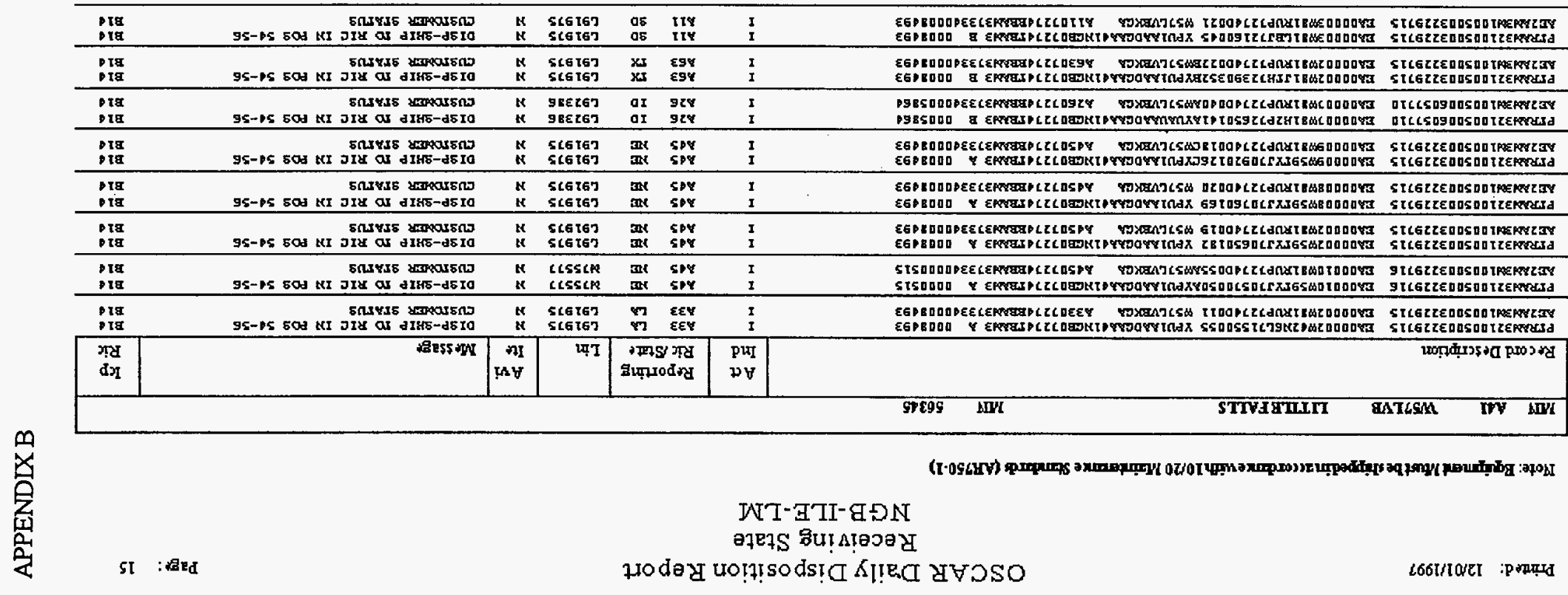




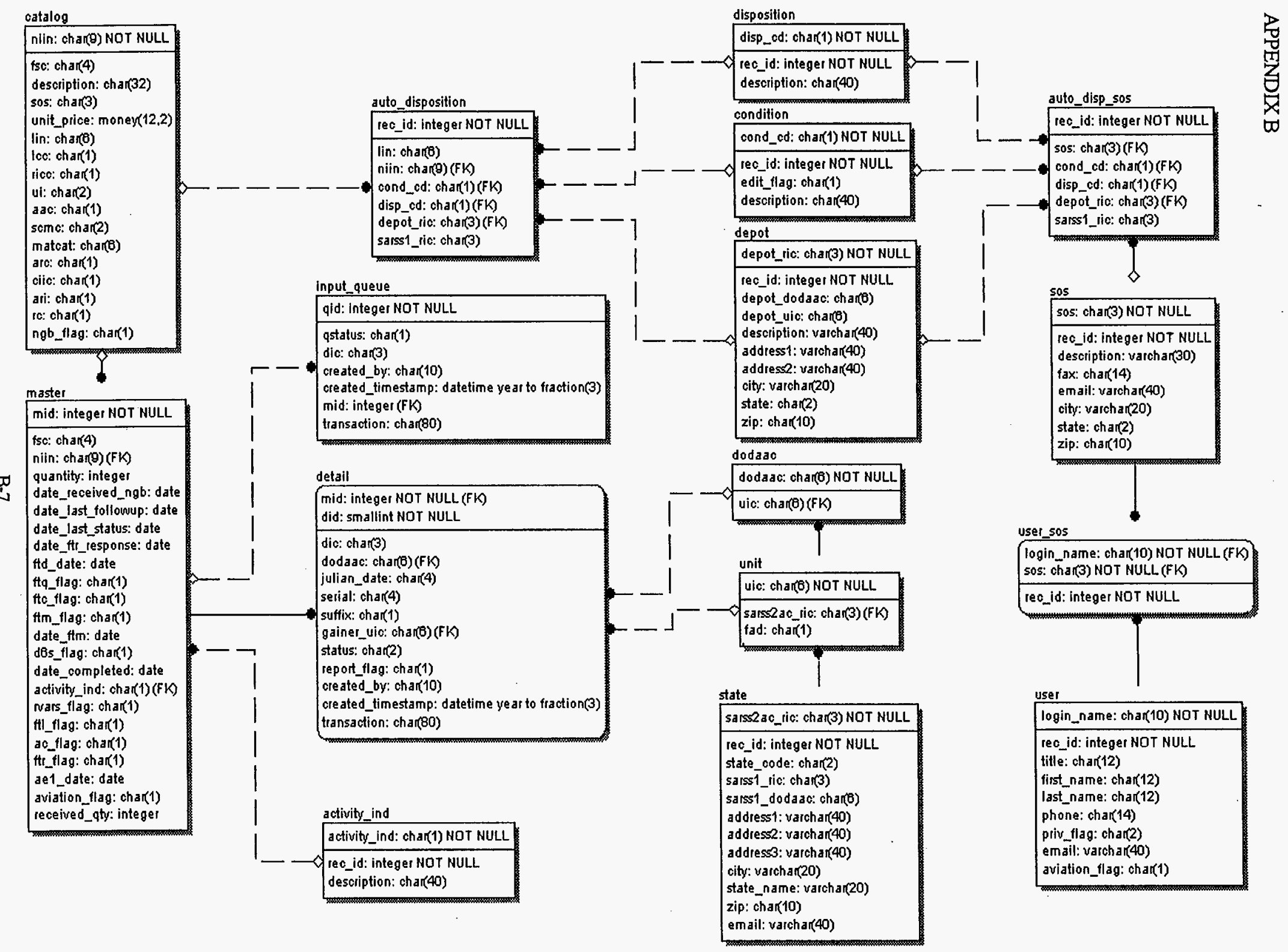




message
\begin{tabular}{|l|}
\hline reo_id: inte ger NOT NULLC \\
\hline dic: char(3) \\
d8s_flag: char(1) \\
ft__flag: char(1) \\
ftm_flag: char(1) \\
activity_ind: char(1) \\
status: chạn(2) \\
message: varchar(40) \\
\hline
\end{tabular}

aviation

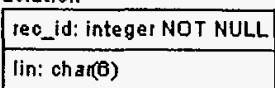

dass_out

rec_id: integer NOT NULL

transaction: chango)

\begin{tabular}{l} 
rice \\
\begin{tabular}{|l|}
\hline ricc: cha(1) NOT NULL \\
\hline reo_id: integer NOT NULL \\
edit_flag: char(1) \\
description: char(40)
\end{tabular} \\
\hline
\end{tabular}

status

rec_id: integer NOT NULL

dic: $\operatorname{chan(3)}$

$\infty$
$\infty$
$\infty$

status: char(2)
description: varch ar(150)

ppt_detall.

ainet_state: char(11) from_nars

\section{reo_id: integer NOT NULL}

sos: char(3)

danor_uic: chang)

lin: chan(B)

nsn: char (13)

gainet_vic: ohan(3)

erc: char(1)

donor_qty: integet

authorized_qty: intege

onhand_qty: integer
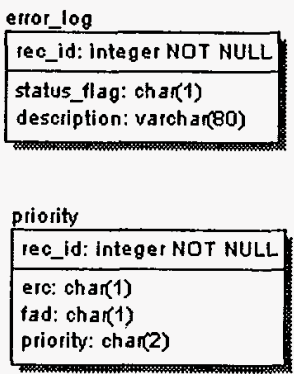

setup

re_id: integer NOT NULL

days_sterm_delay: integer

days_lterm_delay: integer

days_archive: integer

days_mgt_notity: integer

days_ae 1: intege

days_tt__tatus: integer

days_ttm_create: integer

ngb tic: chan(3)

ggbice: char (3)

ngb doda ac:

ngb addracsi: varcharea)

ngto address?: varch ar(40)

ngb city: varcha(20)

ngb_state: chan(2)

ngb_zip: char 10)

ngb_fax: char(14)

start_serial_num: integer

days_fd: intege r

days_ttd: integer

days_as: integer

days_report1: integer

days_report: integer

days report 4 integer

days_lepont4: integer

days_lepott: integet

days report?: integer

days_leports: integer

ngb_project: chan 3 )

sos_default_ric: char(3)

ngb_serial: integer

ngb_serial_date: date

dass_serial: integer

daas_serial_date: date

das_out_datetime: datetime year to fraction(3)

dass_.out_intersal: integer

system_status: char(10) 
APPENDIX B

SUBJECT: OSCAR Message Table

$1 \mid$ AC |||| $\mid$ CUSTOMER REQUESTED CANCELLATION

$2 \mid$ AR ||||||$C U S T O M E R$ REQUESTED CANCELLATION

3 |AE2 || ||BB||CUSTOMER STATUS

$4 \mid$ AS2 |||||| SHIPMENT STATUS

$5|D 6| X||||$ RECEIPT OF SHIPMENT

6|D6|S||||RECEIPT OF SHIPMENT (SYSTEM)

7 |FTC |||||REPORTED EXCESS CANCELLATION

8 |FTD ||||| NGB DELAY STATUS

9|FTE|||A||RECEIVED BY NGB/MGT WORKING

10|FTE ||D||MANAGER PLACED ON LONG-TERM HOLD

11|FTE || $\mid$ I||NGB DISP-STATE ACTION PENDING

$12 \mid$ FTE ||$C||$ EXCESS REPORT (COMPLETED)

13 |FTE || | P ||NGB HAS FORWARDED FTE TO ICP

$14 \mid$ FTF |||| FOLLOW UP RECEIVED BY NGB

15|FTL ||$X||||$ STATE SHIPMENT DELAYED

16|FTL ||S||||STATE SHIPMENT DELAYED (SYSTEM)

$17 \mid$ FTM ||$x||||$ STATE RELEASED FOR SHIPMENT

18|FTM ||S||||STATE RELEASED FOR SHIPMENT (SYSTEM)

19|FTR |||||TB|DISP-SHIP TO RIC IN POS 54-56

20|FTR |||||TC|DISP-TRANSFER TO DRMO

21 |FTR | || $\mid$ SA | EXCESS REPORT CANCELLED BY NGB

$22 \mid$ FTZ |||| $\mid$ EXCESS REPORT (COMPLETED)

$23 \mid$ AE2 ||||$|C B|$ CANCELLED BY SHIPPING STATE

$24 \mid$ FTE ||||$z||$ PASSED TO NGB-AVN MANAGER

$25 \mid$ FTD | || D|| NGB LONG-TERM HOLD (NGB-HOLD)

26|FTR ||||T6|ROUTE FUTURE RESPONSES TO 'AM3'

27|FTR || $\mid$ SD||ITEM NOT IDENTIFIABLE (REVIEW) 
APPENDIX B

SUBJECT: Recommendation for Processing Major End-Item Excess Reports within state/Territories.

1. The purpose of this memorandum is to provide guidance in the development of standard Operating Procedures (SOP) for Reporting Major End-Items within each state or Territory.

STEP 1. Standard Army Retail Supply system (SARSS-1) excess switch will be turned on. SARSS-1 will automatically report excess to SARSS-2AC during the SARSS-1 close out process.

STEP 2. SARSS-2AC Commodity Manager will execute the RVARS standard Query statement (SQL) against the Manager Review File (MRF) which will provide information to be placed on a diskette in RVARS format.

STEP 3. SARSS-2AC manager will provide the diskette to the Property Management Branch for processing through RVARS.

STEP 4. Property Management Branch will execute RVARS and obtain recommendations.

STEP 5. Property Management Branch will obtain unit request(s) for assets required within state/Territory and provide request/recommendations to SARSS-2AC manager.

STEP 6. SARSS-2AC will forward request(s) for issue to SARRS -1 .

STEP 7. SARSS-1 will process requests for issue. SARSS-1 close out process will automatically cancel excess report when asset is issued to customer.

STEP 8. SARSS-2AC will approve remaining excess reports and release 'NGBAM3' file to the Defense Automatic Addressing system (DAAS) per Appendix C for processing to NGB.

2. POC for this action is Mr. Johnson at NGB-ARL-E, DSN 327-7478 or CW3 Pelath, NGB-ARL-S at DSN 327-7458. 


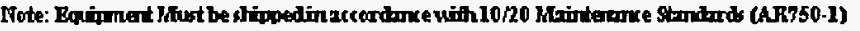

\begin{tabular}{|c|c|c|c|c|c|c|c|c|c|}
\hline \multirow{2}{*}{ Reviuti } & \multirow[t]{2}{*}{ MaI } & \multicolumn{2}{|c|}{ Treine } & \multirow[b]{2}{*}{ Ant } & \multirow[b]{2}{*}{ Strat: } & \multirow[b]{2}{*}{ Lim } & \multirow[b]{2}{*}{$\begin{array}{l}\mathrm{Avi} \\
\mathrm{Im} \mathrm{m}\end{array}$} & \multirow[b]{2}{*}{ Messag: } & \multirow[b]{2}{*}{ 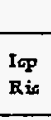 } \\
\hline & & & & & & & & & \\
\hline 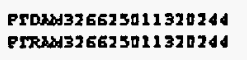 & 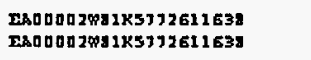 & $\begin{array}{l}\text { A } 32 \\
\text { A } 32\end{array}$ & 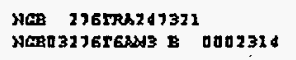 & p & as & 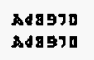 & $\begin{array}{l}\mathbf{N} \\
\mathbf{y}\end{array}$ & 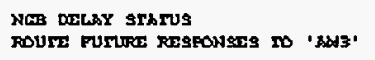 & $\begin{array}{l}864 \\
\text { BE4 }\end{array}$ \\
\hline 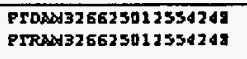 & 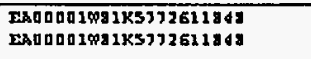 & $\begin{array}{l}\mathrm{OCAB} \\
\mathrm{OCAB}\end{array}$ & 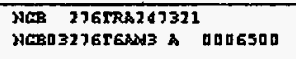 & $\begin{array}{l}\mathrm{P} \\
\mathrm{P}\end{array}$ & $\frac{\mathrm{CB}}{\mathrm{CA}}$ & $\begin{array}{l}\cos 539 \\
\text { C04959 }\end{array}$ & $\begin{array}{l}y \\
x\end{array}$ & 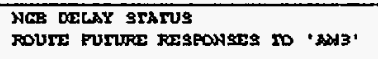 & $\begin{array}{l}854 \\
854\end{array}$ \\
\hline $\begin{array}{l}\text { Pross3321430010301437 } \\
\text { PTRAs321430010301437 }\end{array}$ & 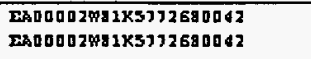 & $\begin{array}{ll}\cos \\
\cos \end{array}$ & 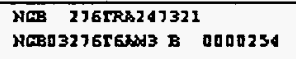 & I & $\cos$ & $\begin{array}{l}\text { C6sadon } \\
\text { c6sano }\end{array}$ & $\begin{array}{l}\text { N } \\
\text { N }\end{array}$ & 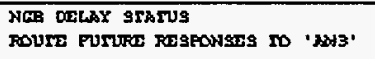 & $\begin{array}{l}\text { BE4 } \\
\text { BE4 }\end{array}$ \\
\hline 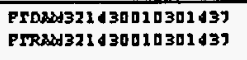 & 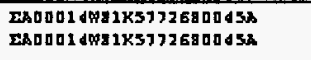 & Das & 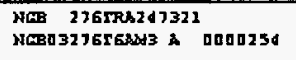 & 1 & as & $\begin{array}{l}\operatorname{ccsana0} \\
\operatorname{cssan0}\end{array}$ & $\begin{array}{ll}n \\
n \\
n\end{array}$ & 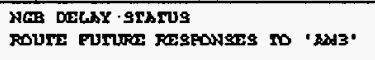 & $\begin{array}{l}\text { BE4 } \\
\text { 864 }\end{array}$ \\
\hline $\begin{array}{l}\text { FrESA316130010129796 } \\
\text { ETRAN326130010199786 }\end{array}$ & 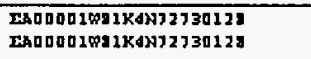 & DCA & 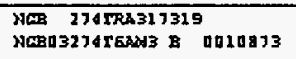 & $\begin{array}{l}2 \\
\mathrm{P}\end{array}$ & $\begin{array}{l}x s \\
x s\end{array}$ & $\begin{array}{l}\text { DS9960 } \\
\text { D99260 }\end{array}$ & W & 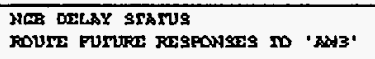 & $\begin{array}{l}\text { 864 } \\
\text { BE4 }\end{array}$ \\
\hline 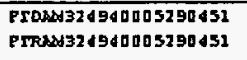 & $\begin{array}{l}\text { ESO000019140L311690013 } \\
\text { ESQ000191 UUL371690013 }\end{array}$ & $\begin{array}{l}\text { A12 } \\
\text { A12 }\end{array}$ & 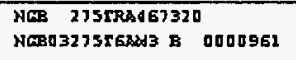 & $\begin{array}{l}I \\
I\end{array}$ & $\begin{array}{l}\text { NHA } \\
\text { NM: }\end{array}$ & $\begin{array}{l}95072 \\
\text { P96012 }\end{array}$ & $\begin{array}{l}3 \\
4 \\
4\end{array}$ & 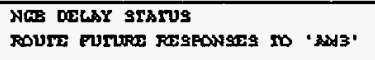 & $\begin{array}{ll}864 \\
864\end{array}$ \\
\hline $\begin{array}{l}\text { PrRasA326625012986361 } \\
\text { FTrRS326523013986361 }\end{array}$ & 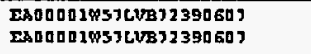 & $\begin{array}{l}\text { DTA } \\
07 \mathrm{~A}\end{array}$ & 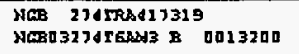 & $\frac{1}{1}$ & sis & $\begin{array}{l}\text { Gea17s } \\
\text { Cado17s }\end{array}$ & N & 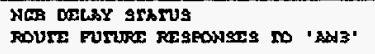 & $\begin{array}{l}864 \\
866\end{array}$ \\
\hline PIDXOXXS6E23010J32439 & 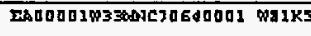 & TDEA & 3RA2d H & P & $\omega$ & C3E4S1 & H & NGE RAS POSWAROEO FTE TO ICP & BES \\
\hline $\begin{array}{l}\text { FrOASA326525010759479 } \\
\text { PITAA326623010758479 }\end{array}$ & 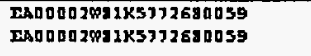 & $\begin{array}{l}\text { DGA } \\
\text { DGA }\end{array}$ & 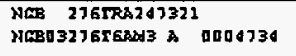 & $\begin{array}{l}P \\
P\end{array}$ & $\begin{array}{ll}\mathrm{CB} \\
\mathrm{CB}\end{array}$ & $\begin{array}{l}\text { G5ES51 } \\
636431\end{array}$ & $\begin{array}{l}\mathbf{H} \\
\boldsymbol{u}\end{array}$ & 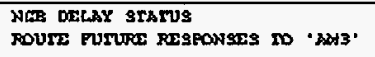 & $\begin{array}{l}\text { BEA } \\
\text { BEG }\end{array}$ \\
\hline $\begin{array}{l}\text { PFo3A326625010744337 } \\
\text { PFR3A325625010741337 }\end{array}$ & 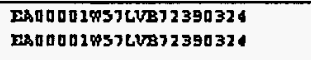 & $\begin{array}{l}\text { DTA } \\
\text { DiA }\end{array}$ & 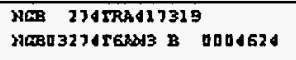 & $\begin{array}{l}I \\
I\end{array}$ & $\cos$ & $\begin{array}{l}\text { J51948 } \\
\text { J51948 }\end{array}$ & $\begin{array}{l}\boldsymbol{N} \\
\boldsymbol{N}\end{array}$ & 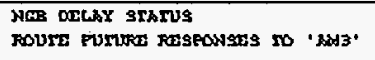 & $\begin{array}{l}\text { BEd } \\
\text { BEA }\end{array}$ \\
\hline $\begin{array}{l}\text { EIOA)321440013231215 } \\
\text { FTRAS32140001323121E }\end{array}$ & 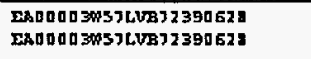 & $\begin{array}{l}\text { DIA } \\
\text { DIA }\end{array}$ & 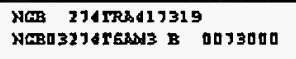 & P & ${ }_{\cos }^{609}$ & $\begin{array}{l}\text { C.45740 } \\
\text { C.45740 }\end{array}$ & $\begin{array}{l}\text { N } \\
\text { N }\end{array}$ & 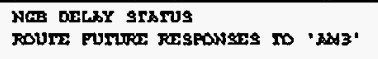 & $\begin{array}{l}\text { BEA } \\
\text { BEd }\end{array}$ \\
\hline $\begin{array}{l}\text { Pross } 326625011432430 \\
\text { PIRAS326625011452430 }\end{array}$ & 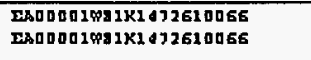 & $\begin{array}{l}\text { A72 } \\
\text { A.2 }\end{array}$ & 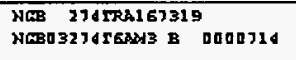 & $\begin{array}{l}I \\
I\end{array}$ & $\begin{array}{l}S A R \\
S R R\end{array}$ & 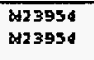 & $\begin{array}{l}\text { N } \\
\text { N }\end{array}$ & 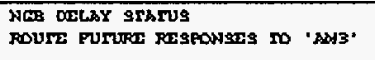 & $\begin{array}{l}\text { BES } \\
\text { BEd }\end{array}$ \\
\hline PTEOXX26625011452430 & FBODO001691 1KR312380294 & A.2 2 & 3rAds : & $\mathbf{P}$ & NJ & Od13954 & N & WCE HhS PAKSAAROED PST IO ICP & 854 \\
\hline $\begin{array}{l}\text { PFDSAd326920002234919 } \\
\text { PIR3AA326920001234919 }\end{array}$ & 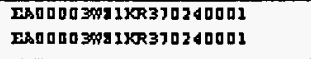 & $\begin{array}{l}\mathrm{DCA} \\
\mathrm{DCAB}\end{array}$ & 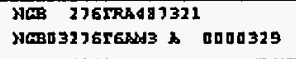 & $\begin{array}{l}I \\
I\end{array}$ & $\begin{array}{l}\text { NI } \\
\text { Nu }\end{array}$ & $\begin{array}{l}\text { MS1419 } \\
\text { AS1 } 1519\end{array}$ & 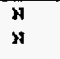 & 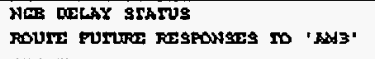 & $\begin{array}{l}\text { 8E4 } \\
\text { BE4 }\end{array}$ \\
\hline 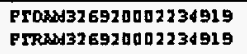 & 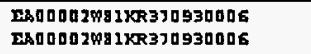 & $\begin{array}{l}\text { Das } \\
\text { Das }\end{array}$ & 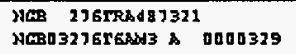 & $I$ & MI & 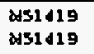 & $\begin{array}{l}\mathbf{N} \\
\mathrm{N}\end{array}$ & 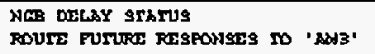 & $\begin{array}{l}\text { BES } \\
\text { BE4 }\end{array}$ \\
\hline
\end{tabular}


THIS PAGE NOT USED

B-12 
APPENDIX C

NGB-ARL-S (700)

19 June 1997

MEMORANDUM FOR INFORMATION

SUBJECT: Routing NGB-AMB Excess File Through DAAS.

1. Directions for sending out NGB FTE(s) through DAAS. These are step-by-Step Instructions and are not intended to insult anyone's intelligence, but rather to ensure everyone understands. States must change 'WCZ' on the following instructions to their SARSS-2AC RIC. In all examples I use the file name FTE97161. States would use whatever makes sense to them.

a. Login as ajpconv and enter password. ajpconv <enter> pwd <enter>

b. Change directory to / var/ajp/exit/ngbam3/SARSS-2AC RIC. cd/var/ajp/exit/ngbam3/wXX <enter>

c. Look at the files in this directory - If more than one, concatenate.

Is -1 <enter>

d. Concatenate the files into one file. cat $0 *>$ FTE 97161 <enter>

e. Sort the file in niin sequence.

(error message occurs if command does not work) sort-ofte97161+0.12-0.20fte97161 <enter>

f. Send to high-speed printer for review by Stock Control, if desired, or old files. IPFTE97161 <enter>

g. Edit file if necessary to remove unwanted transactions. viFTE97161 <shift $\mathrm{ZZ}$ when done>

h. Sign of ajpconv exit <enter>

i. Log on to ajpnet01 ajpnet01 <enter> pwd <enter> 
NGB-ARI-S (700) 19 June 1997

SUBJECT: Routing NGB-AM3 Excess File Through DAAS. (continued)

j. Select Routing Monitor

Routing Monitor <enter>

k. Enter the following information only; all other entries are blank.

SIC: $A J U$

FILE ID: AJU080

PEST ID: HR

SRC ID: WXX <Use SARSS-2AC RIC>

SRC FILE SPEC: /var/ajp/exit/ngbam3/WXX/FTE97161

USER COMMENT: NEB ETES /DAMS

1. Add AJP Network Router

F2 <to exit screen press F7 and control B>

Service Request. Add a separate entry for each

file name.

m. Wait a few minutes. Service requests are processed every 15 minutes.

n. Select Monitor/Activate Transfer

Monitor/Activate Transfer <enter>

o. Select WAN-DDN-5000

WAN-DDN-5000 <enter>

p. Select Status to see if a file exists for AJU080. Status <enter>

q. Verify that the file is for HR2

<enter>, press any key to continue and F8

r. Select Transfer

Transfer <enter>

s. Select yes for override

$y$ <enter>

$\mathrm{C}-2$ 
NGB-ARL-S (700) 19 June 1997

SUBJECT: Routing NGB-AM3 Excess File Through DAAS. (continued)

REMARKS: That's all there is to it. If this is the only file to send out you'll receive the following message: 'No WAN DDN' Transfer Selections. Press any key to continue, F8, F8.

W01 Donna Blackey, Supply System Analyst - NH, DSN: 684-9269 or email blackeydenh-ngnet.army/mil.

NGB-ARL-S CW3 Pelath, DSN 327-7458

email pelathr@ARNGRC-EMH2 army.mil

NGB-ARI-E Mr. Harry Johnson, DSN 327-7478

Email johnsonhCARNGRC-EMH2.army.mil 
APPENDIX C

SUBJECT: STANDARD QUERY LANGUAGE (SQL) FOr Requisition

Validation Automated Redistribution system

(RVARS).

1. This SQL will create a file of all Excess Reports (FTE) transaction currently in the Manager Review File (MRF). It formats these transactions to be used in RVARS. When the information obtain from this file is processed through RVARS assets required within your state are identified. These assets should not be reported to NGB, but redistributed within the state.

SQL follows :

DATABASE sarss END

DEFINE

VARIABLE mrf_qty interger END

OUTPUT

Left margin 0

REPORT TO Y/var/ajp/exit/mbox/wCz/rvars.000'

END

SELECT mrf.dic, transaction, fsc, mrf.niin, mrf.doc_no[1,6], cat.lin

FROM ajumrf mrf, ajrcaprime cat

WHERE mrf.niin = cat.niin AND

mrf.dic = 'FTE' AND mrf.transaction [4, 6] NOT IN

('A35', 'AP5', 'SIT', 'S9A', 'S9F', 'S9I', 'S9P',

'S9Q', 'S9S', 'S9T', 'GSA', 'S9C', 'S9E', 'S9G') AND

cat.ricc IN ('A', 'B', 'C', '2')

ORDER BY niin

END

FORMAT

ON EVERY ROW

IET mrf_qty = transaction [25, 29]

PRINT doc_no $[1,6]$,

Column 7, transaction $[71,71]$,

Column 8, lin,

Column 14, fsc,

Column 18, niin,

Column 33, mrf qty using '

END 
DD FOR 1348-1A NOV 87 ISSUE RELEASE/RCPT DOCUMENT

(REPLICATION)

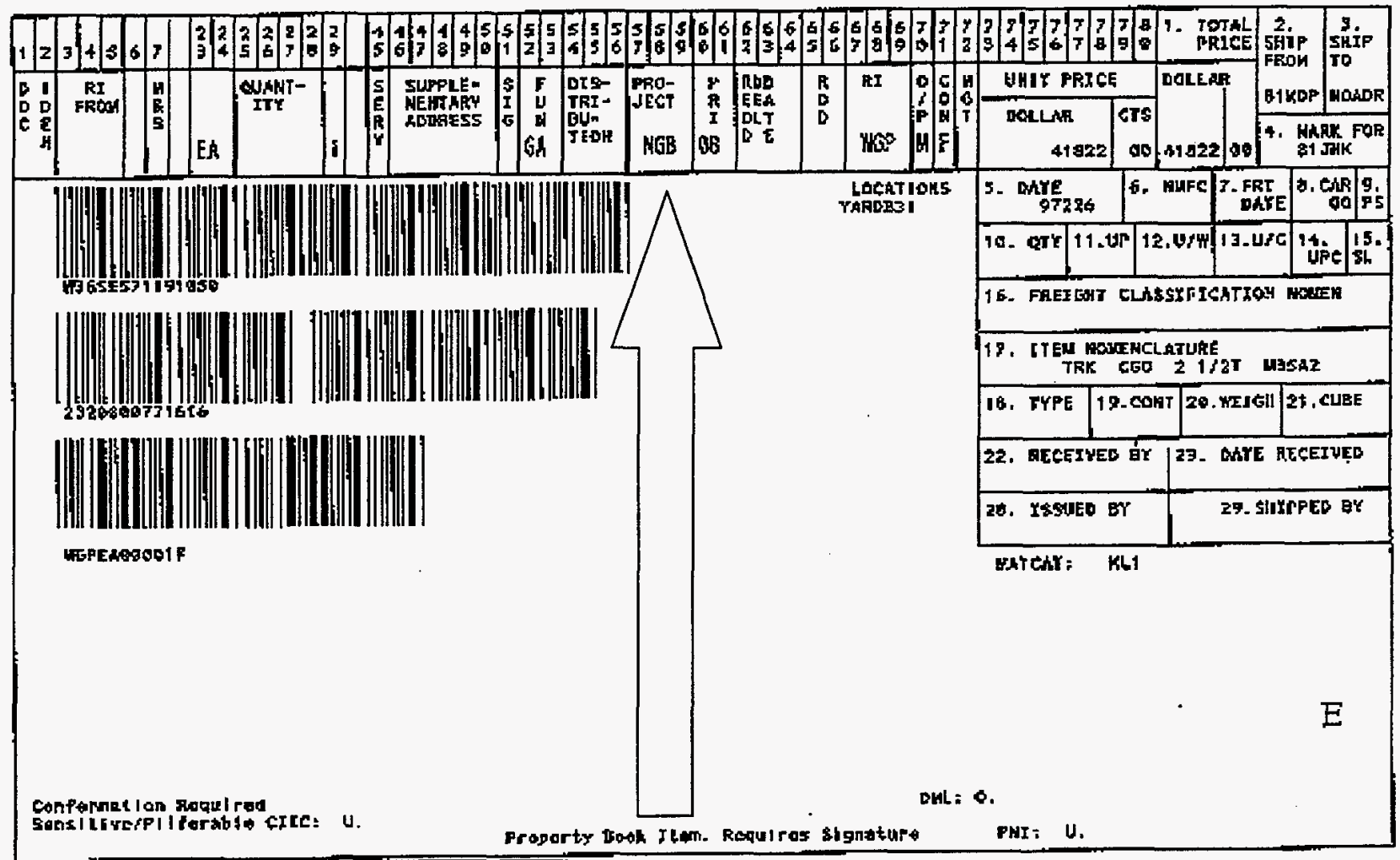

Note: When a DD 1348-1A is a result of a Customer Response (FTR) Erom NGB, "NGB" will be in the the Project code Field. 
THIS PAGE NOT USED

C-6 
APPENDIX D

National Guard Bureau (NGB) Directives/Instruction/Guidance

D.1 General. This appendix contains copies of special NGB Memorandum/Letters/Directives which provide guidance on NGB controlled Assets.

D.2 COMSEC Equipment/Controlled Cryptographic Items. Excess COMSEC equipment will be reported to NGB-ARL-E following normal procedures with the following exceptions:

a. Automatic Return (ARI) which will be shipped directly to RIC 'BL4' DODAAC 'W81U11, COMSEC support Center, BLDG 73, Tobyhanna Army Depot, Tobyhanna, PA. 18466-5110. See TB 380-41 for shipment of classified COMSEC equipment. Reference AR 710-2, para 4-37(6)).

b. Unserviceable CCI equipment will be shipped to RIC 'BL4' DODAAC 'W81U11', COMSEC Support Center, BLDG 73, Tobyhanna Army Depot, Tobyhanna, PA. 18466-5110.

D.3 Medical Equipment. Excess medical materiel will be reported to NGB-ARL-E in accordance with AR 40-61. Medical items can be condition coded as follows:

a. Medical equipment by biomedical maintenance personnel.

b. Medical supplies by logistics personnel. 
APPENDIX D (Continued)

D.4 Radioactive Items. States/Territories will follow procedures outlined in AR 385-11.

D.5 Commercial Vehicles. States/Territories will report commercial vehicles in writing to NGB-ARL-E for disposition. NGB will coordinate with TACOM for disposition instruction.

D.6 GSA Items. The GSA catalog and AR 725-50, Chapter 7, Sect. IV. outlines the criteria for reporting excess items.

a. GSA items in ' $H$ or $P$ ' condition or obsolete may be disposed to DRMO in accordance with DOD 4160-21-M

b. Technical Inspections are only required for those items condition coded ' $F$ or $G$ '.

D.7 DLA Items. Report per AR 725-50, Chapter 7, Sect. V. 
APPENDIX D

SUBJECT: Auto Disposition Table (IIN) (Date: 8 July 1997)

1. This is a list of assets not required within the ARNG. They will be passed directly to the Inventory control Point. (ICP) for actions.

2.

IIN

-----

A01870

A01872

A01898

A01898

A01902

A01905

A01910

A11341

A12290

A13660

A16155

A71438

A72260

B12482

B68790

B72636

B72636

B98309

C05475

C17797

C18047

C20414

C30997

C63630

C68856

C68993

C83610

C83897

C85664

C85732

C85802

C85871

C86076

C86118

C86967

D10741

D60801

D76085

E00533

E02670

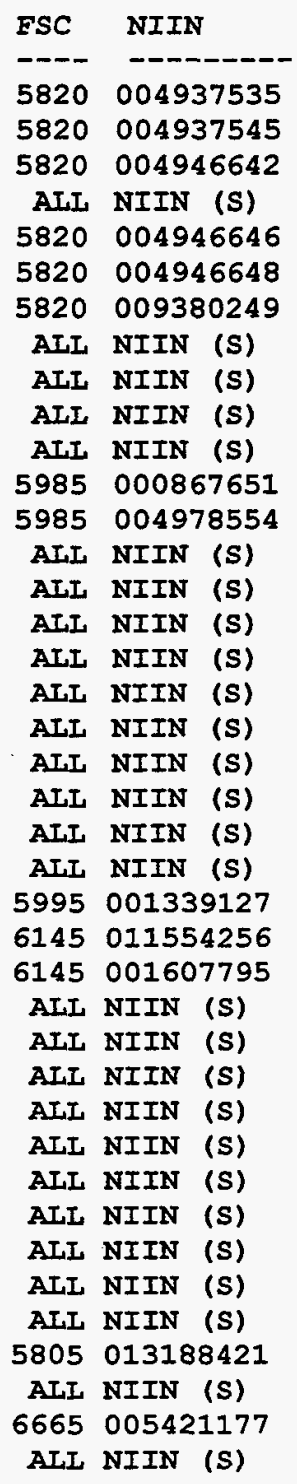

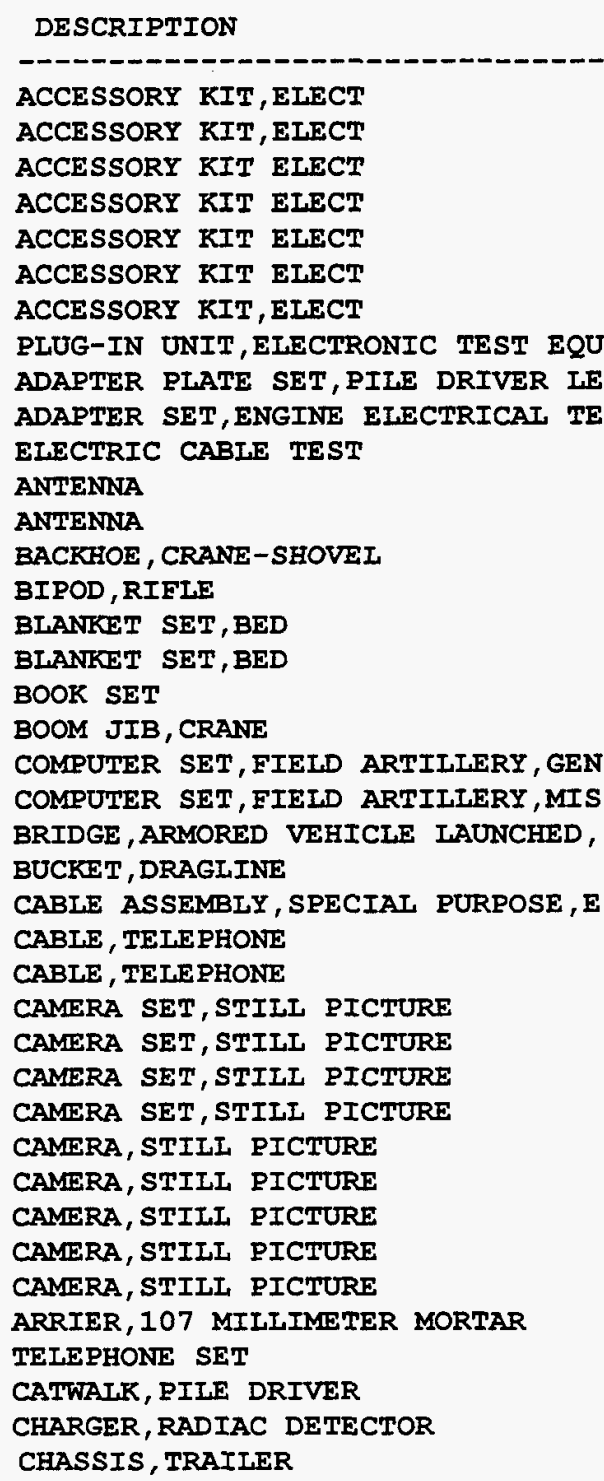

\begin{tabular}{|c|c|}
\hline ICP & REC_ID \\
\hline--- & -ーー-ー- \\
\hline B16 & 1 \\
\hline B16 & 2 \\
\hline B16 & 3 \\
\hline B16 & 289 \\
\hline B16 & 4 \\
\hline B16 & 5 \\
\hline B16 & 6 \\
\hline $\mathrm{B} 64$ & 70 \\
\hline AKZ & 57 \\
\hline B14 & 58 \\
\hline AKZ & 284 \\
\hline B16 & 7 \\
\hline B16 & 8 \\
\hline AKZ & 64 \\
\hline B14 & 71 \\
\hline$S 9 M$ & 72 \\
\hline S9M & 293 \\
\hline S9M & 294 \\
\hline AKZ & 75 \\
\hline B14 & 76 \\
\hline B14 & 77 \\
\hline AKZ & 78 \\
\hline AKZ & 80 \\
\hline B16 & 9 \\
\hline B16 & 10 \\
\hline B16 & 11 \\
\hline B16 & 85 \\
\hline B16 & 86 \\
\hline$B 16$ & 94 \\
\hline B16 & 95 \\
\hline B16 & 96 \\
\hline B16 & 98 \\
\hline B16 & 99 \\
\hline B16 & 100 \\
\hline B16 & 102 \\
\hline AKZ & 285 \\
\hline FFZ & 12 \\
\hline AKZ & 106 \\
\hline B16 & 13 \\
\hline AKZ & 107 \\
\hline
\end{tabular}


APPENDIX D

SUBJECT: Auto Disposition Table (IIN) (continued)

\begin{tabular}{|c|c|c|c|c|c|}
\hline LIN & FSC & NIIN & DESCRIPTION & ICP & REC_ID \\
\hline --ー-ー- & ---- & -------- & 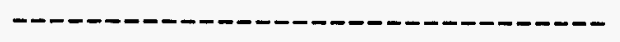 & --- & \\
\hline $\mathbf{E 0 3 0 2 8}$ & 5810 & 011463260 & $\mathrm{KG}-84 \mathrm{~A}$ & B56 & 50 \\
\hline E03826 & 6625 & 013239584 & TEST SET,ELECTRONIC SYSTEMS & B16 & 14 \\
\hline E11657 & ALL & NIIN (S) & CHEST, MEDICAI INSTRUMENT AND SUP & s9M & 295 \\
\hline E11794 & ALL & NIIN & CHEST,MEDICAI INSTRUMENT AND SUP & s9M & 296 \\
\hline E54166 & ALI & NIIN (S) & COLLIMATOR, INFINITY AIMING REFER & B14 & 108 \\
\hline $\mathbf{E 5 6 8 9 6}$ & ALI & NIIN (S) & COMBAT VEHICLE ITV,M901AI & AKZ & 286 \\
\hline E61338 & 6910 & 012230037 & INEORMATION DELIVER & B16 & 15 \\
\hline E63728 & ALI & NIIN (S) & COMPASS, MAGNETIC, UNMOUNTED & $S 9 E$ & 110 \\
\hline E67355 & ALI & NIIN & COMPRESSOR-DEHYDRATOR,DENTAL EQU & s9M & 297 \\
\hline E72804 & ALI & NIIN (S) & COMPRESSOR UNIT, ROTARY & AKZ & 115 \\
\hline E92915 & 5820 & 005431397 & CONTROI, RADIO SET & B16 & 16 \\
\hline E98103 & 5810 & 010269618 & ELECTRICAL TRANSFER & B56 & 51 \\
\hline F18204 & AII & NIIN (S) & COID FOOD COUNTER, MECEANICAILY R & S9G & 117 \\
\hline F43414 & ALL & NIIN & CRANE-SHOVEL, TRUCK MOUNTED & AKZ & 118 \\
\hline F95230 & ALL & NIIN (S) & DENTAI EQUIPMENT SET,OPERATING, F & S9M & 298 \\
\hline F95298 & ALI & NIIN & DENTAL EQUIP SE GEN & S9M & 299 \\
\hline F95601 & AII & NIIN (S) & OPERATING AND TREATMENT,DENTAI,F & S9M & 300 \\
\hline G26890 & 6110 & 009857574 & DISTRIBUTION BOX & B16 & 17 \\
\hline H61326 & 6115 & 011922080 & GENERATOR,DIRECT CURRENT & B16 & 18 \\
\hline H84228 & ALI & NIIN (S) & VETERINARY EQUIPMENT SET,FOOD IN & S9M & 301 \\
\hline J33711 & ALI & NIIN (S) & GENERATOR, PULSE & B64 & 128 \\
\hline$J 34328$ & ALI & NIIN (S) & GENERATOR, PULSE & B16 & 130 \\
\hline$J 46258$ & AIL & NIIN (S) & GENERATOR SET, GASOLINE ENGINE, TR & A12 & 140 \\
\hline$J 48606$ & 5820 & 012081904 & INSTAIIATION KIT,ELECTRONIC EQUI & B16 & 21 \\
\hline J51590 & 3655 & 004084683 & GENERATOR SET & B16 & 22 \\
\hline$J 52686$ & AIL & NIIN (S) & GENERATOR, SIGNAI & B64 & 144 \\
\hline $\mathrm{J} 52960$ & ALI & NIIN & GENERATOR, SIGNAL & B16 & 145 \\
\hline J53645 & ALL & NIIN & GENERATOR, SIGNAI & B64 & 146 \\
\hline J53682 & ALI & NIIN (S) & GENERATOR, SIGNAL & B64 & 147 \\
\hline J53944 & ALL & NIIN (S) & GENERATOR, SIGNAI & B64 & 149 \\
\hline$J 54604$ & ALI & NIIN (S) & GENERATOR, SIGNAI & B64 & 150 \\
\hline J54878 & ALL & NIIN (S) & GENERATOR, SIGNAI & B64 & 152 \\
\hline J55944 & ALL & NIIN & GENERATOR, SIGNAI & B64 & 154 \\
\hline J56367 & $A I I$ & NIIN & GENERATOR, SIGNAL & B16 & 156 \\
\hline J56369 & ALI & NIIN & GENERATOR, SIGNAI & B64 & 157 \\
\hline J57618 & ALL & NIIN & GENERATOR, SIGNAI & B64 & 158 \\
\hline J74852 & AIL & NIIN (S) & GRADER, ROAD , MOTORIZED & AKz & 160 \\
\hline J88343 & 5820 & 011752106 & INSTALIATION KIT,ELECTRONIC EQUI & B16 & 23 \\
\hline J99737 & 6605 & 000698762 & COMPASS, GYRO & B16 & 24 \\
\hline K87243 & 5820 & 004506804 & INSTAILATION KIT,ELECTRONIC EQUI & B16 & 25 \\
\hline K87248 & 5820 & 004696684 & INSTALIATION KIT, ELECTRONIC EQUI & B16 & 26 \\
\hline K87269 & 5820 & 001938348 & INSTALIATION KIT, ELECTRONIC EQUI & B16 & 27 \\
\hline K87449 & 5820 & 010223333 & INSTAIIATION KIT,ELECTRONIC EQUI & B16 & 28 \\
\hline K87454 & 5820 & 010223329 & INSTALLATION KIT, ELECTRONIC EQUI & B16 & 29 \\
\hline K87456 & 5820 & 010223328 & INSTALIATION KIT,ELECTRONIC EQUI & B16 & 30 \\
\hline
\end{tabular}




\begin{tabular}{|c|c|c|c|c|c|c|}
\hline \multirow{2}{*}{$\begin{array}{l}\text { SUBJECT : } \\
\text { IIN }\end{array}$} & \multicolumn{3}{|c|}{ Auto Disposition } & \multicolumn{3}{|l|}{ Table (IIN) (continued) } \\
\hline & FSC & NIIN & & DESCRIPTION & ICP & REC_ID \\
\hline------ & --- & ---- & ----- & - - - - - - - - & --- & -ーーー-ー \\
\hline L22987 & 5810 & 00054 & 9110 & KEY GEN, ELCT & B56 & 52 \\
\hline L49089 & AIL & NIIN & (S) & IFAD SECTION, TOP, PILE DRIVER & AKZ & 165 \\
\hline L63833 & ALI & NIIN & (S) & IIGHT SET,DENTAI OPERATING, FIELD & S9M & 302 \\
\hline $\mathrm{L} 64679$ & ALL & NIIN & (S) & IIGHT, SIGNAI , SURVEYING & S9I & 169 \\
\hline L65501 & ALI & NIIN & (S) & LIGHT, SIGNAI, SURVEYING & S9I & 170 \\
\hline L76556 & ALL & NIIN & (s) & LOADER, SCOOP TYPE & AKZ & 172 \\
\hline M10936 & AIL & NIIN & (S) & MASK, CHEMICAI-BIOLOGICAI & B14 & 173 \\
\hline M11621 & AII & NIIN & (S) & MASK, CHEMICAI-BIOLOGICAI & B14 & 174 \\
\hline M11895 & AII & NIIN & (S) & MASK, CHEMICAI-BIOLOGICAI & B14 & 175 \\
\hline M35691 & ALI & NIIN & (S) & METASCOPE & B16 & 176 \\
\hline$M 74618$ & AII & NIIN & (s) & MOUNT, MACEINE GUN & B14 & 178 \\
\hline M75029 & AII & NIIN & (s) & MOUNT, MACHINE GUN & B14 & 179 \\
\hline M75577 & AII & NIIN & (S) & MOUNT, TRIPOD, MACHINE GUN & B14 & 180 \\
\hline M79728 & AII & NIIN & (s) & MULTIMETER & B16 & 181 \\
\hline M80002 & AII & NIIN & (S) & MULTIMETER & FPZ & 183 \\
\hline M80242 & ALI & NIIN & (s) & MULTIMETER & B64 & 184 \\
\hline M80259 & AII & NIIN & (s) & MULTIMETER & B64 & 185 \\
\hline M80976 & AIL & NIIN & (s) & MULTIMETER & B64 & 188 \\
\hline M80991 & AII & NIIN & (s) & MULTIMETER & B64 & 189 \\
\hline M81037 & AIL & NIIN & (s) & MULTIMETER & $\mathrm{B} 14$ & 190 \\
\hline M81098 & AIL & NIIN & (s) & MULTIMETER & N35 & 191 \\
\hline M81235 & AIL & NIIN & (s) & MULTIMETER & FPZ & 192 \\
\hline M81372 & AII & NIIN & (s) & MULTIMETER & B64 & 193 \\
\hline M81646 & ALL & NIIN & (S) & MULTIMETER & B 64 & 194 \\
\hline N15518 & 5855 & 00906 & 0994 & NIGHT VISION SIGHT, & B16 & 31 \\
\hline N29683 & AII & NIIN & (S) & OSCILIOSCOPE & BI6 & 195 \\
\hline N30094 & AIL & NIIN & (S) & OSCILIOSCORE & B16 & 196 \\
\hline N30231 & AII & NIIN & (S) & OSCILLOSCORE & B64 & 197 \\
\hline N30256 & AII & NIIN & (S) & OSCILIOSCOPE & B64 & 198 \\
\hline N30368 & AIL & NIIN & (s) & OSCILIOSCOPE & B64 & 199 \\
\hline N30572 & AIL & NIIN & (S) & OSCILLOSCOPE & B64 & 200 \\
\hline N30594 & ALL & NIIN & (s) & OSCILIOSCOPE & B16 & 201 \\
\hline N30615 & AIL & NIIN & (S) & OSCILLOSCORE & B16 & 202 \\
\hline N30620 & AII & NIIN & (s) & OSCILLOSCOPE & B16 & 203 \\
\hline N31327 & ALL & NIIN & (S) & OSCIILOSCOPE & B64 & 204 \\
\hline N32148 & AII & NIIN & (S) & OSCILLOSCOPE & B64 & 205 \\
\hline N32160 & 6625 & 00127 & 0079 & OSCILLOSCOPE & B64 & 32 \\
\hline N32934 & ALI & NIIN & (s) & HIGH FREQUENCY SIGN & B64 & 206 \\
\hline N32971 & AII & NIIN & (S) & OSCILLOSCOPE SUBASSEMBLY & B64 & 207 \\
\hline N54691 & ALL & NIIN & (s) & CFARGER, BATTERY & S9G & 208 \\
\hline N82364 & AIL & NIIN & (s) & PERISCOPE, BATTERY COMMAND & B14 & 211 \\
\hline N96193 & ALL & NIIN & (S) & PISTOL, CALIBER . 22, AUTOMATIC & B14 & 212 \\
\hline P11093 & AII & NIIN & (S) & VOLTMETER,DIGITAI & B64 & 213 \\
\hline P11173 & AIL & NIIN & (S) & PLUG-IN UNIT,ELECTRONIC TEST EQU & B16 & 214 \\
\hline P11182 & ALL & NIIN & (s) & AMPLIFIER DUAI TRACE & B64 & 215 \\
\hline P11970 & AII & NIIN & (s) & PLUG-IN UNIT, ELECTRONIC TEST EQU & B64 & 217 \\
\hline
\end{tabular}


APPENDIX D

SUBJECT : Auto Disposition (Table LIN) (continued)

\begin{tabular}{|c|c|c|c|c|c|}
\hline LIN & FSC & NIIN & DESCRIPTION & ICP & REC_ID \\
\hline----- & --- & -------- & $-m--n-m-n$ & --- & \\
\hline P38588 & 6130 & 009857899 & POWER SUPPLY & B16 & 33 \\
\hline P40374 & 6130 & 009537500 & POWER SUPPLY & B16 & 34 \\
\hline P40723 & ALI & NIIN (S) & PLUG-IN , ELECTRONIC & B64 & 220 \\
\hline P41047 & 6130 & 010509536 & POWER SUPPLY & B56 & 53 \\
\hline P45390 & AIL & NIIN (S) & RLUG-IN UNIT,ELECTRONIC TEST EQU & B16 & 222 \\
\hline P45527 & AII & NIIN (S) & PLUG-IN UNIT,ELECTRONIC TEST EQU & $\mathbf{B} 64$ & 223 \\
\hline P45664 & AII & NIIN (S) & PLUG-IN UNIT,ELECTRONIC TEST EQU & B64 & 224 \\
\hline P45801 & ALL & NIIN (S) & AMPLIFIER & B16 & 225 \\
\hline P45817 & AIL & NIIN (S) & PLUG-IN UNIT,ELECTRONIC TEST EQU & B64 & 226 \\
\hline P75541 & 6730 & 001115929 & PROJECTOR, MOTION PICTURE, SOUND & B16 & 35 \\
\hline P77536 & AIL & NIIN (S) & PROJECTOR, STILI PICTURE & B16 & 228 \\
\hline P78221 & ALL & NIIN & PROJECTOR, STILL PICTURE & B16 & 231 \\
\hline Q30964 & A工I & NIIN (S) & RADIO TELETYPEWRITER SET & B16 & 237 \\
\hline $\mathbf{Q} 45779$ & 5820 & 002237412 & RADIO SET & B16 & 38 \\
\hline Q90120 & 5815 & 004435511 & RADIO TELETYPEWRITER SET & B16 & 39 \\
\hline Q91302 & 5815 & 002248130 & RADIO TELETYPEWRITER SET & B16 & 40 \\
\hline Q92118 & AIL & NIIN (S) & RADIO TERMINAI SET & B16 & 238 \\
\hline R25600 & 5820 & 008920624 & RECEIVER, RADIO & B16 & 41 \\
\hline R29799 & 5820 & 000698931 & RECEIVING SET,RADIO & B16 & 42 \\
\hline R30662 & 5820 & 006444554 & RECEIVER-TRANSMITTER CONTROL GRO & B16 & 43 \\
\hline R59160 & 3895 & 004988343 & REELING MACHINE, CABLE, HAND & B16 & 44 \\
\hline R59434 & 3895 & 009008320 & REELING MACHINE, CABLE,MOTOR DRIV & B16 & 45 \\
\hline R71450 & ALL & NIIN (S) & REIINER, BRAKE AND CLUTCE & s9c & 241 \\
\hline R71604 & 6625 & 010269623 & CONTROL, LIGHT SOURCE, REMOTE & B56 & 54 \\
\hline R88696 & ALL & NIIN (S) & RESUSCITATOR AND ASPIRATOR & s9M & 246 \\
\hline R91244 & AII & NIIN & REVOLVER, CAIIBER .38 SPECIAI & B14 & 247 \\
\hline R94703 & ALL & NIIN & RIFLE, CALIBER . 22 & 314 & 248 \\
\hline R95799 & ALL & NIIN & RIELE, CALIBER . 30 & B14 & 249 \\
\hline s39122 & ALI & NIIN (S) & STERILIZER, SURGICAI INSTRUMENT A & s9M & 303 \\
\hline S40645 & 5810 & 012301488 & TELEPHONE， SECURE UNIT & B56 & 55 \\
\hline S66941 & AIL & NIIN (S) & SEARCHLIGHT , INFARED & B16 & 252 \\
\hline$s 67421$ & ALL & NIIN & SEARCHLIGHT GROUP & B16 & 253 \\
\hline$S 74353$ & ALL & NIIN & SEMITRAILER, VAN & AKz & 291 \\
\hline T00161 & ALI & NIIN & STAND, MAINTENANCE, AUTOMOTIVE ENG & AKZ & 255 \\
\hline T05240 & ALL & NIIN & TRAINER, ARMORED VEHICLE TURRET & ARZ & 288 \\
\hline T13169 & ALI & NIIN & TANK, COMBAT, FULL TRACKED & AKz & 287 \\
\hline T60464 & ALL & NIIN & SINK UNIT, SURGICAI SCRUB, FIEID & s9M & 304 \\
\hline $\mathrm{U} 65480$ & AII & NIIN (S) & SURGICAI INSTRUMENT AND SUPPLY $S$ & S9M & 258 \\
\hline 082529 & 5805 & 007082202 & SWITCHBOARD , TELE PHO & B16 & 46 \\
\hline V11001 & AIL & NIIN (S) & TAMPER,VIBRATING TYPE, INTERNAI C & AKZ & 290 \\
\hline V13101 & ALL & NIIN (S) & TANK, COMBAT, FULI TRACKED & AKZ & 262 \\
\hline V31305 & 5805 & 001342599 & TELEPHONE SET & B16 & 47 \\
\hline V64052 & ALL & NIIN (S) & TEST SET, ARMATURE & B14 & 268 \\
\hline V76108 & 6625 & 008200064 & TEST SET,ELECTRON TUBE & B16 & 48 \\
\hline
\end{tabular}


APPENDIX D

SUBJECT: Auto Disposition Table (IIN) (continued)

\begin{tabular}{|c|c|c|c|c|c|}
\hline IIN & FSC & NIIN & DESCRIPTION & ICP & REC_ID \\
\hline -ー-ー- & -ーーー & $--\infty$ & 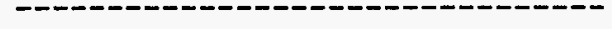 & -- & \\
\hline v82615 & ALI & NIIN (S) & TEST SET,OSCILIATOR & B64 & 269 \\
\hline V87599 & 6625 & 008033399 & TEST SET,RADIO & N32 & 49 \\
\hline V89641 & ALL & NIIN (s) & TEST SET,RADIO FREQUENCY POWER & B64 & 271 \\
\hline v94740 & ALI & NIIN & TEST SET,TELEPHONE & B64 & 272 \\
\hline พ46567 & AII & NIIN & & & 273 \\
\hline พ57801 & ALI & NIIN & TOOL KIT,TURRET MECHANIC'S & B14 & 275 \\
\hline พ95400 & All & NIIN & TRAIIER, CARGO & AKZZ & 276 \\
\hline พ95811 & ALI & NIIN & TRAILER, CARGO & AKZ & 292 \\
\hline X92545 & ALL & NIIN & X-RAY APPARATUS, RADIOGRAPHIC, MED & s9M & 305 \\
\hline Y13224 & ALI & NIIN & VOLTMETER,DIGITAL & B64 & 281 \\
\hline Y13293 & LIL & NIIN & VOLTMETER & B64 & 282 \\
\hline Y35143 & AII & NIIN & & & 283 \\
\hline
\end{tabular}


APPENDIX : D

SUBJECT: NGB Aviation Reportable LIN(s)

1. A06352 31. C19266

2. A06420

3. A27035

4. A27159

5. A27624

6. A28833

7. A28945

8. A35192

9. A35490

10. A55293

11. A56937

12. A57322

13. A58033

14. A69246

15. A 89820

16. A90118

17. A90123

18. A90155

19. A90344

20. A90427

21. A90437

22. A90461

23. A90871

24. A98563

25. B50869

26. B51098

27. B51099

28. B51142

29. C10526

30. C1055I
32. C20404

33. C20472

34. C20722

35. $\mathrm{C} 20831$

36. C26031

37. C31350

38. C85871

39. $C 86076$

40. C99008

41. D03091

42. D03159

43. D03682

44. D04638

45. D20060

46. D98888

47. D99025

48. $\mathrm{E} 03826$

49. E58601

50. E61584

51. E63271

52. E90586

53. E95064

54. F01197

55. F01440

56. F18614

57. F19198

58. F24390

59. F60502

60. F63271
61. G77126 91. J58919

62. G95741

63. G96350

64. G96547

65. H01855

66. Н01907

67. H01912

68. H72892

69. H76352

70. 476489

71. J00593

72. J00730

73. J00867

74. J01004

75. J01713

76. J01849 106. L45016

77. J01917 107. L45063

78. J33711 108. L45131

79. J52472 109. L45199

80. J52549 110. L60295

81. J53508 111. L60318

82. J53645 112. L92260

83. J53712 113. L92323

84. J53782 114. L95939

85. J53944 115. L98359

86. J54741 116. M01100

87. J55837 117. M01374

88. J55944 118. M01511

89. J57344 119. M01648

90. J58303.120. M01922
121. M02013

122. M02036

123. M11621

124. M38609

125. M48996

126. M60449

127. M64001

128. M65673

129. M70652

130. M74207

131. M75200

132. M80002

133. M80259

134. M80413

135. M81372

136. M81646

137. M81783

138. N0 4456

139. N17155

140. N30256

141. N30572

142. P04582

143. P30693

144. P33382

145. P33724

146. P37492

147. P38588

148. P40369

149. P40374

150. P43608 
APPENDIX : D

SUBJECT: NGB Aviation Reportable LIN(s) (continued)

151.P70201 181. S01416 211. T60338 241. V63830 152. P70517 182. S01441 212. T72099 242. V63846 153. Q02968 183. S10034 213. T70380 243. V63881 154. Q03468 184. S26335 214. T72167 244. V663915 155. Q23305 185. S26835 215. T77113 245.V67203 156. Q24882 186. S48255 216. T77181 246. V69816 157. Q25019 187. S48323 217. T77317 247. V69841 158. Q25567 188. S58022 218. T77342 248. V70217 159. Q25978 189. S65581 219. T77410 249.V73847 160. Q25990 190. S87034 220. T87468 250. V74364 161. Q25991 191. T08150 221. T90321 251. V74379 162. Q25992 192. T13751 222. T91428 252. V74738 163. Q26007 193.T15207 223. T93517 253.V76466 164. Q26010 194. T15344 224. T93885 254. V77274 165. Q38335 195. T25961 225. U26605 255. V77512 166. Q42092 196. T25981 226. U54346 256. V77546 167. R25464 197. T35551 227. U68036 257. V79132 168. R27548 198. T42031 228. V59584 258. V79807 169. R30230 199. T45603 229. V59632 259. V81177 170. R31541 200. T49324 230. V60156 260. V81373 171. R36946 201. T49348 231.V61411 261. V81388 172. R37083 202. T49392 232.V61412 262. V81862 173. R37151 203. T49460 233.V61444 263. V81915 174. R44571 204. T53471 234. V61466 264. V82547 175. R44639 205. T54121 235. V61654 265. V83667 176. R74787 206. T54141 236. V61790 266. V84021 177. R82093 207. T55915 237. V61791 267. V84328 178. R84943 208. T59490 238. V62066 268. V84876 179. R85011 209. T59834 239. V63318 269. V85150 180. R93169 210. T60156 240. V63538 270. V85424

271. V86383 272. V86520 273. V86784 274. V87205 275. V87342 276. V87599 277. V89534 278. V89601 279. $V 89641$ 280. V89808 281. V90287 282. V90322 283. V90356 284. V90424 285. V91178 286. V91863 287. V92715 288. V93301 289. V93302 290. V93575 291. V96110 292. V96424 293. V99329 294. V99347 295. V99416 296. V99436 297. V99858 298.W33278 299. W37251 300 . W37388 
APPENDIX : D

SUBJECT: NGB Aviation Reportable LIN(s) (continued)

301. W37483

302 . W37891

303. W59034

304. W59171

305. X04073

306. X20375

307 . $\times 20376$

308 . $\times 22266$

309 . X22267

310. X23840

311. Y13129

312. Y13224

313. Y14526

314. Y14663

315. Y14800

316. Y38404

317. Y54401

318. Z33570

319. Z46320

320. Z49693

321. z50829

322 . Z 52435

323 . Z53926

324 . z56699

325. Z79338

D-10 


\section{INTERNAL DISTRIBUTION}

1. M. A. KULIASHA

2. D. H. PIKE

3. C. H. SHAPPERT

2-5. K. A. RASCH

6. IAABORATORY RECORDS, ORNL-RC DOCUMENT REEERENCE SECTION

7-8. CENTRAL RESEARCH IIBRARY

\section{EXTERNAL DISTRIBUTION}

9-10. OFFICE OF SCIENTIFIC AND TECHNICAL INFORMATION, DEPARTMENT OF ENERGY, P.O. BOX 62, OAK RIDGE, TENNESSEE 37831

11-40. R. P. PELATH, NGB-ARL-S, ARLINGTON HAIL STATION, 111 SOUTH GEORGE MASON DRIVE, ARIINGTON, VIRGINIA 22204-1382

41-42. USPFO FOR ALABAMA, ATTN: SMG MCCORD, 1740 DICKERSON DRIVE, MONTGOMERY, ALABAMA 36109-4801

43-44. USPFO FOR ALASKA, ATTN: MR. MICHAEL WALSH, BIDG 49-140, ET RICHARDSON, AIASKA 99505-2610

45-46. USPFO FOR ARIZONA, ATTN: MS. VIVIAN HOLLY, 5558 E. MOREIAND ST, PHOENIZ, ARIZONA 85008-3442

47-48. USPFO FOR ARKANSAS, ATTN: EXCESS MANAGER, CAMP ROBINSON, BLDG 0319, N. IITTLE ROCK, ARKANSAS 72199-9600

49-50. USPFO FOR CALIFORNIA, ATTN: MR. BRAD SEELER, BIDG 632 CAMP SAN LUIS OBISPO, SAN LUIS OBISPO, CA. 93403-8104

51-52. USPFO FOR COLORADO, ATIN: WILLIAM EARLEY, 660 S. ASPEN ST. BLDG 1005 MS 66, AURORA, CO 80011-9551

53-54. USPFO FOR CONNECTICUT, ATTN: USPF-PM MS. MEAD, 360 BROAD STREET, HARTFORD, CT 06105-3779

55-56. USPFO FOR DELAWARE, ATTN: BILL DANIAL, 1161 RIVER ROAD, NEW CASTLE, DEILAWARE 19720-5199

57-58. USPFO FOR DIST OF COLUMBIA, ATTN: EXCESS MANAGER, ANACOSTIA NAVAI AIR STATION, WASHINGTON DC 20037-5064

59-60. USPFO FOR FLORIDA, ATTN: DOL-S\&S DIV, RT 1, BOX 470, ST AUGUSTINE, FLORIDA 32085-1008

61-62. USPFO FOR GEORGIA, ATTN: WOC GLENN, B-7,935 E.CONEEDERATE AVE, ATLANTA, GA. 30316-0882

63-64. USPFO FOR GUAM, FORT JUAN MUNA ATTN: SFC JAMES, 622 E. HARMON IND PK RD, TAMUNING, GU 96911-4422

65-66. USPFO FOR HAWAII, ATTN: MS GERAIDINE NAGATOSHI, 4208 DIAMOND HEAD RD, HONOLULU, HAWAII 96816-4495

67-68. USPFO FOR IDAHO, ATTN: MSG BECK, 3489 WEST HARVARD ST., BOISE, IDAHO 83705-6512

69-70. USPFO FOR ILIINOIS, ATTN: SFC BEDUHN, 1301 N. MCARTHUR BLVD, SPRINGFIEID, ILI 62702-2399

71-72. USPEO FOR INDIANA, ATTN: PFO-LO, SGT ERINK, 2002 SOUTH HOLT ROAD, INDIANAPPOLIS, IN 46241-4839

73-74. USPFO FOR IOWA, ATTN: MSG WILIIAMS, 7700 NW BEAVER DRIVE, JOHNSON, IOWA 50131-1902

75-76. USPFO FOR KANSAS, ATTN: SMG IAYYDON, $2737 \mathrm{~s}$, KANSAS AVE, TOPEKA, KANSAS 66611-1170

77-78. USPEO FOR KENTUCKY, ATTN: EXCESS MANAGER, 120 MINUTEMAN WAY, FRANKFORT, KY 40601-6192 
79-80. USPFO FOR LOUISIANA, ATTN: MS. TONI TRAVIS, P O BOX 177, ARABI, IA. 70032

81-82. USPFO FOR MAINE, ATTN: MS JACQUELYN CHILDS, CAMP KETES, AUGUSTA, MAINE 04330-0032

83-84. USPFO FOR MARYLAND, ATTN: EXCESS MANAGER, 333 OLD BAY LANE BLDG 2, HAVRE DE GRACE, MD 21078

85-86. USPEO FOR MASSACHUSETTS, ATTN: MAJ SCHAMDELMAYER, 50 MAPLE STREET, MILFORD, MA. 01757

87-88. USPFO FOR MICHIGAN, ATTN: SGT LINGELMAN, 3111 W. ST. JOSEPH STREET, LANSING, MI 48910-5102

89-90. USPFO FOR MINNESOTA, ATTN: LAURA PLANTE; P. O. BOX 288 CAMP RIPLEY, LITTLE FALLS, MN 56345-0288

91-92. USPFO FOR MISSISSIPPI, ATTN: NGMS-DOL-SM CW4 HICKS, 144 MILITARY ROAD, JACKSON, MS 39208-8860

93-94. USPFO FOR MISSOURI, ATTN: EXCESS MANAGER, 6915 ALGOA RD, JEFFERSON CITY, MO. 65101-1468

95-96. USPFO FOR MONTANA, ATTN: EXCESS MANAGER, BLDG P517 FT HARRISON , HELENA, MT. 59624-1157

97-98. USPFO FOR NORTH CAROIINA, ATTN: MR. DAVID TART, 4201 REEDY CREEK RD, RALEIGH, NC 27607-6412

99-100. USPFO FOR NEBRASKA, ATTN: EXCESS MANAGER, 2950 N. PARK RD, LINCOIN, NE 68521-1092

101-102. USPFO FOR NEVADA, ATTN: MS. JUDY FIELDS, 2601 SOUTH CARSON ST., CARSON CITY, NV. 89701-5596

103-104. USPFO FOR NEW HAMPSHIRE, ATTN: MS. BLACKEY, STATE MILITARY RESERVATION, CONCORD, NEW HAMPSHIRE 03301-5652

105-106. USPFO FOR NEW JERSEY, ATTN: EXCESS MANAGER, 131 EGGERT CROSSING RD, IAWRENCEVIILE, NEW JERSEY 08648-2805

107-108. USPFO FOR NEW MEXICO, ATTN: MS MONTOYA, 47 BATAAN BLVD, SANTE FE, NEW MEXICO 87505-4695

109-110. USPFO FOR NEW YORK, ATTN: EXCESS MANAGER, 330 OLD NISKAYUMA RD, LATHAM, NY 12110-2224

111-112. USPFO FOR NORTH DAKOTA, ATIN: EXCESS MANAGER, 4100 E. DIVIDE, BISMARK, NORTH DAKOTA 58506-5511

113-114. USPFO FOR OHIO, ATTN: EXCESS MANAGER, 1217 HOLIAAR LANE, NEWARK, OHIO 43055-1926

115-116. USPFO FOR OKLAHOMA, ATTN: LOG/PMB MS JANE LEWIS, 3505 MILITARY CIRCLE, OKLIAHOMA CITY, OK. 73111-4298

117-118. USPFO FOR OREGON, ATTN: DOL-SDC, CAMP WITHYCOME, CLLACKAMAS, OREGON 97015-9150

119-120. USPFO FOR PENNSYLVANIA, ATTN: MR RICK WOOD, DEPT OF MIL \& VET AFFAIRS BIDG 11-68, FTIG ANNVILIE, PA 17003-5003

121-122. USPFO FOR PUERTO RICO, ATIN: EXCESS MANAGER, P. O. BOX 34069, FT BUCHANAN, PR 00934-4068

123-124. USPFO FOR RHODE ISLAND, ATTN: RIPFO-LA, MR. SCOTT, 330 CAMP STREET, PROVIDENCE, RHODE ISLAND 02906-1954

125-126. USPFO FOR SOUTH CAROLINA, ATTN: SFC ALIEN/MS HUFF, 9 NATIONAL GUARD ROAD, COLUMBIA, SOUTH CAROLINA 29201-4763

127-128. USPFO FOR SOUTH DAKOTA, ATTN: EXCESS MANAGER, $2823 \mathrm{~W}$. MAIN STREET, RAPID CITY, SOUTH DAKOTA 57702-8186 
EXTERNAI DISTRIBUTION (CONTINUED)

129-130. USPFO FOR TENNESSEE, ATTN: EXCESS MANAGER, SIDCO DRIVE, NASHVILLE, TN. 37204-0748

131-132. USPFO FOR TEXAS, ATTN: AGTEX-SLS CW4 HAWKINS, P. O BOX 5218, AUSTIN, TEXAS 78763-5218

133-134. USPFO FOR UTAH, ATTN: EXCESS MANAGER, 12953 MINUTEMAN DRIVE, DRAPER, UTAH 84020-2000

135-136. USPFO FOR VERMONT, ATTN: EXCESS MANAGER, BLDG 3M CAMP JOHNSON, COLCHESTER, VT. 05446-3004

137-138. USPFO FOR VIRGIN ISLAND, ATTN: EXCESS MANAGER, RURAL RT 2, BOX 9200, KINGHILL, ST CROIX, USVI 00850-9200

139-140. USPFO FOR VIRGINIA, ATTN: MS SHAMBIIN, 5001 WALTER ROAD, RICHMOND, VA. 23230-2994

141-142. USPFO FOR WASHINGTON, ATTN: EXCESS MANAGER, CAMP MURRY BLDG 32, TACOMA, WASHINGTON 98430-5000

143-144. USPFO FOR WEST VIRGINIA, ATTN: EXCESS MANAGER, 50 ARMORY RD, BUCKHANON, WEST VIRGINIA 26201-2396

145-146. USPFO FOR WISCONSIN, ATTN: EXCESS MANAGER, CAMP WILLIAMS, 8 MADISON BLVD, CAMP DOUGLAS, WI. 54618-5002

147-148. USPFO FOR WYOMING, ATIN: EXCESS MANAGER, 5500 BISHOP BLVD, CHEYENNE, WY. 82009-3320 

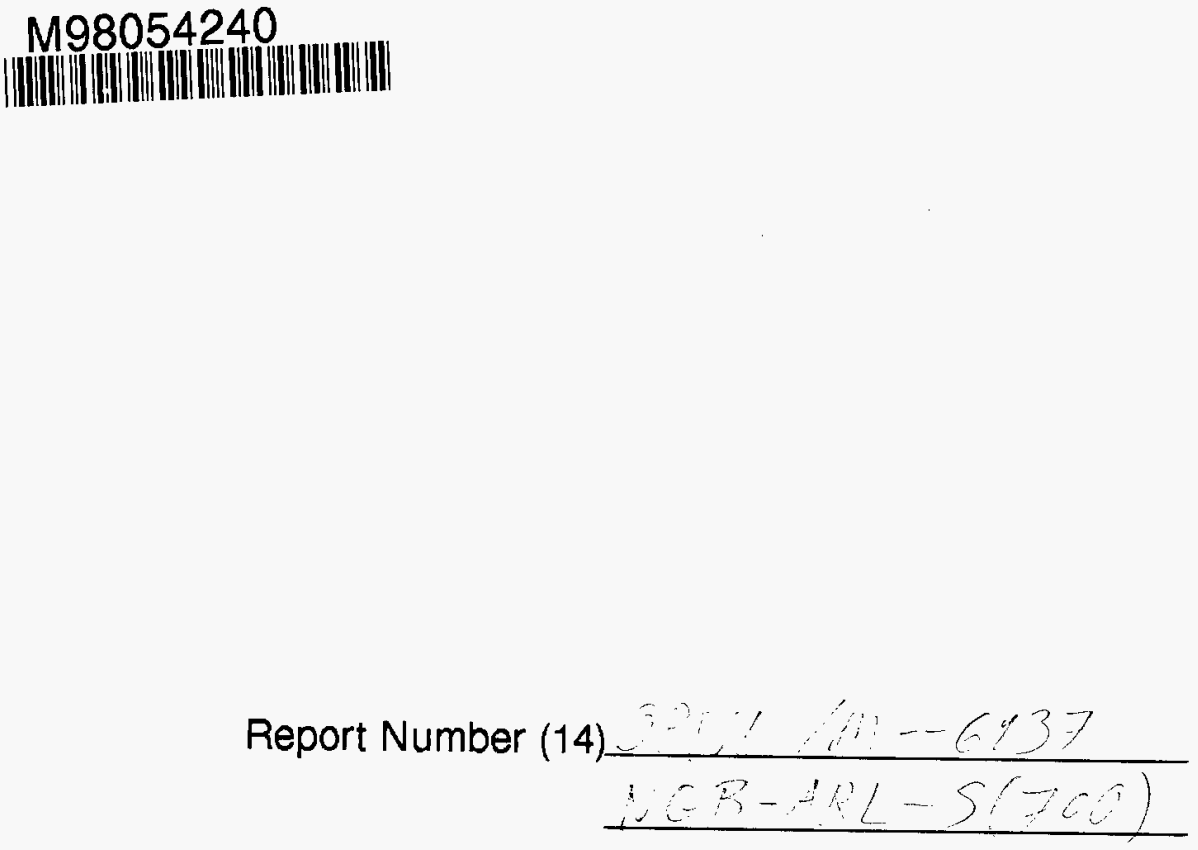

Publ. Date (11)

Sponsor Code (18) $/ C R ; Y G ;, X F$
UC Category (19) UC-900; UC-200,DOE/ER

\section{2}

DTIC QUALITY DVEPECTRD 1 